\title{
Fluoride Salt-Cooled High-Temperature Reactor Technology Development and Demonstration Roadmap
}

September 2013

Prepared by

David E. Holcomb

George F. Flanagan

Gary T. Mays

W. David Pointer

Kevin R. Robb

Graydon L. Yoder, Jr.

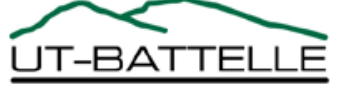




\section{DOCUMENT AVAILABILITY}

Reports produced after January 1, 1996, are generally available free via US Department of Energy (DOE) SciTech Connect.

Website http://www.osti.gov/scitech/

Reports produced before January 1, 1996, may be purchased by members of the public from the following source:

National Technical Information Service

5285 Port Royal Road

Springfield, VA 22161

Telephone 703-605-6000 (1-800-553-6847)

TDD 703-487-4639

Fax 703-605-6900

E-mail info@ntis.gov

Website http://www.ntis.gov/support/ordernowabout.htm

Reports are available to DOE employees, DOE contractors, Energy Technology Data Exchange representatives, and International Nuclear Information System representatives from the following source:

Office of Scientific and Technical Information

PO Box 62

Oak Ridge, TN 37831

Telephone 865-576-8401

Fax 865-576-5728

E-mail reports@osti.gov

Website http://www.osti.gov/contact.html

This report was prepared as an account of work sponsored by an agency of the United States Government. Neither the United States Government nor any agency thereof, nor any of their employees, makes any warranty, express or implied, or assumes any legal liability or responsibility for the accuracy, completeness, or usefulness of any information, apparatus, product, or process disclosed, or represents that its use would not infringe privately owned rights. Reference herein to any specific commercial product, process, or service by trade name, trademark, manufacturer, or otherwise, does not necessarily constitute or imply its endorsement, recommendation, or favoring by the United States Government or any agency thereof. The views and opinions of authors expressed herein do not necessarily state or reflect those of the United States Government or any agency thereof. 
ORNL/TM-2013/401

Reactor and Nuclear Systems Division

\title{
FLUORIDE SALT-COOLED HIGH-TEMPERATURE REACTOR
} TECHNOLOGY DEVELOPMENT AND DEMONSTRATION ROADMAP

\author{
David E. Holcomb \\ George F. Flanagan \\ Gary T. Mays \\ W. David Pointer \\ Kevin R. Robb \\ Graydon L. Yoder, Jr.
}

Date Published: September 2013

Prepared by

OAK RIDGE NATIONAL LABORATORY

Oak Ridge, Tennessee 37831-6283

managed by

UT-BATTELLE, LLC

for the

US DEPARTMENT OF ENERGY

under contract DE-AC05-00OR22725 


\section{CONTENTS}

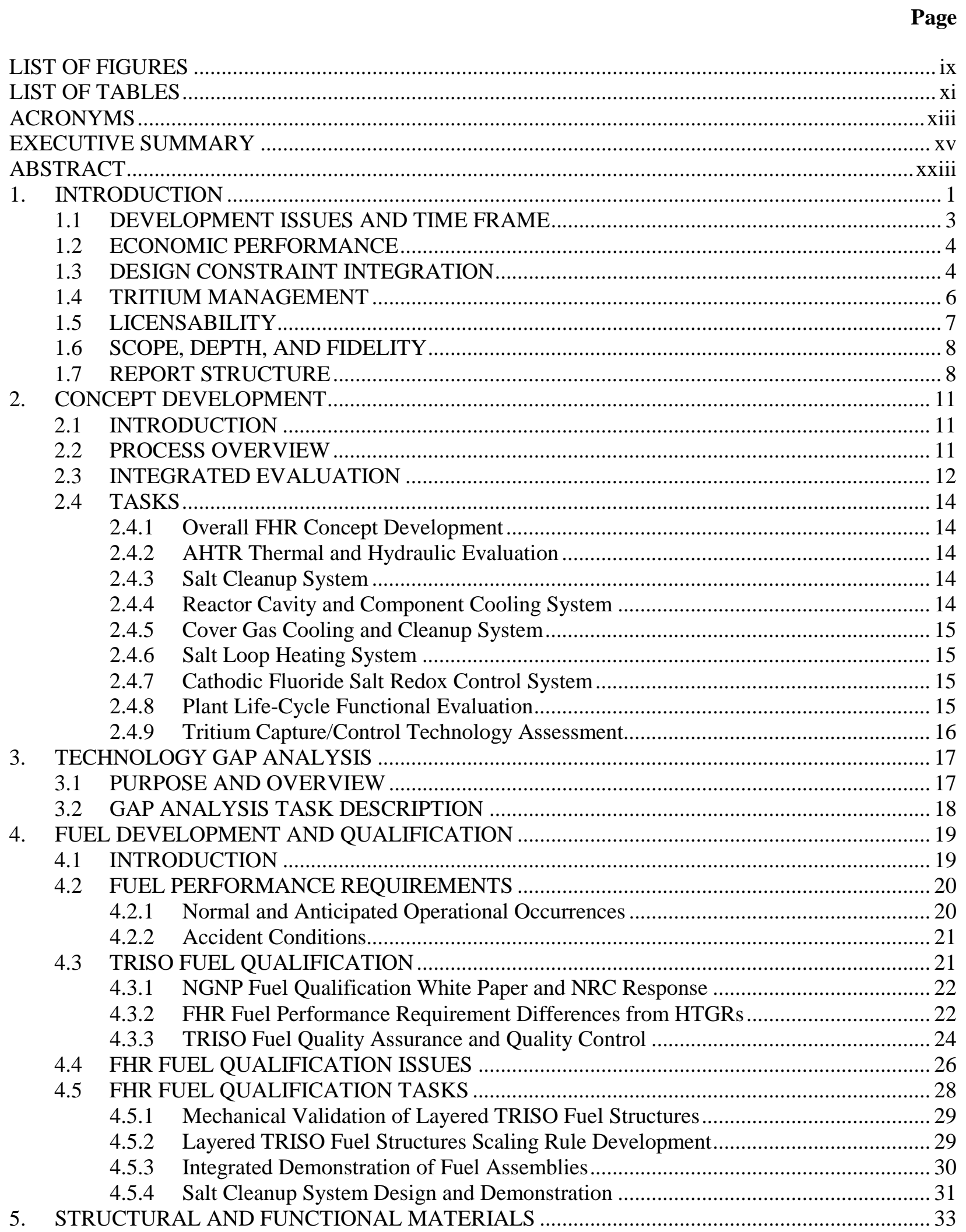




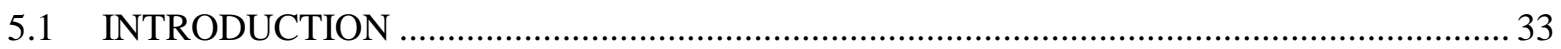

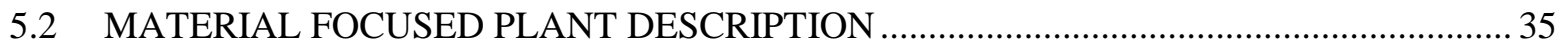

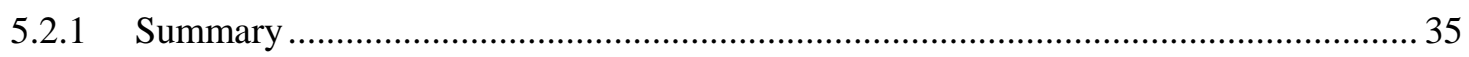

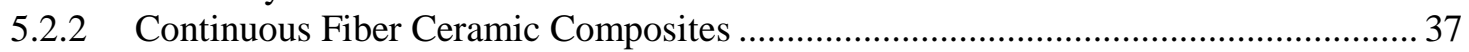

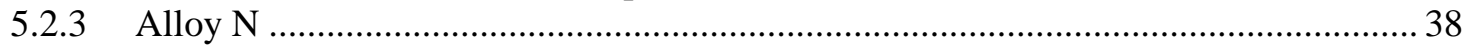

5.2.4 Core

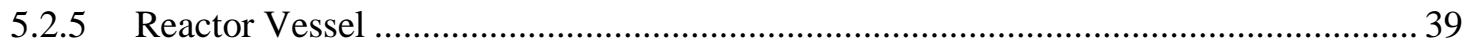

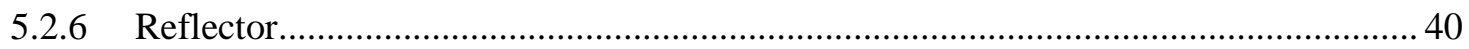

5.2.7 Control Blades ................................................................................................... 40

5.2.8 Reactor Vessel Internals ........................................................................................ 41

5.2.9 Secondary Shutdown Mechanism....................................................................... 42

5.2.10 Primary Loop .................................................................................................. 42

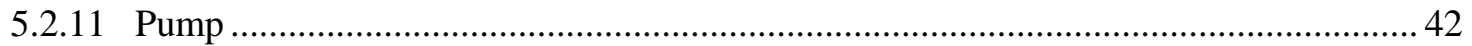

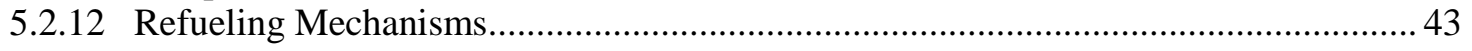

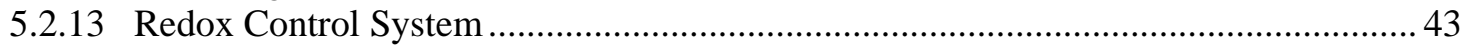

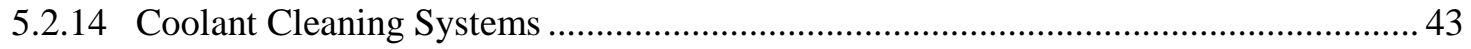

5.2.15 Primary to Intermediate Heat Exchanger...……………………………………….... 44

5.2.16 DRACS In-Vessel Heat Exchanger …………………………………………….... 46

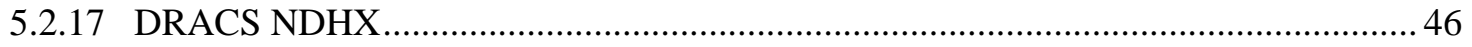

5.2.18 Intermediate Loop ........................................................................................... 47

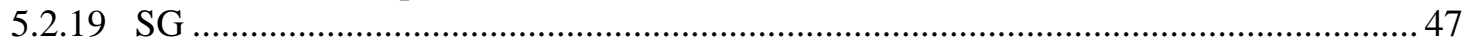

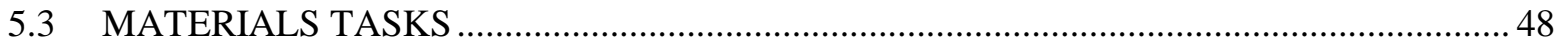

5.4 TEST REACTOR MATERIALS ISSUES ………………............................................... 50

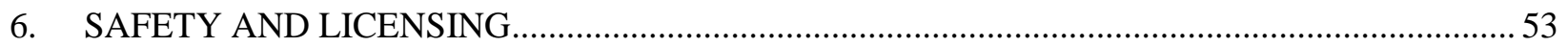

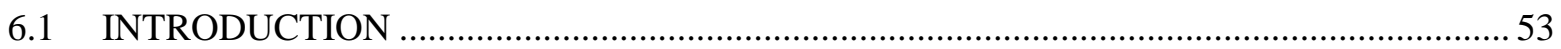

6.2 DEFINING AND SUPPORTING THE SAFETY BASIS .................................................. 54

6.2.1 Define FHR-Specific GDCs ................................................................................ 54

6.2.2 Establish a Quality Assurance Program...................................................................... 55

6.2.3 Establish Response to Transients and Accidents ............................................................ 55

6.2.4 Determine the Adequacy of the Reactor Design and Supporting Information

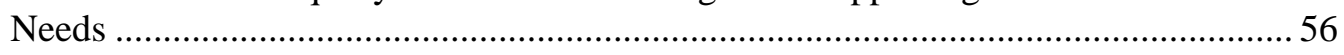

6.2.5 Determine the Adequacy of Codes and Standards ..................................................... 56

6.2.6 Define a Program to Address the Hazards Associated with the Presence of Beryllium in FHR Coolant....................................................................................... 57

6.3 DEMONSTRATE THE ADEQUACY OF MODELS ……………………………………...... 57

6.4 DEMONSTRATE ADEQUACY OF DESIGN …………………………........................... 57

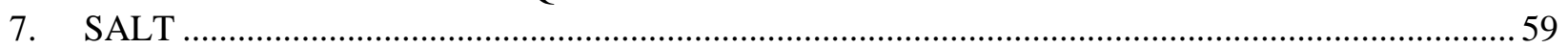

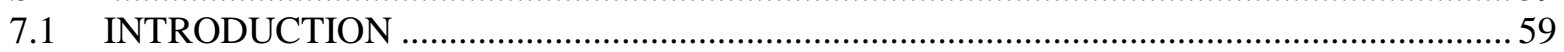

7.2 LITHIUM ISOTOPE SEPARATION ……………………………………………..... 59

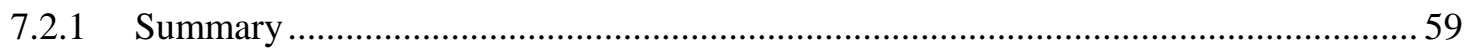

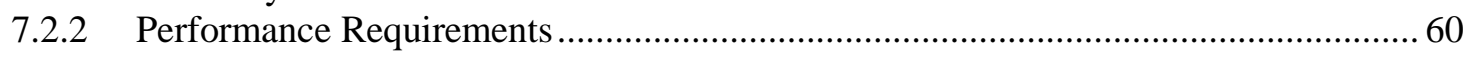

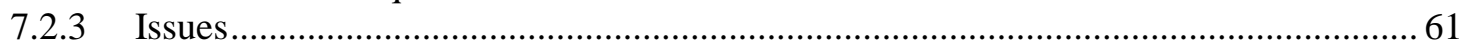

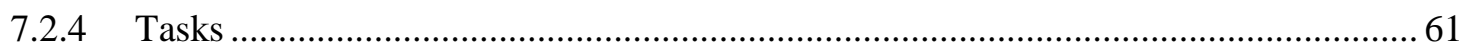

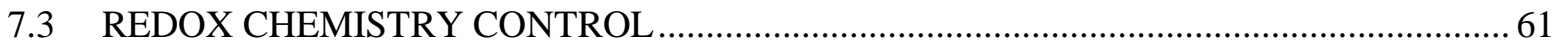

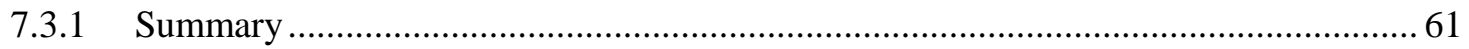

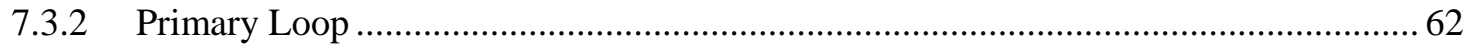

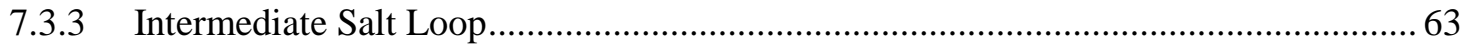

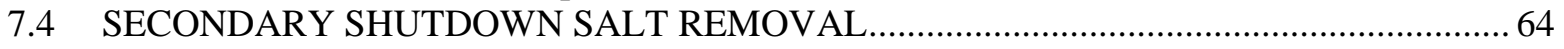

7.4.1 Background ......................................................................................................64

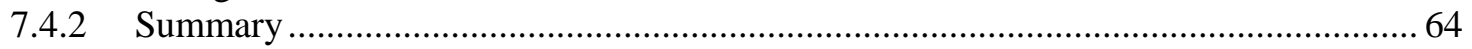

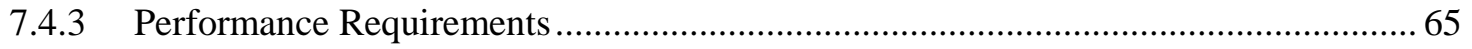




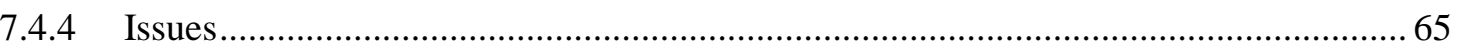

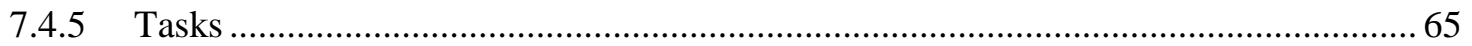

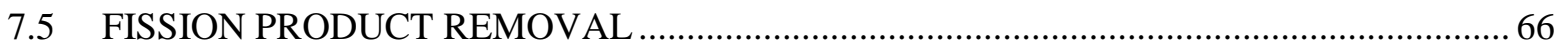

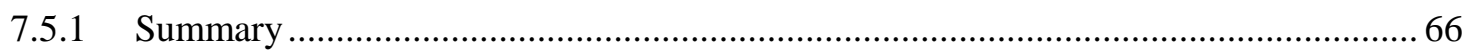

7.5.2 Performance Requirements ......................................................................................6 66

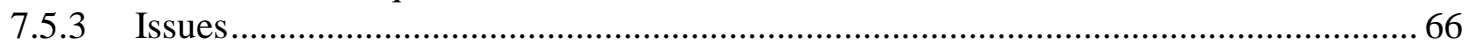

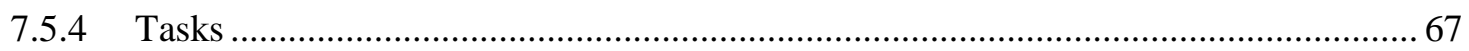

8. COMPONENT DEVELOPMENT AND TESTING …………………………………………....6

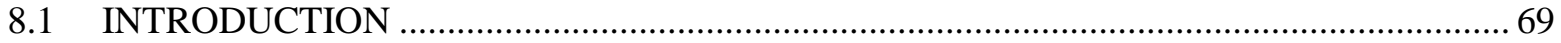

8.2 FHR HEAT TRANSFER AND HYDRAULIC COMPONENTS ............................................ 71

8.2.1 Short-Shaft Salt Pumps ............................................................................................. 71

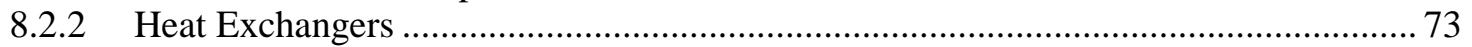

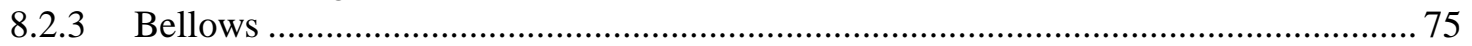

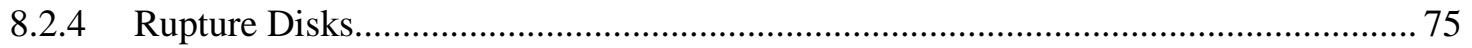

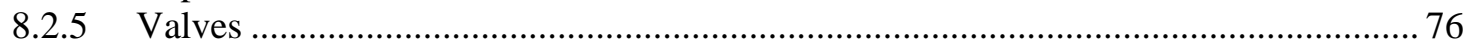

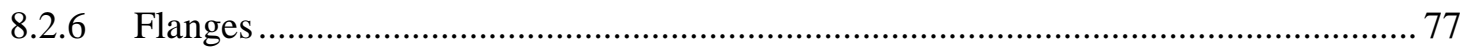

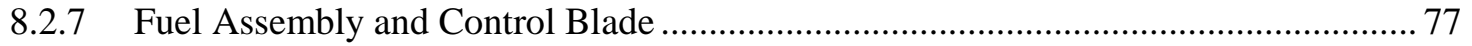

8.2.8 Control Blade Drive......................................................................................... 77

8.2.9 Fluidic Diodes .......................................................................................... 78

8.2.10 Used fuel pool cooling ....................................................................................... 78

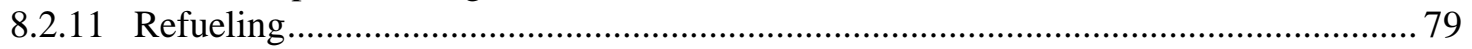

8.2.12 Longer Term Development and Testing ................................................................ 79

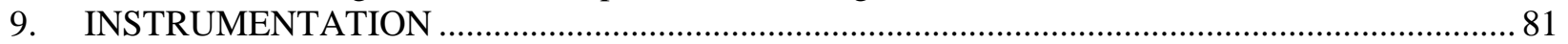

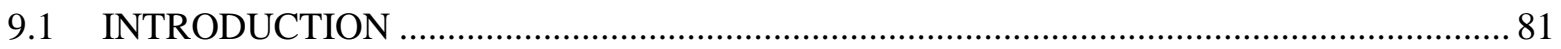

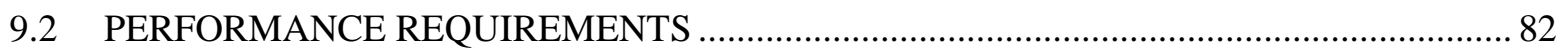

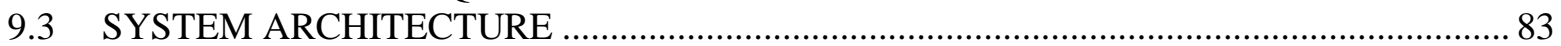

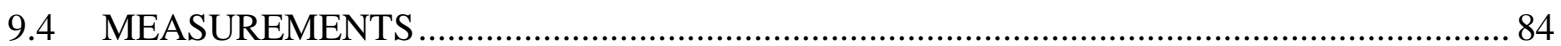

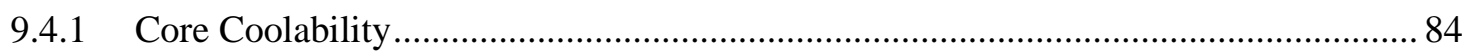

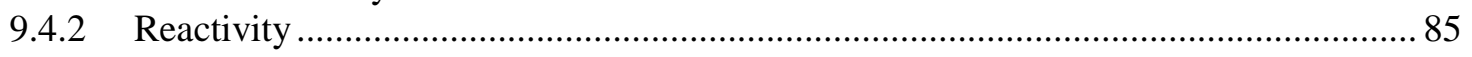

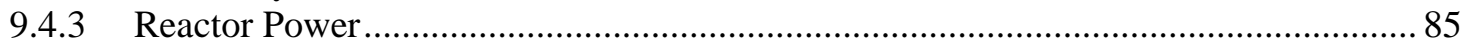

9.4.4 Fuel Leakage ....................................................................................................... 86

9.4.5 Primary Coolant Boundary Integrity......................................................................... 86

9.4.6 Decay Heat Removal Functionality ………………………………………………... 87

9.4.7 Tritium Release ........................................................................................ 87

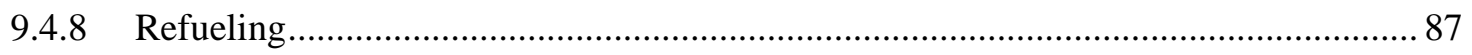

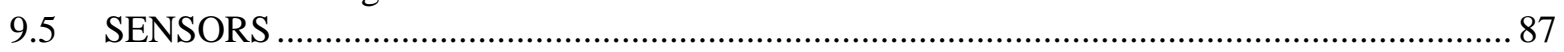

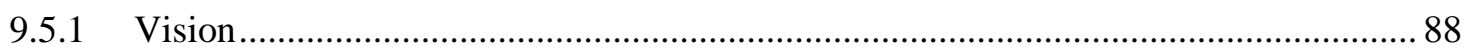

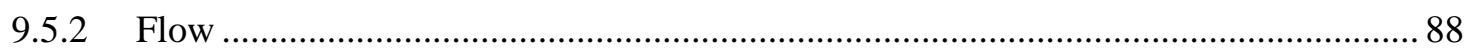

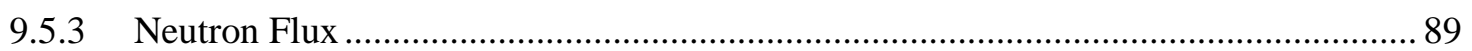

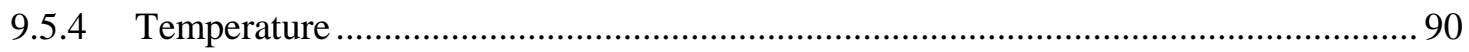

9.5.5 Primary Coolant Redox Condition and Contamination ................................................. 91

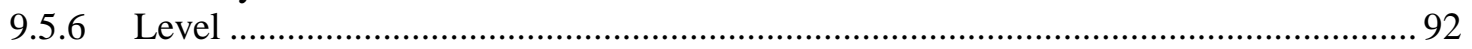

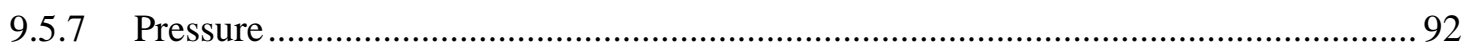

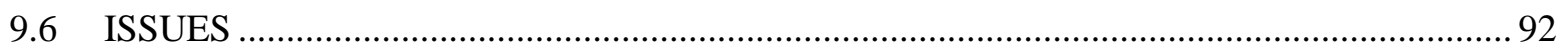

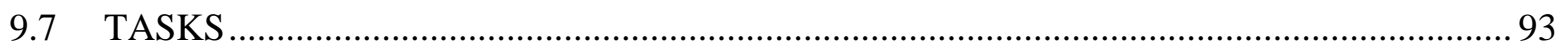

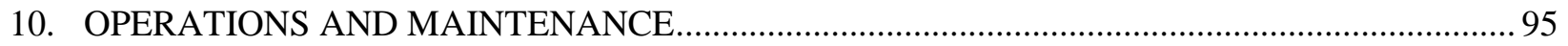

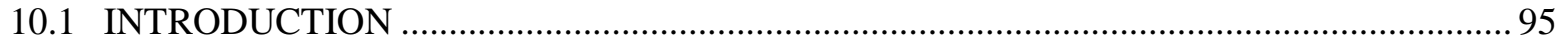

10.2 PERFORMANCE REQUIREMENTS ………………………………………………….... 96

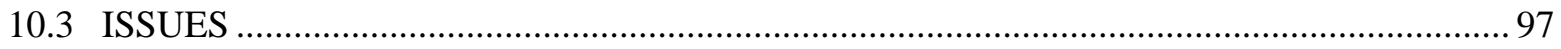

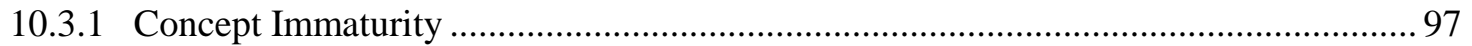

10.3.2 Incorporating Operations and Maintenance into Concept Development ....................... 97 
10.3.3 Incorporating Plant Security Into Concept Development ...................................... 98

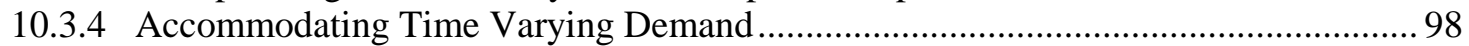

10.3.5 Access to Structures and Components for Inspection............................................. 99

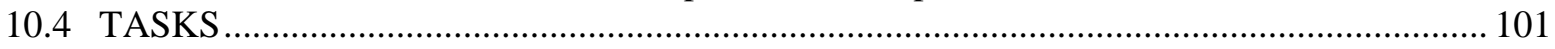

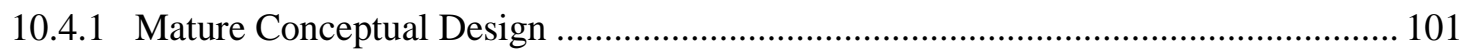

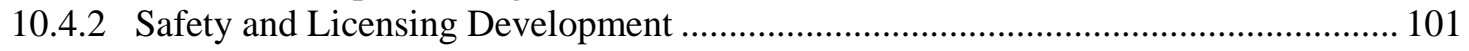

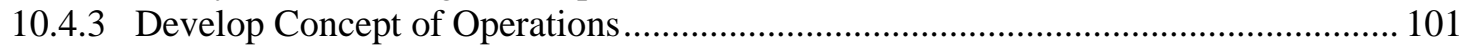

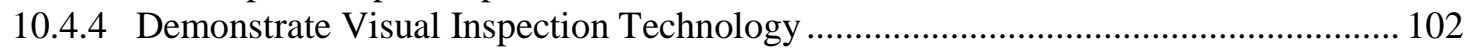

10.4.5 Develop Surveillance and Testing Methods of Control Mechanisms......................... 102

10.4.6 Demonstrate Testing Methods for Secondary Shutdown Mechanisms ....................... 102

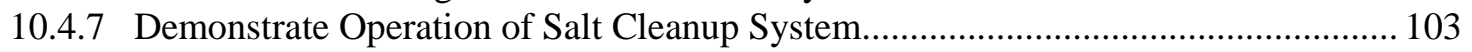

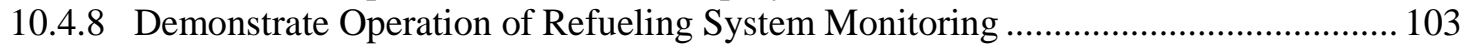

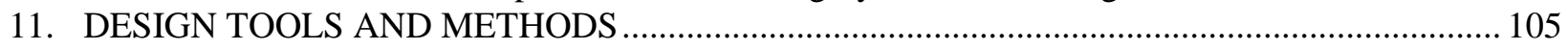

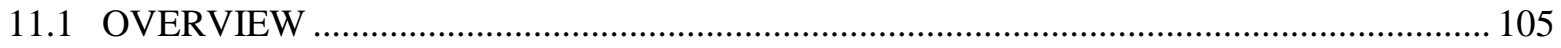

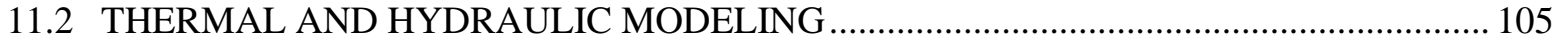

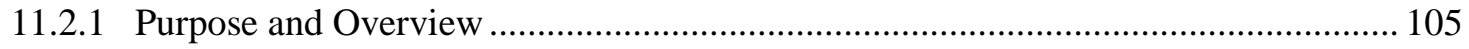

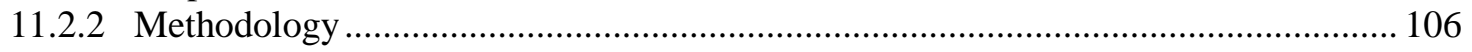

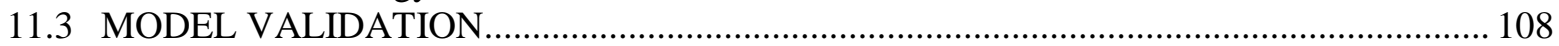

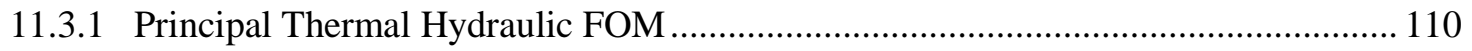

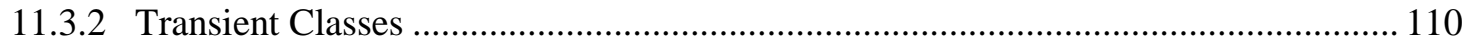

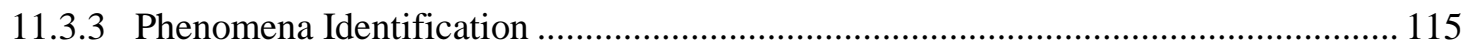

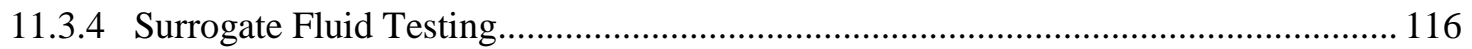

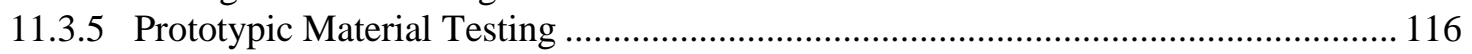

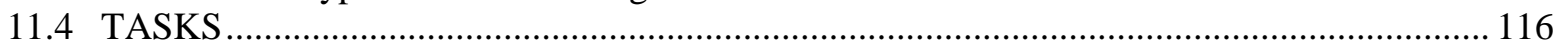

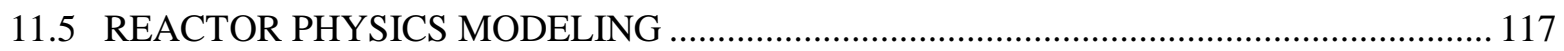

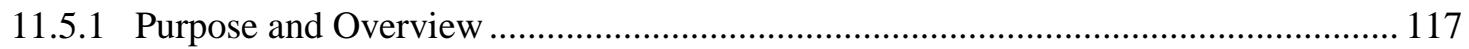

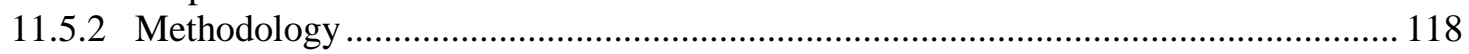

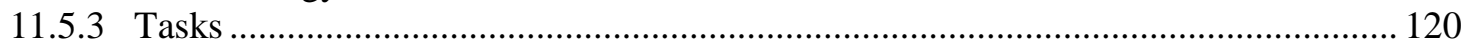

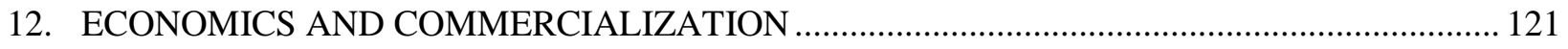

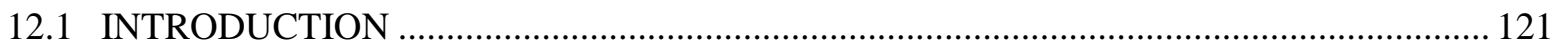

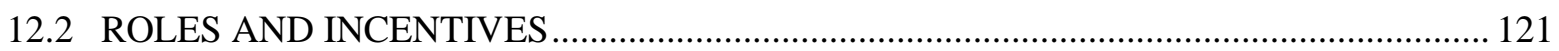

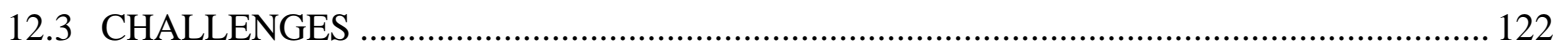

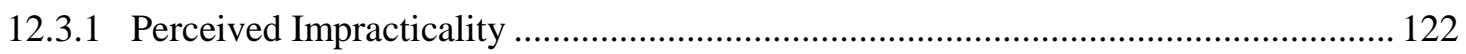

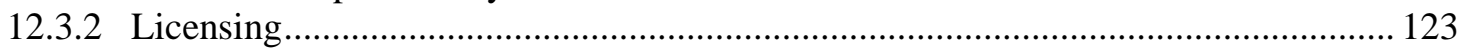

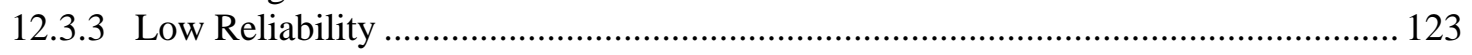

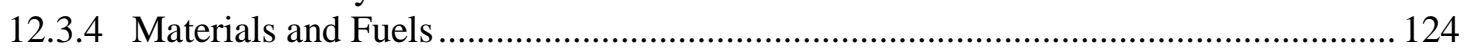

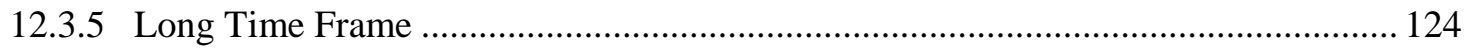

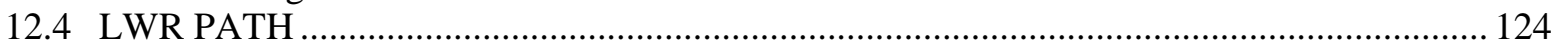

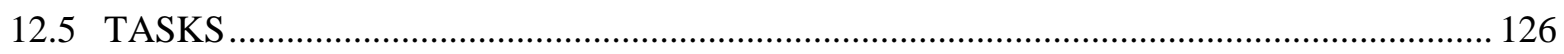

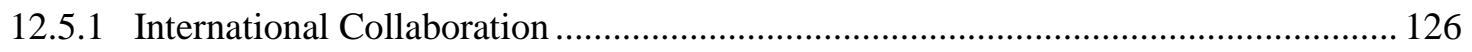

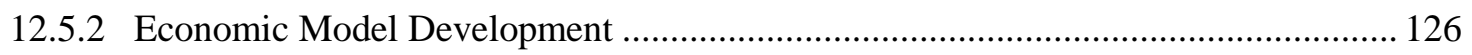

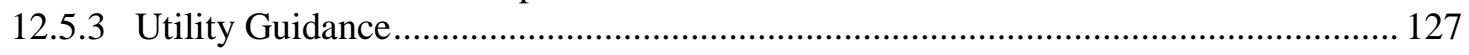

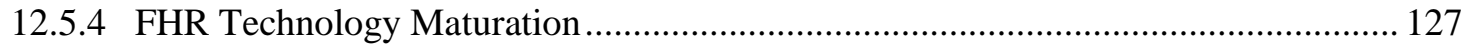

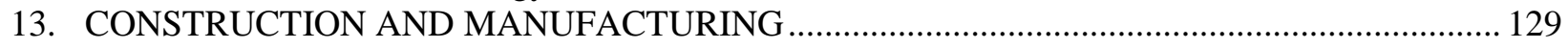

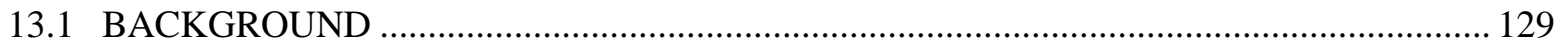

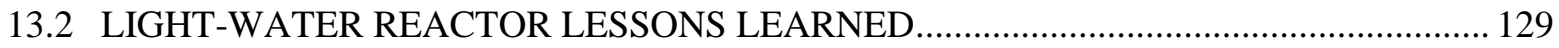

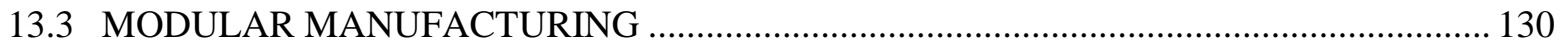

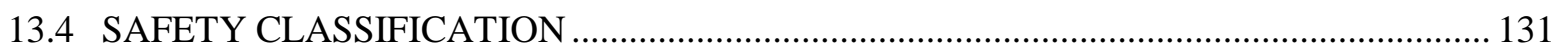

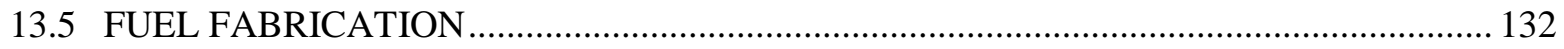

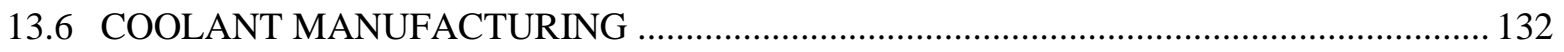

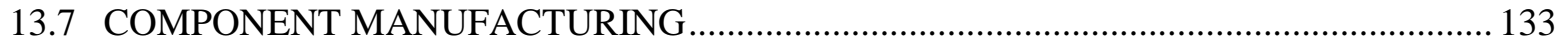


13.8 SEISMIC TOLERANCE AND AIRCRAFT IMPACT RESISTANCE.............................. 133

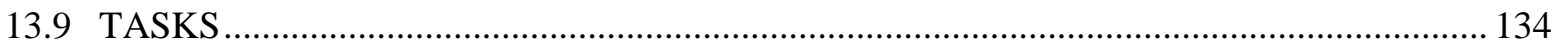

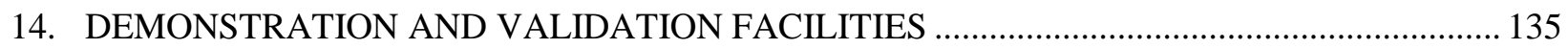

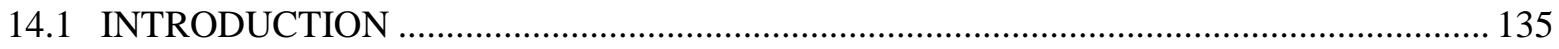

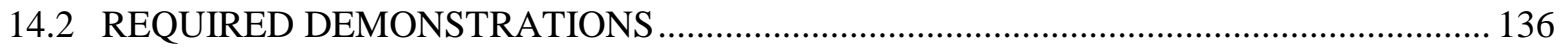

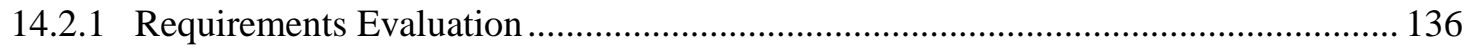

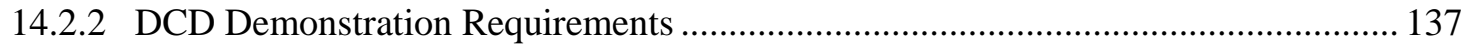

14.2.3 GDC-Required Safety Performance Demonstrations ............................................. 137

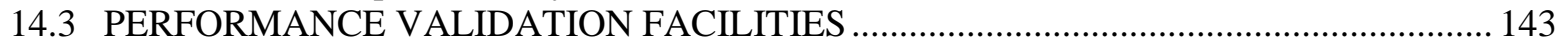

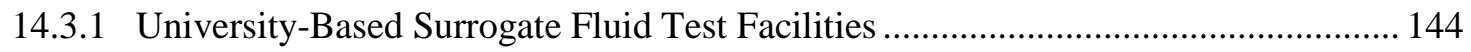

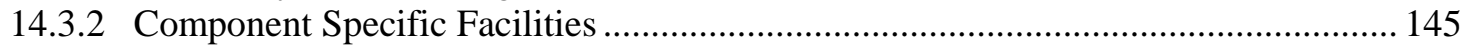

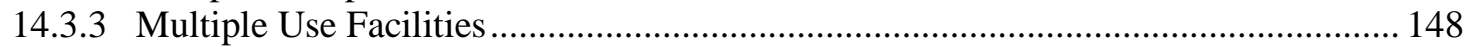

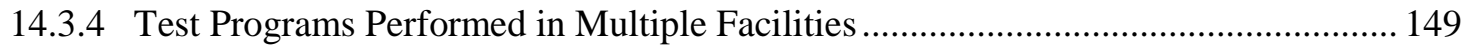

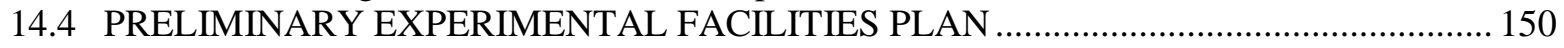

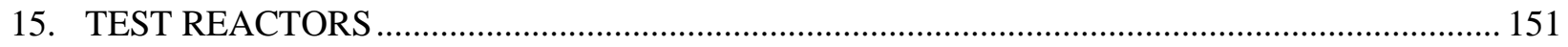

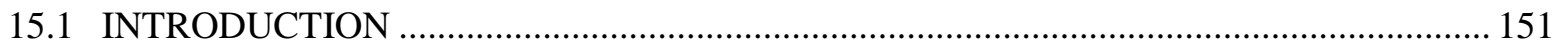

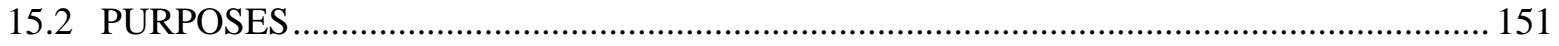

15.3 INTERNATIONAL CRITICALITY TESTING AND TEST REACTOR

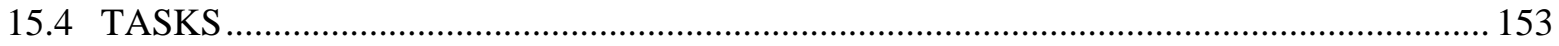

15.4.1 Establish SINAP-ORNL Cooperative R\&D Agreement (CRADA).......................... 153

15.4.2 Collaborate on SPHINX FHR Reactor Physics Benchmark Experiments.................. 153

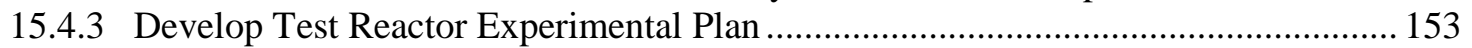

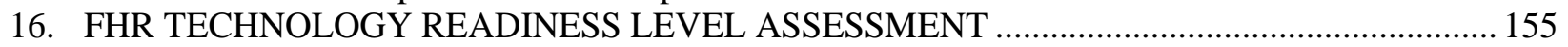

16.1 BACKGROUND ON TECHNOLOGY READINESS LEVELS........................................... 155

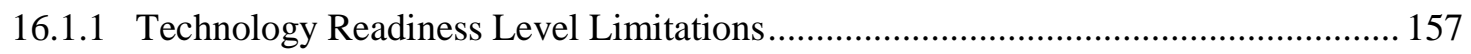

16.1.2 Application of Technology Readiness Level Assessment Process to FHR

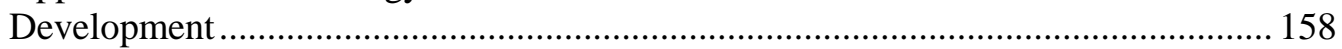

16.2 FHR SYSTEMS, STRUCTURES, AND COMPONENTS TRL ASSESSMENT ................. 160

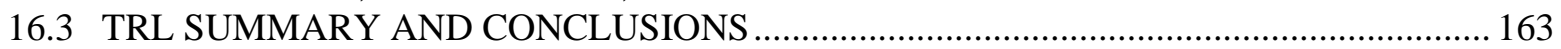

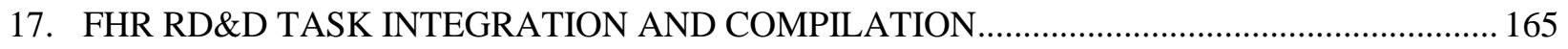

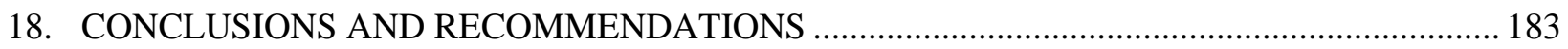

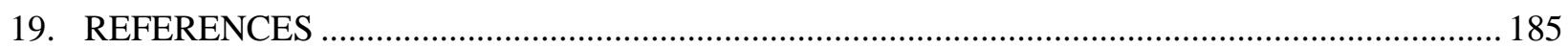




\section{LIST OF FIGURES}

Figure

1. Fluoride salt-cooled high-temperature reactor development task overview............................... xxi

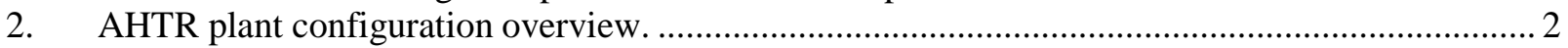

3. Krypton release fraction prediction variance with irradiation temperature [after IAEA

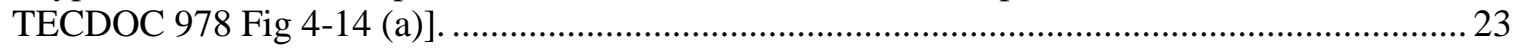

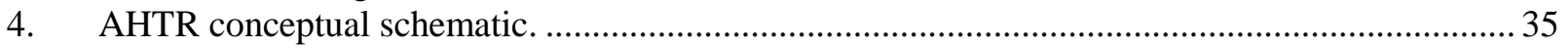

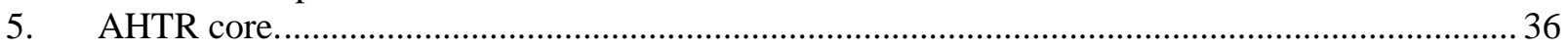

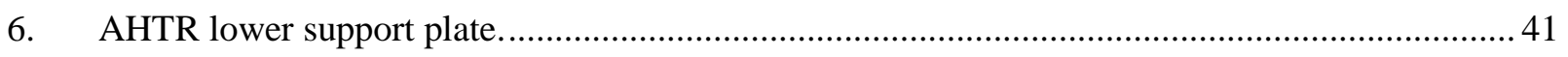

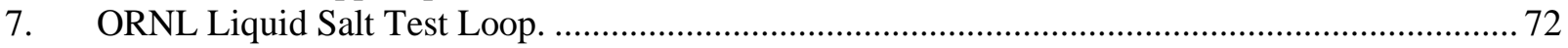

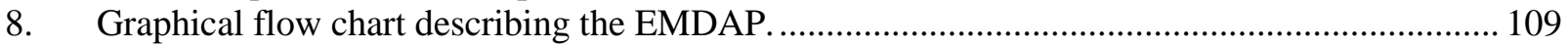

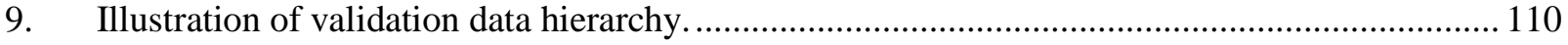

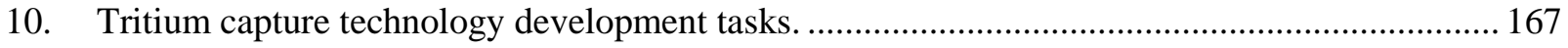

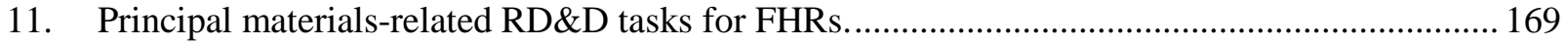




\section{LIST OF TABLES}

Table

Page

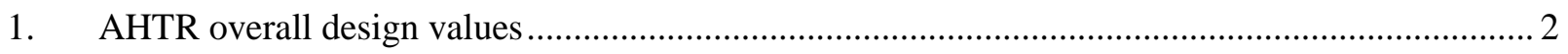

2. AHTR materials for FHR distinctive components and structures .......................................... 37

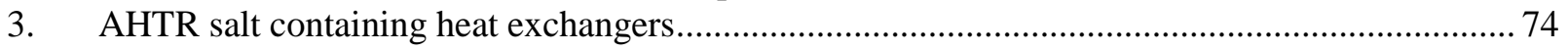

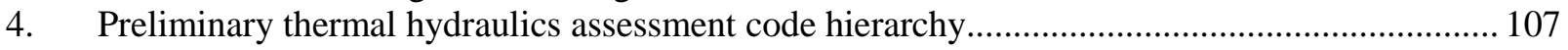

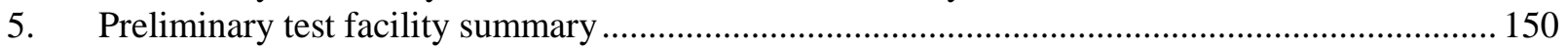

6. Technology readiness level (TRL) categories, description, definition, and examples ................. 156

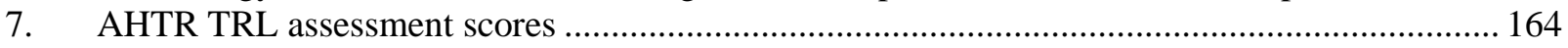

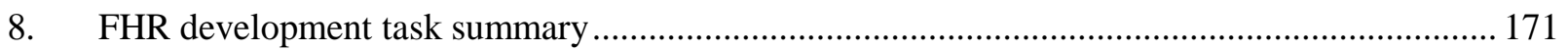




\section{ACRONYMS}

AC

AdvSMR

AGR

AHTR

ANS

AOO

ARC

ASME

ASTM

ATWS

BDBA

BDBE

BOP

BPVC

CAS

C-C

$\mathrm{CDF}$

CFC

CIET

COLEX

CRADA

CSAU

CTE

DBA

DBE

DC

DHX

DOE-NE

DRACS

EMDAP

FHR

FIMA

FLiBe

FOM

GDC

HTR

HTGR

I\&C

IAEA

ID

ILTF

INL

I-PHX

IPS

IPTF

JNT

LBE

LCOE acceptance criteria

Advanced Small Modular Reactor

advanced gas reactor

advanced high-temperature reactor

American Nuclear Society

anticipated operational occurrence

Advanced Reactor Concepts

ASME International

ASTM International

anticipated transient without SCRAM

beyond design basis accident

beyond design basis event

balance of plant

Boiler and Pressure Vessel Code

Chinese Academy of Sciences

carbon-carbon

core damage frequency

continuous fiber composite

Compact Integral Effects Test

column exchange (process)

cooperative $\mathrm{R} \& \mathrm{D}$ agreement

Code Scaling, Applicability, and Uncertainty

coefficients of thermal expansion

design basis accident

design basis event

design certification

DRACS heat exchanger

US Department of Energy Office of Nuclear Energy

direct reactor auxiliary cooling system

evaluation model development and assessment process

fluoride salt-cooled high-temperature reactor

fissions per initial metal atom

lithium fluoride and beryllium fluoride

figures of merit

general design criterion

high-temperature reactor

high-temperature gas-cooled reactor

instrumentation and controls

International Atomic Energy Agency

internal diameter

In-Line Test Facility

Idaho National Laboratory

intermediate-to-power cycle heat exchanger

internal pipe size

Integral Pool Test Facility

Johnson noise thermometry

licensing basis event

levelized-cost-of-electricity 


\begin{tabular}{|c|c|}
\hline LOCA & loss of coolant accident \\
\hline LOFC & loss of forced convection \\
\hline LOFT & loss of fluid test \\
\hline LSTL & Liquid Salt Test Loop \\
\hline LWR & light-water reactor \\
\hline MHC & molybdenum hafnium carbide \\
\hline MSR & molten salt reactor \\
\hline MSRE & Molten Salt Reactor Experiment \\
\hline MSBR & molten salt breeder reactor \\
\hline NDHX & natural draft heat exchanger \\
\hline NEET & Nuclear Energy Enabling Technologies \\
\hline NEUP-IRP & Nuclear Energy University Program-Integrated Research Project \\
\hline NGNP & next generation nuclear plant \\
\hline NO & normal operation \\
\hline NPP & nuclear power plant \\
\hline NRC & US Nuclear Regulatory Commission \\
\hline $\mathrm{O} \& \mathrm{M}$ & operations and maintenance \\
\hline ORNL & Oak Ridge National Laboratory \\
\hline OSU & The Ohio State University \\
\hline PIE & post-irradiation examination \\
\hline P-IHX & primary to intermediate heat exchanger \\
\hline PIRT & phenomenon identification and ranking table \\
\hline PWR & pressurized water reactor \\
\hline QA & quality assurance \\
\hline $\mathrm{R} \& \mathrm{D}$ & research and development \\
\hline RD\&D & research, development, and demonstration \\
\hline RCCS & reactor cavity cooling system \\
\hline RTD & resistance temperature detector \\
\hline SCALE & Standardized Computer Analyses for Licensing Evaluation \\
\hline SFR & sodium-cooled fast reactor \\
\hline SG & steam generator \\
\hline $\mathrm{SiC}$ & silicon carbide \\
\hline SINAP & Shanghai Institute of Applied Physics \\
\hline SPND & self-powered neutron detector \\
\hline SRP & Standard Review Plan \\
\hline SSC & systems, structures, and components \\
\hline SS316 & type 316 stainless steel \\
\hline $\mathrm{TF}$ & tritium fluoride \\
\hline TGA & technology gap analysis \\
\hline TRISO & tristructural isotropic \\
\hline TRL & technology readiness level \\
\hline TRP & Technical Review Panel \\
\hline
\end{tabular}




\section{EXECUTIVE SUMMARY}

Fluoride salt-cooled high-temperature reactors (FHRs) are an emerging reactor class that combines attractive attributes from previously developed reactor classes and power plants. FHRs by definition feature low-pressure liquid fluoride salt cooling, coated particle fuel, a high-temperature power cycle, and fully passive decay heat rejection. FHRs have the potential to economically and reliably produce large quantities of electricity and high-temperature process heat while maintaining full passive safety. Leveraging the inherent reactor class characteristics avoids the need for expensive, redundant safety structures and systems and is central to making the economic case for FHRs. Additionally, as a hightemperature reactor (HTR) class, FHRs can efficiently generate electricity and provide the energy for high-temperature industrial processes (notably including the production of hydrocarbon fuel). Moreover, high-temperature operation increases FHR compatibility with dry cooling.

This roadmap describes the principal remaining technology challenges and the research, development, and demonstration (RD\&D) needed to address the challenges. This roadmap also provides an integrated overview of the current status of the broad set of technologies necessary to design, evaluate, license, construct, operate, and maintain FHRs. FHRs as a reactor class are transitioning from a stage focusing on assessing concept viability to a stage focusing on engineering development and design optimization. While FHRs have the potential for advantageous economics compared to other reactor classes, they are less technologically mature than either high-temperature gas-cooled reactors (HTGRs) or sodium-cooled fast reactors. This roadmap builds upon previous advanced reactor development efforts and is structured to enable comparison of FHR performance and technology characteristics to that of other reactor classes. The early phase FHR RD\&D program described in this roadmap has been funded by the US Department of Energy Office of Nuclear Energy (DOE-NE) as part of its Advanced Reactor Concepts program.

While widespread commercial deployment remains roughly 20 years in the future even with an adequately resourced development program, the technology overview presented in this roadmap demonstrates that no concept viability issues remain to be resolved for FHRs. However, significant technology development and system maturation issues must be addressed. The higher cost of fuel and coolant, the lack of qualified, salt-compatible structural materials, and the potential for tritium release into the environment are the most obvious issues that must be resolved for FHRs to be built and operated. All of the identified challenges can be resolved and/or substantially mitigated through technology advancements that can be reasonably extrapolated from the current state of the art. Additionally, FHRs lack an approved licensing framework. Consequently, the capability for assessing FHR safety will need to be developed and approved.

None of the technology gaps identified are anticipated to take more than a decade to resolve given reasonable resources. Further, the required tasks can largely be performed in parallel, resulting in a resource- as opposed to a schedule-constrained development path. Thus, the key development challenge is not overcoming specific technological deficiencies but obtaining the financial lift necessary to mature technologies with a payoff two or more decades in the future.

This roadmap lays out an expeditious pathway toward commercial deployment of FHRs. Experience repeatedly demonstrates the adverse consequences of proceeding with projects using technologies that are not sufficiently mature. The basic premise underlying the technology development recommendations presented in this roadmap is to focus on the minimum set of developments necessary to demonstrate safe and reliable performance of first-generation FHRs. A key strategy for minimizing the development cost for first-generation FHRs is to focus development efforts on the technology necessary for a reliable reactor and not attempt to optimize every aspect of the design at the outset. This focused approach avoids the mission creep that would broaden the set of the required technology developments and consequently 
delay deployment of first generation FHRs. Thus, later-generation FHRs will have significant remaining potential for design improvements that would be expected to result in lower costs and increased performance. Designing, building, and operating a number of test and demonstration facilities will represent the largest component of the overall cost of an FHR development program. In particular, demonstrating that an FHR's integrated set of technologies will operate as intended can most effectively be performed using smaller scale test reactors.

The United States has invested substantially in advanced reactor technologies over the past several decades. From the 1950s through the 1970s, the United States had an active molten salt reactor (MSR) development program. Over the past decade significant efforts have been undertaken to develop fully qualified coated particle fuel to support the Next Generation Nuclear Plant (NGNP). Advanced structural alloys to support HTRs have been part of the US advanced reactor program since its inception. More recently the materials effort has been expanded to include structural ceramic composites. The RD\&D work done in the aforementioned advanced reactor technology development programs provides a large part of the technological foundation for FHRs.

The Chinese Academy of Sciences (CAS), through its Shanghai Institute of Applied Physics (SINAP), is currently engaged in a significant FHR development program. The SINAP FHR development program features building and operating two test reactors beginning with a 2 MW first-of-a-kind FHR test reactor with planned initial criticality at the end of 2015 followed by a gradual ascent to power over the next two years. A 10-20 MW test reactor is planned to follow roughly 5 years later. DOE-NE and CAS signed a memorandum of understanding on cooperation in nuclear energy science in December 2011 that facilitates collaboration in FHR development. Cooperation between the existing DOE-NE FHR development activities and the CAS program will allow the United States to leverage its available resources while increasing the effectiveness of the CAS program through obtaining access to US expertise.

The currently limited level of FHR development impacts the depth of analysis and evaluation possible in this roadmap. A complete conceptual design does not exist for any FHR nuclear power plant (NPP). A conceptual design that includes all of the reactor systems, structures, and components (SSCs) is necessary to produce a detailed, comprehensive deployment roadmap. Additionally, while the current roadmap provides an overview of the required development efforts, focused planning will be necessary in each of the technology disciplines. Moreover, sufficient technology uncertainty remains to prevent development of a credible resource-loaded development plan. The present effort fills in the design gaps, as necessary, using engineering judgment to provide an initial lower-fidelity roadmap.

While the full set of FHR technology development issues described in the roadmap will eventually need to be addressed, the set of technology development issues recommended as the initial focus of a broadlybased development program are briefly described in the following paragraphs. Table 8 of Chapter 17, "FHR RD\&D Task Integration and Compilation,” of this roadmap provides a compilation of the full set of recommended tasks. The table identifies the report section that describes the task, provides a brief task description, and lists references to other chapters with related technology development discussions.

\section{Tritium control}

Tritium control is an important issue for FHRs because tritium is the only radionuclide that under normal operating conditions, without failed fuel, has the potential for significant release. Tritium is generated primarily by the interaction of neutrons with lithium and beryllium in the primary coolant. FHRs will produce significantly more tritium than light-water reactors (LWRs) but less than heavy-water-moderated reactors. However, tritium capture at FHRs is complicated because at high temperatures tritium permeates available structural alloys. The large contact surface area and thin walls of heat exchanger tubes means 
that heat exchangers will be the primary release pathway. The primary tritium release prevention mechanism planned for first-generation FHRs is chemical capture to form yttrium tritide within doublewalled heat exchangers. Demonstration of the efficacy of tritium capture technology is the first recommended task to resolve this issue.

\section{Fuel development and qualification}

FHRs will use coated particle fuel. DOE-NE is currently testing tristructural isotropic (TRISO) coated particle fuel as part of its HTGR development efforts. Identical TRISO particles are directly applicable to FHRs. The initial TRISO fuel loads for first-generation FHRs will cost substantially more than LWR fuel pellets. TRISO fuel is not currently manufactured at the commercial scale. Consequently, the cost savings resulting from manufacturing scale-up and automation cannot be reliably estimated at this time. FHRs, like LWRs, are thermal spectrum reactors intended to run on a once-through low-enrichment uranium fuel cycle. However, FHRs will require somewhat higher ${ }^{235} \mathrm{U}$ enrichment than that currently employed at LWRs, which will incur substantial costs to modify the existing fuel infrastructure. LWRs can also benefit from higher enrichment fuel. Consequently, planning to increase US commercial fuel enrichment capabilities has already begun. The nonmanufacturing fuel costs for FHR TRISO are expected to be similar to those for the increased enrichment for LWR pellets. Completion of the ongoing TRISO qualification irradiation program is the first recommended task. Also, more detailed evaluation of the qualification differences between TRISO for HTGRs and FHRs is recommended in the near term.

\section{Lithium-7 cost}

Individual units of large-scale FHR NPPs are anticipated to use a few hundred tons of isotopically selected ( 99.995\%) ${ }^{7} \mathrm{Li}$. Developing a reliable, cost-effective supply of ${ }^{7} \mathrm{Li}$ is, thus, necessary for FHRs to be economically preferable. Lithium isotopes can be separated using conventional chemical technologies with well-understood cost vs production volume cost scaling relationships. Several alternative techniques have potential for separating lithium isotopes on an industrial scale and at a reasonable cost. It is not currently possible to specify a technically preferred lithium isotope separation technique. A trade study comparing and evaluating the potential separation technologies is the recommended first task to resolve this issue.

\section{Licensing}

Licensability is a key element of any reactor development effort. Securing licensing approval from the US Nuclear Regulatory Commission (NRC) is based upon demonstrating compliance with the general design criteria (GDCs) for commercial NPPs established in the Code of Federal Regulations. NRC and DOE have initiated a joint initiative to develop a regulatory framework for non-LWR advanced reactors that will include a set of generic GDCs for these types of reactors. Once generic GDCs are developed, a review standard specifically for FHRs could then be developed by NRC to provide guidance on reactorclass-specific aspects. The FHR concept development effort currently under way expressly focuses on those technologies and design features that appear to provide the most direct path to securing generic GDC-based design approval. In particular, this roadmap is structured to follow a risk-informed, performance-based, design basis accident- (DBA-) based development approach. In the envisioned design approach, risk assessments would be used to provide guidance on how to improve the probability of the design to adequately respond to accident scenarios. Similarly, performance-based design would incorporate the consequences of the failure of particular SSCs into the design process to focus resources on the most significant issues. Also, an evaluation of the progression of DBAs would guide the plant design to minimize the risk significance of particular accident scenarios. For example, the significance of a loss of coolant accident within the plant piping would be minimized by only having vessel penetrations well above the reactor core. A design-enhancement approach would be used for beyond-design-basis accidents so that even in the event of a severe accident, critical plant functions would be maintained. 
Defining accident initiators and selecting licensing basis accident sequences are recommended as the first programmatic task within this topic area.

\section{Concept maturation}

A complete preconceptual design incorporating all of the specialized SSCs of FHRs does not yet exist. However, initial candidate technologies have been identified for all required FHR functions. Substantial uncertainty remains in key elements of plant design and technology implementation. Developing a complete conceptual design will provide a unifying framework to enable an integrated set of technology choices to be made. Concept development also identifies technologies that require longer term development (e.g., structural alloy creep testing) that, in turn, assist in determining the overall timeline for development and deployment of the reactor class. The SSCs are interdependent, and thus, all of the plant technology areas should be maintained at about the same level of maturity throughout the development

process. Currently, additional work on evaluating the hydraulic and heat transfer performance is needed to bring this area to a comparable level with other FHR technology areas. Additionally, assessment of plant systems that have received only cursory investigation, thus far, such as the reactor cavity cooling system and the salt cleanup system is also recommended as a near-term concept maturation focus.

\section{Primary coolant redox control}

High-temperature fluoride salts will dissolve oxide protective layers on structural alloys. Hence, in contrast to other reactor classes, the structural alloys for FHRs need to be thermodynamically stable to protect against corrosion by the primary coolant rather than relying on a protective oxide coating. The metal atoms composing the container wall are in their most reduced state, and fluorine only has two redox states. Thus, corrosion by the primary coolant fluoride salt would occur primarily through oxidation of the metal atoms. Oxygen introduced inadvertently is anticipated to be the major cause for the primary coolant becoming corrosive. Sparging the primary coolant with $\mathrm{HF} / \mathrm{H}_{2}$ gas mixtures is the leading candidate technique to remove oxygen from the primary coolant. Periodically contacting the primary coolant with metallic beryllium will also shift the primary coolant into a more reducing condition. Cathodic protection may offer a supplemental capability to provide more precise redox control. Developing an integrated primary coolant redox control system design and validating the utility of cathodic protection in industrial fluoride salt systems are recommended as the leading tasks in this area.

\section{Primary coolant cleanup}

The fuel performance requirements of FHRs will be similar to those of other liquid-cooled reactors. While properly fabricated TRISO fuel will have hundreds of degrees of thermal margin to failure, defective fuel could leak both fission products and fissile material into the primary coolant. Prior MSR experience provides strong evidence that the leaking radionuclides (apart from the noble fission gases) will be retained in the primary coolant. The extent to which defective fuel can be tolerated in an FHR will depend on how effectively the primary coolant can be cleaned up of these contaminants. A lithium-activated bismuth metal contacting system is the leading candidate technology to remove the contaminants. Much of the technology necessary for a bismuth-lithium-based salt cleanup system was demonstrated at the laboratory scale during the earlier MSR program. However, substantial work remains to be done to develop this technology sufficiently for use at FHRs. The first recommended tasks in this area are to develop a conceptual design for a robust salt cleanup system and to begin laboratory-scale investigations of the primary salt cleanup system based upon modern materials.

\section{Liquid salt test loop}

Liquid salt heat transport is central to FHR operation. Experimentally validating the performance of components necessary for heat transfer is central to FHR development. Much of the technology base for FHR hydraulic components comes from the earlier MSR program. Both improved materials and the 
general progression of high-temperature technology over the intervening decades provide an improved technical basis for resolving the remaining issues. DOE-NE has constructed a liquid salt test loop (LSTL) at the Oak Ridge National Laboratory (ORNL) to support development and performance validation of FHR hydraulic components. The first recommended hydraulic experimental task is to commission and begin operation of the test loop in preparation for a series of experimental runs to validate these key components.

\section{Optically based instrumentation}

Fluoride salts are transparent, and FHRs operate well below the coolant boiling point. The current design intent is to rely upon the transparency for a substantial portion of the reactor instrumentation. The ability to locate sensor materials away from the harsh reactor core environment is a significant operational advantage for FHRs. However, the use of optically based instrumentation at FHRs has unresolved technology issues such as ensuring that in-vessel windows and mirrors remain transparent or reflective. In addition, the means to maintain visual alignment throughout the reactor life cycle and to accommodate the motion of the primary coolant surface will need to be developed and demonstrated. Experimental demonstration of optically based and vision-based measurements at LSTL and other salt experimental facilities is recommended as the first task in this area.

\section{Continuous fiber composites}

FHRs will make extensive use of continuous fiber composites (CFCs) for reactor vessel internal components. Some of these components will be large and have complex geometry (e.g., the lower core support plate). CFCs are being evaluated for in-vessel structural applications in other reactor classes (e.g., using silicon carbide-silicon carbide CFCs as channel boxes at boiling water reactors to minimize the core zirconium content); however, a significantly larger role for CFCs is envisioned at FHRs due to their ability to maintain their structural characteristics at high-temperatures. Initiating an FHR-focused CFC development program is recommended as the first task in this area.

\section{Structural alloy development and qualification}

A substantial body of knowledge exists for Alloy N, the leading candidate material for FHR test reactors. Alloy N, however, is not currently approved as a material for high-temperature NPPs. Thus, a materials qualification effort would be required for use of Alloy $\mathrm{N}$ in any part of the containment boundary or to perform any other safety function. Developing a safety case for limited term Alloy $\mathrm{N}$ use at temperatures less than $704^{\circ} \mathrm{C}$ may be possible based upon existing data from the earlier MSR program and/or limited term supplemental qualification testing. The maximum allowable stress for Alloy $\mathrm{N}$ decreases rapidly above $600^{\circ} \mathrm{C}$, becoming too low for practical use above $700^{\circ} \mathrm{C}$. Compared to the leading candidate materials that are usually considered for high-temperature nuclear reactor construction, Alloy $\mathrm{N}$ has significantly lower high-temperature strength. However, developing and qualifying improved performance alloys for longer term high stress applications will require substantial investment over a number of years. ORNL has recently begun the development of successor alloys to Alloy N. Samples of the new alloys show promise for application in high stress applications at higher temperatures along with good fluoride salt corrosion resistance. As a first step, it is recommended to begin early phase, long-term advanced salt-compatible alloy property measurements. Thus, improved alloys can be developed and made available for commercial FHR deployments while a limited-term safety case for use of Alloy $\mathrm{N}$ at test reactors can be developed in parallel.

\section{Surrogate material thermal and hydraulic testing}

Proper fluid flow and heat transfer are central to the normal and accident condition performance of NPPs. However, heat transfer, fluid flow, and fluid structure interactions are complex phenomena that are challenging to model computationally with adequate fidelity for reactor design. Experimental models are, 
therefore, used to validate and provide assurance that the relevant phenomena have been properly accounted for by the computational models. FHRs feature single-phase low-pressure coolant flow. Because of this, experimental models with similar thermal and hydraulic performance can be constructed using surrogate materials at significantly lower temperatures than those in an operating reactor. These lower cost experimental simulations can provide valuable insight into difficult-to-model phenomena such as the start-up of natural circulation cooling or the vibration of in-vessel structures. Several US universities already have significant simulant fluid demonstration facilities under development. It is recommended that these facilities be completed and that their experimental results be documented, under an appropriate quality assurance (QA) program, as a starting point for validating the thermal and hydraulic modeling tools planned to be used for FHR design and approval.

\section{Commercialization path}

The envisioned pathway for FHRs to enter commercial service in the United States is to rely upon the first and second FHR test reactors that are currently planned to be constructed in China to provide a substantial amount of the experience and information necessary for commercialization. The test reactor program will be supported by a number of worldwide technology development efforts, with the US-China collaborative RD\&D project being especially key. A first-generation FHR prototype plant would be reasonable to construct and license in the United States following operation of the second Chinese test reactor with initial criticality of the prototype plant between 2027-30. Constructing the prototype FHR in the United States will subject the plant to full NRC review providing the highest possible degree of confidence in the safety characteristics of the reactor class. The prototype plant would be intended to transition to fully commercial operation (and a commercial operating license) following a probationary period involving restricted operating conditions and enhanced NRC scrutiny. The prototype plant is intended to be the first plant to make use of advanced salt-compatible materials. As material qualification requires long-duration testing, beginning property and performance measurements under a nuclear power QA program is recommended as a key near-term activity. The prototype plant would be anticipated to be commerciallyowned and operated, but with federal support for the prototype and licensing aspects of the plant similar to the current small, modular LWR licensing support program. Subsequent FHR plant designs would then be licensable by NRC under normal commercial conditions.

A high-level overview of the FHR development tasks and time frame is shown in Fig. 1. Most of the required tasks can proceed in parallel with adequate resource availability. Figure 1 incorporates the Czech Republic's plans for FHR critical facility testing, SINAP's plans for constructing two test reactors as precursors to the first prototype reactor, and the technical foundations provided by the long-term investments made by the United States in advanced reactor technologies over the past decades. In addition, the figure shows a 15-year effort culminating in the development and deployment of a prototype FHR intended to be subject to NRC licensing, initially as a prototype reactor and later progressing to a commercial operating license. The figure also reflects a number of implicit assumptions: (1) that the required resources are available, (2) a continued collaborative international RD\&D program, and (3) achieving successful results from the RD\&D tasks. 


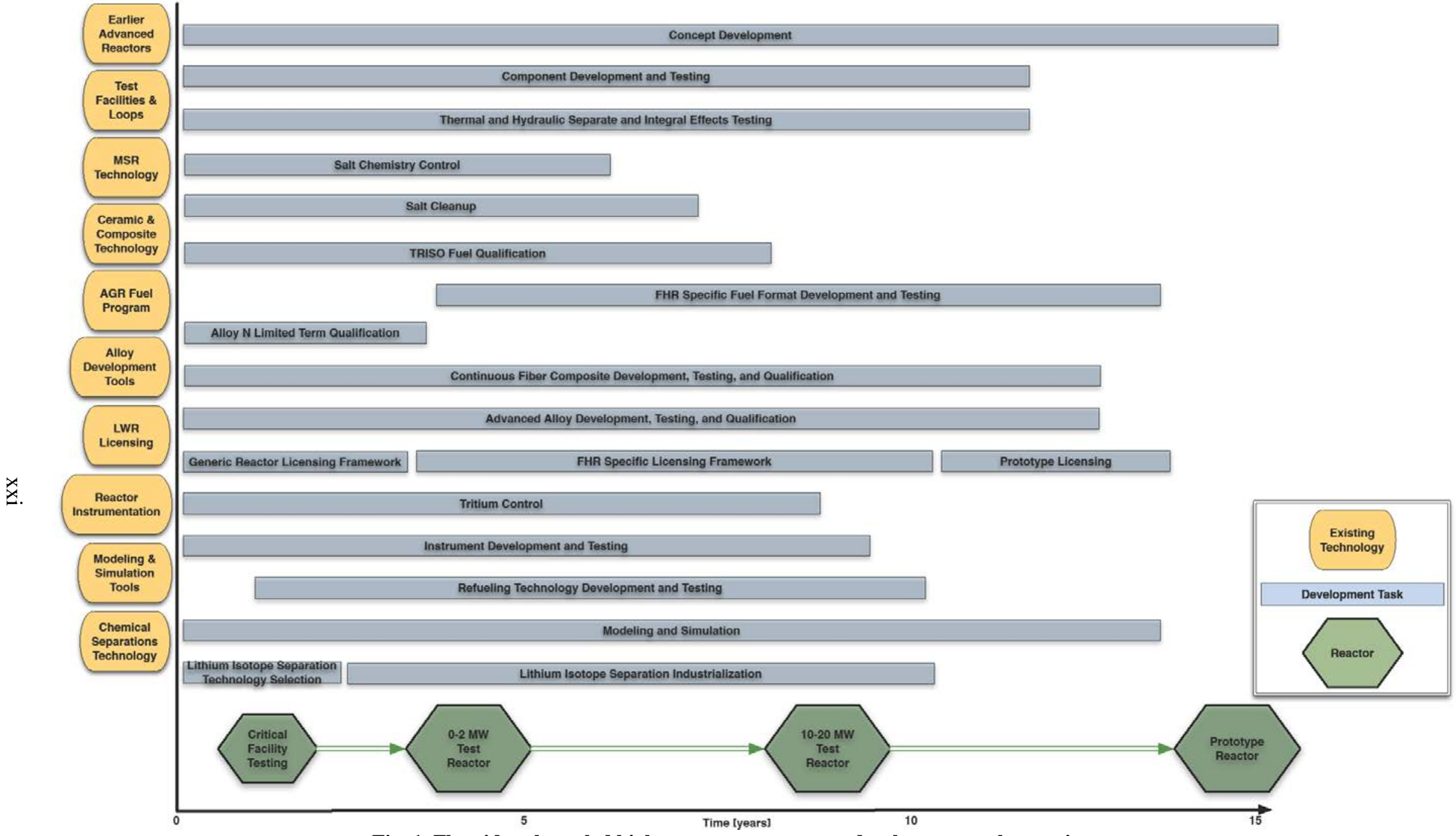

Fig. 1. Fluoride salt-cooled high-temperature reactor development task overview. 


\begin{abstract}
Fluoride salt-cooled high-temperature reactors (FHRs) are an emerging reactor class with potentially advantageous performance characteristics and fully passive safety. This roadmap describes the principal remaining FHR technology challenges and the development path needed to address the challenges. This roadmap also provides an integrated overview of the current status of the broad set of technologies necessary to design, evaluate, license, construct, operate, and maintain FHRs. First-generation FHRs will not require any technology breakthroughs, but do require significant concept development, system integration, and technology maturation. FHRs are currently entering early phase engineering development. As such, this roadmap is not as technically detailed or specific as would be the case for a more mature reactor class. The higher cost of fuel and coolant; the lack of an approved licensing framework; the lack of qualified, salt-compatible structural materials; and the potential for tritium release into the environment are the most obvious issues that remain to be resolved.
\end{abstract}




\section{INTRODUCTION}

The objective of this roadmap is to lay out a research, development, and demonstration (RD\&D) pathway for expeditious commercial deployment of first-generation fluoride salt-cooled high-temperature reactors (FHRs) for electricity generation. This roadmap describes the current technology base for FHRs, the principal remaining technology challenges, and the RD\&D needed to address the challenges. Commercial deployment of any advanced nuclear power plant (NPP) requires demonstration of its cost competiveness, reliability, safety, and licensability. This roadmap, thus, is focused on providing a logical RD\&D pathway for the technologies necessary to design, license, construct, and operate economically advantageous FHRs.

FHRs are an emerging reactor class that combines attractive attributes from previously developed reactor classes and power plants. FHRs by definition feature low-pressure, liquid fluoride salt-cooling, coated particle fuel; a high-temperature power cycle; and fully passive decay heat rejection. FHRs have the potential to economically and reliably produce large quantities of energy while maintaining full passive safety. Developing FHRs into an economically preferable reactor class, however, requires overcoming a number of technical challenges. Early phase, small-scale investigations have already been under way for roughly a decade, enabling assessment of the scope and scale of the remaining challenges. FHRs rely primarily on advancing and combining established technologies, and no technical hurdles have been identified to date that would prevent FHRs from being developed into economically advantageous NPPs.

Designing, building, and operating a number of test and demonstration facilities will represent the largest component of the overall cost of an FHR development program. In particular, demonstrating that an FHR's integrated set of technologies will operate successfully and safely can most effectively be performed using smaller scale test reactors. Developing confidence in the overall system performance and generating the data necessary to support the safety basis for licensing form the fundamental principles for structuring this $\mathrm{RD} \& \mathrm{D}$ roadmap.

The most mature FHR design currently available is for the advanced high-temperature reactor (AHTR). The AHTR is a design concept for a first-generation, large power output [3,400 MW(th)], central station type FHR. The recently published AHTR Mechanical, Structural, and Neutronic Preconceptual Design report provides an overall plant description and includes an overview of the principal safety features (Ref. 1). The AHTR is used as a template in developing the roadmap. However, the AHTR is a concept development platform not a reactor design. It is intended that the capabilities and technologies developed and validated following this roadmap will provide a sufficient basis to enable commercial FHR NPP development. Commercial reactor vendors will develop their own proprietary reactor designs. Using a central-station-scale reactor for the concept development platform is useful in that large-scale systems exhibit the full range of issues of the reactor class. The first commercial reactor will likely have significantly smaller thermal output than the AHTR concept specifies. A schematic of the AHTR plant configuration is shown as Fig. 2 and an overview of its design characteristics is shown as Table 1. 


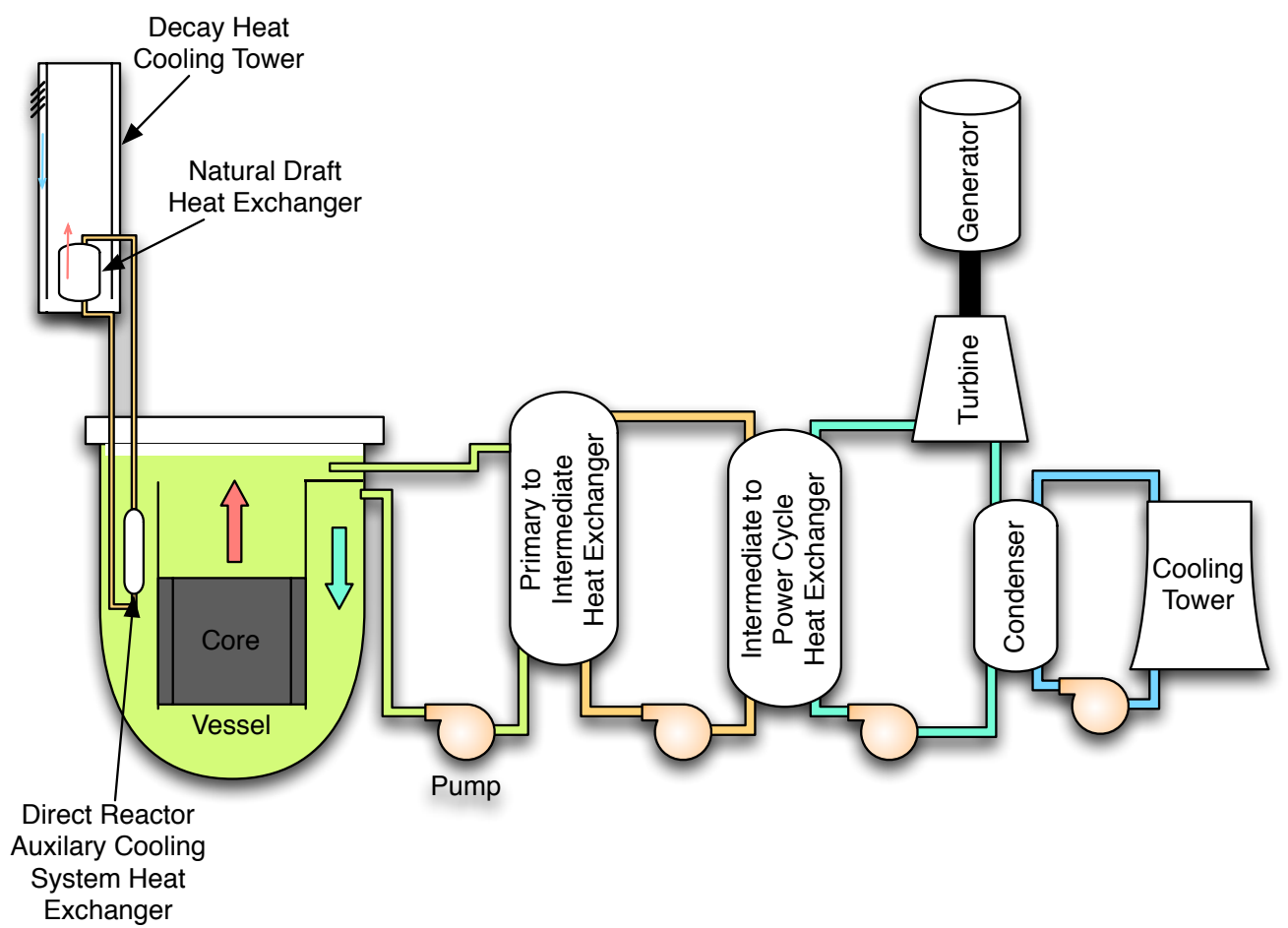

Fig. 2. AHTR plant configuration overview.

Table 1. AHTR overall design values

\begin{tabular}{ll}
\hline Thermal power & $3400 \mathrm{MW}$ \\
Electrical power & $1500 \mathrm{MW}$ \\
Top plenum temperature & $700{ }^{\circ} \mathrm{C}$ \\
Coolant return temperature & $650{ }^{\circ} \mathrm{C}$ \\
Number of primary loops & 3 \\
Primary coolant & $2^{7} \mathrm{LiF}^{-\mathrm{BeF}_{2}}$ \\
Primary coolant flow rate & $28,500 \mathrm{~kg} / \mathrm{s}$ \\
Fuel type & Tri-structural isotropic particles in \\
& carbon plates \\
Fuel plates per assembly & 18 \\
Number of fuel assemblies & 252 \\
Uranium enrichment & $9 \%$ \\
Refueling & $2 \mathrm{batch}, 6$ month interval \\
Core height (fueled region) & $5.5 \mathrm{~m}$ \\
Intermediate coolant salt & $\mathrm{KF}-\mathrm{ZrF}$ \\
Intermediate salt flow rate & $43,200 \mathrm{~kg} / \mathrm{s}$ \\
\hline
\end{tabular}

FHRs are a broad reactor class that maintains strong passive safety at almost any scale and features significant evolutionary potential for higher thermal efficiency (through higher temperatures), process heat applications, online refueling, thorium use, and alternative power cycles. The RD\&D described in this roadmap also supports later generation FHRs. Pebble bed FHRs appear to have significant merit in enabling online refueling. However, online refueling will require additional technology development. Moreover, online refueling is not compatible with the existing NRC licensing framework. Changing the US Nuclear Regulatory Commission (NRC) licensing framework would be an uncertain, time consuming, and expensive endeavor. This roadmap, therefore, is restricted to fixed fuel forms.

The Chinese Academy of Sciences (CAS) is currently engaged in a large, parallel FHR development effort. The Shanghai Institute of Applied Physics (SINAP) is leading the CAS efforts. The SINAP FHR 
development program features building and operating two test reactors beginning with a 2 MW first-of-akind test FHR with planned initial criticality at the end of 2015 followed by a gradual ascent to power over the next 2 years. A 10-20 MW test reactor is planned to follow roughly 5 years later. To avoid duplication, it is intended that the early phase RD\&D described in this roadmap will be coordinated and integrated with the ongoing CAS program. This roadmap does not attempt to differentiate in which program specific tasks will be performed but instead concentrates on identifying the technical RD\&D requirements.

\subsection{DEVELOPMENT ISSUES AND TIME FRAME}

This roadmap identifies and describes the currently known FHR development challenges and the required RD\&D to address them. The higher cost of fuel and coolant, the lack of qualified, salt-compatible structural materials, and the potential for the release of large amounts of tritium into the environment are the most obvious issues that must be resolved for FHRs to be built and operated. All of the identified challenges can be resolved and/or substantially mitigated through technology advancements that can be reasonably extrapolated from the current state of the art. Additionally, FHRs lack an approved licensing framework. Thus, the capability for assessing FHR safety will need to be developed. Another key remaining issue is to demonstrate technology for preventing tritium release. Over the past few decades, tritium control technologies have been developed for related applications (e.g., fusion first wall systems), but will need to be customized for FHRs. No significant FHR concept viability issues have been identified to date. FHRs, as a reactor class, are transitioning from a stage focused on assessing the viability of the concept to a stage focusing on engineering development and design optimization.

None of the technology gaps identified is anticipated to take more than a decade to resolve given reasonable resources. FHRs will make extensive use of the US Department of Energy Office of Nuclear Energy (DOE-NE) on-going advanced gas reactor (AGR) fuel development and qualification program to shorten their fuel development timeline. Additionally, the high-temperature structural materials development efforts currently under way in other DOE-NE programs can be leveraged to avoid FHRs having to bear the entire financial and technology development burden for qualifying continuous fiber ceramic composites for nuclear reactor use. Each of the primary development areas is largely independent and they, thus, can proceed in parallel. The FHR development timeline that emerges from the tasks in this roadmap is, therefore, resource- as opposed to schedule-constrained. Furthermore, versions of all required reactor technologies already available (although not tailored or optimized for FHRs) allow proceeding toward constructing an initial, low-power test reactor. The early test reactor deployment approach, relying on only currently available technology, is the plan currently being executed by the CAS program. Operation of a second-generation higher power test FHR is planned for roughly 5 years following deployment of the initial test reactor by the SINAP team in the 2015-17 time frame.

The basic premise underlying the development recommendations is to focus on the minimum set of technology developments necessary to demonstrate safe, reliable performance. Thus, establishing what constitutes technical adequacy is a central focus of the requirements evaluation. Key elements in reducing the development time and minimizing cost are to (1) refrain from challenging the operating limits of systems, structures, and components (SSCs) and (2) restrict use of advanced technologies to those elements necessary for a reliable, licensable FHR. Introduction of "elegant solutions" and challenging performance goals would entail considerably more time and cost to demonstrate. The introduction of unproven technologies into large projects almost invariably results in increased costs and schedule delays. Prior technology development programs have repeatedly demonstrated that integrated system reliability as opposed to optimal performance is key to cost-effective, timely deployment of first-generation systems. Thus, significant and intentional effort is made throughout this technology roadmap to not introduce new technologies outside of those required for the reactor. FHRs are anticipated to be at least 
economically competitive with and potentially preferable to light-water reactors (LWRs) without having to use advanced technologies beyond those described in this roadmap.

\subsection{ECONOMIC PERFORMANCE}

FHRs must be an obviously economically preferable means to generate energy to justify a significant development program. LWRs are a reliable, mature reactor technology with an established cost and performance basis. Significant effort from the 1970s through the 1990s was required for LWRs to achieve their current high level of reliability and availability. An organizing principle of the FHR development plans is to incorporate the applicable LWR reliability lessons learned to reduce the challenges of introducing and operating a new reactor class. FHRs have the opportunity to combine the LWR legacy of learning with their own advantageous characteristics to provide an even more reliable, lower cost option for generating electricity and providing industrial process heat.

This roadmap focuses upon the RD\&D necessary for initial commercial deployment of FHRs for electricity generation. While FHRs also appear to be desirable for industrial heat production (e.g., to support liquid hydrocarbon fuel production), developing the technologies necessary to support multiple products would dilute the limited resources for FHR development. Moreover, the distinctive issues for NPPs are in the nuclear island portion of the plant and electricity production is a large and proven market for nuclear power. Consequently, industrial heat source utilization technologies are beyond the scope of this initial roadmap.

Both the primary coolant and fuel form of FHRs differ substantially from those of LWRs. The advantageous properties of fluoride salt coolants and tristructural isotropic (TRISO) coated particle fuel provide the potential for improved performance as compared to an LWR and more straightforward licensing as compared to other non-light-water advanced reactors. However, isotopically selected fluoride salts will cost substantially more than water, and TRISO fuel will, at least initially, cost substantially more than LWR fuel pellets simply because of the high cost of small batch TRISO fuel fabrication vs the established infrastructure for industrial-scale manufacturing of LWR fuel. From the 1950s through the 1960s, the United States produced industrial quantities of isotopically separated lithium at a reasonable cost. However, the industrial capability for lithium isotope separation disappeared when further supplies were not needed and the mercury-based separation process raised environmental concerns. Developing and demonstrating improved technologies for economic industrial-scale lithium isotope separation and for lowering the production cost of TRISO fuel are, thus, prerequisites for FHRs to become economically preferable.

\subsection{DESIGN CONSTRAINT INTEGRATION}

The development objective to maximize the system reliability strongly suggests using the minimum core outlet temperature possible in any first-generation FHR. While increasing the core outlet temperature could directly increase the plant thermal efficiency, the metallic primary coolant boundary, the plant hydraulic components, and the process monitoring instrumentation
The primary coolant of FHRs will be a liquid fluoride salt. While several fluoride salts could be used in FHRs, the combination of desirable neutronic properties, good hydraulic performance, and very low activation of $2^{7} \mathrm{LiF}_{-\mathrm{BeF}}$ (FLiBe) makes it the preferred primary coolant. The boiling point of $\mathrm{FLiBe}$ is more than $1400^{\circ} \mathrm{C}$, and its volumetric heat capacity at $700^{\circ} \mathrm{C}$ is $4.67 \mathrm{~J} / \mathrm{cm}^{3}-\mathrm{K}$ (as compared to $4.04 \mathrm{~J} / \mathrm{cm}^{3}-\mathrm{K}$ for water at $100^{\circ} \mathrm{C}$ ).
The TRISO fuel particles selected for FHR use consist of a microsphere (i.e., kernel) of uranium oxycarbide material encapsulated by multiple layers of pyrocarbon and a silicon carbide layer. This multiple-coating-layer system has been engineered to retain the fission products generated by fission of the nuclear material in the kernel during normal operation and all licensing basis events over the design life of the fuel. 
are all significantly more challenged by higher temperatures. The temperatures of a first-generation FHR; however, are not anticipated to challenge the TRISO fuel, fluoride salt coolant, or the ceramic structural elements. Thus, FHRs have an evolutionary development path towards higher temperatures as improved structural and functional materials are developed.

Competing against the imperative to minimize the coolant peak temperature is the requirement to have a sufficiently high thermal efficiency for economic reasons to justify the FHR development costs. Unless a significant increase in thermal efficiency can be achieved, FHRs would likely remain in the research phase until their potential could be demonstrated in practice. While the potential full passive safety of FHRs is attractive, passive safety alone is not sufficient to justify transitioning away from proven (and acceptably safe) LWR technology. During 2011, an economic model was developed for the AHTR's anticipated levelized unit electricity cost with a $700^{\circ} \mathrm{C}$ core outlet temperature (Ref. 2). While considerable uncertainty remains in the cost projections, largely due to the immaturity of the AHTR's design and required technologies, the AHTR is anticipated to be economically preferable given reasonable technology developments.

The practical upper temperature limit for an FHR is dictated by the creep properties of the alloy selected for the thin-walled tubing of the intermediate-to-power cycle heat exchanger (I-PHX). The power cycle working fluid will be at both high temperature and high pressure. The I-PHX is the only location where the liquid salt is adjacent to a high-pressure system. Further, the I-PHX tubing cannot readily be coated to provide chemical protection from the fluoride salt due to the solid-state interdiffusion of alloy and coating constituent elements at elevated temperature and the necessity of keeping the tube walls thin for effective heat transfer. Over time at high-temperature, this interdiffusion would degrade the alloy mechanical properties and the coating's corrosion resistance. Additionally, I-PHXs are sufficiently large and expensive as to be prohibitively difficult to replace. Hence, the I-PHX's longevity and reliability are critical design constraints.

Much as with an FHR, the peak cycle temperature in coal-fired power plants is constrained by the peak temperature and pressure combination of the power cycle working fluid. Insight into optimal choices for the power cycle working fluid and peak cycle temperature can thus be gained by examining the choices made in advanced coal-fired power plant design. The most advanced coal-fired power plants use steam as a working fluid with a peak steam temperature of $650^{\circ} \mathrm{C}$. With steam as the working fluid, an FHR's IPHX becomes a steam generator (SG) with mechanical and structural configuration optimization similar (albeit at higher pressures and temperatures and with different chemistry) to that of a sodium-cooled fast reactor (SFR) SG. The current plans of the Next Generation Nuclear Plant Industry Alliance for commercializing its high-temperature gas-cooled reactor (HTGR) design also rely on a steam cycle for electricity generation. HTGRs have somewhat different design limits than FHRs as they have high pressure on both the steam and helium sides of their heat exchangers, but they have sufficient similarity for their design choices to provide insight into FHR designs. The NGNP Industry Alliance plans to use helical coil SGs with a $750^{\circ} \mathrm{C}$ hot side inlet temperature and a $325^{\circ} \mathrm{C}$ hot side outlet temperature to achieve a peak steam temperature of $566^{\circ} \mathrm{C}$ at $16.7 \mathrm{MPa}$ (Ref. '3).

The technology readiness level (TRL) of the SG varies with the core outlet temperature. Both SFRs and HTGRs use helical coil SGs, and thus, at a sufficiently low temperature, the TRL level of an FHR SG approaches 8, as its design requirements merge with those of proven SGs from other reactor classes. Moreover, the Molten Salt Breeder Reactor (MSBR) program produced a relatively detailed design for a large molten salt SG (Ref. 4). Reducing the core outlet temperature, however, directly decreases the plant thermal efficiency. Consequently, a strong economic driver exists to produce as high a steam temperature as practical. In addition to high strength, the SG alloy needs to be chemically compatible with fluoride salts and steam and have proven forming and joining methods. Alloy $\mathrm{N}$ is both fluoride salt and steam compatible, and forming and joining techniques for it have been validated. However, the time to $1 \%$ creep 
(typical material service limit) of Alloy $\mathrm{N}$ is much shorter than the reactor 60-year design life for reasonable SG tube design parameters above approximately $600-625^{\circ} \mathrm{C}$ (Ref. 5). Thus, the expensive Alloy N SGs would need to be replaced, perhaps multiple times, over the life of the plant; the core outlet temperature would need to be reduced to less than $650^{\circ} \mathrm{C}$; or an improved salt compatible alloy would need to be used for FHR SGs.

Gaining ASME International (ASME) Boiler and Pressure Vessel Code (BPVC) Sect. III Division 5 (“High-Temperature Reactor Components") certification of a new alloy for long service life requires long-duration, expensive qualification testing. Both stainless steel 316 (SS316) and Alloy 800H have 60year design allowances in BPVC Sect. III Division 5, and an effort is currently under way to qualify Alloy 617. However, the available qualified alloys have not been designed for salt compatibility and consequently have much greater fluoride salt corrosion rates than Alloy $\mathrm{N}$. The higher corrosion rates are especially significant in thin-walled heat exchanger tubing. Moreover, the mechanical properties of the available alloys degrade at high temperatures over time (a few years) sufficiently to preclude achievement of significantly higher steam temperatures. Note however, that due to the intermediate loop, the SG of an FHR is not part of the primary coolant boundary, and thus, the SG alloy would likely only need to be qualified for industrial code rules, which reduces the material qualification requirements sufficiently that advanced alloy development becomes a recommended task even for a first-generation FHR.

A dual path structural alloy RD\&D strategy is recommended focusing on building a limited term code case for Alloy $\mathrm{N}$ for use in test reactors while pursing development of higher performing alloys for commercial FHR power plants. Chapter 5 of this roadmap includes further discussion of the alloy selection issues, the heat exchanger configuration options, and a series of recommended tasks to mature the new alloys sufficiently for use in FHR SGs with a core outlet temperature of $700^{\circ} \mathrm{C}$. Chapter 5 also includes a discussion of the trade studies necessary for an optimal first-generation FHR SG design.

\subsection{TRITIUM MANAGEMENT}

FHRs will generate substantially more tritium than LWRs, but much less than heavy-water-moderated reactors. Tritium production is an important safety issue for FHRs because it is the only radionuclide that under normal operating conditions, without failed fuel, has the potential for significant environmental release. The potential for tritium release was cited as a major issue in the WASH-1222 report that was instrumental in the decision to discontinue the US molten salt reactor (MSR) program (Ref. 6). At high temperatures (above $\sim 300^{\circ} \mathrm{C}$ ), tritium can permeate rapidly through structural alloys. The large contact surface area and thin walls of heat exchanger tubes means that heat exchangers would be a primary release pathway into the intermediate loop, the power cycle steam, maintenance heat exchanger coolant, and/or direct reactor auxiliary cooling system (DRACS) natural draft heat exchanger (NDHX) and, eventually, out into the environment.

A sodium fluoroborate eutectic was proposed as the MSBR intermediate coolant salt to trap the tritium as a borohydrate (Ref. 7). This recommendation was based on experiments conducted in an engineeringscale facility that demonstrated the chemical trapping capability of the sodium fluoroborate salt. Boron trifluoride- $\left(\mathrm{BF}_{3}-\right)$ based tritium trapping is not currently the preferred option due to several deleterious properties such as high toxicity and a tendency to hydrolyze to form hydrogen fluoride and hydroxyfluoroborate upon contact with moist air (or in the lung). Any leakage of moisture into the coolant system would rapidly generate highly corrosive $\mathrm{HF}$ and hydroxyfluoroborate. Further, $\mathrm{BF}_{3}$ has a relatively high vapor pressure and even operations such as bubbling an inert gas through the salt can cause plugging problems due to the local depletion of $\mathrm{BF}_{3}$ from the salt and the resultant local increase in the melting point (Ref. 8). 
Chemically trapping of the tritium into a hydride, however, remains a preferred option for preventing tritium release. Trapping the tritium within the reactor building is preferable as this configuration preserves the separation of the nonnuclear power cycle from radionuclides. An optimal configuration for tritium containment has not yet been determined. However, over the past few decades, double-walled heat exchangers, which are expressly designed to prevent contact between the primary and secondary fluids, have become more common. Providing a chemical trap (i.e., a getter) within the central section of a double-walled heat exchanger appears to be an effective tritium containment mechanism. Several rare earth elements (notably yttrium) form high-temperature stable hydrides upon contacting tritium. Several alternate yttrium gettering configurations are possible within the central section of a double-walled heat exchanger ranging from a palladium coated foil layer to a nanoparticulate yttrium suspension within a sodium-potassium liquid. Diffusion barriers can also be used to augment the tritium trapping. Effective diffusion barriers, however, are technically challenging as a crack or pinhole will dramatically reduce their effectiveness much as a small leak reduces the effectiveness of a bucket. Overall, developing and demonstrating an effective tritium containment strategy remains a leading task to enable safe operation.

\subsection{LICENSABILITY}

Consideration of licensability is a key element to any reactor development effort. The licensing basis promulgated by NRC is principally focused on large LWRs. Further, the currently deployed US reactor fleet is entirely composed of LWRs. Consequently, NRC's expertise and experience is considerably greater for LWRs than for non-LWR classes. Thus, developing the capability to demonstrate that particular FHR designs can be operated without undue risk to the public or the environment will be an important aspect to the FHR development program.

Undergoing an NRC safety review is a prerequisite for FHRs to enter into commercial service. Securing a design certification (DC) from NRC is based upon demonstrating compliance with the general NPP design criteria established in the Code of Federal Regulations. Prior reactor certifications have established precedence as to what design features constitute an acceptable means of demonstrating achievement of the general design criteria (GDCs). The FHR development program has already produced an initial candidate set of FHR GDCs (Ref. 9).

A combined effort by NRC and DOE is currently under way to develop a more direct licensing path for advanced reactors. During 2012, DOE instituted an Advanced Reactor Concepts (ARC) Technical Review Panel (TRP) process to evaluate viable reactor concepts from industry and to identify research and development $(\mathrm{R} \& \mathrm{D})$ needs. Early in the process, TRP members and advanced reactor designers noted the need to develop a regulatory framework for advanced non-LWRs to reduce the risk and uncertainty to industry. Concurrently in 2012 and in response to congressional direction, NRC provided a report to Congress on advanced reactor licensing (Ref. 10). In the advanced reactor licensing report NRC noted that several reactor vendors identified the need for regulatory guidance for non-LWR designs. Thus, NRC and DOE initiated a joint program to develop a regulatory framework for advanced non-LWRs that will include a set of generic or technology neutral GDCs. Once the generic GDCs are developed, a review standard for FHRs [analogous to NUREG-0800 (Ref. 11)] could be developed by NRC to provide guidance on reactor class-specific aspects. The American Nuclear Society (ANS) has an FHR design/safety standard development effort (ANS 20.1) currently under way that supports this regulatory approach. The development of a consensus industry design/safety standard for FHRs combined with the NRC-DOE initiative will provide a more defined path forward and more certainty for licensing of FHRs.

The FHR concept development effort currently under way expressly focuses on those technologies and design features that appear to provide the most direct path to securing a DC. In particular, this roadmap is structured to follow a risk-informed, performance-based, design basis accident- (DBA-) based development approach, as recommended in NUREG-2150 (Ref. 12), along with a design-enhancement 
approach to beyond-design-basis accidents (BDBAs). While innovative designs may also fulfill the requirement of being able to be operated without undue risk to the health and safety of the public, following established regulatory practice represents such a large savings in both time and expense that wherever possible regulatory precedent will be used as a guide for option evaluation during concept development.

\subsection{SCOPE, DEPTH, AND FIDELITY}

The scope of this roadmap includes all of the activities necessary to support expeditious deployment of a first-of-a-kind FHR for electricity generation. Emphasis is placed on the distinctive features of FHRs. Common elements such as the turbine building are only addressed to the extent that variance in their designs will impact distinctive FHR features. The AHTR is used as a representative design concept for an FHR to provide substance to the roadmap recommendations. The AHTR design concept will continue to be matured as the technology development tasks progress to enable progressively reducing the uncertainty regarding the costs, risks, and benefits of large-output, central-station-type FHR power plants.

The current level of FHR development limits the depth of analysis and evaluation reflected in this roadmap. The AHTR is nearing a preconceptual level of maturity in that its design is self-consistent, includes all of the major plant structures, and provides an overall plant layout. However, several key plant elements have yet to be addressed. For example, the salt chemistry control system, the component cooling system, the containment and cover gas cooling systems, and elements of the reactor vessel internals remain to be designed. Moreover, basic models of the plant performance (e.g., flow within the reactor vessel and distribution in the core, fuel distortion due to radiation, and beryllium fluoride condensation) have not yet been developed. A conceptual design that includes all of the reactor SSCs is necessary to produce a detailed, comprehensive deployment roadmap.

For some technologies, it is not yet possible to down-select a single preferred option as all choices have remaining unresolved issues. For example, cantilever-style vertical shafted pumps require hightemperature seals and likely long-life, salt-compatible bearings that will be technically challenging on the scale and with the long lifetime required for an FHR. Another pump option is a canned-rotor-magnetic bearing system such as is being used for the helium circulators in HTGRs. However, a fluoride salt compatible version of such a pump remains in early phase development. In these cases, development steps for all options are provided along with criteria for selecting between the options.

This roadmap fills in the design gaps, as necessary, using engineering judgment to provide a low-fidelity map, as a needed first step, in identifying the overall programmatic requirements to advance FHRs from their current state to first-of-a-kind commercial deployment. This roadmap will need to be updated periodically to reflect FHR concept and technology developments. This initial version of an FHR development roadmap is also intended to serve as a basis to solicit additional input to further the discussion on the technology requirements and RD\&D needed for the development of FHRs.

\subsection{REPORT STRUCTURE}

The body of this report is subdivided into technology development topics. Each topic begins with a summary of the current state of the art in the area. Next, the performance requirements for a firstgeneration FHR are presented and the issues that need to be resolved are discussed. Emphasis is placed on establishing what constitutes adequate performance and on avoiding additional RD\&D that, while likely to offer improved performance, would increase the risk and/or costs of the development program. A set of tasks to resolve the identified issues is then provided. A TRL assessment of the associated FHR components and systems and an integrated development timeline follow. Finally, a prioritized list of nearterm tasks is provided. The report concludes with overall programmatic recommendations. 
Following are the technology development topics covered in the remainder of this report.

1. Concept development

2. Technology gap analysis

3. Fuel development and qualification

4. Structural and functional materials
a. metals
b. ceramics

5. Safety and licensing
a. accident initiators
b. Phenomena Identification and Ranking Table analysis
c. beryllium fluoride
d. licensing requirements
e. design/safety standard
f. tritium management

6. Salt
a. lithium isotope separation
b. redox chemistry control
c. secondary shutdown salt removal
d. fission product removal

7. Component development and testing
a. pumps
b. control mechanisms
c. heat exchangers
d. in-vessel flow components
e. DRACS

8. Instrumentation
a. system architecture
b. performance requirements
c. measurements
d. sensors

9. Operations and Maintenance

10. Design tools and methods
a. thermal and hydraulic modeling
b. reactor physics modeling

11. Economics and commercialization
a. roles and incentives
b. risks and challenges
c. LWR path

12. Construction and manufacturing
a. LWR lessons learned
b. modular manufacturing
c. safety classification
d. fuel fabrication
e. coolant manufacturing
f. component manufacturing
g. seismic tolerance and aircraft impact resistance

13. Demonstration and validation facilities
a. licensing demonstrations
b. performance demonstrations 
14. Test reactors

a. purposes

b. international criticality testing and test reactor development 


\section{CONCEPT DEVELOPMENT}

\subsection{INTRODUCTION}

The purpose for this chapter is to explain the role of concept development in the overall FHR development process and to divide the concept development activity into more specific tasks. FHR concept development guides the overall RD\&D effort by screening the "reactor design space" to enable focusing resources on technology options consistent with the design requirements. Concept development is based upon building an understanding of the functioning of the plant's SSCs as an integrated whole. Integrated evaluation facilitates identification of remaining unresolved technical issues, enables assessing the interdependencies among the plant's SSCs, and provides an initial viability screening of innovative design features for consideration. Moreover, concept development enables estimating the impacts and benefits of specific technologies to prioritize resource allocation. Further, concept development identifies technologies that require longer term development (e.g., structural alloy creep testing) that in turn assists in determining the overall timeline for development and deployment of the reactor concept. Thus, concept development progressively refines the plant's SSCs and the development path through evaluating a broad range of technologies to assess the impact, reasonableness, and development resource requirements of particular design options.

The AHTR is used as a template for the concept and technology development activities described in this roadmap. As a large-output central-station-type plant, the AHTR concept enables evaluation of a complete set of reactor technical issues and allows evaluation of design features as they pertain to centralstation-type FHRs. The AHTR, however, is an evaluation platform, not a specific NPP design with fixed technology choices. As the technology development and evaluation process proceeds, the AHTR concept will evolve to reflect current understanding of the status of FHR technologies and SSCs. For example, the AHTR concept currently uses an inert containment atmosphere to minimize the potential for inadvertent oxygen contact with the primary coolant. However, an inert containment environment necessitates full breathing gear for maintenance activities, significantly increasing their cost. As the primary containment will likely also be contaminated with beryllium fluoride powder, full breathing gear may also be required to avoid worker beryllium exposure. However, as the beryllium exposure potential becomes more fully understood and the primary coolant cleanup system capabilities become known, the need for always maintaining an inert containment environment may decrease. Competing against the potential for progressive design improvements is the necessity to establish technical adequacy of design choices to avoid the paralysis-via-analysis that can occur in performing detailed examination of all possible design options. Thus, much of the proposed FHR development program is oriented toward screening potential technology options for SSCs to identify a set that will adequately fulfill performance requirements.

Initial candidate technologies are available for all required FHR technologies as presently identified. However, substantial uncertainty remains in key elements of the plant design and technologies. Thus, development cost estimates have such large uncertainty bounds as to lose value in predicting the overall program resource requirements. Time and resource estimates are provided in this roadmap where adequate information is available to make reasonable estimates. However, it is recommended that a resource-loaded roadmap await development of a more mature preconceptual FHR design.

\subsection{PROCESS OVERVIEW}

Concept development integrates technology developments into an overall system to enable assessment of the properties and performance of the overall plant. Concept development proceeds by first creating a preliminary notion of the plant's SSCs and their required functions and then progressively refining and 
increasing the level of detail within each of the required functions and technologies. The SSCs are interdependent and, thus, all of the plant technology areas should be maintained at about the same level of maturity throughout the development process. Concept development is limited to technology assessment and integrated performance evaluation. Specific technology developments for FHRs are addressed in focused chapters of this roadmap. Because of system interdependencies and interactions, related technology development tasks may be discussed in multiple roadmap chapters. For example, the cleanup of leaking fuel from the primary coolant is assessed from a plant design perspective in this chapter. However, the required technologies are discussed in Chapters 4, 5, and 7. Plant safety and licensing are also intimately related to the plant operations and technology and, thus, also need to advance in concert with the plant technologies. FHR safety and licensing are also addressed in a dedicated chapter of this roadmap (Chapter 6).

Commercial deployment of FHRs requires advancement across a broad range of technologies, and its overall development as a maturing reactor concept is expected to roughly track that of prior reactor development efforts. Concept development provides a unifying framework to enable an integrated set of technology choices to be made. The 10CFR50 Appendix A GDCs dictate minimal design requirements to provide reasonable assurance that an NPP can be operated without undue risk to the public or the environment. The ANS FHR design safety standard, which is currently under development, in combination with the recently initiated DOE-NE project on developing technology neutral GDCs for advanced reactors provide guidance on plant design requirements from an overall safety perspective. Demonstrating fulfillment of FHR-tailored GDCs provides an organizing structure for evaluating concept and technology development requirements. However, fulfilling licensing requirements does not necessarily address minimizing the plant levelized-cost-of-electricity (LCOE) or the cost of the development program. The proposed FHR concept development path certainly considers fulfillment of GDCs along with having objectives of minimizing costs for both the plant and development program.

Safety and regulatory compliance are foundational requirements for any reactor. However, previous advanced reactor development programs demonstrate that advanced reactors have not yet succeeded in the market, not because they do not offer increased safety margins, but because they have not been able to produce power at lower cost. Maximizing economic performance is, therefore, a very important screening criterion for FHR concept development. LCOE is used as the measure of the overall plant economic performance. Construction cost, the ability to receive a DC, and SSC reliability/lifetime are the primary supporting metrics used to evaluate the likely impact of incorporating particular technology options on the LCOE.

\subsection{INTEGRATED EVALUATION}

Integrated evaluation is a key aspect of concept development. Both evaluating plant performance under normal operating conditions and understanding accident initiation and progression depend upon integrated evaluation of the plant's SSCs. For example, integrated evaluation changes the relative value of different primary coolant configuration options. Maintaining a large volume of primary coolant above the AHTR core serves several purposes. First, the large coolant volume provides a large heat sink, which is useful to avoid requiring a rapid safety response to a loss of heat sink accident. The large primary coolant volume, in combination with other features, also potentially obviates the need for a safety-related reactor cavity cooling system (RCCS). In addition, the large coolant volume provides a location for the shortlived activation products to decay (similar to a pool type LWR), substantially decreasing the incontainment radiation environment. Finally, the deep pool provides biological shielding during used fuel transfer operations. Without understanding combined purposes of the large upper plenum, cost minimization would dictate reducing the volume of expensive primary coolant. 
Another example showing how integrated system evaluation has the potential to change the AHTR concept is the result of applying tritium retention requirements to the design of the DRACS components. Under normal operating conditions, the NDHXs at the base of the DRACS cooling towers are a potential release pathway for tritium into the environment. To mitigate this potential, the NDHXs are planned to be enclosed within an insulated shell. Airflow through the shell would be initiated under accident conditions by passively melting (accident conditions would increase the temperature of the DRACS loop) mechanical fuses that hold the airflow inlet and outlet of the shell closed. Preventing the tritium release thus also minimizes the parasitic heat loss via the DRACS loops and minimizes the potential for NDHX freeze-up. Decreasing the parasitic heat loss decreases the value of high diodicity for flow through the invessel DRACS heat exchangers (DHXs). While minimizing bypass flow though the core remains important to avoid excessive primary loop pumping power, the desired flow directionality can potentially be provided using simpler structures, such as directional fins on the DHX tubing, rather than requiring a dedicated fluidic diode in the downcomer below the DHX.

Another area where integrated plant performance significantly shifts technology requirements is in the relationship of the accident source term with fuel qualification. Source term reduction due to the combination of radionuclide retention in the surrounding carbon material and liquid salt combined with the circulating activity reduction of the salt cleanup system reduces the fuel performance requirements relative to those of gas-cooled reactors.

To use development resources effectively, the goal of the FHR concept development process is to advance FHR plant technology areas in parallel with respect to technology maturity since most FHR technology development areas are interdependent. Consequently, a significant design change in one area will reverberate throughout the plant. In the early phases of concept development, significant design changes are likely as the consequences of technology choices are evaluated. As an FHR concept matures, the magnitude of design modifications is reduced and concept development is focused on concept refinement and optimization rather than concept validation.

FHR concept development has been under way intermittently for several years now. The prior development efforts have been used to inform the recommended future development path. Core neutronic design was an initial focus to establish general reactor performance parameters. Initial candidate suites of reactor materials, fuels, and instrumentation were also developed to assess overall concept viability and to identify remaining technology needs. Structural and mechanical layout of the AHTR was the focus of the 2012 development effort.

Currently additional work on evaluating the hydraulic and heat transfer area of the AHTR design is needed to bring this area to a comparable level with other FHR technology areas. Consequently, AHTR thermal and hydraulic evaluation is recommended as the next concept development focus area. Assessment of plant systems that have received only cursory investigation thus far is also recommended as a near-term concept development focus. For example, while a leading candidate technology for removing radionuclides resulting from leaking fuel from the primary coolant loop has been selected (see Chapter 7), the basic system parameters (e.g., how large the system will need to be, how it can be connected to the primary coolant loop, what materials it should be fabricated from) remain to be determined. The salt redox control system and reactor cavity/component cooling systems also still require basic layout and requirements evaluation. Further, tritium capture in a double-walled primary to intermediate heat exchanger (P-IHX) has been identified as a key distinctive FHR licensing/safety issue. Evaluating P-IHX design options for tritium capture is thus also a near-term concept development issue. 


\subsection{TASKS}

\subsubsection{Overall FHR Concept Development}

The central purpose for the overall FHR concept development task is to integrate the results of design and technology developments into an FHR plant model. As technologies are identified, evaluated, and developed, the overall concept development task modifies the plant concept and the associated development plan to reflect the new information. Technology assessment and integration will thus continue throughout the FHR development process. This roadmap is an output of the overall FHR concept development effort.

\subsubsection{AHTR Thermal and Hydraulic Evaluation}

The AHTR hydraulic and heat transfer evaluation would begin with developing an integrated system model of the normal operating condition fluid flows and heat transfer. Additional details would then be progressively added to the model to enable evaluation of flows within individual fuel assemblies, the impact of fuel plate warping and potential vibration, upper plenum flow mixing, and core support plate stress. Transient evaluation capabilities would then be added to the model to enable assessment of both anticipated transients and a limited set of accidents. Start-up, power level changes, and use of the maintenance cooling system and core cooling during refueling would be included in the modeling effort. The primary loop hydraulic component designs would also be refined as part of the evaluation process. The modeling effort will likely consist of several different simulations with varying levels of detail depending on the required output.

\subsubsection{Salt Cleanup System}

The technology for the salt cleanup system is discussed in Chapter 7 of this roadmap, and the rationale for the salt cleanup system is described in more detail in Chapter 4 . The concept development aspect of the salt cleanup system would involve performing an initial assessment of how to couple the salt cleanup system to the primary coolant loop and the required system size, plant location, and construction materials. The leaking fuel aspect of the salt cleanup system performance requirements will be derived primarily from worker dose limits (i.e., 10CFR20 limits) from performing maintenance activities. While using similar technology to the bismuth-lithium system planned for the MSBR, AHTR leaking fuel will result in low concentrations of fission products, fuel, and transuranic materials within a large volume of primary coolant. Thus, the leaking fuel cleanup system likely will have substantial technology differences from previously demonstrated technology.

Moisture and oxygen impurities will also need to be removed from the primary coolant. Technologies for moisture and oxygen removal are discussed in Chapter 7 of the roadmap. This task will focus on evaluating the required system size and how best to couple the moisture and oxygen removal systems to all of the salt loops.

\subsubsection{Reactor Cavity and Component Cooling System}

The primary coolant loop for the AHTR is intended to be well-insulated with the containment atmosphere actively cooled during normal operation (NO). The cooling system design and the necessary ducting to ensure cooling of the reactor vessel silo remain to be determined. The design intent is to rely upon the NO cooling and the primary loop insulation to avoid the necessity for a safety-grade RCCS to remove decay heat during accident conditions. The current status of the AHTR cavity cooling system is described in the 2012 AHTR status report (Ref. 1). 
The in-containment components (especially, the primary coolant pumps) will also require cooling. Using water-based cooling would result in the potential for a phase change accident and thus pressurizing containment. Requiring a high-pressure containment would significantly increase the cost for FHRs. Thus, the base concept for cooling the primary pumps is with inert gas (e.g., the containment atmosphere). The layout and configuration of the containment and RCCS remain to be defined. This task will perform basic reactor cavity and component system layout and refine the reactor cavity heat-up models to develop confidence that even during loss of forced flow accidents, the reactor cavity will not heat up unacceptably.

\subsubsection{Cover Gas Cooling and Cleanup System}

The purpose for this task is to evaluate the technology options and design requirements for the AHTR cover gas cooling and cleanup system. Based upon the technology options selected, an initial system layout will also be performed. During NO, tritium will evolve from the primary coolant pool. Also, noble fission gasses from leaking fuel will bubble up into the cover gas. Tritium will likely be stripped from the cover gas by passing the cover gas through a metal bed forming a metal tritide. Any evolved impurity oxygen and/or moisture will also be chemically stripped from the cover gas.

A primary function of the cover gas is to keep the upper vessel flange and flange seal adequately cool. The cover gas flow rate and temperature necessary to keep the upper vessel structures adequately cool has not yet been determined. However, cryogenic distillation is an effective means to remove krypton and xenon from an argon stream. Hence, the current design intent is to cool a portion of the cover gas flow stream below the liquefaction point of krypton, remove the krypton and xenon, and reblend the remaining chilled argon into the cover gas stream.

\subsubsection{Salt Loop Heating System}

The purpose of this task is to perform a preliminary system layout for the salt electrical heaters and electrical power distribution system. Issues to be addressed include location of power transformers, system size, and power requirements. The design intent for all of the AHTR salt loops is to use external electrical heaters to preheat the loops before filling with salt. During NO, fission power will prevent the salt from refreezing. However, during extended outages, especially when fuel has been removed from the core, the loops may be vulnerable to freezing up. The DRACS loops will include NDHX in which ambient air is only separated from the hot salt by thin tube walls. If the NDHX were to freeze solid, the DRACS loops would not function. The electrical power system must be of sufficient size to prevent loop freeze-up and allow start-up to be performed following initial loop filling.

\subsubsection{Cathodic Fluoride Salt Redox Control System}

The purpose for this task is to develop a mechanically robust cathodic type redox protection system for the primary coolant loop. The technology for cathodic redox protection of the primary coolant-wetted materials is discussed in Chapter 7 of this roadmap. This task will focus on developing a robust implementation of cathodic protection suitable for deployment in the primary loop of FHRs. System implementation issues such as mechanically robust electrode design, number of electrodes, means to access the primary coolant, and robust measurements of the salt redox condition remain to be resolved.

\subsubsection{Plant Life-Cycle Functional Evaluation}

The purpose for this task is to ensure that the full AHTR plant life cycle has been considered in the concept development process and that the SSC requirements reflect all of the required functions. This task will consist of breaking the plant life cycle into states and assessing the SSC performance requirements 
for each state. This task will include allocating particular functions to specific SSCs. The resultant plant life-cycle functional evaluation will provide a starting point for the concept of operations planning.

\subsubsection{Tritium Capture/Control Technology Assessment}

The purpose for this task is to assess and demonstrate tritium trapping and control technology and to develop an acceptable means to block tritium transport into the AHTR intermediate coolant loop. Tritium capture/control technology for the P-IHX is discussed in Chapter 5 of this roadmap. Issues to be considered are basic system configuration and layout, overall effectiveness in preventing tritium from entering the intermediate loop, and maintenance and repairs. This task will include a significant experimental aspect as field demonstration is key to success 


\section{TECHNOLOGY GAP ANALYSIS}

\subsection{PURPOSE AND OVERVIEW}

The purpose for technology gap analysis (TGA) is to provide confidence through a structured peer review process that all of the technology hurdles required to develop a test FHR and a first-of-a-kind commercial power plant have been identified and assessed. Gap analysis begins with dividing the planned FHR RD\&D effort into a set of technology areas (similar to the chapters of this roadmap report). A small set of experts within each technology area are then engaged to assess the gap between the current state of the art and the required technical maturity necessary for an FHR NPP. The result of the gap analysis is a consensus set of focused RD\&D roadmaps intended to fill in the identified gaps. Because of this, the TGA effort is a follow-on to this initial RD\&D roadmap that both increases the depth of analysis and, through peer review, provides additional confidence in the necessary tasks and the estimates of the time and resources required.

The phenomenon identification and ranking table (PIRT) process developed by NRC is closely related to TGA, but with a slightly different focus. TGA focuses on developing a plan for adequately and expeditiously identifying and resolving the technology gaps that might prevent achievement of the overall program goal of first-of-a-kind commercial deployment. In contrast, the PIRT process focuses on evaluating and ranking physical phenomena to determine which are most important to a particular design element. The PIRT process was originally developed as part of the NRC Code Scaling, Applicability, and Uncertainty (CSAU) evaluation method. CSAU is a method to allow use of the best estimate computer codes in licensing activities. The PIRT process involves ranking of phenomena using scoring criteria to help determine what is most important. That ranking, as well as the information obtained to explain the ranking, allows prioritizing research needs for a safety issue or to support some other decision-making process. The PIRT method brings into focus the phenomena that dominate an issue while identifying all plausible effects to demonstrate completeness.

Both TGA and PIRT evaluations conducted using committees and as such inherently possess the strengths and weaknesses of collaborative efforts. Expert peer review is an effective, well-proven technique for ensuring completeness and quality. Further, providing a pathway for the technical community to gain a deeper understanding of FHR technologies, through reviewing the project details, and to suggest improvements to the design can cross-fertilize supportive technology developments and help educate future staff. Yet, design-by-committee has become an aphorism for excessively complex, inconsistent design. Thus, defining the scope and objective of analysis and the form of the output to be produced is a major issue for a successful TGA. Avoiding unnecessary increases in complexity and unproven technology introduction are key to preventing TGA from becoming a cost escalation driver.

TGA is especially important for FHRs as their characteristics and materials do not have a sufficient pedigree to enable anticipation of technical challenges by relying on established design rules. Thus, the program cost and schedule could be severely impacted by unanticipated technical issues. Applying focused expertise to all aspects of the reactor system design provides a high level of confidence that the overall design will function as intended. The lower level of FHR technical maturity necessitates a more empirical development approach, much as was used in the first nuclear era of the 1950s-'70s. The phenomenological uncertainty combined with the level of complexity within the reactor system precludes ab initio computational modeling for most aspects of the design and licensing. The high degree of passive safety afforded by the combination of favorable neutronic characteristics; large thermal capacity and margin; robust fuel; and low-pressure, non-chemically reactive coolant avoids the potential for rapidly progressing accidents. On the other hand, the new materials and higher temperatures characteristic of FHRs can aggravate vulnerabilities as compared to LWRs. For example, high-temperature structural alloy 
creep is not a significant issue for LWRs, nor are LWR fuel rods vulnerable to brittle fracture. TGA is key to developing confidence that all FHR vulnerabilities have been accounted for in the design.

\subsection{GAP ANALYSIS TASK DESCRIPTION}

Performing a TGA requires a sufficiently mature system description to allow experts to assess the planned suite of technologies without having to engage in basic design. A complete preconceptual design does not yet exist for all aspects and systems of the AHTR. Because of this, comprehensive gap analysis will need to be delayed until the remaining SSCs have undergone initial design and evaluation. The series TGA and PIRT evaluations produced for SFRs and HTGRs [e.g., Chikazawa 2008 (Ref. 13), Ball 2008 (Ref. 14), or Morris (Ref. 15)] provide examples of the structure and content of previous advanced reactor technology gap evaluations.

A key element in a successful TGA is engaging the proper experts and providing them with adequate background information. Each TGA technical area committee typically consists of 5-7 experts. The committees thus consist of a small enough number for active discussion, but are large enough to obtain a statistically relevant consensus.

The technology areas for an FHR TGA are the same as those for any other NPPs and are generally aligned with the topics identified in this report's introduction. The new and distinctive technologies of FHRs will be the major focus of the TGA. As the initial mission for FHRs is intended to be economic electricity production, the economics and commercialization committee will fill an especially key advisory role. The construction committee will have more prominence than with earlier generation plants given the design modifications planned to mitigate seismic vulnerability combined with the economic importance of recent construction technology advances such as heavy transport dirigibles and modular manufacturing. The construction committee will also encompass plant security given the close connection of below-grade construction, seismic vulnerability, and aircraft impact tolerance. The safety and licensing committee's mandate will also be somewhat broader than would be the case for an LWR in that tritium and beryllium management do not have equivalents in LWR design and FHR accidents and evaluation tools remain to be established. 


\section{FUEL DEVELOPMENT AND QUALIFICATION}

\subsection{INTRODUCTION}

FHRs will use coated particle fuel. The NGNP/AGR program has been developing TRISO coated particle fuel (Ref. 16). Identical TRISO particles are directly applicable to FHRs. FHRs, however, have different physical characteristics than HTGRs and as such their fuel qualification requirements will differ from those of HTGRs. As a liquid cooled reactor, acceptable FHR fuel performance also has similarities to that of LWRs. Prior TRISO fuel performance evaluations for HTGRs (Ref. 17) have relied upon analogies between TRISO and LWR fuel.

LWRs have established, acceptable fuel performance specifications providing a template to develop the requirements for FHRs. One purpose of this document is to compare and contrast the fuel performance requirements for LWRs, HTGRs, and FHRs, in terms of the reactor classes' inherent physical characteristics. Additionally, this document provides an initial roadmap for the distinctive (relative to those required for HTGRs) FHR fuel qualification steps. FHRs, however, remain at a lower level of development than HTGRs. Key steps to developing a mechanistic source term such as identifying design basis events (DBEs) and accident initiation sequences have yet to be performed for FHRs. Further FHR concept and technology development will be necessary before a comprehensive FHR fuel qualification plan can be developed.

HTGRs and FHRs have different core heat transfer mechanisms and, thus, fuel configuration design requirements. HTGRs will transfer their heat to the primary coolant during $\mathrm{NO}$ and primarily out through the vessel walls via conduction during loss of forced flow accidents. The requirement to transfer decay heat via conduction out of the vessel limits the maximum amount of core thermal power possible for the fuel to remain below failure temperature under loss of forced flow conditions. The lower total core power coupled with the accident condition conduction-based heat rejection creates a principal design requirement to intimately couple the fuel kernels with the core carbon materials. In contrast, in FHRs, the fuel heat will be removed from the core via the primary coolant during both NO and during loss of forced flow accidents. FHRs will have over twice the power density of HTGRs, and the thermal conductivity of the carbonaceous fuel element matrix material is too low to rely upon conduction to reject decay heat through the reactor vessel during loss of forced cooling accidents. Moreover, the thermal conductivity of the carbonaceous fuel matrix materials is also too low to maintain the fuel particles at an acceptable operating temperature under normal operating conditions with significant intervening material between the fuel kernels and the coolant. Locating the fuel kernels near the surface of the fuel element for effective heat transfer to the primary coolant is thus the principal kernel configuration design requirement for FHRs. Additionally, maintaining the fuel well below the maximum design temperature of HTGR operation provides thermal margin to trade against the required fidelity of accident performance assessments.

A key design concept for FHRs is to leverage their large safety margins to offset the uncertainties inherent in their first-of-a-kind technologies. A central objective for the FHR development program is thus to shorten the time to market by minimizing the design complexity and establishing adequate performance using the simplest possible methods. The tasks planned as part of the fuel qualification effort are intended to provide assurance of adequate, but not necessarily optimal, fuel design and performance.

The large margin provided by FHRs minimizes the precision necessary in modeling toolsets. Key LWR issues such as critical heat flux to avoid boiling or HTGR issues such as localized flux peaking are much less important to represent beyond what idealized models can provide. Further, several difficult to computationally model issues such as flow induced fuel vibration and flow distribution prediction within 
the core can be relatively inexpensively physically modeled using simulant materials. Any detailed FHR fuel qualification computational modeling efforts thus need to focus on characteristics that need to be extrapolated outside of areas where inexpensive physical simulations or simplified computational models can provide adequate understanding.

\subsection{FUEL PERFORMANCE REQUIREMENTS}

NRC has developed a process for licensing nuclear power reactors based upon paragraph 103 of the Atomic Energy Act of 1954 and its amendments and the Energy Reorganization Act of 1974. The legal requirements are principally embedded in two sets of reactor-focused regulations-10CFR50 -

"Domestic Licensing of Production and Utilization Facilities," which has been the basis for all the power reactors in operation today (with the exception of the DOE or Department of Defense-owned facilities), and 10CFR52- “Licenses, Certifications, and Approvals for Nuclear Power Plants,” which has been used for the Generation III and III+ reactor licensing process since 1997. Additionally, the 10CFR20“Standards for Protection Against Radiation” applies to all reactors.

In either process (Part 50 or 52), the nuclear power reactor applicant must provide the principal design criteria for the reactor. The principal design criteria establish the necessary design, fabrication, construction, testing, and performance requirement for SSCs that provide reasonable assurance that the facility can be operated without undue risk to the health and safety of the public. The minimum requirements for principal design criteria are contained in Appendix A of 10CFR50 and are referred to as GDCs. The GDCs are written to provide the minimal design criteria requirements for LWRs similar in design and locations to plants for which construction permits have been issued by NRC. The introduction to Appendix A of 10CFR50 states that the GDCs are considered to be generally applicable to other types of reactors and are intended to provide guidance in establishing the principal design criteria for such other types of reactors.

\subsubsection{Normal and Anticipated Operational Occurrences}

10CFR50 - Appendix A Criterion 10, Reactor Design—provides the basis for the fuel performance requirements for normal and anticipated operational occurrences (AOOs).

The reactor core and associated coolant, control, and protection systems shall be designed with appropriate margins to assure that specified acceptable fuel design limits are not exceeded during any condition of normal operation, including the effects of anticipated operational occurrences.

The NRC staff must make a determination as to whether a reactor design ensures adequate protection of public health and safety and to be in accordance with the common defense and security. NRC has established a Standard Review Plan (SRP) (NUREG 0800) (Ref. 11) that guides the review process by comparing the design against the regulatory requirements. Conformance with the SRP is not a regulatory requirement, but it references the requirements as acceptance criteria (AC).

NUREG 0800 Sect. 4.2-1.B. Fuel Rod Failure establishes that a small number of leaking rods represent acceptable fuel performance in an LWR.

Although the staff recognizes that it is impossible to avoid all fuel rod failures and that cleanup systems are installed to handle a small number of leaking rods, the review must ensure that fuel does not fail as a result of specific causes (hydriding, cladding collapse, overheating of cladding, overheating of fuel pellets, excessive fuel enthalpy, pellet / 
cladding interaction, bursting, mechanical fracturing) during normal operation and AOOs.

Following the LWR precedent, acceptable fuel failure performance for FHRs would be based upon having radionuclide release consequences similar to or less than the already established acceptable LWR fuel rod leakage consequences and having equivalent cleanup systems. To base FHR fuel AC on that for LWRs, a means to demonstrate that the quality of FHR fuel is sufficient to ensure that its radionuclide leakage rate consequences do not exceed the allowable LWR fuel rod leakage criteria must be established. Further, the conditions and mechanisms for potential in-service TRISO fuel failure must be established and assurances provided that FHR normal and AOO fuel use conditions do not cause fuel failure. Additionally, quality control and quality assurance (QA) programs must be developed to ensure that the resultant fuel manufacturing criteria are being met in practice. Finally, adequate monitoring and surveillance must be provided in-service to establish that both the fuel operating conditions and radionuclide release amounts remain within design limits.

\subsubsection{Accident Conditions}

FHR fuel must also meet the requirements resulting from 10CFR100_ " "Reactor Site Criteria," which establishes the allowable fission product releases quantities from major accidents based upon doses received at specified distances from the reactor. The design analysis for 10CFR100.11 is based upon the hazards that would result from a maximum credible accident. The radiological dose consequences criteria given in 10CFR50.34(a)(1), are referenced in 10CFR100.21— "Non-Seismic Siting Criteria.” Severe accident analysis is beyond the scope of this fuel qualification roadmap document. However, FHRs are a fully passively safe reactor class and it is the design goal to avoid significant radioactive material release from even severe accidents via a combination of prevention and mitigation.

Accident condition fuel performance requirements for FHRs do not have a strong correspondence to those for LWRs or HTGRs. In the case of LWRs, the principal barrier to prevent fission product release is damage to the fuel cladding. In most LWR accidents, this is the barrier that is challenged first during the accident. In the case of an FHR, the principal barrier to fission product release is not direct failure of the fuel particles, which is not challenged in most events due to the robust nature of the fuel and the large margins to failure, but instead is low point failure of the primary coolant boundary. Both the boiling point of the primary fluoride salt coolant and the fuel thermal failure limit are well above temperatures where nickel-based reactor vessel alloys are structurally sound. Thus, in terms of radionuclide release pathway, the reactor vessel is the most vulnerable component.

DBEs in HTGRs include the potential for significant temperature increases within the TRISO and chemical attack of the fuel due to water or air ingress. The combination of fuel immersion in a lowpressure liquid fluoride salt and the lack of large quantities of water within the reactor building appear to effectively preclude these DBE stressors on FHR fuel. Establishment of validated FHR design evaluation tools and an FHR design safety standard, including customized GDCs and DBAs, are thus key developmental tasks necessary to provide reasonable assurance that FHRs can be operated without undue risk to the health and safety of the public. An initial draft set of FHR GDCs has been produced to serve as a starting point for further evaluation (Ref.9).

\subsection{TRISO FUEL QUALIFICATION}

The ongoing NGNP/AGR fuel development program is focused on improving the characteristics and quality of TRISO fuel. In contrast, the goal of fuel qualification is to provide assurance that manufactured fuel has adequate performance characteristics to meet licensing requirements. 


\subsubsection{NGNP Fuel Qualification White Paper and NRC Response}

The NGNP program has been interacting with NRC with respect to qualifying TRISO fuel for its use. Much of the data and logic contained within the "NGNP Fuel Qualification White Paper" (Ref. 18) and the subsequent NRC response (Ref. 19) pertains directly to FHRs.

The NGNP fuel qualification white paper identifies five common elements for TRISO fuel qualification for NGNP use:

1. Establishment of a fuel-product specification,

2. Implementation of a fuel-fabrication process capable of meeting the specification,

3. Implementation of statistical QA procedures to demonstrate that the specification has been met,

4. Irradiation of statistically sufficient quantities of fuel with monitoring of in-pile performance and post-irradiation examination (PIE) to demonstrate that NO performance requirements are met, and

5. Safety testing of statistically sufficient quantities of irradiated fuel to demonstrate that accident condition performance requirements are met.

NRC review of the proposed NGNP fuel qualification program identified three additional NGNP fuel qualification program elements:

1. Establishment of fuel design service conditions and performance requirements for NO and accidents,

2. Irradiation and accident proof testing of NGNP fuel fabricated on the production lines of the NGNP fuel fabrication facility, and

3. Establishment and implementation of NGNP prototype preoperational and operational programs to verify and supplement the developmental technical basis for fuel qualification and mechanistic source terms.

\subsubsection{FHR Fuel Performance Requirement Differences from HTGRs}

FHRs, however, have inherent differences from HTGRs that change the consequences of TRISO fuel failures and, thus, the acceptable fuel design limits. While FHRs have higher power density than HTGRs, the accelerated testing being used by the AGR program places the test fuel at higher power density, kernel powers, and temperatures than would be used in an FHR. Thus, the data currently being generated by the AGR irradiations will be conservative for FHRs.

\section{Molten salt coolant retains radionuclides}

FHRs, by definition, use molten fluoride salts as their primary coolant. All but the noble fission products dissolve readily and are bound into the salt. MSRs have demonstrated that fluoride salts are an effective solvent/carrier for radionuclides. Even the more volatile elements (e.g., iodine) have no tendency to leave the salt (Ref. 20). Thus, the fraction of radionuclides leaking from failed TRISO fuel in an FHR that are chemically/physically available to leak past the next containment layer is much smaller than in an HTGR. Essentially the entire primary coolant functions similarly to the resin beds used to trap radionuclides that leak into the primary coolant in LWRs.

\section{Low primary circuit pressure}

FHRs operate at near atmospheric pressure thus no large driving forces exist to cause radionuclides that leak from failed TRISO fuel to leak beyond the primary circuit. Note that the vessel cover gas may be at slightly elevated pressure relative to the remainder of the containment to minimize the potential for 
moisture ingress. Consequently, the noble gas fission products would tend to migrate out from a ruptured primary coolant boundary.

\section{Lower temperature fuel}

Flowing liquid salt provides very effective heat transfer from the fuel. The lower volumetric moderating efficiency of carbon as compared to hydrogen necessitates that FHR cores have a significantly lower power density than LWRs. Unlike in an HTGR where the TRISO particles are distributed throughout the fuel pebbles or emplaced in compacts separated from the coolant by a significant amount of graphite (prismatic cores) the fuel in an FHR is positioned as closely as possible to the coolant flow.

More intimate coupling of the fuel with the primary coolant lowers the fuel temperature during both normal and accident conditions. Further, the viscosity of fluoride salts decreases with increasing temperature (unlike helium), so that coolant flow increases to hotter regions of the core decreasing fuel temperature peaking. The current peak fuel temperature prediction for the AHTR is less than $900^{\circ} \mathrm{C}$. The maximum time-average fuel particle temperature in the NGNP under normal operating conditions may be up to $1250^{\circ} \mathrm{C}$ and the maximum, normal operating condition, fuel particle temperature up to $1400^{\circ} \mathrm{C}$.

The lower fuel temperature decreases the stress on the silicon carbide (SiC) containment layer by decreasing the internal gas pressure. The mechanisms for radionuclide transport in TRISO kernel and carbon matrix will be identical in HTGRs and FHRs. The lower fuel temperature in FHRs decreases the diffusion rate of mobile radionuclides (e.g., cesium and silver) through the SiC containment layer. International Atomic Energy Agency (IAEA) TECDOC 978 shows the impact of lowering the irradiation temperature on the predicted ${ }^{85} \mathrm{Kr}$ release fraction (see Fig. 3).

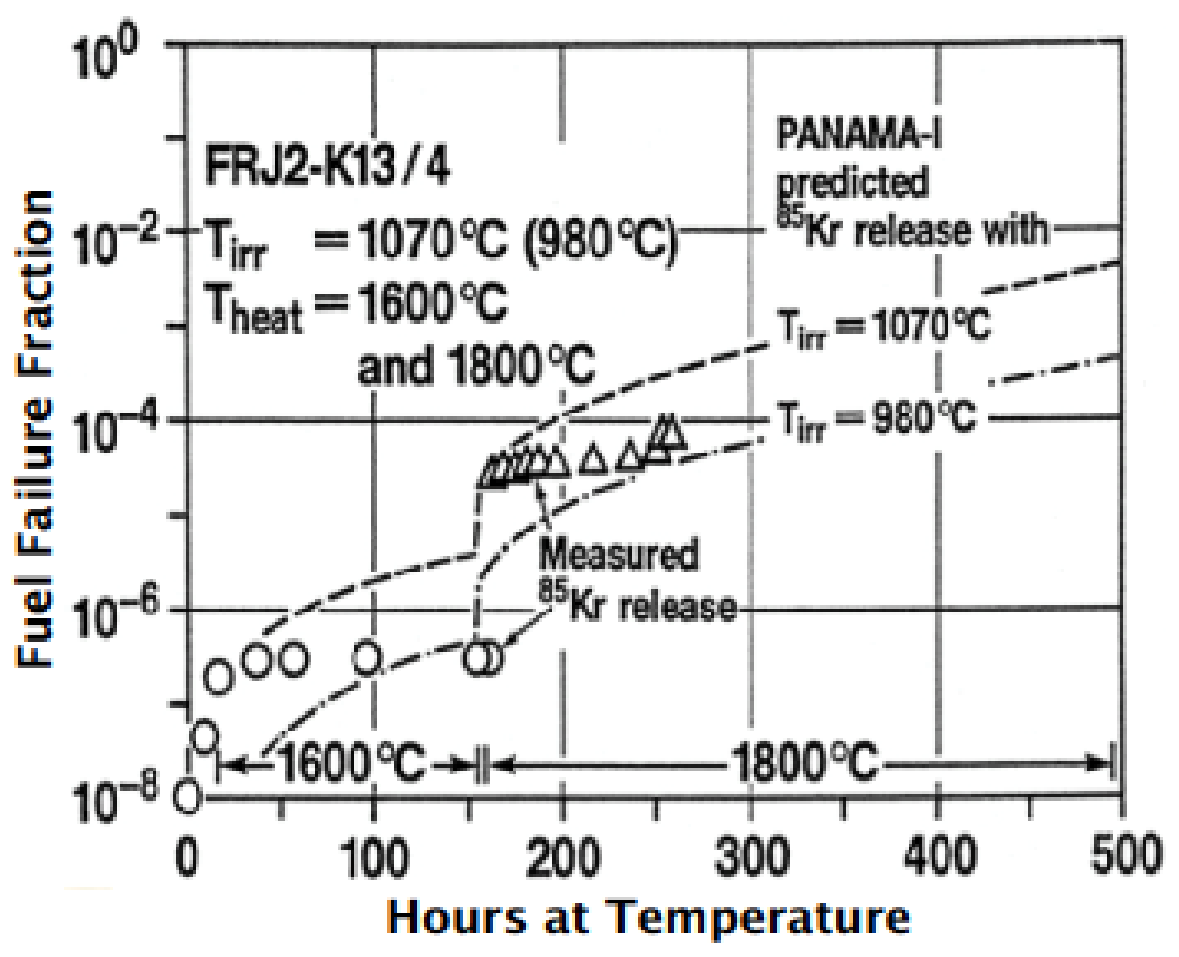

Fig. 3. Krypton release fraction prediction variance with irradiation temperature [after IAEA TECDOC 978 Fig 4-14 (a)]. 
The Electric Power Research Institute has created an overview of TRISO leakage during normal operating conditions for HTGRs showing the importance of the lower temperature and benign chemical environment provided by FHRs (Ref. 21).

\section{Multiple layers of containment}

FHR reactor buildings contain no significant amounts of materials that can either chemically or physically react to pressurize containment-specifically including no large volumes of water. FHRs have several hundred degrees of temperature margin to primary coolant boiling under normal and AOO conditions. Thus, FHRs have no means available to pressurize their containments. To minimize the potential for oxygen to leak into the primary circuit and cause corrosion, the environment around the primary coolant will be an inert gas. FHRs will be sited below grade to assist in complying with the NRC aircraft impact assessment rule (10CFR50.150). The combination of the below grade location (with its inherent flooding vulnerability) and the practical necessity of having a dry, non-inert atmosphere location for reactor support (e.g., electrical switchgear and rad waste handling) necessitates an additional layer of lowpressure (watertight) radionuclide containment. The multiple independent external layers of radionuclide containment decrease the probability for radionuclide release into the environment as a result of fuel leakage for an FHR relative to an HTGR.

\section{Benign chemical environment}

Carbon is chemically compatible with fluoride salts. The outer surface of both the fuel particles and the fuel assemblies are carbon. The Molten Salt Research Experiment (MSRE) solid graphite elements remained pristine after thousands of hours in service in core (Ref. 22). The presence of a small amount of water impurity in HTGR helium can hydrolyze exposed fuel kernels (e.g., those with defective SiC containment) fuel during NO (or due to water or air ingress during accident conditions) leading to an increase in radionuclide release (Ref. 23). The fluoride salt filled, intermediate coolant loop of an FHR effectively prevents water ingress from the power cycle. The Gibbs free energy requirement for carbon to react with the fluoride salt is such that it is energetically infeasible for the carbon fuel elements to be attacked by the salt. However, if oxygen is present in the fuel assemblies prior to loading into the primary salt, it will react with the carbon immediately upon introduction into the hot fluoride salt. While the limited amount of oxygen that can be adsorbed onto the fuel assemblies limits the amount of fuel damage that can occur, an important quality control for FHR fuel is oxygen/water removal prior to loading into the primary coolant.

\subsubsection{TRISO Fuel Quality Assurance and Quality Control}

The low primary circuit pressure, the filtering action of the carbonaceous material enveloping the TRISO fuel in an FHR, and much higher metallic radionuclide solubility in molten salt means that in-service fuel leaks will result in much lower environmental radionuclide release potential than cladding leakage in an LWR. As with LWRs, FHRs will have salt cleanup systems to mitigate contamination resulting from leaking fuel. Consequently, achieving what would be an acceptable in-service radionuclide fuel leakage quantity for an LWR would also be conservatively expected to be an acceptable in-service fuel leakage quantity in an FHR.

The AGR-3/4 tests are intended to develop the data needed to assess radionuclide retention and transport in TRISO fuel particle kernels and the carbonaceous fuel elements. This information is anticipated to be useful for providing a comparison of the severity of radionuclide release from leaking TRISO fuel particles versus leaking fuel rods. 
Conservatively limiting the "small number of leaking rods" to two and using the AP-1000 design for comparison [41,448 rods (264 rods per assembly $\times 157$ fuel assemblies)] yields an acceptable LWR in service leaking fuel fraction of $48.3 \times 10^{-6}$.

FHRs inherently have very large thermal margins (e.g., several hundred degrees) from normal and AOO conditions to fuel failure. FHRs will also have much lower fissions per initial metal atom (FIMA) (7-8\% AHTR) than that the NGNP program is testing fuel to (17\%). The lower FIMA also results in lower amounts of plutonium fission, which in-turn, results in a lower yield of silver, palladium, and rare earths. Consequently, properly manufactured FHR fuel is not anticipated to develop failures in normal service or AOOs. However, FHR fuel may contain manufacturing defects that only become apparent in service.

LWR fuel rod manufacturing provides a demonstration of first level containment leak tightness prior to service via a helium leak check. FHRs have much larger numbers of first level containment structures (e.g., SiC cladding within individual TRISO particles) as opposed to zirconium alloy clad rods in an LWR (e.g., 83 billion coated particles in the AHTR vs 41,448 fuel rods in the AP-1000) making batch cladding integrity inspection a practical necessity for FHR fuel. The leak tightness of coated fuel particles at operating temperature and pressure can be verified by immersing completed particles in molten fluoride salt. Fuel kernels are largely soluble in liquid fluoride salts and uranium contamination is readily detectable in the salt. A molten salt leach test is thus similar to the acid leach test often used during coated particle manufacturing, but with the added benefit of bringing the fuel to near operating temperature to observe thermally induced failures. A molten salt leach test thus is a more realistic first layer containment demonstration than the helium leak test used for LWR fuel rods as it can be performed at prototypic temperature and pressure. Further, by dissolving kernels with grossly failed cladding layers, the test will inherently remove the fissile material from defective particles prior to encapsulation within carbon matrix fuel bodies.

Gross and systematic defects in the manufacturing process or materials for TRISO fuel would be identified through the fuel manufacturing plant QA process. Throughout the production process the characteristics of both individual kernels and the bulk properties of fuel batches are observed. The quality of the final product will be ensured through both product specification and process control. Developing guidelines for oversight and inspection of a TRISO fuel manufacturing plant was the subject of a recent NRC-sponsored research project (Ref. 24).

Irradiation and accident proof testing of fuel fabricated on each production line as an additional step in the FHR fuel qualification process, as NRC has indicated is necessary for the NGNP, would represent an additional impediment to FHR commercialization. Avoiding individual production line qualification would require demonstrating that variations between production lines yield insignificant variance of the fuel failure consequences during normal or AOO conditions and insignificant increases in radionuclide releases during DBEs. The key element to being able to use a production specification, instead of a production line based qualification, is to show that compliance with the production specification results in fuel kernels that perform adequately. The quality control procedures that would be required to be applied throughout the manufacturing process to all production lines provide high assurance that similar fuel is manufactured by all production lines. The very large margins to fuel failure provided by the characteristics of FHRs provide confidence that any remaining differences between fuel kernels manufactured to the same specification will perform adequately. Unlike in HTGRs, FHR fuel is not required to operate near its thermal performance limits. The combination of temperature and burnup is the principal fuel kernel stressor. The hundreds of degrees of additional thermal margin provided by liquid cooling and the lower FIMA for FHRs, as compared to the AGR testing program, combine to provide so much margin to fuel failure that fuel performance differences from within production specification fuel would not approach fuel failure limits. 
The necessity of the final NRC-identified NGNP fuel qualification program element, to establish significant programs of preoperational and operational testing, monitoring, inspection, and surveillance in a prototype reactor to confirm safety-related design predictions and, thereby, verify and supplement the developmental technical basis for fuel qualification and mechanistic source terms, has not been established for FHRs. While testing AGR 5/6 fuel performance is planned at an FHR test reactor under prototypic conditions, the necessity of repeating the testing at a prototype reactor has not been demonstrated. The very large margins inherently afforded by FHRs and the ability for a test reactor to provide matching chemical and physical environments for test fuel assemblies to commercial plants appears to make confirmatory measurements the only fuel qualification steps necessary during the prototype phase of the first commercial plant.

\subsection{FHR FUEL QUALIFICATION ISSUES}

As has been indicated earlier in this document, FHRs will have more benign fuel service conditions than those of HTGRs. However, the specific parameters of FHR service conditions for normal, AOO, DBE, and beyond design basis event (BDBE) conditions have yet to be established. This is largely because AOOs, DBEs, and BDBEs have yet to be specified. Thus a prerequisite to an FHR specific fuel qualification program is advancing the safety and licensing evaluation sufficiently to determine the accident conditions that the fuel would need to survive.

The fuel assemblies planned for use in FHRs will more closely resemble those of other liquid-cooled reactors than those of HTGRs. Thus, the mechanical and hydraulic requirements of FHR fuel assemblies will have closer analogy to those of LWRs than HTGRs. Specifically, the in-service conditions for the fuel assemblies may not damage the fuel or cause it to change geometry sufficiently to prevent coolability or control element insertion.

The fuel assembly testing will need to establish whether the in-service conditions can cause the fuel assemblies to fail. The first steps in developing confidence in fuel assembly performance are to identify and prioritize the key physical phenomena involved in the fuel assemblies failing. Much of the necessary information is materials performance data that needs to be generated prior to more detailed modeling.

The next few paragraphs provide an overview of already identified fuel performance issues that need to be resolved. The issues are both evolving and interrelated. For example, increasing the density of the matrix carbon material between the fuel particles (as has occurred during the AGR program) will both shift the neutron spectrum and potentially change the brittle failure characteristics of the layer. Fuel failure may take the form of mechanical damage to the fuel plates (e.g., vibration or chattering), loss of a coolable configuration due to radiation induced warping, prevention of control blade insertion due to mechanical distortion (e.g., radiation induced warping), surface erosion resulting in fuel particles becoming loose in the coolant stream, or mechanical debonding of the various layers within the fuel plates.

FHR fuel assemblies will be composed entirely of ceramic and ceramic composite materials. Ceramic materials are vulnerable to brittle fracture. The in-core service environment must thus not create flow induced vibration and/or mechanical chattering sufficient to damage the fuel assemblies or to prevent control element insertion. The liquid flow velocity through FHR cores will be smaller than in LWRs as FHR core power density will be lower than LWRs (due to the larger moderating volumetric efficiency of water as compared to carbon) and as such the flow-induced mechanical motions are anticipated to be less in FHRs. Moreover, SiC leaf springs, intended to mitigate grid-to-rod fretting in LWRs have recently been investigated (Ref. 25). Similar springs will be incorporated into the next revision of the AHTR fuel assembly design. 
The AHTR design concept calls for plate type fuel assemblies. The extent and nature of mechanical distortion of the fuel assemblies both during manufacturing and in-service will need to be established during the FHR fuel qualification effort. The fuel assemblies of the AHTR will be a mechanical structure formed from the central carbon-carbon (C-C) composite support ' $\mathrm{Y}$,' the fuel plates, and the surrounding $\mathrm{C}-\mathrm{C}$ composite channel box. From a mechanical perspective, the fuel plates will be rigid, compression molded carbon-based structures. During assembly, the fuel plates are slid into preformed guide slots in the support ' $Y$ ' and channel box. The fuel plates are, thus, mechanically supported on both edges. Further, the current design for each fuel plate includes spacer ridges to prevent in-service mechanical distortion from blocking the coolant flow channels. The assembly procedure including amounts of clearance and required dimensional precision will need to be established as part of the fuel development process.

The final firing of ceramics results in some mechanical distortion. While the mechanical distortion of C-C composites is less due to the preestablished internal structure provided by the carbon fibers, C-C composites cannot be machined post-firing without significant deleterious impacts on their properties. The unfueled edges of the fuel plates, however, can be machined following firing to provide a close fit into the guiding slots. The unfueled carbonaceous spacer ridges on each fuel plate also can be machined to fit following firing. The amount of mechanical clearance that needs to be provided to allow mechanical assembly of the fuel assemblies is a function of the manufacturing precision obtainable in practice and the assembly procedure. Too loose a fit will enable large flow-induced vibration and consequent mechanical failure. Too tight a fit may result in fuel plate cracking in-service due to constraint of fast flux induced dimensional changes. While fuel plate cracking due to too tight a fit would be counter intuitive, due to the low total fast fluence before replacement $\left(<4 \times 10^{21} \mathrm{n} / \mathrm{cm}^{2} \mathrm{E}>50 \mathrm{keV}\right)$, the thermal expansion and thus looser fit at operating temperature, and radiation induced stress relaxation, in-service fuel plate cracking remains a significant potential failure mechanism.

The fast flux environment within core will cause mechanical distortion of FHR fuel assemblies. The design intent is to replace fuel assemblies well before mechanical distortion begins impede coolability or control element insertion. Previously liquid-cooled reactors with plate type fuel have used curved fuel plates [e.g., the High Flux Isotope Reactor at Oak Ridge National Laboratory (ORNL) and the Materials Test Reactor at Idaho National Laboratory (INL)] to minimize the potential for fuel warpage to block coolant flow. The value and necessity of mechanical design modifications of the AHTR fuel assemblies to minimize the impact of fuel plate warpage will also need to be established.

The AHTR fuel plates are intended to be layered structures of fuel particles, carbonaceous powder, and burnable poison particles. While the technology to manufacture compression molded carbon plates and TRISO fuel compacts is well established, a specific process to fabricate the AHTR fuel plates has yet to be established or refined. Issues that will have to be addressed in the AHTR fuel fabrication process development include plate warping during manufacturing (achievable dimensional repeatability), fuel plate integration into fuel assemblies, layer separation (delamination), and in-service erosion vulnerability (potentially leading to stray fuel particles).

The current design for the AHTR fuel plates calls for them to be significantly larger than available reactor testing volumes. Further, the planned test reactor core will be significantly smaller than a commercialscale power reactor. The fuel qualification testing will, thus, of necessity need to extrapolate the mechanical fuel properties to the larger structures of the AHTR core. Size extrapolation of fuel physical properties cannot currently be effectively performed for layered TRISO fuel from the measured properties of small, irradiated coupons. Further, the technical challenge of handling recently irradiated fuels provides strong incentive to develop FHR fuel coupon scaling rules even for relatively small fuel pebbles that would be used in an FHR pebble bed core. 
The degree to which an FHR can accommodate a small leaking fuel fraction depends on the effectiveness of its primary coolant cleanup system. Several different technologies are candidates for removing radionuclides from the primary coolant salt. Electronegative impurities (e.g., iodine and oxygen) will likely be removed via an electrochemical reaction using a sacrificial carbon electrode. Metallic fluorides will likely be removed from the primary coolant through a bismuth metal contacting system (Ref. 26). In the bismuth based separation process, the primary coolant salt is countercurrently contacted with liquid bismuth containing a reductant such as lithium. Bismuth is essentially immiscible with the salt. The metal is subsequently removed from the bismuth by contacting it with $\mathrm{LiCl}$. Separation factors of $10^{4}$ have been demonstrated for the trivalent rare earths dissolved in 66\% lithium fluoride and 34\% FLiBe using this technique (Ref. 27). However, the AHTR's primary coolant cleanup system has yet to be designed. It is envisioned that the coolant cleanup system will function on a flow side stream much as with the chemical and volume control system of an LWR.

\subsection{FHR FUEL QUALIFICATION TASKS}

The first step in FHR fuel qualification is for the NGNP/AGR program to complete its planned irradiation campaigns. The data generated through this testing and evaluation program will provide the fundamental TRISO performance information necessary for FHR fuel qualification. Apart from specifying the FHR fuel design service conditions, which applies to both the fuel particles and fuel elements, the FHR fuel qualification tasks described here are intended to provide a roadmap for qualifying the larger fuel elements and assemblies relying upon the data generated by the AGR program to qualify the particles.

Several additional interrelated areas will require additional effort to develop qualified FHR fuel:

1. fuel design service conditions and fuel performance specification for normal, AOO, DBE, and BDBE conditions;

2. plate fuel assembly manufacturing process development and qualification including process variance impact analysis;

3. hydraulic modeling and evaluation of fuel assemblies;

4. fuel assembly structural materials qualification;

5. mechanical property evaluation of plate fuel both during assembly and after irradiation;

6. integrated demonstration of fuel assemblies using C-C composite mechanical supports;

7. primary salt cleanup technology development and demonstration; and

8. fuel coupon scaling rule development and validation.

To establish the fuel design service conditions, accident scenarios and plant performance models will need to be developed and validated. Identifying the design issues to ensure that the safety assessment process has addressed all of the critical phenomena will be a key initial step. The general area of accident evaluation will be addressed in Chapter 6 of this roadmap.

A structured TRISO plate fuel manufacturing process development roadmap will also need to be generated. The report will include an evaluation of the quality control aspects of the manufacturing process and an evaluation of the impacts of process variance on fuel performance.

The in-vessel flow and decay heat removal hydraulic design of the AHTR are significant remaining issues to be resolved before achieving a preconceptual level of maturity. Flow induced vibration of complex structures are notoriously difficult to computationally model with sufficient fidelity as seen in the recent San Onofre Nuclear Generating Station SG tube vibration issue. However, the flow through the AHTR core is a single phase liquid. Relatively simple, surrogate material hydraulic models can provide confidence in the mechanical and flow interaction characteristics of AHTR fuel assemblies. Thus the hydraulic design and validation tasks are necessary supports to the fuel qualification. A task description 
for core level hydraulic design and experimentation will be the subject of another roadmap development effort.

Ceramic composite materials are not currently qualified for use as structural elements in nuclear reactors. The AHTR's fuel assemblies use C-C composite ceramics as their mechanical support elements. Qualifying the fuel mechanical support structures is required for fuel qualification. However, traditionally structural materials are addressed separately from fuels in nuclear reactor qualification programs and the development path for qualifying the fuel assembly support structures will be addressed under the structural materials topic.

\subsubsection{Mechanical Validation of Layered TRISO Fuel Structures}

\section{Purpose}

The purpose for this task is to demonstrate mechanical characteristics of layered TRISO fuel structures to ensure adequate mechanical performance in service.

\section{Work scope}

This task will use the design data generated by the AGR 5/6 fuel irradiation testing and the plate fuel manufacturing process description as inputs. The first phases of this task can begin once the plate fuel manufacturing process has been developed. However, irradiation testing of layered fuel coupons will need to await the results of the AGR 5/6 series of TRISO qualification tests.

The mechanical properties of interest in layered fuel forms are (1) the shear properties of the various layers, (2) the thermal conductivity of the fuel and outer coating, (3) the hardness/erosion resistance of the fuel surface, and (4) mechanical distortions and/or cracking of the fuel element resulting from either radiation damage or thermal stress.

Apart from the radiation influence on the fuel element performance, all of the tests are standard mechanical evaluations of ceramics and can be performed by ceramic materials testing laboratories. None of the properties should be influenced by the presence of the primary salt. Hence, dedicated testing apparatus would not be required.

Post-irradiation mechanical property testing will need to be performed in a hot cell under inert atmosphere. Thermal conductivity testing will require custom measurement design as the fuel decay heat will add to any externally applied heat source.

\section{Activities and costs}

1. Fabricate layered TRISO fuel coupons with surrogate fuel kernels.

2. Perform mechanical testing on fuel coupons with surrogate fuel kernels.

3. Fabricate layered TRISO fuel coupons with low-enriched uranium oxycarbide kernels.

4. Fuel irradiation capsule testing.

5. Perform post-irradiation mechanical testing on low-enriched uranium (LEU) fuel coupons.

\subsubsection{Layered TRISO Fuel Structures Scaling Rule Development}

\section{Purpose}

The purpose for this task is to develop the capability to extrapolate the performance of large multilayer ceramic nuclear fuel structures using materials property data acquired by testing small-scale coupons. 
Project success will provide the technical basis to enable the qualification of layered fuel plates for the AHTR.

\section{Work scope}

Beginning with small pressed test coupons composed of the graphite matrix developed for HTGR fuel applications, the physical and mechanical properties of test articles of increasing size and complexity of structure will be measured to determine how the properties scale. Since the matrix provides the core strength of the fuel plank, initial test coupons will be TRISO particle-free and consist solely of the matrix material. Physical and mechanical properties [e.g., dynamic and static modulus, tensile strength, thermal conductivities, coefficients of thermal expansion (CTE)] will be measured and microstructural analysis will need to be performed. The matrix material is predominantly graphite and will inherently have some degree of anisotropy between the $\mathrm{X}-\mathrm{Y}$ direction and the $\mathrm{Z}$ direction due to preferential alignment of the graphitic particles during the fabrication process. For this reason, testing will be conducted in each orientation and the effects will be determined.

The mechanical strength of the material (e.g., tensile and flexural) will be determined using American ASTM International (ASTM) approved geometries. The measured strength will be modeled and predicted for smaller and larger volumes using Weibull theory and analysis. The larger volume test data developed by the testing program, along with ASTM compliant specimen data will allow extrapolation of the derived strength-volume relationship to larger volumes, representative of the final component. Weibull size scaling will also allow interpretation of data generated from specimens with very small volumes, typical of the volumes used in irradiation capsules, which of necessity are constrained in their available test specimen volumes and geometry. Other physical properties will be modeled for the appropriate scaling relationships.

\section{Activities and costs}

1. Fabricate test coupons of various sizes - the coupons will be made from RDKrS graphite matrix material, which is a blend of natural graphite, synthetic graphite, and a resin binder.

2. Irradiate coupons.

3. Test the effects of size for each property on both irradiated and nonirradiated coupons.

\subsubsection{Integrated Demonstration of Fuel Assemblies}

\section{Purpose}

The purpose for this task is to ensure that no unforeseen issues arise as a result of fabrication, assembly, or thermal cycling. Test reactor evaluation using scaled fuel assemblies would provide additional confidence with regard to radiation-induced distortion.

\section{Work scope}

This task will fabricate AHTR fuel assembly segments from prototypical materials. All of the mechanical issues about fuel assembly fabrication, handling, and thermal cycling should be apparent with a fuel assembly of less than 1-meter in length.

Test reactor fuel assembly development is beyond the scope of the current roadmap effort. However, test reactor fuel assemblies will likely retain the general character of the commercial-scale fuel assemblies and be differentiated primarily in length and somewhat in width. 


\section{Activities and costs}

1. Fabricate series of AHTR fuel plate segments using surrogate fuel kernels.

2. Fabricate support ' $\mathrm{Y}$ ' segment.

3. Fabricate channel box segment.

4. Develop assembly process for integrating fuel plates into fuel assembly.

5. Assemble prototype fuel assembly segment.

6. Assemble thermal cycle and flow test fuel assembly segment.

\subsubsection{Salt Cleanup System Design and Demonstration}

\section{Purpose}

The purpose for this task is to develop the capability to cleanup small fuel leaks from the primary salt system and, thus, enable FHRs to follow the fuel approval pathway established for LWRs in NUREG 0800 Sect. 4.2 (Ref. 11).

\section{Work scope}

The techniques necessary for cleaning fluoride salts are already known and have been previously demonstrated on laboratory- and engineering-scales under the MSR program. However, the engineering aspects of the primary salt cleanup system remain to be developed. For example, in order to perform the cleanup operation on a side stream of primary coolant, a means to provide a controlled amount of primary salt into the cleanup facility and then return it to the reactor needs to be demonstrated. Also, as the chemical separation of contaminants from salt depends on the carrier salt composition, the developments and demonstration will need to take place using beryllium bearing salt (e.g., without separated lithium isotopes). The work will, most cost, effectively be performed at facilities that already have practice with using beryllium bearing fluoride salts.

\section{Activities and costs}

1. Design and demonstrate fluoride salt extraction techniques.

2. Design bismuth-lithium based metallic impurity removal apparatus.

3. Design online fluoridation apparatus.

4. Demonstrate and prototype salt cleanup components. 


\section{STRUCTURAL AND FUNCTIONAL MATERIALS}

\subsection{INTRODUCTION}

The objective of this chapter is to describe an acceptable materials development path to support deployment of first-generation FHRs while minimizing both development time and cost. Materials are a dominant issue with the viability and performance of all high-temperature reactors (HTRs). Several materials development roadmaps for advanced reactors with broad authorship and significant technical depth have been written in the past decade. However, FHRs were largely not included in these efforts. Even the 2008 Generation IV Integrated Materials Program Plan: Focus on Very High Temperature Reactor Materials (Ref. 28) does not address the materials needs of FHRs or the uranium carbonate based thermochemical cycle for hydrogen production that matches FHR output temperatures. A notable exception to the lack of inclusion of FHRs is the 2007 assessment of SiC composites for salt-cooled reactors (Ref. 29). Also, the Composite Technology Development Plan (Ref. 30) while focused on HTGRs has large technical overlap with the requirements for FHRs. Consequently, the FHR composite technology development requirements are largely drawn from the HTGR focused evaluation. Notably, the Composite Technology Development Plan (Sect. 6.6) provides cost and schedule estimates for reactor use of continuous fiber composites (CFCs) by 2021 in reactor environments.

The present effort has been informed by the earlier reports, but is focused solely on FHRs and is significantly less detailed than the focused evaluations as materials are only one aspect of this more general roadmap. Also, FHRs are less mature than either HTGRs or SFRs and some aspects of their materials requirements are, thus, less well-defined. A focused investigation of FHR materials development and qualification issues is recommended as a subsequent task.

In an FHR, the upper temperature limit, and, thus, the achievable plant thermal efficiency, is principally determined by the structural properties of the primary coolant container material. The FHR's structural alloy performance constraint is markedly different from an LWR where the heat transfer rate from the fuel is the design limiting constraint. Enhanced structural materials are thus especially important to ensuring the economic desirability of FHRs. Further, FHRs have a natural evolutionary path to higher temperatures as improved structural materials are developed.

At high temperatures, thermally activated processes produce a number of time-related degradation mechanisms that must be recognized in the design and operation of high-temperature components. Creep, creep-fatigue, creep ratcheting, and corrosion appear to be the most life-limiting factors in FHR hightemperature structural integrity. Many of the material stressors are temperature dependent and at sufficiently low temperature more mature, reliable solutions exist. The AHTR's design core outlet temperature is $700^{\circ} \mathrm{C}$. The design core outlet temperature is a compromise between the requirement to have a sufficiently high thermal efficiency for a plant to be economically appealing and feasible material temperatures for high-reliability and long life. With a $700^{\circ} \mathrm{C}$ core outlet temperature, the peak steam temperature is likely to be roughly $650^{\circ} \mathrm{C}$, which remains substantially below that envisioned for currently planned advanced ultra-supercritical coal fired steam cycles (Ref. 31).

ASME BPVC qualification and NRC approval of functional and structural materials are key elements in the development of viable FHR designs. The ASME BPVC with respect to HTRs has been restructured over the past few years. Sect. III, Division 5 was issued in November 2011. The new division now includes design rules and qualification procedures for graphite. Otherwise, the new division is essentially an editorial compilation of existing subsections and code cases to include the high-temperature creep regime. The ASME recently issued a Roadmap to Develop ASME Code Rules for the Construction of HTGRs (Ref. 32). As FHRs are also an HTR class that uses coated particle fuels and use graphite as a 
moderator, much of the ASME HTGR code development roadmap directly supports FHRs. However, only in 2012 did the ASME working group on liquid metal-cooled reactors increase its scope to include all liquid-cooled reactors. Consequently, the Division 5 rules do not explicitly include FHRs at present. Further, the BPVC does not provide specific guidelines for environmental effects, especially the effect of corrosion on the high-temperature behavior (e.g., fatigue, creep, and creep-fatigue). Also, NRC has not endorsed the compliance with Division 5 as an adequate means of demonstrating the safety of reactor materials.

This initial roadmap does not provide a comprehensive evaluation of all possible materials choices and design options for first-generation FHRs, but relies upon the AHTR design choices as a reasonable selection for a first-generation FHR plant. Other material options are possible for some functional and structural materials. For example, the AHTR has elected to use CFC materials for its vessel internal structures. The only metallic components planned for deployment in a substantial radiation environment in the AHTR are the molybdenum hafnium carbide (MHC) control blades. While metallic internals remain a design alternative, their development issues are not addressed in this roadmap. Also, different power cycles such as supercritical carbon dioxide or open-air Brayton cycles are possible alternatives. Further, FHRs can be used as process heat sources. However, the reactor materials requirements are largely independent of the power cycle or heat consuming process.

Fuels, coolant (including the fission product cleanup systems), and instrumentation materials are addressed in separate chapters of this roadmap. This roadmap also does not address materials challenges that are common across reactor classes such as seismic isolator materials or steel form concrete construction technologies. Materials issues for a test FHR are addressed separately as the licensing requirements and safety issues of small, non-power reactors differ substantially from those for power reactors.

The AHTR has not yet reached a full conceptual design level of maturity. Dimensions included in the report are only for visualization purposes. The dimensions and specific core layout will change as the design matures. ORNL/TM-2012/320 (Ref. 1) provides the current AHTR conceptual layout and component description. The materials performance and reactor design are intertwined. As the reactor design matures, more specific component and materials requirements specification become possible. As more detailed material properties become available they feed back into the reactor design.

The structural and functional materials evaluation begins a brief overview of the two distinctive structural materials (CFCs and Alloy N) anticipated for first-generation FHRs and continues with a description of the major reactor SSCs for the AHTR and candidate materials for each. Brief descriptions of the planned operating conditions are also included as some of the high-temperature degradation phenomena (e.g., creep fatigue) depend on the time history of the applied stressors. The chapter also includes an overview of the design constraints for each SSC.

The subsequent sections briefly describe an initial set of tests or tasks necessary to develop the materials sufficiently so that they can be used for their intended purposes in the AHTR. Test reactor materials issues are then addressed in a final subsection. 


\subsection{MATERIAL FOCUSED PLANT DESCRIPTION}

\subsubsection{Summary}

A schematic showing the AHTR's proposed reactor building layout is shown in Fig. 4.

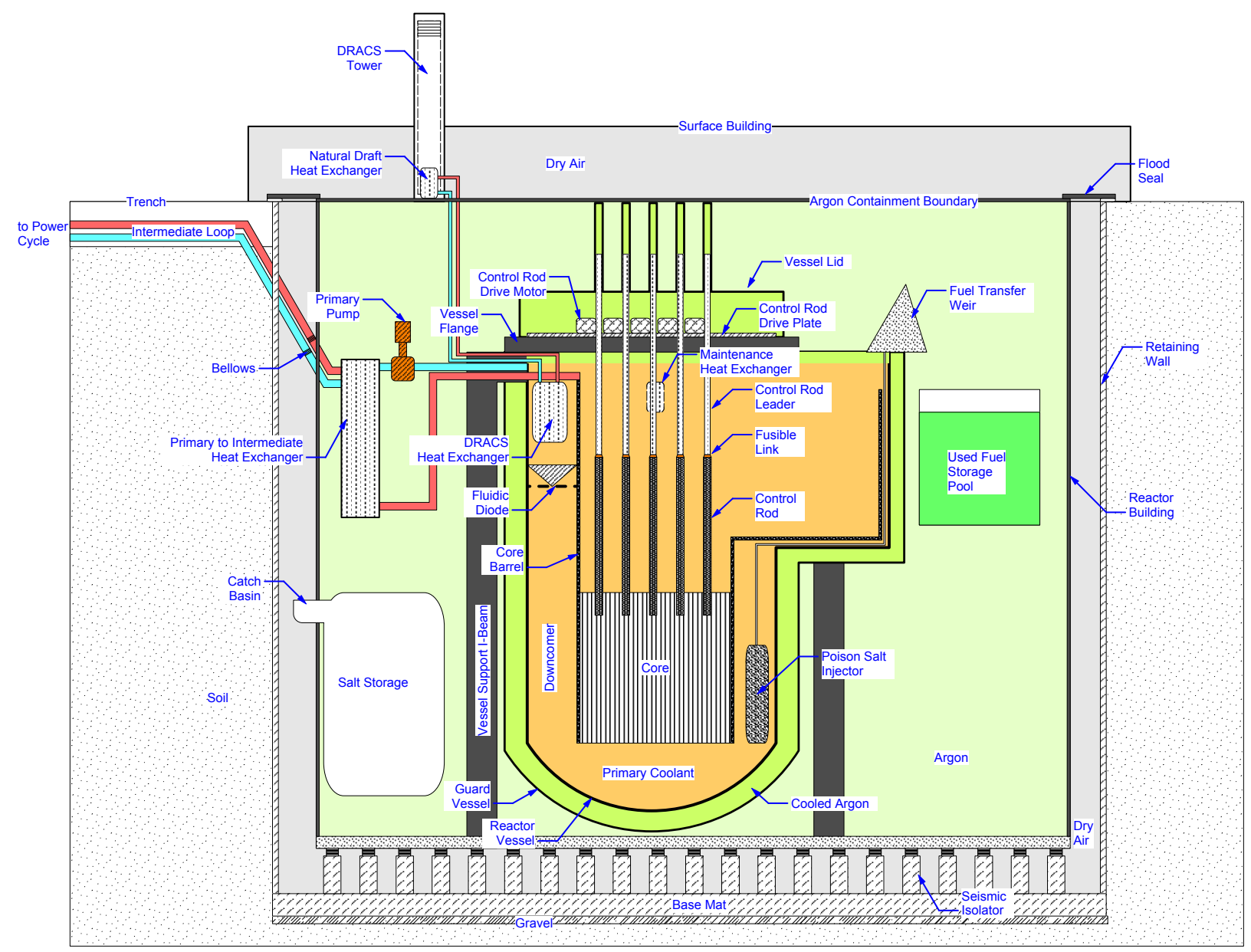

Fig. 4. AHTR conceptual schematic.

Fig. 5 shows an external view of the AHTR core from above. 


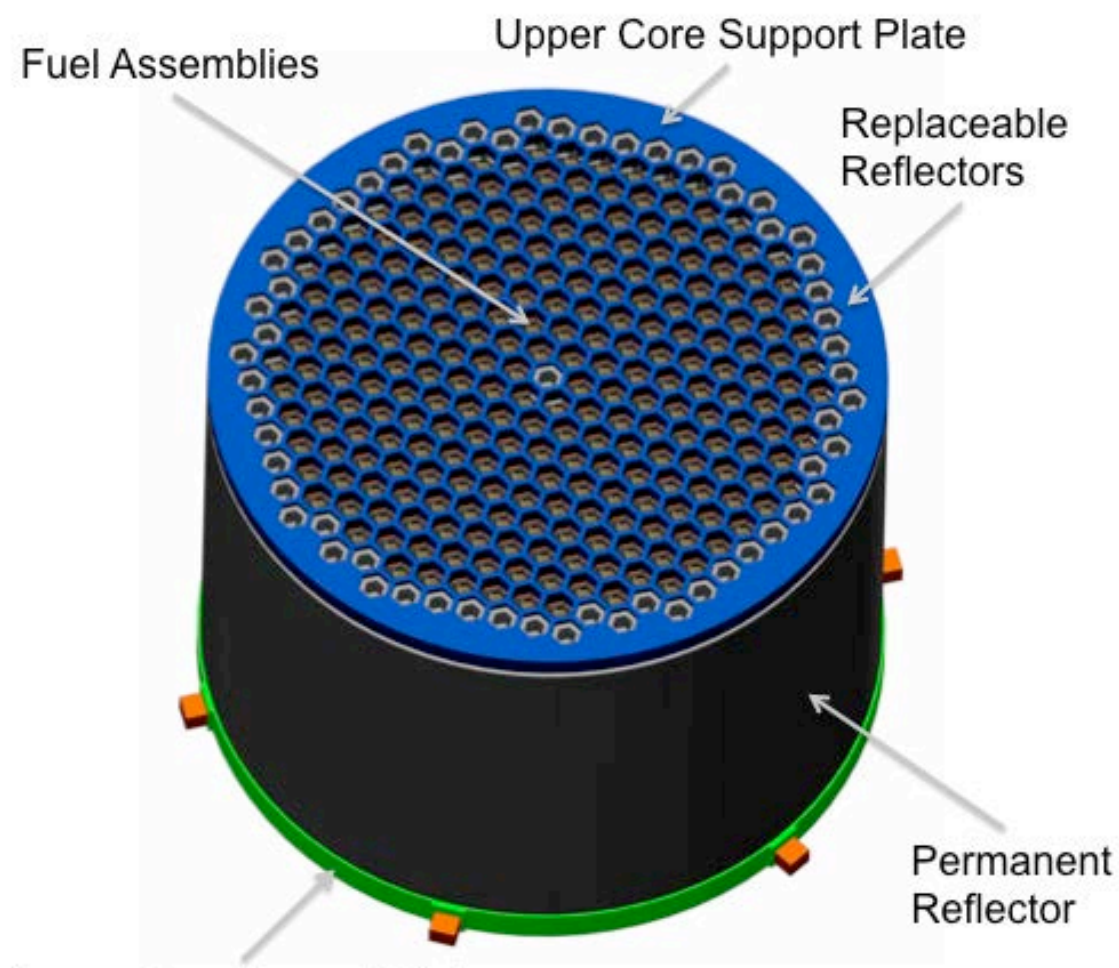

Lower Core Support Plate

Fig. 5. AHTR core.

The leading candidate materials (and likely alternatives) for distinctive AHTR components and structures are listed in Table 2. 
Table 2. AHTR materials for FHR distinctive components and structures

\begin{tabular}{|c|c|}
\hline Component or structure & $\begin{array}{l}\text { Material } \\
\text { Alternate }\end{array}$ \\
\hline Reactor vessel and primary piping & $\begin{array}{l}\text { Alloy } 800 \mathrm{H} \text { with nickel or Alloy } \mathrm{N} \text { liner } \\
\text { New creep resistant nickel alloy }\end{array}$ \\
\hline Guard vessel & 316 stainless steel (SS316) \\
\hline $\begin{array}{l}\text { P-IHX DHX } \\
\text { Maintenance heat exchanger }\end{array}$ & $\begin{array}{l}\text { New creep resistant nickel alloy } \\
\text { Alloy } N\end{array}$ \\
\hline Pump (wetted components) & $\begin{array}{l}\text { Alloy N } \\
\text { New high-strength nickel alloy }\end{array}$ \\
\hline Core barrel & $\begin{array}{l}\text { C-C } \\
\mathrm{SiC} / \mathrm{SiC}\end{array}$ \\
\hline Fuel assembly mechanical structure & $\mathrm{C}-\mathrm{C}$ \\
\hline Core support plates & $\mathrm{SiC} / \mathrm{SiC}$ \\
\hline Ex-core control blade guide & $\mathrm{SiC} / \mathrm{SiC}$ \\
\hline Wetted refueling mechanisms & $\mathrm{SiC} / \mathrm{SiC}$ \\
\hline Control blades & MHC \\
\hline Fusible links & Au-Sn alloy \\
\hline Vessel lid & SS316 \\
\hline Replaceable reflector & Nuclear grade graphite \\
\hline Permanent reflector & Nuclear grade graphite \\
\hline Primary salt cleanup reducing agent & Bi-Li alloy \\
\hline Cleanup system container & $\begin{array}{l}\text { C-C } \\
\text { Molybdenum }\end{array}$ \\
\hline High-temperature tritium trap & $\begin{array}{l}\text { Yttrium } \\
\text { Samarium }\end{array}$ \\
\hline Intermediate loop piping & $\begin{array}{l}\text { Alloy } 800 \mathrm{H} \text { with nickel or Alloy } \mathrm{N} \text { liner } \\
\text { New creep resistant nickel alloy }\end{array}$ \\
\hline $\begin{array}{l}\text { Intermediate to supercritical water heat } \\
\text { exchanger }\end{array}$ & $\begin{array}{l}\text { New } \gamma^{\prime} \text { strengthened nickel alloy } \\
\text { Alloy } N\end{array}$ \\
\hline
\end{tabular}

\subsubsection{Continuous Fiber Ceramic Composites}

FHRs will make extensive use of CFCs for reactor vessel internal components. The principal difference between FHR and HTGR environmental tolerance requirements for CFCs lies in the difference between the chemical environments provided by the fluoride salt as compared to helium. Both $\mathrm{SiC}$ and carbon are known to be chemically compatible with fluoride salts. However, the primary coolant will inevitably include impurities and the CFCs may include both impurities and binder materials. Demonstrating the chemical compatibility of the primary coolant with production grade CFCs is thus necessary. Establishing chemical compatibility will include developing a standard test procedure for chemical compatibility. Unlike HTGRs, FHRs do not have a severe oxidation DBA and are intended to be operated with a somewhat reducing primary coolant chemical environment.

Design code development and licensing are the critical barriers limiting the use of CFC materials in nuclear systems. QA procedures with regard to final licensing of reactor components utilizing ceramic 
composites has been identified as a critical path issue. Needed standards will broadly consist of design rules for composite components and standards of materials specifications, practices for materials characterization, and methods of materials properties data acquisition.

\subsubsection{Alloy $\mathbf{N}$}

Alloy N (UNS No. N10003), also known as Hastelloy N or INOR-8, is a nickel-based alloy containing $\mathrm{Mo}, \mathrm{Cr}, \mathrm{Fe}, \mathrm{C}$, and small amounts of several other elements. Alloy N was developed at ORNL specifically for structural applications in molten fluoride salt systems. The current status of Alloy $\mathrm{N}$ for FHR application was the topic of a recent review (Ref. 33). Alloy $\mathrm{N}$ has very good corrosion resistance to molten fluoride salts. Alloy $\mathrm{N}$ also has good oxidation resistance in air environment and may be used for continuous operations at temperatures up to $982^{\circ} \mathrm{C}$. The maximum allowable stress for Alloy $\mathrm{N}$ decreases rapidly above $600^{\circ} \mathrm{C}$ becoming too low for practical use above $700^{\circ} \mathrm{C}$. Compared to the leading candidate materials that are usually considered for high-temperature nuclear reactor construction, the hightemperature strength of Alloy $\mathrm{N}$ is noticeably weaker.

Alloy $\mathrm{N}$ is not currently approved under the NPP (Sect. III) portion of the BPVC. Thus, a materials qualification effort would be required for use of Alloy $\mathrm{N}$ in any part of the containment boundary or to perform any other safety function. Developing a BPVC case for limited-term Alloy N use at temperatures less than $704^{\circ} \mathrm{C}$ may be possible based upon existing data from the earlier MSR program and/or limited term supplemental qualification testing (Ref.5). The principal issue with the use of Alloy $\mathrm{N}$ appears to be the limited time to $1 \%$ creep under appreciable stress at likely use temperatures. Alloy $\mathrm{N}$ appears to be a preferred alternative for both a limited lifetime test FHR and for initial designs of a lower temperature, first-generation FHR power plants for structures such as primary heat exchanger tubing where a monolithic alloy is desirable and replacement is possible. However, developing and qualifying improved performance alloys for longer term high stress applications appears advisable rather than generating additional long-term Alloy N performance data.

MSRs have a more complex primary loop chemical environment, due to the presence of fuel and fission products, than do FHRs. However, the primary loop of FHRs will contain tritium fluoride (TF) as a result of tritium production in the salt. A primary route for corrosion of the primary salt-wetted materials is fluoridation due to the chemical reaction with TF. Alloy N was developed for the MSR program. The design of Alloy $\mathrm{N}$ thus placed more emphasis on corrosion resistance and somewhat less on hightemperature strength than would be desirable for an FHR. ORNL has recently begun the development of successor alloys to Alloy N. Alloy N is primarily a solid solution strengthened alloy. Samples of several precipitation strengthened alloys show promise for application in high stress applications at higher temperatures. All of the new alloys appear to have good corrosion resistance to molten fluoride salts, but are slightly inferior to Alloy $\mathrm{N}$ in that respect.

\subsubsection{Core}

Apart from the fuel plates, the AHTR core consists primarily of fuel assembly mechanical support structures and flow channel boxes. The in-core mechanical structures are planned to be fabricated from continuous fiber $\mathrm{C}-\mathrm{C}$ composites. $\mathrm{C}$-C composites are selected both due to the good chemical compatibility of carbon with fluoride salts and the necessity for adequate neutron moderation for efficient fuel utilization.

In general, C-C composites are desirable for load bearing applications where high temperatures are encountered and/or high-temperature stiffness are required. A key limitation of C-C composites for incore application is their dimensional instability due to displacement damage. Hence, the useful life of C-C composites is dependent on the fast neutron fluence. The design intent of the AHTR is to replace in-core 
components before mechanical warping becomes functionally limiting. Another issue for qualification of $\mathrm{C}$ - $\mathrm{C}$ composites is the wide range of the fabrication techniques and raw materials. A nuclear grade $\mathrm{C}-\mathrm{C}$ specification will thus entail additional complexity.

\subsubsection{Reactor Vessel}

The AHTR's preconceptual design for the reactor vessel calls for the use of an Alloy $800 \mathrm{H}$ vessel with a thick $(1 \mathrm{~cm})$ nickel or Alloy $\mathrm{N}$ lining. The lining only provides corrosion protection of the reactor vessel from the primary salt and is not credited for any structural strength. As the reactor vessel will be a thin $(<5 \mathrm{~cm}$ ) walled structure, external strengthening-trusses (also of alloy $800 \mathrm{H}$ ) will also be used to increase the mechanical stability. The design intent for a thick $(1 \mathrm{~cm})$ liner is to provide sufficient liner thickness that materials performance issues arising from solid state inter-diffusion does not become life limiting. The lining is likely to be applied as a welded on layer. However, Division 5 of the BPVC currently only has limited, structurally focused design rules (NH-3227.8 and NB-3122) for welded on liners.

The AHTR's reactor vessel will be large (10.5 m diam $\times 19.1 \mathrm{~m}$ height) and expensive to replace. The AHTR vessel will thus be designed for a service life of at least 60 years. Alloy $800 \mathrm{H}$ has existing 60 -year design allowances in Sect. III, Division 5 of the ASME BPVC. Note, however, that at high-temperatures, especially when combined with additional environmental stressors, structural alloys can degrade more rapidly than anticipated due to the combined effects of several complex, interrelated, time-dependent mechanisms, not all of which are fully understood. Thus, 60+ years of service life may not yet be achievable in-practice for high-temperature, nuclear reactor structural components. An important design feature of the AHTR that derives from the combination of its thin-wall, removable-top containment, and its thin- walled reactor vessel, is, thus, the long-term potential for reactor vessel replacement as part of a plant life extension process.

The reactor vessel temperature under normal operating conditions will be thermally coupled to the primary coolant return flow $\left(650^{\circ} \mathrm{C}\right)$. The primary stressors on the reactor vessel during NO are the hydrostatic load of the vessel contents combined with the high temperature. The core's thick neutron reflector and the large downcomer are intended to prevent the reactor vessel from being exposed to sufficiently high lifetime neutron fluence and so limit significant embrittlement. If necessary, a layer of boron containing ceramic can be used as a neutron shield just outside of the permanent reflector. Several different boron-containing ceramics (e.g., boron carbide, boron nitride, titanium diboride) are commonly used within molten cryolite cells for aluminum production, which suggests that boron-based shielding ceramics might be chemically compatible with the primary coolant.

In order to accommodate the vessel thermal expansion upon heat-up, the AHTR vessel will be hung from its upper flange. Additionally, the large reactor vessel must be strong enough to accommodate seismic loads. The required thickness of the reactor vessel will thus be determined by the combination of the 60year design allowance for mechanical creep combined with the hydrostatic and seismic load limits. The reactor vessel is intended to be kept hot for its entire operating life. If the low cycle thermal-fatigue properties of the structural alloys are not design limiting, the primary salt temperature could be lowered to $\sim 550^{\circ} \mathrm{C}$ during refueling. The viscosity of the primary coolant would increase undesirably if its freezing point were approached. Hence, all refueling and maintenance operations will need to be performed with the primary coolant at at-least $550^{\circ} \mathrm{C}$. Thus, the structural alloy could be subjected to a limited number (<200 cycles) of $100 \mathrm{~K}\left(650-550^{\circ} \mathrm{C}\right)$ temperature cycles over its design life.

Alternate material choices are possible for the reactor vessel. Type SS316 could be substituted for the Alloy $800 \mathrm{H}$. SS316 has been shown to have a very low corrosion rate (assuming uniform weight loss; depth of attack can be expected to exceed that calculated for uniform mass removal) in FLiBe provided that the salt is maintained in a moderately reducing condition by the addition of beryllium (Ref. 34). 
However, the Gibbs free energy of iron fluoride indicates that iron is only slightly less likely to dissolve into the fluoride salt than chromium. Recent work on fluoride salt corrosion of steels shows that both iron and chromium are readily dissolved into the salt via reaction with TF, which would be generated in the primary coolant (Ref. 35). Moreover, the corrosion properties of SS316 have not been examined under the combined set of stressors of an FHR vessel. Other complex, high-temperature phenomena are known to exist in similar temperature and mechanical environments such as the reduction in corrosion resistance of austenitic stainless steels when subjected to low cyclic fatigue loading at high temperature (Ref. 36). SS316 would, thus, need to receive additional study of its performance in the intended use conditions prior to its recommendation as a baseline design choice. Clad Alloy $800 \mathrm{H}$ is thus currently preferred as it introduces fewer complexities into the design. Alternatively, a new precipitation strengthened nickelbased alloy has recently demonstrated promise for long term, structural applications in fluoride salts. While a monolithic alloy that could survive the entire reactor design life would be preferable, qualifying a novel alloy for long-term, nuclear reactor service will require at least a decade of dedicated effort.

The AHTR's vessel will be both large and heavy ( 300 tons). Transportation of a completed vessel to the plant site will be challenging for locations without direct barge access. The ongoing development of heavy lift hybrid aircraft may enable worldwide transport of completed vessels to otherwise inaccessible sites. In the near term, however, the AHTR's truss supported, thin-walled vessel is designed to be rail transported to the construction site in sections and welded together in a local workshop.

\subsubsection{Reflector}

Both the permanent and replaceable reflectors will be composed of nuclear grade graphite. The MSR program demonstrated the compatibility of graphite with liquid fluoride salts. The largest change of the addition of Division 5 to Sect. III of the ASME BPVC was the approval of graphite design rules for hightemperature nuclear reactor application. Additionally, ASTM recently updated D7301-11 Standard Specification for Nuclear Graphite Suitable for Components Subjected to Low Neutron Irradiation Dose, which provides graphite specifications for where neutron irradiation induced dimensional changes are not a significant design concern such as the AHTR reflector blocks. However, a technical issue with the reflectors is the operational issue of ensuring that the graphite does not contain moisture upon initial introduction into the salt.

\subsubsection{Control Blades}

Each AHTR fuel assembly is intended to have its own control blade. The AHTR control blades will be fabricated from a commercially available MHC (1.2\% Hf, $0.1 \%$ C, balance Mo) alloy. Due to the uniformly distributed, extremely fine carbides, MHC exhibits outstanding heat and creep resistance to over $1500^{\circ} \mathrm{C}$. Molybdenum has very good chemical compatibility with fluoride salts and good neutron flux tolerance. However, the chemical compatibility of the specific alloy with the primary coolant remains to be established. Significant leaching of the hafnium from the alloy would be deleterious to the reactor safety. Also, the specific amount of shutdown margin provided by the control blades can be adjusted by altering the amount of hafnium within the alloy (e.g., using 1.4\% hafnium instead of 1.2\%). Acceptable tolerances for the design variances will also need to be established. Moreover, the control blades are intended to be formed from a series of links to accommodate any mechanical distortion of the C-C guides. Maximum credible bowing of the C-C composite needs to be established to determine the specific mechanical design of the control blades links.

FHRs can use primary coolant temperature excursions as mechanisms to activate their safety features. The principal negative impact of a primary coolant temperature increase is increased creep of the coolant containment alloy. As creep is a slow degradation mechanism, many hours are available for design transients before lifetime material creep limits would be exceeded. The control blades feature a thermal 
fuse in their mechanical linkage such that if the upper plenum temperature exceeds the design intent, the control blades will automatically drop into the core. The thermal fuse alloy is intended to be a gold-tin braze whose specific release temperature is set by the alloy composition. Chemical compatibility of the alloy with the primary salt, as well as, the mechanical strength of the joint, remains to be established. Finally, while the control blades will travel with the fuel assemblies to the used fuel storage pool, upon emerging from the pool (once the activation products have decayed sufficiently), the control blades could be reused. Consequently, a control blade lifetime evaluation procedure will be necessary.

\subsubsection{Reactor Vessel Internals}

The reactor vessel internals (e.g., upper core support plate, upper core support plate mounting struts, fuel assembly headpiece, lower core support plate, lower core support plate sliding mounts, core barrel, control blade guide tubes, and the control blade leader rods) are all intended to be fabricated from $\mathrm{SiC} / \mathrm{SiC} \mathrm{CFC}$. None of the intended $\mathrm{SiC} / \mathrm{SiC}$ pieces are required to be hermetic. Descriptions and illustrations of the in-vessel components are available in the recent AHTR Mechanical, Structural, and Neutronic Preconceptual Design Report. The DOE-NE Nuclear Energy Enabling Technology (NEET) program is currently sponsoring an investigation of the application of SiC/SiC CFCs as channel boxes within boiling water reactor (BWR) cores. As the in-core BWR environment has a substantially more intense radiation environment than near core FHR environment, successful completion of the current program is anticipated to provide the necessary material radiation tolerance evidence.

The upper and lower (see Fig. 6) core support plates will be mechanically large ( $\sim 9 \mathrm{~m}$ diam.) honeycomb type structures. The plates will serve both mechanical and hydraulic functions. As the AHTR hydraulic design remains at a very early stage, the plate designs have substantial remaining uncertainty. Much of the technical challenge is anticipated to be in demonstrating adequate precision in the mechanical fabrication techniques and in the design of the plate honeycomb structures such that the overall plate can be fabricated within a reasonable period of time. Even the large CFC plates are anticipated to be light enough to be able to be transportable by air, avoiding the necessity for either on-site fabrication and/or expensive, large-piece road transport to sites that lack direct barge access.

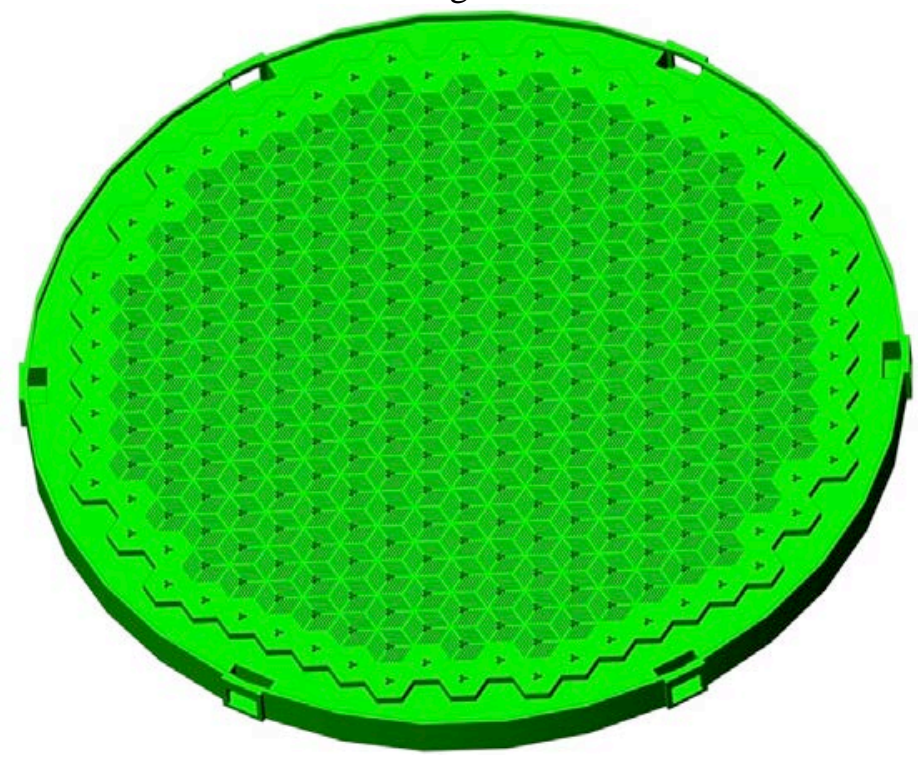

Fig. 6. AHTR lower support plate. 


\subsubsection{Secondary Shutdown Mechanism}

The secondary shutdown mechanism for the AHTR is intended to be a passively, thermally (or ondemand) triggered injection of neutron absorbing rare earth fluoride salt into the lower reactor plenum. The major materials issue that remains to be resolved for the poison salt injector is the thermal release trigger. The poison salt injection system lid will be normally restrained by a gold-tin braze alloy release restraining the injection cylinder lid. The release temperature of the lid is determined by the specific alloy composition. Both mechanical strength of the joint and its chemical compatibility with the primary salt remain to be demonstrated.

\subsubsection{Primary Loop}

The primary loop piping has similar design constraints as the reactor vessel. As such, its baseline design calls for it to be fabricated from Alloy $800 \mathrm{H}$ with a thick nickel or Alloy $\mathrm{N}$ liner. The piping will be $1.25 \mathrm{~m}$ in interior diam. Consequently, the liner could be applied using directional techniques such as arc welding.

As the piping would be somewhat easier to replace than the reactor vessel, it has a higher probability of being fabricated from the new creep resistant nickel-based alloy. Developing long-term data to support multi-decade component lifetimes requires long-term testing. Only shorter term testing is required for components with limited service lives. Shorter-term qualification data for a new alloy could be generated to enable its use for a limited term in replaceable components. Alloy testing and qualification would continue while the components are in service, enabling generation of longer term data. The components fabricated from the short-term qualified alloy could then be replaced as necessary depending on the results of the continuing testing. In practice, the piping would most likely be somewhat overdesigned (thicker walls) to minimize the likelihood for replacement being necessary during the plant design service life.

\subsubsection{Pump}

Existing liquid salt pump designs derive chiefly from the prior MSRE program. The MSRE pump was fabricated from Alloy N. MSRE era pumps were vertical shaft centrifugal pumps with external motors. External motor pumps require both bearings and seals to transfer both radial and axial forces and separate the interior and exterior environments. Pumps with oil lubricated bearings outside the shaft seal (referred to as cantilever pumps) and pumps with salt lubricated bearings were used during the MSRE program era. The salt-wetted components of a cantilever pump are the impeller and volute. In order to operate efficiently, the impeller and volute need to be manufactured from the same material so that impeller fit within the volute remains tight at the operating temperature.

Salt lubricated metal bearings were a significant source of corrosion concern during the MSR era. Over the course of the past several decades, significant progress has been made on high-temperature motors, journal bearings, and seal technology. For a vertical shaft pump a combination of a labyrinthine seal and a gas-lubricated, noncontacting, mechanical, end-face seal could be used to separate the salt environment from the external motor environment. Dry gas sealing has now become commonplace dominating the commercial marketplace for applications where fluid purity is key or human contact with the fluid needs to be avoided. However, maintaining a dry gas seal over several hundred degrees of temperature variance requires high precision mechanisms, which remain a design concern for large shafts extending into a high-temperature environment.

Shaft bearings can be either immersed in the salt or above the gas seal. Liquid salt compatible ceramic journal bearings are now commercially available. Both high-purity, stoichiometric $\mathrm{SiC}$ and diamond 
bearings are compatible with liquid fluoride salt to high temperatures. However, neither of the advanced ceramic bearings has been demonstrated in an FHR operating environment.

Pump design has not been performed for the AHTR. No fluoride salt pump of the size necessary for a large output power plant has ever been constructed. The AHTR pump is intended to be installed on the cold leg of the primary coolant loop. Thus its wetted components will operate at $650^{\circ} \mathrm{C}$. The AHTR has a design coolant flow rate of 9,500 kg/s for each of its three legs. Pump impellers are high stress

components. Decreasing the impeller mass would increase the pump efficiency. Increasing the impeller material creep resistance would thus have a direct impact on the pump efficiency and the replacement/maintenance interval.

In 1967, a study was made on optimal centrifugal pump configuration for liquid salt service. The cannedrotor pump was concluded to be a very desirable configuration (Ref. 37), since it does not have orientation or elevation limitations on its application. Additionally, as the rotor is fully immersed in the primary coolant, using a canned rotor avoids the potential for the primary pump to introduce bubbles (along with their reactivity impact) into the core due to entraining gas in the primary coolant loop. However, high-temperature canned-rotor pumps were judged to be technically infeasible at the time. Magnetic bearings avoid issues altogether with bearing/salt compatibility. Combining the canned-rotor, magnetic bearings, and high-temperature electric motor could yield a much-improved FHR pump. The DOE NEET program is currently using the development of such a pump as a demonstration vehicle for showing how applying advanced instrumentation and controls (I\&C) can result in significantly improved component performance. If the development effort is successful, the AHTR design will be altered to use canned-rotor, magnetic bearing pumps. Canned-rotor, magnetic bearing pumps have a number of integrated materials issues to be resolved. Their development and testing tasks are mentioned briefly in Chapter 8 of this roadmap.

\subsubsection{Refueling Mechanisms}

The AHTR will use a series of mechanisms, all with their drive mechanisms located above the salt pool, to transfer fuel into and out of the reactor. The most likely materials for the mechanisms are Alloy N, SS316, and SiC/SiC. The mechanisms will only contact the salt for limited periods and only during refueling when the salt temperature is lowered somewhat.

\subsubsection{Redox Control System}

The intended functioning of the salt redox control system is described in Chapter 7 of this roadmap. The primary salt-wetted component of the redox control system will be the sacrificial carbon electrode. Detailed performance requirements for the sacrificial electrode have yet to be determined. The initial candidate deployment location is in the refueling lobe of the upper vessel plenum.

\subsubsection{Coolant Cleaning Systems}

The primary coolant salt can acquire contaminants from a number of routes.

1. The salt may acquire moisture during the transportation to the plant site or during the loading process.

2. The salt may pick up contaminants from the container materials or cover gas during operation.

3. The fuel may fail during operation or have initial surface contamination.

4. The secondary shutdown mechanism may activate.

5. The primary to intermediate or DHX tubes may fail. 
6. The coolant cleaning system alloy may carry over into the primary loop.

7. NO will transmute salt constituents.

The contaminants acquired from any of these routes need to be removed from the primary coolant salt. Chapter 7 of this roadmap provides an overview of the operation of the primary and intermediate salt cleanup systems. The electronegative impurities (primarily oxygen) will be removed via the redox control system. The reductive extraction-based contaminant control system will be used to remove electropositive impurities. Mechanical filtering through a nickel mesh will be used to remove any noble metal fission fragments.

The salt cleanup system for the AHTR has yet to be designed. Both the proposed redox control system and the reductive extraction systems have substantial remaining performance uncertainty. The size and mechanical configuration of the bismuth contacting reductive extraction system has yet to be determined. However, the materials required do not depend on the size. The basic extraction process involves contacting the primary coolant with liquid bismuth that incorporates dissolved lithium. The mechanisms for providing the mixing have not been decided upon. Pulse columns, mixer settlers, and centrifugal contactors are candidate contacting mechanisms. Additionally, the cleaned primary salt must be essentially free of bismuth before being returned to the loop as bismuth is not compatible with the structural alloys and activates significantly.

The earlier MSRE program demonstrated the required separations processes in small-scale experiments, but engineering-scale demonstrations have not yet been performed and the container materials for the bismuth based reductive extraction remain to be proven (Ref. 38). The intent of the earlier program was to fabricate the contacting system from graphite or molybdenum (Ref. 39). Today, the necessary reaction vessel and agitators would likely be fabricated from C-C composite.

\subsubsection{Primary to Intermediate Heat Exchanger}

The P-IHX in an FHR will be a salt-to-salt heat exchanger. The P-IHX serves as part of the radionuclide containment boundary and as such will be required to be constructed in accordance with Sect. III of the ASME BPVC. The P-IHX also provides a boundary for the beryllium in the primary coolant and for the dissolved tritium in the primary coolant.

The AHTR's primary salt is intended to be FLiBe with highly isotopically separated lithium and its intermediate salt to be the low melt point eutectic of $\mathrm{KF}_{\mathrm{ZrF}}$. The intermediate salt does not contain lithium to avoid the potential to mix natural isotopic distribution lithium with isotopically separated lithium in the event of a tube failure. The AHTR's baseline design calls for the primary coolant inlet temperature to be $700^{\circ} \mathrm{C}$ and its outlet temperature to be $650^{\circ} \mathrm{C}$ with a flow rate of $9,500 \mathrm{~kg} / \mathrm{s}$ to each of three parallel systems. The outlet temperature of the intermediate coolant will be $675^{\circ} \mathrm{C}$ and its inlet temperature $625^{\circ} \mathrm{C}$.

An optimal configuration for tritium containment has not yet been determined. A double-walled tube-andshell heat exchanger has been selected as the base case for the AHTR. Tritium barrier layers have been attempted previously for molten salt environments. However, the conclusions reached have been that the barrier layers work well in laboratory environments, but "fail miserably" in field use (Ref. 40). Trapping the tritium within the reactor building is preferable as this configuration preserves the separation of the nonnuclear power cycle from radionuclides. The double-wall configuration has been selected to provide a tritium-trapping (e.g., gettering) layer between the primary and intermediate loops. Several alternative materials are useful as tritium getters into hydrides at FHR operating temperatures (Ref. 41). Yttrium has been selected as the baseline candidate high-temperature tritium getter. Tritium getter materials tend to be vulnerable to surface fouling with oxides. Thus, getter material surfaces are often coated with a thin 
platinum or palladium layer. Several alternate gettering configurations are possible within the central section of a double-walled heat exchanger ranging from a yttrium foil layer between coextruded nickel alloy tubes to a yttrium nano-particulate suspension within a sodium-potassium liquid between separately fabricated tubes. Supplemental tritium extraction from the primary coolant may also be provided using palladium-coated yttrium structures (Ref. 42) configured similarly to the resin beds at LWRs.

The MSRE included an 8 MW U-tube, salt-to-salt tube and shell heat exchanger fabricated from Alloy N. The heat exchanger design and fabrication procedures were extensively documented as were the Alloy $\mathrm{N}$ characteristics and its fabrication and joining technologies. Salt flows tend to have larger momentum than water due to their larger density and thus tube vibration is a significant design issue for liquid salt heat exchangers. Tube vibration in the MSRE P-IHX was observed during water hydraulic testing. As a result some peripheral tubes were plugged prior to operation.

Protective layers are unlikely on high-temperature heat exchanger tubing as significant value accrues from using tube walls as thin as possible to minimize component size. Solid-state diffusion during hightemperature operation, which could also occur during the layer application process, will result in intermixing of the material layers. This intermixing alters the material composition. Thus, as the diffusion progresses the material composition could shift outside of qualified limits. Further, the integrity and adherence of the thin cladding layer could degrade over time or when subjected to operational transients. Developing adequate knowledge in the performance of an integrated material system that forms part of a radionuclide containment layer would significantly increase the level of development effort required. Further, Division 5 BPVC rules only address clad alloys in terms of not crediting the cladding for structural strength. Moreover, high-temperature materials performance issues such as creep and creepfatigue for thin, layered nickel-alloy structures remain substantially unknown. Overall, a monolithic alloy represents the lowest risk option for first-generation FHR heat exchanger tubing.

While design rules for tube and shell heat exchangers are well-known, an initial heat exchanger design has not yet been performed. Design considerations will include tube wall thickness, mechanical support requirements, inspection capabilities, overall heat exchanger size, fabrication complexity, and component lifetime. The P-IHX is the highest temperature point in the reactor where thin components are particularly desirable to improve component performance. Hence, the capabilities of the P-IHX may set the achievable upper temperature of first-generation FHRs. Ideally, the P-IHX design would be based upon an integrated economic model of the impact of design choices on the plant's profitability. However, the plant's performance is not known at a sufficient level of precision to enable direct economic model driven design. Optimally, the P-IHXs would be designed to last the entire plant life they are large structures that will be difficult and expensive to replace. However, acceptable performance is likely possible provided that the tubing provides multi-decade service. The relationship between operational parameters and service lifetime requires additional investigation as reactor operations can be shifted to maintain the heat exchanger at normal operating temperatures during outages if creep-fatigue is life-limiting property. All of the salt components will include external heaters to allow initial filling without freeze-up. During refueling outages the components can be kept hot either by maintaining the coolant at full temperature and/or by using the external heaters.

As P-IHX degradation is the temperature-limiting component in first-generation FHRs, structural material development should be targeted at heat exchangers. Multi-decade lifetimes are a key requirement for all major power plant components. Most microstructure-based strengthening mechanisms degrade over time at useful temperatures for FHRs. A key assessment of improved alloys is thus their lifetime. One of the new creep resistant nickel-based alloys recently demonstrated by ORNL has shown very promising creep resistance at useful FHR temperatures while maintaining adequate corrosion resistance. As testing and qualifying advanced alloys for high-temperature nuclear power plant use requires long-term testing due to the limited capability of extrapolating materials performance beyond test duration, initiating further 
assessment of the new alloy is a near term technology development recommendation. In general, a core science need for advanced materials is to develop a validated capability to extend the extrapolation range of alloy performance. The current ARC program, task to develop mechanism-based predictive models for data extrapolation of design allowables, is thus directly supportive of FHRs.

\subsubsection{DRACS In-Vessel Heat Exchanger}

The function of the DRACS is to provide a safety grade heat sink for the core's decay heat following a loss of heat removal accident such as a loss of forced flow accident. Each of the AHTR's DRACS loops are intended to remove $0.25 \%$ of full power $(8.5 \mathrm{MW})$ under fully developed flow conditions at $700^{\circ} \mathrm{C}$. A baseline DHX design has not yet been performed for the AHTR. The DRACS loop salt is intended to be the low melt point eutectic of $\mathrm{KF}_{-} \mathrm{ZrF}_{4}$ as in the intermediate loops. During normal plant conditions, the principal DRACS design issues are limiting tritium escape and preventing system freeze-up. As the entire DRACS loop is within the nuclear portion of the plant, the DRACS loop does not have as strong a design driver to capture the tritium prior to it entering the DRACS loop. Thus, the initial concept for the invessel DHX calls for a single walled, Alloy N, tube-and-shell heat exchanger.

The DRACS loops operate under natural circulation flow. Thus, both the primary and DRACS salts will be in laminar flow regimes. The thermal conductivity of fluoride salts is not large (e.g., about the same as water) and their kinematic viscosity at operating temperature is about 20 times that of water at room temperature. Heat transfer enhancement features such as twisted tapes that cause the fluid boundary layer to mix into the bulk of the fluid are thus especially useful. Heat transfer enhancement features involve more complex geometries than straight tubes. Thus, material forming and joining issues will tend to be more complex than in other FHR heat exchangers.

\subsubsection{DRACS NDHX}

The DRACS NDHX transfers the core decay heat to ambient air under loss of heat removal accident conditions. As such, it is a safety related component required to be fabricated of materials qualified for high-temperature nuclear reactor service. A baseline design for the AHTR's DRACS NDHX has not yet been performed.

A principal design concern for the NDHX is to avoid freeze-up under both normal and accident conditions. Several mechanisms are available to ensure that the NDHX remains sufficiently hot to avoid freeze-up. First, the DRACS will always remain operational, as it is a passive system. During NO sufficient heat will always be rejected to maintain the system in a liquid state. During maintenance outages and/or refueling operations, however, electrical heaters may be useful to prevent the DRACS loop temperature from decreasing. The DRACS would still be capable of entering operation during these outages as the fuel decay heat provides the thermal drive for the natural circulation flow. One potential DRACS design option is to use thermally triggered insulation on the NDHX. Under normal conditions, the thermal insulation would prevent excessive heat transfer thus potential freeze-up. Much as with the thermally triggered negative reactivity insertion mechanisms, if the temperature of the NDHX were to exceed a threshold, a thermal barrier such as flappers on the air side of the heat exchanger could be released under thermal transients greatly increasing the heat transfer.

Avoidance of tritium release is another design requirement for the DRACS NDHX. Two primary mechanisms appear useful to prevent tritium releases during NO. First, when the NDHX airside flappers are closed, the NDHX would be located in stagnant inert gas. The gas could be continuously cleaned of tritium using a heated getter material such as a titanium or zirconium sponge. Developing and demonstrating the flapper thermal release alloys and mechanisms are thus a required materials task. Additionally, tritium barrier coatings on the airside of the heat exchanger tubing appear to be possible. 
The NDHX will have somewhat less severe operating conditions than other heat exchangers and will be more easily accessible for repair or replacement. Both titanium and aluminum oxide coating layers have shown promise in laboratory conditions as effective tritium migration barriers. However, the NDHX will be part of the FHRs safety system and the same material qualification issues favoring monolithic P-IHX tubes apply to the NDHX. Thus, developing tritium barrier layers would be a lower priority item to be investigated for future FHR designs.

\subsubsection{Intermediate Loop}

The intermediate loop connects the P-IHX with the SG. Its major function under normal operating conditions is to transfer hot intermediate salt between the two heat exchangers. The intermediate loop also serves to isolate the nuclear portion of the plant from the electricity generation section. One of the primary issues in providing the isolation is to prevent pressure waves from propagating from the power cycle into the nuclear portion of the plant in case of major ruptures of the I-PHX. The power cycle steam is at substantially greater pressure than the intermediate loop and without adequate pressure relief tube failure would cause a pressure wave to propagate back down the intermediate loop with the potential to damage the reactor's radionuclide containment boundary. In order to avoid this accident, the intermediate will use large, fast acting rupture disks on the intermediate piping near the SG. Rupture disks are a common technology for pressure relief. However, a baseline design and sizing analysis for the rupture disks has yet to be performed for the AHTR.

As the P-IHX forms the outermost credited radionuclide containment layer, and two independent decay heat removal paths, separate from the power cycle, exist in the AHTR design, the design intent is that the intermediate loop not be considered a safety-related item, apart from its rupture disks, and thus be fabricated according ASME B31.1 Power Piping code rules.

An FHR's high temperature will result in substantial thermal expansion upon heat up. Also, the AHTR's nuclear island is designed to be mounted on a base isolation system. Bellows will be incorporated into the intermediate loop in order to provide the compliance necessary for thermal expansion and to decouple seismic events impressed upon the intermediate loop from the nuclear island. While bellows on lowpressure piping are known items, developing fluoride salt compatible bellows remains a materials/component development task.

Demonstrating corrosion/redox control of the intermediate loop is another remaining development task. The redox control issues for the intermediate loop are somewhat less challenging for the intermediate loop as tritium is not produced within it and redox couples can be used within it to set the salt redox condition. A particular redox couple for the intermediate loop has not yet been selected. Contacting the salt as necessary with metallic zirconium is the initial design intent to set the salt redox condition. A driven sacrificial electrode or a hydrogen fluoride bubbling system would be used initially to remove the oxygen/moisture in the salt upon start-up.

\subsubsection{SG}

The AHTR's SG is the only location where substantial pressure differences exist in the AHTR design. The most mature liquid salt SG design comes from the MSBR SG design (Ref. 4). The baseline design for the AHTR SG is a counter flow, once-through, tube-and-shell configuration. The MSBR's SGs were intended to be constructed from Alloy N. The MSBR's SGs were designed for a 30-year life with 10,000 $20 \%$ power transients. With a $700^{\circ} \mathrm{C}$ core outlet temperature and allowing for a $25^{\circ} \mathrm{C}$ temperature loss at the P-IHX, the AHTR's SG inlet salt temperature will be $675^{\circ} \mathrm{C}$, which is $\sim 54^{\circ} \mathrm{C}$ hotter than the existing MSBR's SG design. Thus, relatively high confidence is available in the ability to produce an AHTR SG if the core outlet temperature were reduced to $650^{\circ} \mathrm{C}$. 
The MSBR SG was designed under Sect. III design rules as to provide decay heat removal under some accident conditions. The AHTR's design intent is to not rely on the normal heat rejection path for any safety-related actions or properties. Further, the failure of the SG is designed not to impact the performance of any plant nuclear safety function. Thus the SG would be designed under ASME Sect. I rules for the construction of power boilers.

Application of Sect. I instead of Sect. III design rules substantially broadens the potential range of alloys and construction methods that can be used in an FHR's SG. The fossil industry is currently developing alloy combinations for steam conditions up to $760^{\circ} \mathrm{C}$. Higher output temperatures directly increase the economic performance of FHRs. The principal limitation to the upper temperature for the MSBR heat exchanger was the properties of Alloy $\mathrm{N}$. Both the ultimate tensile strength and the time to one percent creep decrease rapidly at temperatures above $600^{\circ} \mathrm{C}$ in Alloy N. Alloy N primarily uses solution strengthening mechanisms with a small amount of carbide precipitation strengthening. Solution strengthening has the advantage that it is largely time independent and the alloy strength does not depend substantially on the time at temperature. Precipitation based strengthening, however, can result in substantially increased yield strength and creep resistance for limited periods of time. However, the microstructure, and consequently mechanical performance, of precipitation-strengthened alloys degrades at temperature over time necessitating component replacement or repair. Such degradation is accelerated by the application of external stress.

A particularly useful class of alloys for FHRs are nickel-based alloys with limited chromium content and gamma-prime strengthening. However, known nickel-based precipitation strengthened alloys are not thermally stable over multi-decade periods nor have any been optimized for fluoride salt corrosion resistance. Alloy microstructure is developed by thermal and mechanical treatment. In nickel-based alloys, gamma prime precipitates are formed by heating alloys with the proper composition to 900 $1000^{\circ} \mathrm{C}$, holding for a few minutes, and then rapidly quenching the alloys to $\sim 600^{\circ} \mathrm{C}$. Fluoride salt SGs provide an especially advantageous location to apply this heat treatment process in situ, increasing the SG lifetime dramatically. Any molten salt SGs would include external heaters and thermal insulation to heat the SG up above the melting point of the salt for initial filling. After bringing the reactor to a maintenance shutdown condition, the SG alloy reconditioning process would thus consist of

1. stopping the coolant pumps on both sides of the SG,

2. letting down the steam side pressure,

3. heating the entire SG (along with its liquid salt contents) to $\sim 950^{\circ} \mathrm{C}$ using the external heaters,

4. waiting for the entire structure to come to equilibrium temperature,

5. turning off the external heaters, and

6. turning on the intermediate loop pumps to quench the SG tubes and shell with the cool salt $\left(500^{\circ} \mathrm{C}\right)$ already in the intermediate loop.

An ORNL Laboratory Directed R\&D project has resulted in new fluoride salt corrosion resistant, improved strength, nickel-based alloys and on an in situ reconditioning method intended to recover the alloy's improved strength and creep properties. The new alloy and SG reconditioning method appear to offer such a substantial FHR efficiency improvement with limited developmental risk due to the AHTR's ability to use nonnuclear power code rules beyond the P-IHX that maturing the alloy and technique sufficiently to bring them into industrial practice even for a first-generation FHR is recommended.

\subsection{MATERIALS TASKS}

Designing, building, and operating two molten salt test reactors and performing conceptual design of a large MSBR forms the foundation of the salt-wetted FHR materials knowledge base. High-temperature nuclear materials technology development has been a significant DOE-NE focus in both its HTGR and 
SFR programs. A key to avoiding duplication of materials and component development efforts is to appreciate and build upon current and/or previous development efforts. Neither Alloy N nor graphite requires an extensive development program to enable it to be used in first-generation FHRs.

The recommended FHR materials program will thus have a strong engineering focus seeking to develop technically adequate solutions rather than optimized systems for first-generation FHRs. Plant operations are a distinctive element to the engineering focus as creep fatigue is among the most significant issues for high-temperature alloys, and plant operations have the potential to largely eliminate creep-fatigue from FHRs by continuously keeping the plant hot throughout its lifetime even during extended outages. In parallel with the first-generation focus, however, a longer term alloy property measurement program is recommended, as some of the testing required for long life components requires substantial duration testing. The testing needs to be implemented soon for materials to become available in the next 10-15 years.

Several directly FHR relevant materials tasks are currently being performed under other DOE-NE programs. Other existing materials projects only require incremental broadening to include FHRs. The updates to the ASME BPVC Sect. III Division 5 to include CFCs currently being supported by the NGNP program are directly relevant to FHRs as is the ARC project to develop mechanism-based predictive models for data extrapolation of design allowables. Additionally, the SiC/SiC BWR channel box development effort would only need to be augmented by salt compatibility testing to be directly relevant to FHRs. Further, the currently dormant effort to qualify C-C composites for core support structures in HTGRs could be revived with an additional focus on fluoride salt compatibility.

CFCs are especially important to FHRs. C-C and SiC/SiC composites must be qualified for specialized usage in selected high-temperature components, such as core barrel, upper and lower core support plates, and fuel assembly structural elements. This will require development of component- specific designs and fabrication processes, materials characterization, assessment of environmental and irradiation effects, and establishment of codes and standards for materials testing and design requirements. The particular areas of emphasis need to be on QA and design code issues required to qualify generic composite materials as practical and accepted nuclear engineering materials. Environmental testing of FHR CFC materials beyond the proof of principal stage, but not to the point of ultimate design data is also required. The recommended FHR CFC program will specifically address four outstanding R\&D issues: (a) design methodology and QA, (b) test procedure standards, (c) effects of neutron irradiation, and (d) effects of chemical environment.

The highest priority materials development tasks recommended for first-generation FHRs are as follows.

1. FHR focused materials development roadmap-The overall FHR development roadmap only broadly addresses materials development. Substantially more depth is required to assess the specific tasks that need to be performed for FHRs to transition from model to real reactors. The FHR materials development roadmap will need to address codes and standards as well as materials technology development.

2. Salt compatibility augmentation of existing CFC development programs-The existing DOE-NE sponsored CFC development programs do not include fluoride salt compatibility testing within their program scope. Adding fluoride salt environmental qualification during the development process would expand the applicability of the existing program results to FHRs at comparatively low cost.

3. Revival of C-C environmental qualification efforts - Any nuclear CFC program will address the four outstanding development issues: (a) design methodology and QA, (b) test procedure 
standards, (c) effects of neutron irradiation, and (d) effects of environment. Much of this work is already under way in other programs. Both neutron irradiation and environmental effects are specifically relevant to C-C composite in FHRs. C-C composites have a wide range of feedstock materials and preparation techniques. Adequate specification and quality control procedures are thus a near term development issue. Dimensional stability under fast neutron irradiation is the most significant environmental qualification issue remaining for C-C CFCs.

4. Completion of Alloy $\mathbf{N}$ inclusion into Division $\mathbf{5}$ of Sect. III for limited term use-Alloy N has a substantial existing body of knowledge and is the leading candidate material for test FHRs. A relatively low-level of effort would be necessary for limited term qualification of Alloy N.

5. Code case development of weld on liners-Separation of the material strength function from the chemical compatibility function within FHRs would enable the application of higher performance structural materials to FHRs. Cladding low alloy steel with stainless steel is a wellestablished procedure for pressurized water reactors (PWRs). Adding design rules and procedures to apply these techniques to HTRs is recommended.

6. Evaluation of online redox control to enable use of SS316 in primary loop-SS316 has existing design allowables under ASME BPVC Sect. III Division 5. While the environmental tolerance of SS316 is less well-known than Alloy N in liquid fluoride salt service, SS316 is both much more readily available than Alloy $\mathrm{N}$ and has higher strength in the $650-700^{\circ} \mathrm{C}$ temperature range of a first-generation FHR. If SS316 can be shown to have adequate performance under the required environmental conditions, it will become the preferred salt-wetted, structural alloy for first-generation FHRs.

7. Continuation of advanced nickel-based alloy property assessment-The improved strength alloys are highly promising for substantially improved FHR performance. However, alloys used as part of the primary containment will require full Sect. III qualification, which will require a substantial commitment for a number of years. While the gamma prime alloy is only intended to require Sect. VIII qualification, this too will require extensive property and performance measurement and fabrication technology development. As FHRs remain in early phase development, it is recommended to begin early phase, long-term property measurements so that improved alloys may be available for future use. It is recommended that fabrication issues such as tube drawing and welding of complex shapes be included in the development program as initial deployment of the advanced alloys is most likely to be in complex components such as pump impellors and heat exchangers.

\subsection{TEST REACTOR MATERIALS ISSUES}

Overall test reactor development issues and objectives are addressed in the Chapters 6 and 15 of this roadmap. This chapter is limited to the unique materials concerns of a test FHR. Some aspects of test FHR materials issues cannot yet be specified, as the overall design and mission for the test reactor remain to be determined. Focused, progressively larger, test FHRs or HTR science and testing facilities are credible alternative test reactor strategies. An HTR science and testing facility could address a much broader set of materials challenges as such a facility could encompass demonstrations with different fuel forms, coolants, and even replaceable coolant boundaries. However, the CAS FHR program is intending to follow the focused test FHR pathway. The extent to which the US program makes use of the knowledge gained from the CAS test reactors will largely be determined by the degree of cooperation between the two programs. The present discussion presumes that deep and extensive collaboration between the United States and China will exist throughout the early phase FHR development. 
The distinctive materials issues for a test FHR stem from (1) earlier deployment, (2) smaller source term, decay heat, and physical size, (3) experimental mission, and (4) lack of a power cycle. The primary materials challenge to earlier deployment of a test FHR is to obtain adequate material pedigrees to demonstrate and document that the facility is designed and can be operated in a manner consistent with applicable regulations so that the health and safety of the public, the facility staff and users, and the environment are protected. Alloy $\mathrm{N}$ will most likely be used for the primary coolant boundary due to its pedigree with molten fluoride salts and the CAS's intent to use Alloy $\mathrm{N}$ in their test reactor. The central reason for creating Division 5 within Sect. III of the ASME BPVC was to accommodate material performance changes at high temperatures. All of the additional potential high-temperature material failure mechanisms are gradual and progressive. Alloy $\mathrm{N}$ already has an extensive pedigree, as it will have by that time been used in both the MSRE and the CAS test reactor. A combination of the existing Alloy $\mathrm{N}$ knowledge, conservative design, and a surveillance program coupled to degradation limits is believed to be adequate means of demonstrating the safety of an FHR test reactor's coolant boundary. Essentially, sufficient information is already available to demonstrate and document that Alloy $\mathrm{N}$ vessels and piping will not unexpectedly fail catastrophically.

The material selection for the test FHR vessel internals will be determined by the maturity and qualification of CFCs prior to the test reactor deployment. If CFCs are not sufficiently mature, SS316 is the most likely material for the vessel internals. Alloy $\mathrm{N}$ is a high nickel alloy, and as such it will become embrittled when subjected to sufficient neutron flux at high temperatures. While SS316 will corrode more severely than Alloy N, gross corrosion is more readily observable than embrittlement and replacement can be planned well before degradation becomes performance limiting.

A major purpose for a test FHR will be to perform safety demonstrations. While the design intent of safety performance demonstrations would not be to extensively damage the reactor's SSCs, the outcome of experiments is not fully predictable. Thus, more extensive damage may accrue to the core, fuel, vessel, and internals than was anticipated. If aggressive safety performance demonstrations are planned, the test reactor will require redundant, qualified containment layers external to the test system. The qualified primary coolant containment layer may be external to the reactor vessel in a test FHR. A relatively close fitting guard vessel that is not normally wetted by salt and that is maintained at lower temperature could be used as the primary coolant container allowing fuel to remain covered by the primary coolant following accident simulation. The guard vessel would only need to perform until safe reactor shutdown was achieved. All of the external containment layers would be comprised of conventional, qualified materials.

No specific test reactor materials development tasks beyond developing a limited term code case for Alloy $\mathrm{N}$ are recommended until the test reactor concept development has progressed sufficiently to enable differentiation of its materials issues from those of the overall FHR development program. 


\section{SAFETY AND LICENSING}

\subsection{INTRODUCTION}

The purpose for this chapter is to provide a high-level reference to the necessary information for obtaining a DC for a first-generation FHR power plant. A significant portion of the remainder of the roadmap is dedicated to the specific tasks necessary to obtain and validate the required supporting information. No FHR class reactor has ever been constructed even as a test reactor, so no operational experience is available to serve as the basis for the safety/licensing case. The current NRC regulations are principally tailored to LWRs. However, NRC has previously licensed two advanced reactors: an LMR (Clinch River Breeder Reactor) and an HTGR (Fort St. Vrain). Because FHR class reactors have characteristics of both these reactors, some of the information generated by these licensing activities may be applicable to FHRs.

In August 2012, NRC provided a report to Congress that listed several areas where R\&D is needed to support the safety case for an advanced reactor such as the FHR (Ref. 10).

- Demonstrate safe performance of the proposed design and applied technology.

- Provide the technical basis for the application.

- Demonstrate sufficient margins to safety-significant SSC design and safety limits.

- $\quad$ Search for, identify, assess, and resolve safety issues involving large uncertainties.

- Develop, verify, and validate the proposed safety analysis evaluation methods.

- Provide the technical basis for requirements, criteria, codes, or standards that are proposed for the licensing design basis.

- Quantify the failure thresholds for safety-significant SSCs.

In addition to the information from the report to Congress, NRC has issued the Policy Statement on the Regulation of Advanced Reactors where it outlined its expectations as stated below (Ref. 43):

Furthermore, the Commission expects that advanced reactors will provide enhanced margins of safety and/or use simplified, inherent, passive, or other innovative means to accomplish their safety and security functions.

Among the attributes that could assist in establishing the acceptability or licensability of a proposed advanced reactor design, and therefore should be considered in advanced designs, are

- Highly reliable and less complex shutdown and decay heat removal systems. The use of inherent or passive means to accomplish this objective is encouraged (negative temperature coefficient, natural circulation, etc.).

- Longer time constants and sufficient instrumentation to allow for more diagnosis and management before reaching safety systems challenge and/or exposure of vital equipment to adverse conditions.

- $\quad$ Simplified safety systems that, where possible, reduce required operator actions, equipment subjected to severe environmental conditions, and components needed for maintaining safe shutdown conditions. Such simplified systems should facilitate operator comprehension, reliable system function, and more straightforward engineering analysis.

- Designs that minimize the potential for severe accidents and their consequences by providing sufficient inherent safety, reliability, redundancy, diversity, and independence in 
safety systems, with an emphasis on minimizing the potential for accidents over minimizing the consequences of such accidents.

- Designs that provide reliable equipment in the balance of plant (BOP) (or safety system independence from $\mathrm{BOP}$ ) to reduce the number of challenges to safety systems.

- Designs that provide easily maintainable equipment and components.

- Designs that reduce potential radiation exposures to plant personnel.

- Designs that incorporate the defense-in-depth philosophy by maintaining multiple barriers against radiation release, and by reducing the potential for, and consequences of, severe accidents.

- Design features that can be proven by citation of existing technology, or that can be satisfactorily established by commitment to a suitable technology development program.

- Designs that include considerations for safety and security requirements together in the design process such that security issues (e.g., newly identified threats of terrorist attacks) can be effectively resolved through facility design and engineered security features, and formulation of mitigation measures, with reduced reliance on human actions.

- Designs with features to prevent a simultaneous loss of containment integrity (including situations where the containment is by-passed), and the ability to maintain core cooling as a result of an aircraft impact, or identification of system designs that would provide inherent delay in radiological releases (if prevention of release is not possible).

- Designs with features to prevent loss of spent fuel pool integrity as a result of an aircraft impact.

- Designs with features to eliminate or reduce the potential theft of nuclear materials.

- Designs that emphasize passive barriers to potential theft of nuclear materials.

To accomplish these high level expectations and requirements, this roadmap has been developed to define specific items that will need to be accomplished to support the safety case for an FHR.

\subsection{DEFINING AND SUPPORTING THE SAFETY BASIS}

\subsubsection{Define FHR-Specific GDCs}

The GDCs found in Appendix A of 10CFR50 serve as the fundamental requirements that must be met in a reactor design for the design to be licensed by NRC. However, these criteria are based on LWR designs and will need to be modified for use as the basis for licensing an FHR. The introduction to Appendix A further states that the GDCs are considered to be generally applicable to other types of reactors and are intended to provide guidance in establishing the principal design criteria for such other types of reactors. ORNL has published a draft set of FHR GDCs (Ref. 9). These draft criteria are under review by a multinational ANS standards working group (ANS 20.1). The resulting standard if adopted all or in part by NRC will serve as the basis for FHR design. 


\subsubsection{Establish a Quality Assurance Program}

Without an operational reactor, the safety basis will rely on analyses anchored by a series of tests. For this information, generated by either analyses or testing, to be useful in supporting the safety basis of an FHR with NRC, it is important that a QA program be defined based on either the requirements in Appendix B of 10CFR50 and/or the ASME NQA-1 program. The QA program should be implemented on a graded approach focused on the importance of the information's applicability to making the safety case.

\subsubsection{Establish Response to Transients and Accidents}

\subsubsection{Identify accident initiating events}

Without operational experience and lacking a completed preconceptual design, defining accident sequence initiators will necessarily be an iterative process as the design matures. A recent study by ORNL, Identification of Initiating Events for aSMRs, examined initiating events for two classes of reactors, LMRs and HTGRs (Ref. 44). Because the FHR has characteristics of both of these reactor types, much of this may be applicable to an FHR design. The list of initiating events would need to be supplemented with FHR specific events as necessary. Estimates of the event frequencies will need to be generated for the initiating events.

\subsubsection{Select licensing basis events}

Once initiating events are defined, accident sequences [licensing basis events (LBEs)] that represent the FHR designed response to these initiators can be developed. The LBE end state for LWRs is typically core damage frequency (CDF). However, for TRISO-fueled reactors, CDF as used in LWR systems, is not applicable. Another recent report by ORNL, Development of Surrogates for Core Damage Frequency and Large Early Release Frequency for Advanced Small Modular Reactors, examined and recommended loss of primary system boundary integrity as a surrogate for CDF for TRISO-fueled systems (Ref. 45). It is recommended that the surrogate measure be used as the accident sequence end state for the FHR LBE development process.

\subsubsection{Categorize licensing basis events}

Estimates of the frequencies of the LBEs should be developed and AC will need to be established, which together will be used to categorize the LBEs into abnormal operational occurrences, DBAs, or BDBAs. This information will form the basis for the Transient and Accident Analysis required in Sect. 15 of NUREG 0800 (the SRP) (Ref. 11). The information needs from this activity will define much of the safety-related analysis and testing needed for building an adequate safety case for licensing an FHR and for guiding future design aspects of the reactor.

\subsubsection{Identify and classify systems, structures, and components}

This task will categorize the SSCs based upon their function and safety significance. The safety classification determines the level of scrutiny applied to these SSCs over the lifetime of the reactor and defines their failure thresholds. The safety classification of SSCs will be determined by a combination of deterministic and probabilistic methods. Specifically, SSCs shall be considered safety-related if

- $\quad$ they are part of the primary system boundary;

- they are assumed to remain functional during LBEs to shut down the reactor, cool the reactor core, and maintain the reactor in a safe shutdown condition; and 
- their failure could lead to radiation exposure of operating personnel or members of the public in excess of established limits.

\subsubsection{Determine the Adequacy of the Reactor Design and Supporting Information Needs}

In addition to transient and accident information, the licensing process examines the adequacy of the design of the reactor. Chapter 4 of the SRP indicates how NRC will evaluate the adequacy of the design using the GDCs as AC for the fuel (including fuel qualification), the reactor physics design (steady state and transient), and the thermal hydraulics design. Chapter 5 of the SRP provides similar criteria for the primary cooling system. Chapter 6 examines the engineered safety features of the reactor, including passive systems. Chapter 7 examines the I\&C system. Chapter 8 examines electrical systems. Chapter 9 examines auxiliary or support systems, including spent fuel storage. Chapter 10 examines the steam and/or power conversion system. Chapter 11 examines the radioactive waste systems. All of the system design evaluation criteria in NUREG 0800 (Ref. 11) are LWR specific.

\subsubsection{Perform a regulatory gap analysis}

Before applying the LWR-focused SRP requirements, a gap analysis should be performed to determine applicability of the LWR to an FHR and to define separate or additional requirements associated with the unique features or systems of the FHR. The gap analysis should be done chapter by chapter for Chapters 4-11 of the SRP.

The results of the gap analysis will define the information needs (analyses and tests) to determine the design adequacy with respect to the safety requirements contained in the GDCs.

\subsubsection{Implement a fuel qualification program}

It is expected that the DOE-NE AGR fuel-testing program will serve as the primary basis for FHR fuel qualification data. FHR fuel qualification issues are more extensively described in Chapter 4 of this roadmap. FHRs, however, have different physical characteristics than HTGRs such as the NGNP and as such their fuel qualification requirements will differ from those of HTGRs. Because FHR is a liquidcooled reactor, acceptable FHR fuel performance has similarities to that of LWRs. While FHRs have higher power density than HTGRs, the accelerated testing being used by the AGR program places the test fuel at higher power density, kernel powers, and temperatures than would be used in an FHR.

\subsubsection{Develop severe accident evaluation capability}

Chapter 19 of the SRP addresses the design margin of LWRs related to severe accidents. A similar assessment is needed for an FHR along with severe accident modeling capability to ensure that consequences of these events are adequately estimated. The results of this analysis should feed into the definition of an FHR-specific source term that can be used for siting requirements contained in 10CFR100.

\subsubsection{Determine the Adequacy of Codes and Standards}

NRC uses codes and standards to establish requirements for the design, analysis, construction, testing, and operation of NPPs. Further, some codes and standards are incorporated into the regulations, as in the case of the ASME BPVC and IEEE Standards 279 and 603, or are embodied in regulatory guides as accepted methods to meet certain NRC requirements. A gap analysis needs to be performed to determine the codes and standards that are applicable to FHRs, determine required changes in existing codes and standards, and identify new codes and standards that address the unique features of an FHR. 


\subsubsection{Define a Program to Address the Hazards Associated with the Presence of Beryllium in FHR Coolant}

NRC is responsible for ensuring that all hazards, including chemical hazards, are adequately addressed as part of its design review. It is necessary to define a program that will ensure that all aspects of beryllium handling and storage (including waste) will meet applicable federal and state requirements for test loops, test reactors, and commercial reactors. The beryllium hazard will need to be addressed as part of the consequence analysis in case of an accident (nuclear or nonnuclear) at any FHR facility. It is expected that the tritium hazard will be addressed as part of the review of adequacy of the design to meet GDCs 60 and 64.

\subsection{DEMONSTRATE THE ADEQUACY OF MODELS}

An evaluation model for codes and simulations that would be used to support the safety case for an FHR will need to be developed. Model validation is discussed more extensively in Chapter 11 of this roadmap. The process requires the development of a PIRT for the reactor. It also addresses the uses of integral and system effects tests to supplement the database and establishes the need for a model/simulation QA program.

\subsection{DEMONSTRATE ADEQUACY OF DESIGN}

NRC has established a precedent for requiring a prototype reactor for non-LWR reactors, even when multiple test reactors have previously been constructed, by insisting that the NGNP be licensed as a prototype reactor. As no FHRs have been built to date, it is possible that the process identified in 10CFR50.43(e)1 for non-LWRs will not be sufficient to license a first-of-a-kind FHR without invoking the need for a prototype reactor. China has a program in place to build initial FHR test reactors [one $2 \mathrm{MW}$ (th) and a successor 10-20 MW(th)]. Information gained from close involvement with the Chinese program will be useful to NRC in developing the capability to license FHRs. Close involvement with the Chinese FHR program may enable the United States to avoid the necessity to build an FHR test reactor while providing the Chinese the international acceptance resulting from NRC scrutiny.

Because test reactors are not held to the stringent requirements placed on commercial systems and do not undergo the NRC licensing process, the Chinese test reactors may not be sufficient to prevent the first US FHR from being initially licensed to operate as a prototype plant. However, 10CFR50.2 describes a prototype plant as "similar to a first-of-a-kind or standard plant design in all features and sizes, but may include additional safety features to protect the public and the plant staff from the possible consequences of accidents during the testing period.” Given the extensive instrumentation planned for all FHRs, the most significant consequence of initially being licensed to operate as a prototype plant would be the establishment of a series of hold-points during the plant commissioning and initial operations that would require NRC permission to proceed beyond. Requiring external approval to proceed through the holdpoints does not appear to differ significantly from the cautious approach to initial operations that would be used to minimize the risk to the plant. 


\section{SALT}

\subsection{INTRODUCTION}

Fluoride salts will serve as the primary coolant in FHRs. They also serve as intermediate loop and DRACS coolant loop materials. The selection criteria among fluoride salts for an FHR primary coolant are:

1. low neutron absorption,

2. low activation,

3. chemical stability at $\mathrm{T}>800^{\circ} \mathrm{C}$ with low volatility,

4. high radiation stability,

5. melt point below $500^{\circ} \mathrm{C}$, and

6. compatibility with high-temperature alloys and graphite.

Low neutron absorption is important both to enable the reactor to achieve criticality and to obtain an acceptably low coolant (or negative) void reactivity coefficient. Low activation is key both to avoid extensive biological shielding as required at SFRs, facilitate maintenance, and enable the use of electronics for instrumentation within containment. The intermediate and DRACS coolant salts have similar requirements as the primary coolant with the exception of the nuclear performance issues. Assessments of candidate primary coolant and heat transfer loop salts for FHRs were performed earlier in the FHR development program (Refs. 46 and 47). Based upon these assessments a mixture of FLiBe was selected for the primary coolant of the AHTR. The lithium within the FLiBe is required to be highly isotopically separated to avoid the presence of ${ }^{6} \mathrm{Li}$ with its high neutron absorption cross-section in the primary loop. The use of isotopically selected lithium in the primary coolant imposed the additional constraint of avoiding lithium in interconnected loops to avoid the potential mixing non-isotopically selected lithium into the primary coolant due to a heat exchanger tube leak. The low melt point eutectic of $\mathrm{KF}$ and $\mathrm{ZrF}_{4}$ was selected as the heat transfer loop salt.

The primary issues for fluoride salt performance are lithium isotope separation, corrosion and material compatibility, and salt cleanup and purification during operation. Each of these topics is addressed in sequence in this roadmap chapter. The use of low atomic number materials in the primary coolant salt also results in significant production of tritium within the primary coolant. Technologies for trapping and blocking tritium escape are discussed in Chapters 5 and 14 of this roadmap. The current design intent is not to actively strip tritium from the primary coolant but to rely on blocking and/or trapping the tritium as it leaves the primary coolant.

\subsection{LITHIUM ISOTOPE SEPARATION}

\subsubsection{Summary}

Lithium fluoride salts have the most advantageous combination of chemical, physical, and in the case of ${ }^{7} \mathrm{Li}$ neutronic properties to serve as a major FHR primary coolant component. As FHRs feature swimming pool type primary vessels, a large, deep pool provides a massive thermal sink to decrease the rate of core heat-up in the event of loss of force cooling. Individual units of large-scale FHR power plants are anticipated to use a few hundred tons of isotopically selected $(\sim 99.995 \%){ }^{7} \mathrm{Li}$. Developing a reliable, costeffective source of supply of ${ }^{7} \mathrm{Li}$ is thus necessary for FHRs to be economically preferable. Isotopically selected lithium is also important to both PWRs and fusion technologies, albeit at smaller scales than would be necessary for FHRs. The lithium hydroxide-mercury amalgam column exchange- (COLEX-) based separation process was used in the United States in the 1950 s and '60s at large scale to separate ${ }^{6} \mathrm{Li}$ 
from ${ }^{7} \mathrm{Li}$ for the thermonuclear weapons program. The MSR program made use of the non-weapons useful ${ }^{7} \mathrm{Li}$ resulting from the process, which was further separated again using the COLEX process.

As industrial-scale mercury usage presents large environmental contamination and health risks, alternative lithium isotope separation processes will be necessary. Lithium isotope separation technology development is currently an active area of research in support of fusion power. Several alternative techniques have potential for industrial-scale, reasonable cost lithium isotope separation.

Two different processes based upon the differential rate of electromigration of the different mass lithium isotopes across membranes are currently under investigation. The first technique is based upon applying electrophoresis from an electrolyte bath containing lithium ions through a lithium superionic conducting ceramic membrane. Ceramic lithium superionic conducting membranes intended to support lithium isotope separation are currently available commercially (Ref. 48). While promising, the technique has not been demonstrated beyond laboratory scale. A related technique involves applying electrodialysis through an ionic-liquid impregnated organic membrane (Ref. 49). Both electromigration techniques are reported to have higher separation coefficients than the mercury amalgam process.

Displacement chromatography using a crown ether resin immobilized on porous silica beads also appears to be capable of large-scale, economic separation of lithium isotopes (Ref. 50). The equilibrium separation factor of crown ether resins is larger than ion exchange resins, used in earlier lithium isotope separation efforts, by an order of magnitude. A full displacement chromatography system involving all of the required processes has yet to be demonstrated. In particular, the displacement and regeneration steps within displacement chromatography remain to be demonstrated to develop a practical system.

Liquid-liquid ion exchange-based processes are another potential lithium isotope separation technique that is based upon transferring lithium ions between two immiscible solvents. The COLEX process is an example of a liquid-liquid (aqueous-liquid mercury amalgam) separation system. Crown ethers dissolved in an organic solvent can replace the liquid mercury amalgam enabling an environmentally acceptable variant of the older separation technique.

Recently Raizen and Klappauf described a novel magnetically-activated and guided laser-based lithium isotope separation process (Ref. 51). The magnetic separation process exploits the relatively large separation between the optical wavelengths to excite the lithium isotopes from the ground ${ }^{2} \mathrm{~S}_{1 / 2}$ state to the magnetically active ${ }^{2} \mathrm{P}_{1 / 2}$ state and the recent development of inexpensive high-power semiconductor lasers. Raizen and Klappauf also describe the use of a hemispheric ion source providing hundreds of $\mathrm{kg} /$ year per beam source. While the laser-based process is significantly less mature than the competing processes, it provides the potential for single stage isotope separation and thus may eventually be highly desirable due to the potential lower capital costs.

\subsubsection{Performance Requirements}

The principal issue for lithium isotope separation is cost. FHRs, if widely deployed, will require hundreds of tons of highly separated ${ }^{7} \mathrm{Li}$. However, initially the demands will be much more modest. Hence, the preferred separation technology needs to be readily scalable. The economics of the laser-based process will depend on the throughput that can be achieved while maintaining very high separation factors. The electromigration, the liquid-liquid extraction, and the displacement chromatography-based techniques all appear to meet the scalability requirement either through the deployment of parallel systems or using industrial-scale separations equipment. Corn sweetener refining is an example of displacement chromatography that is commercially performed at a large scale. 


\subsubsection{Issues}

Several different techniques may be viable for large-scale economic separation of lithium isotopes. However, all have unresolved technical issues that directly impact their cost and performance. For example, long-term durability of the organic membrane remains to be proven and the purity of the feedstock necessary to minimize fouling the crown ether resin remains to be established. Also, all of the separations techniques have dual use potential. Lithium-6 in addition to supporting fusion power can be used in thermonuclear fusion weapons. As a consequence, the United States imposes export control restrictions on lithium isotope separations equipment (see 10CFR110.8). Given the international nature of fusion power development and the resulting broad interest in lithium isotope separation, it is unclear how the international control of lithium isotope separation technologies will evolve.

\subsubsection{Tasks}

It is not currently possible to specify a technically preferred lithium isotope separation technique. A trade study comparing and evaluating the potential separation technologies could provide a balanced comparison of the relative merits of the different technologies. Engineering designs and economic evaluations should be performed for the most promising technologies. Following the trade and engineering studies, a small-scale demonstration of one or two of the most advantageous lithium isotope separation process would reveal and facilitate resolution of any remaining technical issues. A key issue is demonstrating a complete separations system as challenging technical issues may lie in items such as

1. feedstock purification,

2. trade study on lithium isotope separation technologies,

3. engineering and economic evaluations of selected lithium isotope separation technologies, and

4. small-scale end-to-end demonstration of one or two leading candidate technologies.

\subsection{REDOX CHEMISTRY CONTROL}

\subsubsection{Summary}

The fluoride salt and container material system must be thermodynamically stable to avoid chemical corrosion. The metal atoms comprising the container wall are in their most reduced state. Thus, corrosion would occur primarily through oxidation of the metal atoms by the fluoride salt melt. The redox condition of the fluoride salt melt will become more oxidative if electronegative impurities (e.g., oxygen or sulfur) are introduced into it. In practice, electronegative impurities tend to be introduced into the salt either from impurities in (or on) its component materials or from inadvertent exposure to air and/or moisture. The native oxide layer on oxide forming alloys will also be a source of oxygen impurities upon initial heat-up. Further, the redox conditions of the primary salt will likely change during operation due to issues such as fuel leakage, long-term corrosion or erosion of materials in contact with the salt, operation of the salt cleanup system, and production of tritium within the salt and its subsequent escape from the salt.

The current design intent is to use the combination of $\mathrm{HF}$ and $\mathrm{H}_{2}$ sparging developed in the MSR program to remove oxygen and moisture impurities from the coolant loops (Ref. 52). However, system integration issues such as whether to use a batch or continuous process, how large a system will be required, and whether the oxygen/moisture removal system will generally be operated as part of refueling operations or throughout the fuel cycle remain to be addressed. 


\subsubsection{Primary Loop}

In the MSRE the redox condition of the salt was maintained as slightly reducing by using the U(IV/III) soluble redox couple as an electrochemical buffer. Maintaining a sufficient concentration of $\mathrm{U}^{4+}$ dissolved within the salt balanced any oxidative impurities introduced into the salt, as well as the slightly oxidative fission process. Maintaining sufficient $\mathrm{U}^{3+}$ within the salt prevented the salt from becoming highly reducing and tending to plate out fission products and/or corrode nonmetallic components in contact with the salt (principally carbon). Over the course of the MSRE operating life, the fuel salt produced only very minor, barely detectable levels of corrosion, whereas corrosion was not detected at all in the MSRE intermediate loop demonstrating compatibility of the salt, the graphite moderator, and the Alloy $\mathrm{N}$ container. Other multivalent fluoride salts could be used as redox couples to maintain the electrochemical balance within fluoride salt melts. However, no acceptable electrochemical couple exists for the primary loop of an FHR as all of the potential elements exhibit a combination of high neutron absorption along with strong activation. Having high neutron absorption materials within the primary salt is unacceptable, as it would result in a strongly positive void coefficient. Additionally, producing radioactive daughter products would significantly increase the radiation environment near the primary loop.

A common alternative technique used to prevent corrosion of metal surfaces is to make them the cathode of an electrochemical cell. A sacrificial anode material then preferentially corrodes instead of the metal cathode. In the Hall-Héroult process for electrowinning aluminum metal from aluminum oxide dissolved into a fluoride salt melt, a large carbon electrode serves as the sacrificial anode and the pool of aluminum metal as the cathode. The oxygen from the aluminum oxide reacts with the carbon in the sacrificial anode (maintained at a few volts of positive potential) to form carbon dioxide. A similar configuration can be used at FHRs to actively remove oxygen from the melt.

In the MSRE, the $\mathrm{U}^{3+} / \mathrm{U}^{4+}$ ratio was maintained during the oxidative fission process by periodically contacting the primary coolant with metallic beryllium. Measuring the $\mathrm{U}^{3+} / \mathrm{U}^{4+}$ ratio enabled feedback control. The redox condition of an FHR's primary coolant salt can also be shifted into a more reducing condition by introducing metallic beryllium. Similarly, introducing nickel fluoride into the melt can be used to shift the redox to a more oxidizing condition. However, without a circulating redox buffer large shifts in the primary salt's redox state will be possible with relatively small control changes. Both highly oxidative and highly reducing conditions would be deleterious to the salt-wetted materials. Having key, long-life materials depend on a precise control system is not a preferred design option. Hence, improving the understanding and measurement of the redox state of the primary salt and its response to control actions under operating conditions is a key element in ensuring the long-term materials performance.

\subsubsection{Performance requirements}

The primary coolant needs to be maintained in a somewhat reducing condition. A combination of a sacrificial carbon electrode and additions of beryllium metal or nickel fluoride can be used to maintain the redox condition. The principal performance requirement for a biased sacrificial anode type corrosion protection scheme is that the system must function at a sufficient rate under all plant conditions. Some moisture will almost inevitably be introduced into the system during maintenance and/or refueling. Also, tritium will be produced in the salt and migrate out of the melt. The surface of the sacrificial anode cannot become fouled and the current density through the surface cannot become so high as to cause other local undesirable electrochemical effects. The specific resistivity of FLiBe at operating temperature is $\sim 0.4 \Omega$-cm (Ref. 53). Consequently, a high surface area carbon electrode and a few kilowatt electrical power supply will be required to avoid causing undesirable reactions due to high current density. The central challenge to the chemical addition-based redox control methodology is accurately measuring the salt's redox potential and providing a precise amount of balancing addition. The initially intended redox 
control strategy for the AHTR is to use periodic chemical additions as a balance to larger shifts in the redox condition and continuous, more precise control using the driven, sacrificial carbon electrode.

\subsubsection{Issues}

The primary issue with implementing a driven sacrificial anode type cathodic protection system in the FHR primary loop is that this type of corrosion protection has not previously been implemented in this specific configuration. Thus, the engineering details remain to be resolved. Issues such as the size, number, and location, of sacrificial anodes and their integration into the plant control and diagnostics system remain to be determined. Also, an online primary salt redox state measurement technology will need to be developed (likely either electrochemically or optically based). Additionally, some of the dissolved hydrogen will evolve out of the melt as anhydrous hydrofluoric acid. Control of this high vapor pressure contaminant will be required. HF may be an issue at the salt-cover gas metal interface. If no moisture is present, HF will not attack exposed metal. The cover gas control system will be relied upon to minimize the HF and moisture concentrations.

\subsubsection{Tasks}

The performance of the selected redox control method needs to be demonstrated in an electrically heated fluoride salt loop to provide confidence that the protection system will in practice perform as anticipated. As the effects will be similar between $\mathrm{KF}_{\mathrm{ZrF}}$ and FLiBe melts, it is not anticipated that a beryllium salt melt demonstration will be required for the initial demonstrations of cathodic protection. However, for the chemical addition based controls representative primary salt will be necessary. Further, a robust fluoride salt redox measurement electrode system will need to be developed and demonstrated.

\subsubsection{Intermediate Salt Loop}

The low melting point eutectic of potassium zirconium fluoride is the leading candidate for both the intermediate and DRACS loops. The intermediate loop can use a redox couple as its means to maintain the electrochemical condition within the melt. Several different multivalent elements will dissolve into $\mathrm{KF}-\mathrm{ZrF}_{4}$. However, using a redox couple will not remove dissolved oxygen from the melt; just mitigate its adverse consequences. An electrically-biased sacrificial carbon electrode can be used as in the primary loop both to set the redox condition of the selected redox couple and to react with dissolved oxygen forming carbon dioxide. While a highly neutron absorbing redox couple appears to be advantageous as a large-scale leak between the intermediate and primary loops would then result in negative reactivity insertion into the core, both the chemistry and engineering aspects of implementing a redox couple on an intermediate heat transfer loop remain to be investigated. For example, tellurium dissolved in the MSRE primary loop had adverse chemical reactions with the structural alloy.

\subsubsection{Performance requirements}

The major performance requirement for the intermediate loop redox control system is to effectively set the electrochemical condition of the intermediate salt as somewhat reducing (must not become sufficiently reducing to break down the salt components) without adversely impacting the loop functioning.

\subsubsection{Issues}

The biggest issue with chemistry control of the intermediate loop is the general immaturity of the technology. Both chemistry and engineering details remain to be resolved. Issues such as couple selection 
and concentration and size, configuration, number, and location of sacrificial anodes remain to be determined, as well as their integration into the plant control and diagnostics system.

\subsubsection{Tasks}

The first task is to establish the $\mathrm{KF}-\mathrm{ZrF}_{4}$ phase diagram and heat transfer properties. While historic investigations of $\mathrm{KF}_{-} \mathrm{ZrF}_{4}$ properties have been performed, its thermal and hydraulic properties are less well known than other fluoride salts. A second task is to evaluate and rank candidate redox couples for the intermediate loop. Issues to be addressed include compatibility with nickel-based alloys as well electrochemical properties of the redox couple's two oxidation states. Once a candidate couple has been selected its performance needs to be demonstrated in combination with a sacrificial carbon electrode in

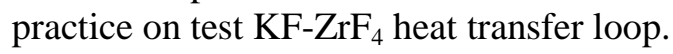

\subsection{SECONDARY SHUTDOWN SALT REMOVAL}

\subsubsection{Background}

The secondary shutdown mechanism is only intended for deployment under severe accident conditions in which the core has been so damaged that blades used by the primary shutdown mechanism cannot be inserted. The AHTR design includes three means to insert the control blades (1) melt point fuses in the mechanical links, (2) pinion gear release upon depowering the engagement solenoid, and (3) use of the control blade drive motors. As one of the mechanisms is passive and another features a safe failure (depowered) state, high confidence is available in the primary shutdown mechanism. Further, the AHTR design enables periodic demonstration of control blade insertion during operation. The AHTR design calls for 252 control blades. The blades perform both a control and shutdown function. The blades will be repositioned over the course of the fuel cycle to compensate for reactivity decrease and to flatten the power profile. The large number of control elements decreases the importance of any particular element enabling online blade drop testing without substantially disturbing power generation. Essentially, one rod after another could be fully withdrawn and then dropped into core providing periodic demonstration of the both the control and safety function of each blade in sequence.

The multiple rod insertion mechanisms provided by the primary shutdown mechanism may eventually provide adequate confidence of reactivity control to meet the requirements of 10CFR50 Appendix A Sect. III (Protection and Control Systems) similarly to the separate rod insertion mechanisms used by SFRs. However, a diverse passive system is recommended to provide additional confidence for first-generation plants. The poison ball based shutdown systems intended for HTGRs are not appropriate for FHRs in that the deployed balls would restrict coolant flow through the core preventing decay heat rejection via natural circulation.

\subsubsection{Summary}

The secondary shutdown mechanism selected for the AHTR is the injection of a rare earth fluoride neutron poison $\left(\mathrm{EuF}_{3}\right.$ and/or $\left.\mathrm{GdF}_{3}\right)$ into the primary coolant. A dissolved-poison-based shutdown mechanism provides high confidence that the reactor can be brought and held subcritical under all accident conditions and minimizes the required $R \& D$ effort. The rare earth injection-based secondary shutdown mechanism is thus judged to be an adequate system for first-generation FHRs with significant potential for improvement in later generation reactors.

The poison salt injection mechanism design is currently immature. Both $\mathrm{EuF}_{3}$ and $\mathrm{GdF}_{3}$ have melting points well above the operating temperature of an FHR. However, their Gibbs energy lies between that of $\mathrm{LiF}$ and $\mathrm{BeF}_{2}$, indicating that the poison salts will mix with the primary coolant fluorides and not plate out 
onto the container surfaces. Further, both $\mathrm{EuF}_{3}$ and $\mathrm{GdF}_{3}$ have low temperature $\left(<700^{\circ} \mathrm{C}\right)$ eutectics with $\mathrm{LiF}$, indicating that both will dissolve readily into the primary salt.

Removing a rare earth fluoride from the primary coolant will be expensive and time consuming. However, as the secondary shutdown mechanism is only intended to be deployed in the case of a severe core damage accident, cleaning the primary coolant will not be the primary concern following intentional deployment. However, avoiding minimizing the potential for unintentional deployment will be a primary secondary shutdown mechanism design criteria. Other less difficult to remove salts such as ${ }^{7} \mathrm{Li}$ tetrafluoroborate might be an acceptable alternative for the rare earth fluorides if minimizing the potential for inadvertent deployment becomes a significant design challenge. Optimally, a suspended solid such as nano-particulate boron nitride that could readily be mechanically separated from the primary coolant following the conclusion of the accident (or inadvertent deployment) would be introduced into the primary coolant by the secondary shutdown mechanism.

The poison salt will need to be removed from the primary coolant following conclusion of an accident. The MSR program developed and demonstrated technology for removing rare earth fluorides (including $\mathrm{EuF}_{3}$ ) from FLiBe (Ref. 54). In the rare earth fluoride separation process, the poisoned salt is countercurrently contacted with liquid bismuth containing a reductant such as lithium. Bismuth is essentially immiscible with the salt. The reductive extraction reaction between $\mathrm{EuF}_{3}$ in salt and metal phases can be represented by the equation

$$
\mathrm{EuF}_{3}+3 \mathrm{Li}(\mathrm{Bi}) \leftrightarrows \mathrm{Eu}(\mathrm{Bi})+3 \mathrm{LiF}
$$

The rare earth metal is subsequently removed from the bismuth by contacting it with LiCl. Separation factors of $10^{4}$ have been demonstrated for the trivalent rare earths dissolved in FLiBe using this technique (Ref. 27).

\subsubsection{Performance Requirements}

Secondary shutdown must insert sufficient negative reactivity so as to confidently shut down the reactor. Consequently, a large amount of poison salt will be injected into the primary coolant. The cleanup system will slowly dilute the rare earth elements from the primary coolant. The system needs to be sized to be able to remove nearly all of the poison within a reasonable period of time.

\subsubsection{Issues}

The major remaining unresolved issue for relying upon a bismuth contacting process for rare earth extraction from the salt is the immaturity of the engineering aspects of the system. The system chemistry is reasonably well-known from prior demonstrations. However, system scale for a plant implementation has not been determined, nor have the mechanisms for interconnecting the system to the primary loop been determined. The valve and pumping system required to transfer a side stream of the primary loop to the cleanup system remain to be developed. In addition to removing the secondary shutdown salt, bismuth-lithium contacting will also remove rare earth fission products from the primary coolant, and thus the poison salt cleanup system will also serve as part of the overall primary coolant cleanup system, which is required to enable the reactor operating with imperfect fuel.

\subsubsection{Tasks}

Design, build, and demonstrate a side-stream, lithium-bismuth-based rare earth extraction system. The initial demonstration can be performed using a surrogate fluoride salt. However, as the system effectiveness is directly impacted by the primary salt chemistry the extraction system will require 
demonstration using non-isotopically selected FLiBe. These tasks will be closely related to the demonstration of the functionality of the secondary shutdown system described in the Shutdown Systems subdivision of this roadmap.

\subsection{FISSION PRODUCT REMOVAL}

\subsubsection{Summary}

The primary coolant salt in an FHR is intended to be free from fission products and fuel material. However, the coated particle fuel will not be perfect and some amount of fuel and fission products will leak into the primary circuit. A primary salt cleanup system will therefore be required. The efficacy of the fission product removal will in large part determine the technical specification of the quality of the fuel, much as the amount/number of leaking fuel rods in a PWR restricts its operation. Many of the fission products (including cesium and strontium) can be removed from the primary salt by a metal transfer process into a bismuth-lithium alloy (Ref. 55). The noble metal fission products form colloids within the salt and either plate out onto surfaces, volatilize (primarily in the pump bowl), or can be extracted by mechanical filtering (Ref. 56). Uranium, iodine, and most of the plutonium were intended to be removed from fuel salt by fluoride volatilization in the MSBR processing scheme. Fluoride volatilization was included in the processing scheme as uranium was a significant portion of the fuel salt and readily forms volatile fluorides. Fluoride volatilization could be used at an FHR. However, the small amounts of uranium, iodine, and even smaller amounts of plutonium that could leak from coated particle fuel would also be expected to be removable from the primary coolant via extraction into the bismuth-lithium alloy. Only relying on a single process for cleaning the primary salt would simplify (and thus lower the cost) of an FHR.

The earlier MSR program demonstrated the required separations processes in small-scale experiments, but engineering-scale demonstrations have not been performed and the container materials for the bismuth-based reductive extraction remain to be proven. Later dynamic extraction demonstration studies have shown that it may be possible to increase the mass transfer rates by increasing the agitation speed (Ref. 57). However, bismuth is not compatible with nickel-based alloys at high-temperature, so carryover of bismuth into the primary coolant must be avoided. The intent of the prior program was to fabricate the contacting system from graphite. Today, the necessary reaction vessel and agitators would likely be fabricated from C-C composite representing a significant improvement in the technology as compared to earlier generation systems. Additionally, as both the fuel isotopes and halogens were intended to be removed by fluoride volatilization even the process parameters for reductive extraction of these elements remain to be determined.

\subsubsection{Performance Requirements}

The degree to which the primary salt would be required to be cleaned should be derived from accident performance models as the tolerable amount of fission products in the primary coolant is mostly determined by its potential for aggravating a DBA.

\subsubsection{Issues}

A number of practical mechanical and hydraulic issues remain to be resolved for the primary salt cleanup system. A conceptual system design needs to be developed in order to select and assess the required technologies. At the current level of understanding a number of required development and demonstrations are already apparent. A high-pressure molten salt pump will be required if noble metal colloids are to be removed by fine mesh mechanical filtering. A highly effective means for separating liquid bismuth from the primary salt needs to be developed to prevent carryover back to the reactor. The process chemistry for 
reductive extraction of uranium, plutonium, and iodine into a bismuth phase need to be investigated. Also, acceptable (bismuth and salt compatible) materials (likely CFCs) need to be selected and demonstrated.

\subsubsection{Tasks}

The first task is to develop a basic conceptual design for the primary salt cleanup system and integrate it into the AHTR. This task would include developing chemical engineering models for the extraction processes and proposing initial candidate materials for the components. Once a conceptual model has been developed the proposed system needs to be demonstrated on a laboratory scale. Once a functional laboratory-scale system has been demonstrated, an engineering-scale unit will need to be designed, developed, and demonstrated. 


\section{COMPONENT DEVELOPMENT AND TESTING}

\subsection{INTRODUCTION}

The objective of this chapter is to describe an acceptable FHR component development path to support deployment of first-generation FHRs. FHRs are thermal power plants, and heat and fluid transfer are central to accomplishing their primary function. Because of this, FHRs will use fluoride salt compatible versions of traditional power plant hydraulic and heat transfer components. Much of the technology base for FHR hydraulic components comes from the MSR program of the 1940-70s. However, some technical issues were not resolved during the MSR program. Moreover, commercial power-plant-scale components were not developed in the earlier program. Both improved materials and the general progression of hightemperature technology over the intervening decades provide an improved technical basis that can be used to resolve the remaining technology and scaling issues.

AHTR hydraulic design has not yet been performed beyond simplistic calculations, nor have a full set of accident initiators yet been developed. The lack of a nontrivial hydraulic design limits the extent to which component development planning can yet be performed. System safety classification has also not yet been performed, and thus key aspects of component performance requirements are also not yet available. For example, other reactor classes require flywheels as part of their primary coolant pumps to provide flow coast down in the event of loss of power. FHRs may tolerate abrupt loss of flow changing the primary coolant pump design requirements. Also, the AHTR's design features such as melt-point links in the control blade drive strings may prevent the active control blade drive mechanisms from being necessary for a safe response to accident scenarios. As such, the AHTR control blade drives may be part of the control system, not the protection system, significantly widening the design options.

Some of the AHTR systems have not yet received significant design attention and thus design testing and validation cannot be planned beyond very high-level aspects. For example, the salt cleanup system and the corrosion control system (both outlined in Chapter 7 of the roadmap) have not yet been designed, and thus their constituent components cannot yet be described at a sufficient level of detail to permit performance evaluation. However, the general performance parameters and overall configuration of the heat transport systems for the AHTR have already been specified providing guidance on requirements for key components.

The in-vessel structural hydraulic components (e.g., the core barrel and core support structures) are described from a materials perspective in Chapter 5 of this roadmap and are only briefly addressed in this chapter. Completing a hydraulic model for the AHTR, as well as increasing the detail of the structural layout, is required to create a vessel internal development plan. While much of the testing program for structural hydraulic components will derive from the material qualification effort, having adequate material and design rules does not ensure that a particular design has been properly implemented or that unanticipated issues would prevent a structural component from adequately performing its function. For example, developing an understanding of the leakage between segments of the core barrel would be necessary to understand the potential for core bypass flow and understanding the flow conditions in the AHTR upper plenum is required to assess whether flow induced vibrations will be a significant design concern for the control blade guide tubes. However, a structural hydraulic development roadmap cannot be developed until both a model for the AHTR hydraulic performance has been created and more detailed materials and structural design information is available on the components. Thus, developing a more comprehensive FHR component development roadmap with greater technical depth is a recommended task once both the AHTR hydraulic design and accident response have undergone initial analysis. 
The design and functioning of hydraulic components often has significant scale dependence. For example, fluoride salt freeze valves have been demonstrated to work with smaller pipe sizes but are unrealistic for larger scale piping. Component development nearly always begins with bench-scale systems that are only extended to larger sizes once the technology has been evaluated at a smaller scale. Thus, part of the component development planning process is selecting component technologies that are suitable for scaleup to the larger sizes.

Proper component functioning depends upon component materials and operations and maintenance (O\&M). The materials and operations aspects of the plant components are addressed in the roadmap chapters devoted to these topics. Additionally, component performance validation will be performed largely using the validation facilities and eventually the test reactors described in their respective focused roadmap chapters.

This roadmap uses a proven technology bias. It is acknowledged that more advanced component technologies may offer superior performance to several of the first-generation component technologies selected. However, overall system reliability is the dominant metric for selecting between competing technologies, and proven deployment under similar conditions is judged to be the most effective means of demonstrating reliability. The component technologies selected are believed to provide adequate performance with more advanced technology introduction reserved, to the extent possible, to future FHR generations.

FHRs, however, remain in early phase engineering development. A limited number of advanced technologies may provide sufficient performance advantage to be introduced into the program plan once they demonstrate adequate reliability. For example, the monolithic cast heat exchangers currently under development at Sandia National Laboratories appear to provide such a combination of strength, high performance, reduced size, and reduced cost that they may be recommended for adoption as soon as their performance is confirmed in practice. Also, pumps have been a continuing challenge at NPPs. The MSRE experienced oil-seal leakage and excessive foam development. While gas shaft seals have been developed since then and appear to be adequate for smaller diameter shafts, maintaining the precision required in the rotation of a larger shaft (as would be required for commercial-scale power plants) is more technically challenging. Similarly, salt-wetted bearings had performance issues during the MSR era, but modern ceramic materials may mitigate the challenge. Nevertheless, the canned-rotor, magnetic-bearing pump currently under development under DOE-NE NEET program sponsorship appears to alleviate any remaining issues with pump bearings, seals, and orientation and avoids the potential to entrain cover gas into the primary coolant. However, higher performance, less well-developed technologies will be incorporated into the FHR design basis only when they mature into reliable systems.

The earlier MSR program developed, tested, and documented many of the required salt reactor component technologies. Several reports document the component development and testing activities (Refs. 58, 59, and 64). MSR technology status and development issues were summarized in 1972 in ORNL-4812, The Development Status of Molten-Salt Breeder Reactors (Ref. 63). More recently, the status and development needs for several FHR components were reported in ORNL/TM-2009/297, An Analysis of Testing Requirements for Fluoride Salt-Cooled High Temperature Reactor Components, and with respect to heat transport systems in ORNL/TM-2010/156, An Overview of Liquid-Fluoride-Salt Heat Transport Systems.

This roadmap chapter lists and describes near-term component development and demonstration tasks and provides a general outline of longer term development tasks. It is organized on a component-bycomponent basis with (1) an overview of each FHR hydraulic component with respect to its performance requirements, development status, and additional technical developments required followed by (2) initial development tasks for each component and (3) anticipated testing requirements. 


\subsection{FHR HEAT TRANSFER AND HYDRAULIC COMPONENTS}

\subsubsection{Short-Shaft Salt Pumps}

\subsubsection{Overview and current status}

The AHTR design includes a number of short-shaft salt pumps on the primary loops, intermediate loops, the reactor maintenance cooling loop, and the used fuel heat rejection loop. The current AHTR design has three heat transport loops with each requiring a 4,700 L/s (75,000 gpm) pump on the primary leg and a $5,200 \mathrm{~L} / \mathrm{s}(82,000 \mathrm{gpm})$ capacity pump on the intermediate loop. The primary system maintenance heat rejection loop is sized for $5 \%$ decay heat removal, requiring a pump capable of approximately $820 \mathrm{~L} / \mathrm{s}$ (13,000 gpm), assuming a $75 \mathrm{~K}$ temperature drop in the loop. The pumping power requirements have not yet been determined as a detailed pressure drop evaluation has not yet been performed.

The AHTR pumps must operate reliably for years between maintenance outages. The pumps must be able to withstand anticipated thermal and pressure transients. The design of the pump and nearby structures must account for planned maintenance activities, such as replacing bearings, seals, motor drives, and potentially the pump impellor.

A significant amount of development and testing of salt pumps were conducted as part of the MSR program as documented in ORNL-TM-1993 and ORNL-TM-2987 (Refs. 37 and 60). A number of shortshaft pumps with pumping capacity up to $100 \mathrm{~L} / \mathrm{s}(1,500 \mathrm{gpm})$ were built and tested for tens of thousands of hours, at temperature, in a salt environment. Less experience is available with long-shaft salt pumps, which require salt-wetted bearings.

Using design tools of the time, designers of the MSBR were confident that short-shaft pumps with capacities of at least $630 \mathrm{~L} / \mathrm{s}(10,000 \mathrm{gpm})$ could be designed. The AHTR design requires the development of larger pumps, comparable in size to those used in a 4-loop PWR. New salt pump designs can take advantage of advancements in motor control drives, bearing and seal technologies, manufacturing and design tools. The first steps along the development path have recently been taken. The short-shaft MSRE primary coolant pump required oil lubricated ball bearings and shaft sealing. A small, short-shaft, variable speed pump [2.2 L/s (35 gpm) at $125 \mathrm{kPa}$ (18 psid) head] with a gas-lubricated shaft seal has recently been designed and fabricated for the ORNL Liquid Salt Test Loop (LSTL). The performance of its gas-lubricated shaft seal and flexible drive shaft connection; however, remains to be demonstrated. Also, the high-temperature DRACS facility currently under construction at The Ohio State University (OSU) is planned to use a $63 \mathrm{~cm}^{3} / \mathrm{s}$ (1 gpm) nominal flow cantilever sump pump operating with fluoride salt at $700^{\circ} \mathrm{C}$.

As part of past work at ORNL, a number of pumped salt loops were designed and operated. A small [250 $\left.\mathrm{cm}^{3} / \mathrm{s}(4 \mathrm{gpm})\right]$, belt driven, greased bearing, oil-lubricated mechanical face seal pump was used in the for corrosion tests under flowing salt conditions (Ref. 61). The loop operated at $510-588^{\circ} \mathrm{C}$ for thousands of hours. The loop piping was resistively heated and heat was rejected through an air-cooled coiled tube heat exchanger. The system was primarily constructed of $1.06 \mathrm{~cm}$ ID Hastelloy N tubing. A test stand built for the aircraft reactor test was modified and used for development activities for the MSRE and later for the MSBR program (Ref. 62). The loop included a pump, two air-cooled heat rejection sections, a throttle valve and a Venturi flow meter. The loop was primarily made of $102.3 \mathrm{~mm}$ ID (4 in. IPS) Inconel pipes. The loop operated at $50 \mathrm{~L} / \mathrm{s}(800 \mathrm{gpm})$ at $482-691^{\circ} \mathrm{C}$ for thousands of hours.

A number of components, such as heat exchangers, valves, fluidic diodes, the core, etc., require testing in flowing salt. These testing campaigns provide opportunities to test salt pumps for both performance and endurance. 


\subsubsection{Development tasks}

\section{Demonstrate current pump design}

The first pump development task is to demonstrate the performance of the recently built pump within the LSTL (see Fig. 7). The first step in the demonstration process is to commission the loop. Commissioning the loop includes a number of tasks such as confirming the instrumentation connections, confirming the control software performance, closing the SiC to metal flange seal, backfilling the loop with argon, cleaning the loop salt, and flushing/refilling the loop to remove oxides. Demonstrating the pump performance includes several supporting tasks including constructing liquid salt flow and pressure calibration test stands.

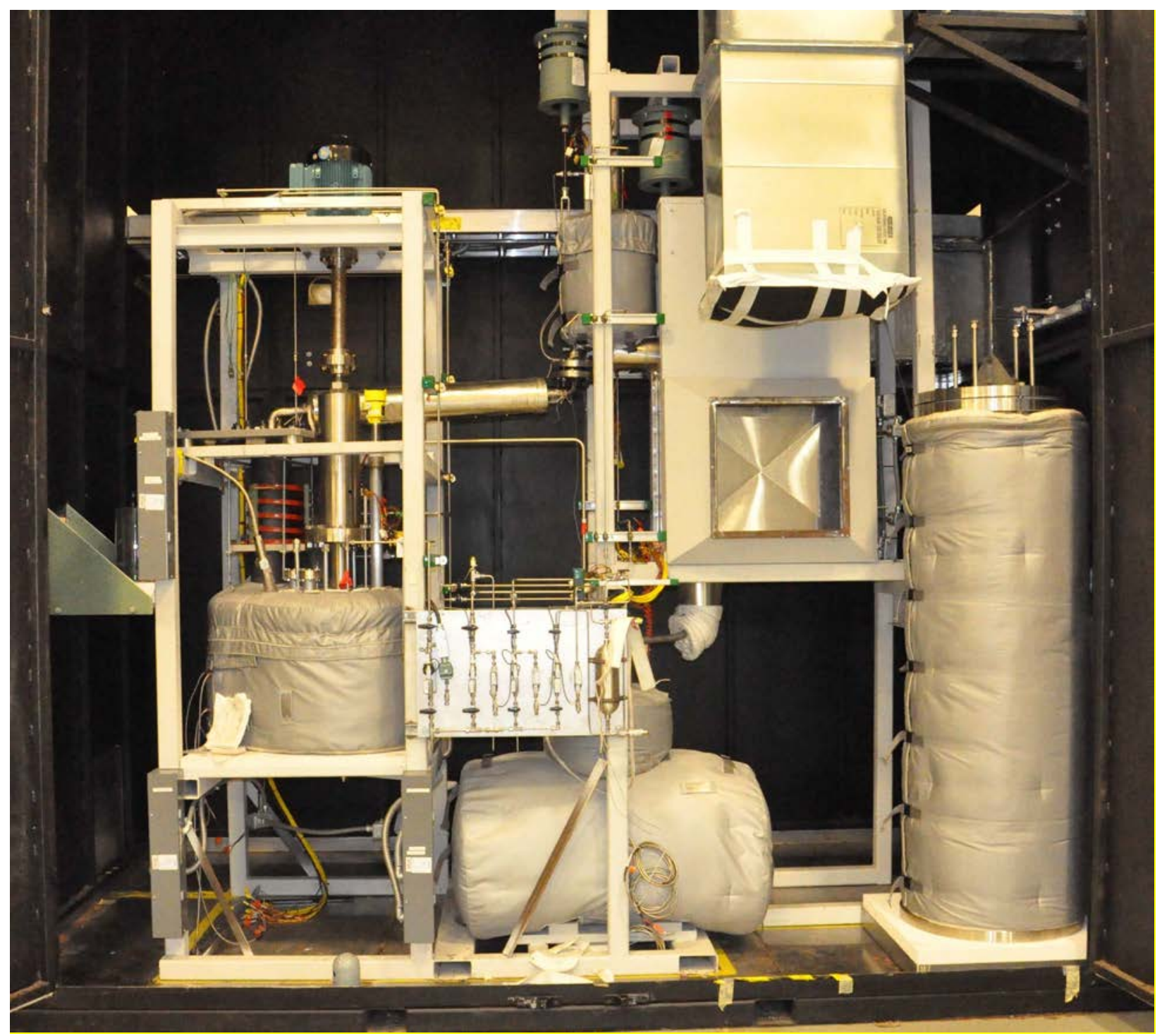

Fig. 7. ORNL Liquid Salt Test Loop. 


\section{Refine and optimize the current pump}

Once initial operation of the liquid salt pump has been achieved, the next step is to characterize its performance to establish a baseline. The performance characterization will include the pump efficiency (volume and head as a function of electrical power and rotational speed across the operable temperature range) and seal performance. Based upon the measured pump efficiency and performance simulations, an improved impeller and volute combination would then be designed, fabricated, and evaluated. Finally, guidelines and recommendation for larger scale pump design would be written based upon the results of the design improvement process and the refined pump performance.

\section{Evaluate design issues for larger pumps}

The first element of this task would be to assess what aspects of liquid salt pump design are most sensitive to larger scale. Issues that may become more important as the pumping power increases include

- the vertical support bearing configuration,

- the mechanical shift required to be accommodated by the gas foil bearings due to the larger shaft size,

- the larger impact of pump transients, and

- the larger equipment required to perform maintenance and subcomponent replacement.

\subsubsection{Heat Exchangers}

\subsubsection{Overview and current status}

All FHRs will contain multiple heat exchangers and their reliable performance is key to cost-effective plant performance. Fluoride salts have reasonably well-known, single phase heat transfer characteristics and thus their fabrication technologies, materials, lifetime, transient tolerance, and lifecycle cost rather than the heat transfer performance are the primary, nonacademic, development areas for FHRs. An overview of the planned AHTR heat exchangers, including their design, performance, and materials issues, is provided in Chapter 5 of this roadmap.

In addition to removing heat from the core, recently removed fuel in the used fuel cooling pool also requires heat rejection and thus heat exchangers. The currently planned set of AHTR heat exchangers are listed in Table 3. Some aspects of the AHTR's heat transfer configuration have not yet received significant design effort and are thus likely to change upon evaluation. In particular, the used fuel pool cooling configuration has substantial remaining design uncertainty. Currently, only a single used fuel pool forced cooling loop is planned due to the long coping time provided by the large coolant volume. Under long-term loss of forced flow conditions, the pool would reject its heat primarily through natural draft cooling of an air tube bank (similar to an RCCS) dipped into the used fuel pool. 
Table 3. AHTR salt containing heat exchangers

\begin{tabular}{|c|c|c|c|c|}
\hline Connections & $\begin{array}{c}\text { Pressure } \\
\text { difference }\end{array}$ & Media & Flow drive & Number \\
\hline $\begin{array}{l}\text { Primary-intermediate } \\
\text {. }\end{array}$ & Low & FLiBe-KF-ZrF ${ }_{4}$ & Forced-forced & 3 \\
\hline Intermediate-power cycle & High & $\mathrm{KF}-\mathrm{ZrF}_{4}-\mathrm{H}_{2} \mathrm{O}$ & Forced-forced & 3 \\
\hline Primary-maintenance loop & Low & FLiBe-KF-ZrF ${ }_{4}$ & Buoyancy-forced & 1 \\
\hline Maintenance loop-ambient air & Low & $\mathrm{KF}-\mathrm{ZrF}_{4}$-air & Forced-forced & 1 \\
\hline Primary-DRACS & Low & FLiBe-KF-ZrF 4 & Buoyancy-buoyancy & 3 \\
\hline DRACS-ambient air & Low & $\mathrm{KF}-\mathrm{ZrF}_{4}$-air & Buoyancy-buoyancy & 3 \\
\hline Used fuel pool-used fuel loop & Low & $\mathrm{KF}-\mathrm{ZrF}_{4}$-air & Buoyancy-forced & 1 \\
\hline Used fuel pool-ambient air & Low & $\mathrm{KF}-\mathrm{ZrF}_{4}$-air & Forced-forced & 1 \\
\hline Used fuel pool-ambient air & Low & $\mathrm{KF}-\mathrm{ZrF}_{4}$-air & Buoyancy-buoyancy & 1 \\
\hline
\end{tabular}

Several of the heat exchangers are intended to fulfill safety-related functions and so must operate reliably over a range of accident scenarios. Also, over the course of their design life the heat exchangers must endure a number of thermal transients resulting from both planned and unplanned reactor shutdowns and start-ups. The P-IHXs and the DHXs are also part of the primary containment boundary and their leak tight status must be capable of being periodically verified as required by GDC 35 .

\subsubsection{Development tasks}

\section{Tritium trapping}

The AHTR design uses a double-walled heat exchanger with an interior yttrium getter layer as the primary means to prevent tritium escape from the primary coolant loop. Chapter 5 of this roadmap discusses the materials issues of tritium trapping. Chapters 6 and 14 discuss the compliance aspects of tritium control.

This task will involve building a series of successively more complex and realistic tritium trapping and double-walled heat exchanger tube demonstrations. Initial testing will be performed using hydrogen and deuterium. Initial testing will focus on supporting the design of the trapping system and integrating it into the heat exchanger design. Validation testing will not start until a candidate tube and trap design has been selected. Only following successful technology demonstration will FLiBe and tritium be used. Note, if a yttrium foil barrier can be directly sandwiched between two tube walls (likely via co-extrusion or explosion bonding) the heat exchanger reverts to a single walled design.

\section{Heat exchanger design}

The current AHTR design intent is to rely upon classical tube and shell heat exchangers. Design rules for tube and shell heat exchangers are well-known, and Alloy $\mathrm{N}$ heat exchangers already have a comparatively high TRL. However, salt heat exchangers with buoyancy driven flows do not have a large experience base. As fluoride salts are not highly thermally conductive, integrating heat transfer enhancement features into the tubes may provide significant performance and economic advantages. The combination of buoyancy driven flow, complex geometry, and flow development results in complex modeling. Further, integrating features such as preheaters and thermally fused dampers on the shell side of the NDHX is nonstandard. As the NDHX is a key element of a DRACS system demonstrating that modeled performance can be achieved in practice is recommended as an early phase task. 
SGs that can be reconditioned in situ (as described in Chapter 5) are a novel development with potentially dramatic economic impact on component lifetime and thus FHR capital cost. Developing and demonstrating heat exchanger designs that take maximum advantage of the new capability is also recommended.

\section{Salt-to-air heat exchanger performance validation}

It is desirable to reestablish the capability to design, construct, and operate fluoride salt heat exchangers. While the initial MSR program did establish and document salt heat exchanger design and operation capability, sufficient time has passed that knowledge of the practical aspects of fluoride salt component design, fabrication, and operation has diminished significantly. Exercising fluoride salt heat-exchanger design and operation capability is a key element to ensuring future, larger, more expensive demonstrations do not suffer from unanticipated difficulties. A salt-to-air heat exchanger is recommended as an initial component demonstration task as it combines both more challenging modeling and a lesser experience base.

\subsubsection{Bellows}

The high operating temperature of FHRs results in large thermal expansions upon heat-up. Bellows are a piping element intended to accommodate mechanical shifts. Bellows are not intended to be part of the primary coolant boundary at the AHTR. However, bellows are included in the intermediate loop of the AHTR. While DBA have not yet been selected, it is intended that the design requirements of the intermediate loop be those of nonNPPs. The intermediate loop piping would then need to comply with ASME B31.1 piping system rules for electrical power generating stations. Appendix X of ASME B31.1 addresses metallic bellows expansion joints.

A key economic objective of the AHTR is to limit nuclear power design requirements to within the reactor containment and the cooling towers that project above containment. The intermediate cooling loop thus cannot be called upon to respond to any accident condition, be credited to confine radionuclides, or couple any potential accidents within the power cycle into containment. Mechanical bellows are a key aspect of decoupling the intermediate and primary loops. Providing a flexible, thin walled interconnection prevents seismic events or other mechanical events that might impact the intermediate loop from being transmitted to the primary loop.

The requirements for the bellows include the ability to maintain integrity under the static and dynamic loading from the piping and salt. The bellows must withstand thermal cycling and possibly freeze-thaw cycles. The bellows should also be designed to accommodate salt draining. Testing of bellows can be incorporated into facilities required for the testing of other components. The initial task for bellows validation is to select a particular bellows configuration based upon performance requirements estimates, identify a manufacturer, and integrate a test part into a test facility.

\subsubsection{Rupture Disks}

Rupture disks are the intermediate loop piping element intended to decouple any potential pressure excursions within the power cycle from the primary loop. The ASME BPVE Sect. VIII Division 1 provides rules for the use of rupture disks for overpressure protection. Note, as the intermediate loop salt is at low pressure, if rupture disk code compliance is judged to be too expensive, a large vertical pipe segment connected to an atmospheric pressure inert gas reservoir can be used as an alternative for preventing pressure waves from being transmitted from the power cycle loop to the primary loop. The initial rupture disk task is to assess the licensing issues involved with implementing rupture disks as a 
safety element on the intermediate loop of the AHTR. This task would take place as part of the overall licensing strategy development activity.

\subsubsection{Valves}

\section{Mechanical valves}

Mechanical valves are a basic hydraulic component with several potential applications at FHRs. For example, being able to isolate and drain components within or attached to the primary loop of the AHTR would significantly decrease maintenance time and expense. The maintenance issues for valves at FHRs are discussed in Chapter 10 of the roadmap. A scenario has not been identified for which isolating the reactor primary-loop from the reactor vessel or the intermediate loop would be a preferred safety response. Thus, containment isolation valves on either the primary or intermediate loops are not currently part of the AHTR baseline design.

The MSR program did not achieve an adequate pipe closure mechanical valve. Galling, sticking, and leakage were unresolved issues. However, bellows sealed mechanical throttling valves (for $\sim 100 \mathrm{~mm}$ piping) for flow control were tested for over 100,000 hours as part of the MSR program (Ref. 63). A primary reason for mechanical galling and sticking for nickel based alloy valves is that the fluoride salts remove the surface oxide layer from the metals. Johns Hopkins University, under DOE-NE sponsorship, has, therefore, been investigating depositing durable carbide coatings onto nickel alloys and has begun to test valve and seal features using the carbide-coated alloys. If this project is successful, gas-operated fluoride salt mechanical valves should become practical. The results of the carbide-coated material development effort are recommended to be included in an early phase FHR development task to design, fabricate, and demonstrate fluoride salt mechanical valves. Other materials, such as refractory alloys, that do not depend on protective oxide coatings are also recommended to be considered for the valve plugs and seats.

\section{Freeze valves}

Freeze valves are slower acting (several to tens of minutes) flow blockages suitable for application to small lines ( $<\sim 35 \mathrm{~mm}$ ID). Freeze valves were successfully developed and demonstrated during the MSR program. If the advanced materials development program does not result in adequately performing mechanical valves, novel valve configurations that combine the properties of freeze valves and freeze flanges should be considered. Using valve designs where the mechanical valve seal is around the periphery of the piping, where salt freezing can be used to create a seal, would result in a slow acting, large pipe diameter compatible mechanical valve.

In general, MSR era freeze valves performed adequately. However, fluoride salts expand upon melting. During the plug melting process excessive stress can occur within the valve body, potentially cracking the metallic boundary. The MSRE used freeze valves between the primary system and the storage and drain tanks and between the secondary loop and the drain tank. These valves experienced a number of thermal cycles and performed well. However, in one instance a freeze valve thawed unexpectedly, draining the fuel salt to the drain tank. Also, during the final drain of the MSRE primary salt, a small leak occurred at or near the bottom freeze valve. The MSRE operating history with freeze valves and freeze flanges is documented in ORNL-TM-3039 (Ref. 64).

Mechanical valves would generally be preferable to freeze valves due to their more rapid operation, less demanding controls, and potential applicability to a broader range of pipe sizes. Additionally, as adequate performance freeze-valves were demonstrated during the MSR program for smaller pipe diameters, developing modern freeze valves is a lower priority item. 


\subsubsection{Flanges}

The ability to use bolted flanges to join hydraulic components (instead of cutting out components and welding in their replacements) would significantly simplify FHR maintenance. Chapter 10 of this roadmap describes the technical challenges for mechanical flanges. Maintaining proper loading on the flange seal gasket through the initial heat-up and over repeated thermal cycles is the origin of the design challenge. Both spiral wound carbon-nickel gaskets and metallic, pressurized O-ring type gasket materials show promise for use in flange joints in liquid fluoride salt loops. The MSRE used freeze flanges to produce the required sealing. However, the melting process resulted in significant mechanical stress on the flange limiting the number of allowable flange cycles. Developing fluoride salt flange design guidance is a recommended near term task.

An LWR's vessel head flange includes two concentric, self-energizing, metallic O-rings positioned inboard of the bolt circle. The AHTR will use similar vessel head closure technology. While the upper flange bolting will be substantially less massive than an LWR due to the near atmospheric internal pressure, a double concentric metallic O-ring configuration will also likely be used. Due to the lower pressure and higher temperature, pressure-filled metallic O-rings (instead of self-energizing O-rings) will likely be used. As pressured filled, metallic O-rings are commercial technology for conditions similar to those required for FHRs, gas flange demonstration does not appear to be necessary in the near term.

\subsubsection{Fuel Assembly and Control Blade}

The AHTR fuel assemblies are hexagonal groups of fuel plates contained within a C-C composite channel box with a central ' $Y$ ' shaped control blade. Qualification of the fuel is discussed in Chapters 4 and 5 . Control blade performance and endurance testing is addressed in Chapter 14 of the roadmap. This chapter describes the activities necessary to demonstrate the performance of the fuel assemblies as hydraulic components.

One significant potential issue for the full core height fuel plates is the potential for destructive fluid induced plate-plate and plate-channel box vibrations. As described in Chapter 5, it is the design intent to use $\mathrm{SiC}$ leaf springs in the fuel assemblies and to maintain a relatively low inter-plate flow velocity $(<2$ $\mathrm{m} / \mathrm{s}$ ) to minimize the vibration potential. Nevertheless, flow induced vibrations remain a potentially significant issue for ceramic plate fuel and both experimental and computational investigation of flow induced vibrations is recommended as a near term task. Surrogate material reduced-scale testing appears to be an especially useful technique to resolve this issue given for computational challenge of simulating flow induced vibration.

\subsubsection{Control Blade Drive}

The control blade drives for the AHTR reside on top of the vessel flange. Safety classification has not yet been performed for the AHTR SSCs. Given the independent passive control blade insertion mechanism provided by the melt point links in drive chain, the control blade drives may be part of the control system not the reactor protection system in the AHTR. Nevertheless, reliable performance of the control blade mechanical drives is required for reliable reactor operation. For example, if the rack teeth do not drain of salt upon withdrawal from the upper plenum, the pinion gear might no longer be able to engage (due to the presence of solidified salt) preventing driven withdrawal of the blade. Demonstrating performance of representative control blade drive mechanisms in representative operating conditions (using $\mathrm{KF}-\mathrm{ZrF}_{4}$ instead of $\mathrm{FLiBe}$ ) is thus a recommended near term component conceptual design validation task. 


\subsubsection{Fluidic Diodes}

Fluidic diode can be incorporated into an FHR's in-vessel DRACS cooling loop to minimize bypass flow and thus the pumping power requirements during NO. During loss of forced flow accidents the flow direction through the diode would reverse. The diode's proper forward operation is, therefore, necessary to accomplish achieve a safety objective. As FHRs can be operated without fluidic diodes, their cost and reliability need to be balanced against the pumping power savings to assess whether to incorporate them into the plant design. Note, if the NDHX are not insulated during NO, significant additional thermal power loss would occur changing the value assessment for the fluidic diodes. If fluidic diodes are not included, the DHX design would incorporate diode like characteristics. Significantly improved fluoride salt heat transfer can be achieved under natural circulation flow conditions by incorporating surface enhancement features (e.g., fins) on the heat exchanger tubes. The tube surface fins would be oriented to increase the hydraulic resistance to forced flow in during NO, partially compensating for the lack of a fluidic diode. Hydraulic design for the AHTR has not yet been performed. Hence, no decision has been reached as to whether to include fluidic diodes in the in-vessel DRACS loops.

While fluidic diodes have significant operational history in safety-related applications, they have not previously been used as part of a reactor's DRACS system. Also, fluidic diodes have not previously been used with fluoride salts. Preliminary computational analysis and water loop testing have recently been performed on a vortex fluidic diode to help understand the implementation issues at FHRs (Ref. 65). Also, the integral high-temperature DRACS facility being constructed at OSU incorporates a fluidic diode. It is recommended to complete the AHTR hydraulic design to enable assessment of whether to incorporate fluidic diodes into the in-vessel loops before performing significant additional fluidic diode development.

\subsubsection{Used fuel pool cooling}

Used fuel pool cooling at the AHTR has only received basic mechanical layout and has not yet undergone hydraulic design. Hence, only basic performance requirements are yet available. The maximum heat load for the used fuel pool will be $\sim 10 \mathrm{MW}$ shortly after receiving half of a used core. Over the next few weeks the heat load will decrease to about $5 \mathrm{MW}$. The used fuel storage pool will contain roughly 1500 $\mathrm{m}^{3}$ of $\mathrm{KF}-\mathrm{ZrF}_{4}$ salt and will be at $\sim 500^{\circ} \mathrm{C}$ under normal operating conditions.

Normal heat transfer from the used fuel pool will be via a pumped salt loop. The salt will reject its heat to ambient air using a forced flow heat exchanger similar to that used at the MSRE. A similar system is currently installed in the LSTL. The high temperature of the used fuel presents the intriguing possibility of auto powering the heat rejection loop using the Stirling cycle and heat pipe system currently under development by the National Aeronautics and Space Administration for space fission power. This option preserves used fuel pool heat rejection (and site emergency power) in the case of grid disconnection. However, high-temperature Stirling engines and high-temperature heat pipes remain at relatively low technical readiness levels. Consequently, it is recommended to only monitor the technology progression and not to use them in first-generation FHRs.

Under long-term (multiple day) station blackout conditions, AHTR used fuel pool heat rejection will use a natural draft air cooling system, similar to the RCCS envisioned for HTGRs and SFRs. The primary difference for FHRs will be the good thermal coupling provided by placing the lower end of the system in the used fuel pool. Additionally, significant additional heat transfer will occur as the used fuel pool temperature rises due to the natural convection loop set up between the containment roof and the pool surface. It is recommended in the near term to perform hydraulic and heat transfer modeling of the used fuel pool cooling to enable sizing and design of the passive air-cooling system and assessment of the effectiveness of the inherent heat transfer from the pool surface to the containment roof. 


\subsubsection{Refueling}

The AHTR refueling system preconceptual design is now complete, and a workable approach to refueling the reactor has been developed. The AHTR refueling systems and process description are documented in ORN/TM-2012/292 (Ref. 66). As some of the underlying technologies are not yet mature enough to proceed to more detailed concept development, progress in the AHTR refueling system development will now be dictated by technology developments, primarily in instrumentation, controls, and human-machine interface technology.

The next recommended development step for the refueling system is to create a computer-based model interacting with I\&C. As the overall refueling system is complex, augmenting the computer-based modeling with progressively more realistic physical mock-ups will provide higher confidence in proper refueling system operation. A scaled surrogate material mock-up followed by a more detailed mock-up using $\mathrm{KF}-\mathrm{ZrF}_{4}$ in place of $\mathrm{FLiBe}$ is then recommended.

\subsubsection{Longer Term Development and Testing}

As component testing and development progresses, system and integral effects testing will need to be initiated. System and integral effects testing largely cannot yet be defined at present as key systems and components have yet been designed. However, the demonstrations that will be necessary to receive a DC are discussed in Chapter 14. Chapter 14 has also been augmented with demonstration facilities that enable system and integrated testing. Completion of the AHTR preconceptual design that includes all of the required systems and components is recommended as the next step in the development path. Development of a revised roadmap reflecting the completed preconceptual design would then be recommended. 


\section{INSTRUMENTATION}

\subsection{INTRODUCTION}

The objective of this chapter is to describe an acceptable instrumentation development and demonstration path to support deployment of first-generation FHRs. DOE and NRC have sponsored development of general-purpose instrumentation, controls, and human-machine interface technology development assessments have over the past decade (Refs. 67 and 68). Also, the recent NRC sponsored HTGR measurement and instrumentation technology assessment has significant overlap with FHR instrumentation needs (Ref. 69). The present effort has been informed by the earlier reports, but is focused on FHRs and is less detailed than the prior, in-depth evaluations as instrumentation is only one aspect of this more general roadmap. Also, FHRs are less mature than other reactor classes and some aspects of their instrumentation requirements are thus less well-defined. This chapter is limited to those aspects of FHR instrumentation that are distinctive to the reactor class. Well-established instruments that are common to several reactor classes are not addressed. This instrumentation development roadmap will need to be reexamined and expanded to include additional systems and functional allocation between automated systems and the plant staff as specific performance requirements are developed and FHR concept development advances.

This chapter begins with an overview of an FHR's instrumentation system functionality and then discusses the system architecture design. Next, overall performance requirements are introduced. Much of the instrumentation overview is based upon contrasting an FHR's measurements with those of LWRs. Specific plant measurements are then described and candidate instruments capable of performing the required measurements are introduced. Next, measurement development issues are discussed and finally an initial set of tasks to develop and demonstrate an acceptable instrument suite for an FHR are introduced.

As with any NPP, the overall function of an FHR's instrumentation system is to provide the information necessary to safely and efficiently operate the plant over its entire lifetime under the full range of conditions it may experience. Measurements include process conditions (both online and during outages), component health, and accident progression monitoring. Specific FHR instrumentation technology requirements derive from their performance requirements. For example, the required accuracy and response time of the primary loop temperature and mass flow measurement arises from the necessity of knowing the thermal power generation rate facilitating efficient power cycle operation, providing assurance of core cooling, and enabling calibration of the neutron based power measurements. A thorough understanding of the plant performance requirements is thus necessary to establish technology requirements.

FHR DBAs and BDBAs have not yet been established; so specific instrumentation performance and environmental tolerance requirements are not yet possible. However, the general plant layout and basic mechanical configuration of the AHTR has been developed. Consequently, an early phase FHR instrumentation system description is now possible that will require updating as the reactor concept matures and the accident performance requirements are analyzed.

As a rule, safety-related instrumentation should be simplified to the extent possible to provide the highest possible assurance of reliable, safe operation while minimizing equipment qualification challenges. The more complex, higher-speed signal processing made possible by modern electronics; however, frequently enables both improved performance and increased probability of correct operation (or failure to a safe state). Probability of safety is thus a key differentiating element for safety-related instrumentation. Correctly, allocating requirements between simple, easily verifiable safety instrumentation and more 
complex, higher performance control instrumentation is, therefore, a key instrumentation system design task.

Qualification of instrumentation for application in a nuclear safety system is both expensive and time consuming. Minimizing the amount of specialized, safety-related instrumentation in first-of-a-kind power plants is also important due to the lack of a preexisting supplier base. Lacking an existing market, commercial instrumentation suppliers typically cannot justify the expense of developing and maintaining qualified, specialized instrumentation products. Digital instrumentation with its greatly increased internal complexity has proven challenging to introduce even into LWRs largely due to the necessity of providing high-assurance of its correct operation. To the extent possible, therefore, preexisting, nuclear power qualified technologies are recommended for safety-related measurements reserving more advanced technologies to the plant control system.

FHR instrumentation systems will more broadly rely on standard, industrial-grade, high-quality control electronics than LWRs because the reactor inherent passive safety reduces the active safety response requirements. Use of industrial-grade components, instead of the bespoken production common for LWR safety system electronics, changes the system design and obsolescence paradigms. FHR instrumentation development tasks will thus have a dual path approach. The plant passive safety features will be relied upon to minimize the subset of instrumentation necessary to perform safety functions. The safety instrumentation will be as simple as possible and fully qualified for NPP safety applications. Plant control instrumentation, in contrast, will use best commercially available technologies and will likely include complex algorithms and advanced system diagnostic technologies. The functional allocation between the safety and control instrumentation systems will, of necessity, await evaluation of potential accidents and the required safety response.

\subsection{PERFORMANCE REQUIREMENTS}

The performance requirements for an FHR's instrumentation system arise from its functional requirements, which in turn derive from the plant's physical characteristics and potential accident scenarios. Understanding potential FHR accidents including their initiating events and the resultant plant conditions is required to perform a full-scope instrumentation system design. Key design issues such as measurement precision and physical layout can only be addressed as part of developing a plant conceptual design. For example, the NO and accident condition in-containment temperature and radiation environments will largely dictate the acceptable in-containment measurement electronics technologies and locations, which are, in turn, key to selecting specific measurement technologies. Lacking a completed conceptual design, only general instrumentation performance requirements can currently be provided.

The instrumentation performance requirements of LWRs do not directly apply to FHRs as the different reactor class characteristics yield different vulnerabilities. FHRs have low-pressure, moderate power density ( $\sim 15 \mathrm{MW} / \mathrm{m}^{3}$ for an FHR vs $\sim 110 \mathrm{MW} / \mathrm{m}^{3}$ for a PWR), high-temperature tolerant ceramic cores, a large thermal margin to fuel damage, no primary coolant phase-change accidents, strong negative reactivity thermal feedback, no requirement for auxiliary power in case of long-term station blackout accidents, and inherently slow accident progression scenarios. As such, FHRs will require significantly different safety measurement capabilities than would an LWR. The differences will inevitably be reflected in the instrumentation system architecture. While general design principles such as high quality, diversity, and defense-in-depth remain requirements for any reactor, the lack of a pressure differential to disperse radionuclides and the much larger time and temperature margins inherently afforded by an FHR to respond to any accident may, in addition to altering the instrumentation, affect the allocation of responsibility for safety response from equipment to operator or even to a remote expert. 
The instrumentation system's basic safety function can be expressed in how it supports the plant's three fundamental safety functions: (1) confinement of radioactive material, (2) control of the core reactivity, and (3) removal of the heat from the core. During NO safety-related measurements confirm that the plant parameters remain within design limits and that SSCs remain capable of responding correctly to accident sequences. Since FHRs are thermal power plants, the focus of the parameter measurements is on confirming proper heat balances throughout the plant subsystems. The SSC monitoring function confirms that the major radionuclide release barriers remain in place and that both safety-related equipment is functioning as intended (e.g., that the control blade drive mechanisms position the blades as intended) and accident mitigation equipment remains ready to respond (e.g., power is available to the maintenance cooling system). Additional monitoring is performed to assess the amount of radioactive material leaking from the plant (e.g., tritium from the DRACS towers) and to map dose and/or contamination levels within the plant. The plant security status is also continuously monitored.

Safety-related instrumentation is generally used in the protection systems to ensure a timely and appropriate response to an accident or AOO. Much as for LWRs, a combination of safety-related and nonsafety-related instrumentation is used during NO. For example, control blade position monitors (likely safety-related) are used by the control system (nonsafety-related) in performing a power level transition. Non-power operations also involve safety-related instrumentation. The decay heat from the used fuel needs to be rejected to the environment. The AHTR's design calls for used fuel storage in a liquid salt filled pool within containment for 6-12 months following removal from the core. Monitoring the condition and performance of the used fuel pool and its decay heat removal systems thus requires safetyrelated instrumentation. Note, however, unacceptable used fuel pool heat-up is a long-duration phenomenon and the unpressurized, in-containment, below-grade fuel storage pool does not have a strong mechanism to release radionuclides from even failed fuel to the environment. The safety-related plant monitoring requirements also change during an outage. During refueling, the fuel handling process needs to be monitored to ensure that fuel is not mechanically damaged during handling and that worker dose is minimized.

\subsection{SYSTEM ARCHITECTURE}

Unlike LWRs, FHRs have no known accident scenarios that require a rapid response. The high likelihood for lack of requirement for rapid response derives from the combination of the lower core power density, the large thermal mass in vessel, the large margin to boiling, and the high tolerance of core temperature rise. All known reactivity insertion and loss of core coolability accidents progress slowly. FHRs have no mechanisms to overpressure the primary coolant boundary, and even a flow blockage accident would only lead to local fuel heat up before inherent negative thermal reactivity feedback would mitigate the accident. Further, even following a fuel damage accident, the released radionuclides except for the noble gases would not rapidly escape but remain trapped in the fuel structural carbon or primary coolant.

The longer time afforded for communication means that no obvious imperative exists for sensor signals to have direct point-to-point wiring. Indeed, the timing requirements for an FHR's digital communications network can be significantly relaxed from those for an LWR. Given the large time (days) for accident response at an FHR, the passive nature of the safety response functions, and the ability to manually perform safety system actuation in the event of simultaneous communication and passive safety system actuation failure, separating the digital control network from the safety network may no longer be necessary. The continuous use of the control network provides online, albeit limited, functionality and end-to-end testing of the communications network. This may result in a higher reliability automatic system, while the manual backup provides the defense-in-depth ordinarily provided by the separation of the control and safety systems. 
A major portion of the rationale for redundant instrumentation networks is to maintain the capability to operate when any single component has failed. Since highly reliable operation is as valuable to an FHR as any other power plant, its instrumentation redundancy will closely resemble that of an LWR or other large industrial facility. In contrast, it is anticipated that the much larger time allowance for accident response provided by an FHR may enable actions by human operators to mitigate the potential for common cause failure. Human thought patterns are diverse from digital instrumentation systems and the days likely available to take safety actions at an FHR allows human-based action to be highly effective in performing correct safety functions and diagnosing instrumentation system failures even in the case of limited and unreliable system information. Note, neither the primary or secondary passive shutdown systems nor the passive decay heat removal systems can be disabled by the operators. Thus, the potential safety-issue that the control system, due to its lower level of verification and validation, may provide incorrect information to the operators resulting in damaging actions is significantly mitigated.

The cost for laying communications network wiring during plant construction is not especially costly or difficult as compared to other construction activities. Further, in most deployment scenarios, a wire (or optical fiber) based communications path provides a defined communications path with higher bandwidth than is readily achievable with a wireless network. Moreover, wireless communications within power plant environments (with their large reflective metal structures and strong electromagnetic emissions) are much more technically restricted than in less complex environments. In addition, the cyber intrusion vulnerability is greater for a wireless network. Hence, a fully wired communications network would, on initial consideration, appear to be technologically preferable. However, wireless communications networks (especially when coupled with environmental power scavenging) provide aging, flexibility, diversity, and severe accident survivability capabilities that cannot be matched by a wired system.

Overall, FHR network architectures are likely to consist of a mixture of wired and wireless networking. The wired network is likely to consist of high-bandwidth cabling with wireless network access points distributed along its length. The additional accident response time inherently provided by an FHR is anticipated to eliminate all point-to-point wiring connections to the control room with the exception of manual shutdown systems. The wired network may be an all ceramic-and-metal configuration designed to last the life of the plant or may be designed for periodic replacement. A significant lesson learned from LWR operation is that installing new wiring and/or replacing buried wiring is a difficult, expensive maintenance activity. Powered actuators (e.g., control rod drive motors) are thus likely to route their communications over their associated power lines to reduce and simplify the wiring requirements. Individual sensing elements remain likely to have a wired connection to the nearest environmentally benign area where their measurement electronics will survive, as electronics remain the most environmentally sensitive component in the instrumentation system.

\subsection{MEASUREMENTS}

The purpose for this subdivision is to provide an integrated reference to currently envisioned FHR measurements and instruments and to show where further technology development and demonstrations are required. The subdivision begins with a description of the measurements envisioned for safe plant operation. The following subdivision introduces distinctive sensors for the FHR with advantageous characteristics. The measurement and sensor selection is preliminary, as neither a completed power plant conceptual design nor a potential accident condition assessment has yet been accomplished.

\subsubsection{Core Coolability}

Maintaining core coolability is a primary reactor safety function. Similar to pool type light-water-cooled research reactors, an FHR's transparent, low-pressure, single-phase primary coolant potentially enables online, visual observation of the reactor core and its upper and lower plenums. In other power reactor 
classes the status of the reactor core and its cooling are inferred from indirect measurements. Observation of core coolability is a significant reactor class advantage as accidents as diverse as the Fermi- 1 inlet nozzle blockage (SFR) and the Three Mile Island Unit 2 (LWR) feedwater shutoff would be much less likely if the reactor core were under constant visual surveillance. Providing and maintaining the optical access into the reactor vessel and to the lower plenum will be the principal technology challenge for enabling continuous core coolability surveillance. Observing the core from above also allows continuous monitoring of the degree of mechanical warpage of the fuel. Additionally, if the primary coolant flow distribution were to change due to in-core restriction/blockage, the temperature distribution at the top of the core would change. Because the core is a carbon structure, its blackbody emissions can be used as a temperature indication. Visual observation of the top of the core thus needs to include near infrared wavelengths to provide an online map of the coolant exit-temperature distribution. Supplementary primary coolant level switches will also likely be used as a diverse backup to the visual measurements to provide additional assurance that the core remains submerged in the primary coolant.

\subsubsection{Reactivity}

Measuring and controlling the core reactivity is a primary reactor safety function. The core reactivity needs to be observed and controlled throughout the plant's lifecycle. Providing continuous monitoring of the degree of subcriticality during shutdown periods will be required to obtain an operating license. Reactivity is determined by monitoring the change in the neutron flux with time. The specific measurement sensitivity required during shutdown is determined by the combination of the required measurement response time, the start-up neutron source strength, and how far below criticality is required to be monitored. The likely comparatively low consequences for an unintended criticality in an FHR appear to limit the required sensitivity. However, the specific measurement sensitivity requirements will arise from the, yet to be performed, accident analysis. Start-up range flux monitoring is likely to be performed by a high-sensitivity fission chamber that is actively cooled within a thermally insulated thimble that is withdrawn from the reactor core during power ascension. Fission chambers are commercially available to $\sim 550^{\circ} \mathrm{C}$. Thus the fission chamber would need to be cooled $100-150^{\circ} \mathrm{C}$ below the surrounding primary coolant salt.

As the reactor transitions from start-up into the intermediate and power ranges, the neutron flux becomes much larger and more prominent. The core will produce an intense Cerenkov glow in the primary coolant, the intensity of which is proportional to the reactor power. The reactivity of pool type reactors has been monitored with Cerenkov detectors for more than 50 years now (Ref. 70). However, as with all intensitybased measurements, a Cerenkov glow measurement would be vulnerable to changes in the optical absorption of the signal path between the core and the optical detector. A rapid Cerenkov-based fission power measurement can, however, be recalibrated by delayed, but more accurate power measurements. The potential for monitoring the power range core reactivity by observing the Cerenkov light emission may avoid the necessity for high-temperature tolerant, power-range neutron flux monitors. The reason for local power range flux monitoring in LWRs is to ensure boiling stability in BWRs and to ensure that the local heating rate does not approach a fuel limiting condition in PWRs. In FHRs fuel and coolant are robust with large margins to fuel failure during NO. Currently available, self-powered neutron detectors (SPNDs) would be capable of measuring the in-core power flux distribution in an FHR core. However, no major technical driver has thus far been identified for power range local flux monitoring in an FHR.

\subsubsection{Reactor Power}

Reactor power is monitored as a safety indicator and to enable proper operation of the power cycle. The most common reactor thermal power measurement system at PWRs is based upon accurately monitoring the temperature rise of the primary coolant along with its mass flow rate. A heat balance based reactor power monitoring system will also be relied upon at FHRs. Accurate primary coolant temperature and 
mass flow, thus, remain key measurements at FHRs. Accurate, primary coolant temperature measurement has significant technical challenges even at LWRs. The temperature distribution within the primary coolant flow will be both nonuniform and time varying. Most mass flow rate measurement systems are vulnerable both to drift due to transducer degradation and to inaccuracy due to flow distributions that are not well characterized.

Neutron flux monitors are also commonly used as fast responding surrogates for reactor power. Ex-core fission chambers are the most commonly selected technology for quick response, neutron flux monitors. However, fission chambers only measure the neutron flux level in their local area and thus a flux distribution model is required to calculate the overall reactor power. Further, the sensitivity of flux monitors degrades as their neutron transducing elements are consumed during use. Heat balance power monitoring is, therefore, used to periodically recalibrate the neutron flux based measurement.

LWRs have also used ${ }^{16} \mathrm{O}(\mathrm{n}, \mathrm{p}){ }^{16} \mathrm{~N}$ based activation power monitors (Ref. 71). In an LWR activation power monitor, the level of ${ }^{16} \mathrm{~N}$ activity in the primary coolant is monitored in the primary coolant loop as an integrated, albeit delayed, indication of the reactor power. ${ }^{16} \mathrm{~N}$ based power monitoring at LWRs is, however, somewhat burn-up dependent in that ${ }^{16} \mathrm{O}(\mathrm{n}, \mathrm{p}){ }^{16} \mathrm{~N}$ has a neutron energy threshold of $\sim 10 \mathrm{MeV}$. The number of these high-energy neutrons is somewhat larger for ${ }^{239} \mathrm{Pu}$ fissions than ${ }^{235} \mathrm{U}$ fissions. Roughly compensating for the burnup sensitivity, is the slightly larger recoverable energy yield of a ${ }^{239} \mathrm{Pu}$ fission than a ${ }^{235} \mathrm{U}$ fission. FHRs, however, will require less compensation than LWRs to use activation power monitors. The ${ }^{19} \mathrm{~F}(\mathrm{n}, \boldsymbol{\alpha}){ }^{16} \mathrm{~N}$ cross-section has a $2.5 \mathrm{MeV}$ threshold, which is largely below the fission neutron creation energy of both ${ }^{239} \mathrm{Pu}$ and ${ }^{235} \mathrm{U}$. Additionally, the ${ }^{19} \mathrm{~F}(\mathrm{n}, \gamma){ }^{20} \mathrm{~F}$ activation crosssection has an inverse velocity dependent component (and is thus larger in the lower energy portion of the neutron energy spectrum where thermal spectrum reactors have larger neutron fluxes) and yields a 1.634 $\mathrm{MeV} \gamma$-ray during its decay. Monitoring both the ${ }^{20} \mathrm{~F}$ and ${ }^{16} \mathrm{~N}$ decays in the primary loop of an FHR can thus provide an overall measurement of the reactor core power level.

\subsubsection{Fuel Leakage}

Fuel leakage will be monitored by a combination of cover gas activity monitoring and gamma monitoring of the primary coolant loop. Note, at the lower fuel operating temperature of FHRs, the fuel carbonmatrix material will act as a filter to fission product release, and a smaller fraction of released fission products will escape from the fuel assembly into the primary coolant in FHRs as compared to HTGRs.

The circulating radionuclides within the primary coolant would both be a potential source for maintenance worker dose and would be more vulnerable to release into the environment than those retained within the fuel. Apart from the noble gas fission products, no significant fission-product release mechanisms from the primary coolant have yet been identified. Thus, the required sensitivity of fuel leakage monitoring has not yet been determined. However, given the larger potential for radionuclide release from LWR coolant loop due to the high pressure, the FHR circulating activity limits will likely be higher than those permitted for LWRs. The primary activation products of FLiBe (apart from tritium) have short decay times and would be anticipated to contribute negligible dose within a few minutes after shutdown.

\subsubsection{Primary Coolant Boundary Integrity}

Maintaining the integrity of the primary coolant boundary is both a capital asset preservation measurement and part of the reactor safety case. Monitoring the reactor coolant level serves as a primary online indication that the reactor vessel and piping have not developed significant leaks. The visual ability to monitor important regions of the reactor vessel from the interior while the reactor remains online and the entire vessel periodically during maintenance outages can provide assurance that unacceptable 
corrosion will not have occurred over the previous inspection interval. Additionally, preemplaced coupons of the reactor materials can periodically retrieved and examined to observe the amount of degradation.

\subsubsection{Decay Heat Removal Functionality}

The DRACSs are critical safety systems at FHRs that are relied upon in the event of loss of all other heat removal systems. As such their functionality must be constantly monitored. The DRACS loops will be in constant operation, albeit at low power, throughout the reactor lifetime and will represent a small parasitic heat load during NO. The key parameters to monitor in the DRACS loops to provide assurance of operability are: (1) the loop temperature, (2) the coolant flow, and (3) the loop fill status. The DRACS loops will also likely be monitored for salt redox condition and perhaps for the presence of corrosion products within the loop. The loop temperature and coolant flow measurements demonstrate that the DRACS loop is not near freeze-up condition. The loop fill status (level in the salt surge tank) will be monitored to demonstrate the loop has not developed a significant leak. The DRACS coolant will also activate if it leaks into the primary coolant. Thus the primary coolant circulating activity monitor will also provide assurance that the DHX are not leaking.

\subsubsection{Tritium Release}

Tritium release will be monitored at multiple locations within the plant, as tritium is the only radionuclide with significant potential for release into the environment. The cover- and containment-gas cleanup systems will include a heated metal particle bed similar to that used in the helium cleanup system of HTGRs to convert any hydrogen into a metal hydride. As part of the cleanup system, a flow-through ionchamber can be used to measure the tritium soft beta emissions. If the cover gas contains significant noble gas activation products, a cold trap will be necessary in the fore line of the ion chamber to allow differentiation of the tritium signal. Similarly, the DRACS tower stacks will include flow-through ionchamber type tritium detectors. The current design concept for the NDHX at the base of the DRACS towers calls for them to be enclosed within a shell. Flow blockage flaps at the entrance and exit of the shell would enable tritium diffusing through the heat exchanger tubes to be captured as a hydride and minimize heat loss during NO while reducing the potential for loop freeze-up. The flow blocking flaps would be configured to open automatically (using melt point alloys) if the loop temperature were to increase, as would occur upon loss of forced cooling.

\subsubsection{Refueling}

All of the grasping and positioning actions will be performed visually from above the salt pool. Views of the vessel interior will be provided to both the operators and the control system via relay lenses located around the periphery of the top cover flange. The optical system design is at a very early phase.

\subsection{SENSORS}

The sensor selection remains immature, as thus far only limited effort has been expended to evaluate the required measurements and instrumentation options. Alternate sensors and measurement methods may be recommended over the course of the development program. However, the selected sensors and measurements provide a reasonable level of information about an FHR power plant throughout its life cycle. While significant development effort remains, no fundamentally new sensor types appear to be required to operate FHRs safely and efficiently. 


\subsubsection{Vision}

Providing visual access into the reactor vessel requires overcoming several technical challenges.

1. The interior surface of the top cover flange and control blade flange are at elevated temperature. While the flange temperature will be lower than the salt due to argon flow in the region above the pool, the optical elements within the flange will need to accommodate elevated temperatures. The current design envisions only relay lenses in the top flange with cameras located above the vessel in a controlled environment.

2. The optical alignment will change as the core expands and contracts with temperature. Cameras will have to reposition automatically according to the changes in the location of the relay lens.

3. The salt surface will include ripples as the salt flows. The optical effect of rippling will need to be removed computationally to enable accurate imaging of the underlying components.

4. The $\mathrm{BeF}_{2}$ will evaporate from the salt surface and deposit as a polycrystalline film on cool surfaces, rapidly clouding lenses. The first-surface lenses will need to be either heated or mechanically cleaned.

5. The radiation dose due to radionuclide generation with the salt can cause window materials to darken. Window material selection will thus be restricted to radiation tolerant materials.

Additionally, the cameras (and all detector electronics) will need to be remotely located from the primary loop to minimize their radiation dose.

Providing optical access to the lower plenum also requires developing both salt and radiation-tolerant window materials and mirrors as a periscope type device is envisioned to enable viewing the lower plenum without providing a significant bypass coolant flow path. While precious metal mirrors and diamond windows are generally compatible with an FHR in-vessel environment, instrument design remains to be performed and only a limited amount of diamond window performance data is available.

\subsubsection{Flow}

The most likely conventional methods for primary coolant flow measurements at an FHR are either to correlate the pressure drop across a flow obstruction (such as a Venturi orifice) or the ultrasonic signal transit time variance across the flow, as measured from the exterior of the piping, with flow rate. However, the accuracy of differential-pressure-based flowmeters is vulnerable to corrosion of the obstruction changing the pressure drop. In addition, differential pressure flowmeters become less accurate with flow stratification and nonuniformity of the flow pattern. Moreover, high-temperature, molten-saltcompatible differential pressure taps are not currently commercially available. Ultrasonic flowmeters are also somewhat vulnerable to flow stratification and nonuniformities. To overcome their flow distribution vulnerability, multiple ultrasonic flowmeters are attached across a single pipe cross-section producing an integrated flow rate. Ultrasonic flowmeters require coupling elements (buffer waveguide blades) to separate their thermally sensitive piezoelectric elements from the high-temperature environment. A further consideration is that the containment radiation environment at an FHR may limit the lifetime of the ultrasonic transducer element.

Radionuclide transport monitoring appears to be a preferable primary coolant flow measurement technology at FHRs. The primary coolant flow in PWRs can also be measured by tracking the movement of radionuclides in the primary coolant. Flowmeters based upon ${ }^{16} \mathrm{O}(\mathrm{n}, \mathrm{p}){ }^{16} \mathrm{~N}$ were developed in the 1970 s and early 1980s (Refs. 72 and 73). These flowmeters function by tracking the spatial location of the 
decaying nitrogen-16 as it transported along the primary coolant piping. Nitrogen-16 decay flowmeters have been implemented in operating plants with a reported accuracy of about 2\% (Refs. 74 and 75). Similar phenomena are also present in FHRs. The fluorine-19 of the primary coolant has two separate activation reactions that yield useful decay gamma rays. FHR reactor core irradiation of ${ }^{19} \mathrm{~F}$ will yield both ${ }^{16} \mathrm{~N}$ and ${ }^{20} \mathrm{~F}$. Nitrogen-16 has a 7.13-second half-life and emits a $6.123 \mathrm{MeV}$ gamma ray with an intensity of $67 \%$ during its decay. Nitrogen-16 also emits a $7.115 \mathrm{MeV}$ gamma ray with $4.9 \%$ intensity. Fluorine-20 has a half-life of 11.163 seconds and emits a gamma ray of $1.634 \mathrm{MeV}$ with an intensity of over $99.99 \%$ during its decay.

A technical challenge for the ${ }^{16} \mathrm{~N}$ decay based measurement scheme in PWRs is the low intensity of the signals limiting measurement accuracy. FHRs in contrast will produce more gamma rays due to the larger neutron interaction cross-sections. In particular, the threshold for nitrogen-16 production from interaction with oxygen-16 is roughly $10 \mathrm{MeV}$. In contrast, nitrogen-16 can be produced by lower energy neutrons (beginning at about $2.5 \mathrm{MeV}$ ) in FHRs, and fluorine-20 will be produced throughout the neutron spectrum. In addition, FHRs will have significantly less shielding of the radiation detectors due to shielding by the thin primary coolant pipe walls. PWRs, in contrast have high primary coolant pressure ( 15.5 MPa) and use thick wall steel piping (70 mm thickness is typical). FHR pipe wall thickness is likely to be less than $10 \mathrm{~mm}$, significantly decreasing the pipe wall shielding of fluid signal. The lower pipe wall thickness will necessitate collimating the emerging gamma rays to isolate a particular location on the pipe.

Thermal pulse propagation tracking appears to be the preferred flow monitoring technique for natural circulation flow in the DRACS loops. In a thermal pulse propagation-based flow measurements, a thermal pulse is impressed low within the loop and buoyancy causes the thermal pulse to rise within the loop. Pipe surface thermometers deployed along the loop track the motion of the thermal pulse.

\subsubsection{Neutron Flux}

Neutron flux sensors include both direct and inferential measurement methods and both start-up and power range measurements. High-temperature fission chambers can provide high sensitivity neutron flux measurement. High-sensitivity, high-temperature tolerant fission chambers have been developed in support of SFRs. As such, the maximum temperature of commercially available units is $\sim 550^{\circ} \mathrm{C}$. This is $100-150^{\circ} \mathrm{C}$ below the planned operating temperature of first-generation FHRs and as such, a higher temperature tolerant, high-sensitivity fission chamber would be desirable. A high-temperature fission chamber suitable for FHR, HTGR, and/or lead-cooled fast reactors is currently under development under DOE-NE sponsorship in its NEET program. However, as a fallback position, a current generation fission chamber can be located in an insulated thimble near the reactor core. The sensor would be cooled by cover gas flow and would be withdrawn upon the reactor achieving criticality when less sensitive flux measurements become useful.

SPNDs are currently commercially available for FHR power range flux and temperatures. SPNDs can provide local neutron flux maps. The exterior sheath material for the SPNDs will require custom specification (Alloy N, SS316, or molybdenum) for fluoride salt compatibility. Gamma thermometers are another alternative for power range energy deposition monitoring. While gamma thermometers have close technical analogies to thermocouples and are thus quite likely to perform at the temperatures of an FHR core. Gamma thermometers are not as commonly deployed as SPNDs and would require a development program to produce an FHR customized variant.

Cerenkov detectors monitor the light emitted as charged particles (energetic electrons) traveling faster than photons in the primary coolant slow down. The light emission is strongly peaked in the ultra-violet region and decreases in intensity roughly linearly with increasing wavelength. Cerenkov light detection 
must overcome all of the technology issues listed in the Vision subdivision of this document. Additionally, at low reactor power, a significant fraction of the Cerenkov photons are due to beta decays of fission products and are thus do not represent the current reactor power.

Activation power monitors are based upon measuring the intensity of the gamma flux within the primary coolant loop. Scintillation type detectors are the most likely technology for the gamma measurements. A potentially confounding measurement issue is the photo-neutrons produced by energetic ${ }^{16} \mathrm{~N}$ decay gamma rays impacting the beryllium component of the primary coolant. Neutrons can directly interact with the photomultiplier tubes and detector crystals of the gamma measurement systems. Overall, however, the gamma ray measurement technology suitable for use in the containment environment of an FHR is commercially available.

\subsubsection{Temperature}

Temperature measurement is commonly performed in all NPPs. As HTGRs are also HTRs, the recent review of their temperature measurement technologies is directly relevant to FHRs (Ref. 3). In LWRs, the core exit temperature is monitored using several thermocouples. Type $\mathrm{N}$ thermocouples with a salt compatible sheath alloy could also be used at FHRs. However, FHRs will more likely use remote pyrometry as their primary core exit temperature measurement technique to avoid the cost and difficulty of multiple in-vessel, salt-wetted sensors that both may interfere with refueling operations and will likely require periodic maintenance and/or replacement. The core exit temperature of a first-generation FHR will be $\sim 700^{\circ} \mathrm{C}$. The core and upper vessel internals will in thermal equilibrium. Infrared sensitive cameras can be used to measure the emitted light from these materials. The infrared light measurement will have the same measurement issues listed in the Vision subdivision. Additionally, as in-vessel structures exist above the core (e.g., upper core support plate, control blade guide tube, fuel assembly headpiece) multiple cameras will be necessary to enable viewing of the entire core outlet.

Accurate heat balance measurements require accurate thermometry. The high temperature of HTRs causes their temperature transducing elements to degrade over time. Two different thermometry techniques appear especially useful for FHR primary heat balance measurements. Both Johnson noise thermometry (JNT) and gold-platinum thermocouples offer the potential for high-stability temperature measurements at FHRs.

For high stability and precision temperature measurement, the pure element (99.999\%), non-letterdesignated $\mathrm{Au}-\mathrm{Pt}$ thermocouple can achieve precision of approximately $\pm 10 \mathrm{mK}$ at temperatures up to $1000^{\circ} \mathrm{C}$ (Ref. 76). The Au-Pt thermocouple is markedly superior to platinum-rhodium alloy thermocouples in terms of stability, homogeneity, and sensitivity (about double a Type S) and thus is a preferred option for ex-vessel temperature measurement. However, the stability and durability of mechanically rugged, metal-sheathed, mineral-insulated versions of the Au-Pt thermocouple have yet to be demonstrated sufficiently for immediate application to safety-important measurements at NPPs. In particular, the CTEs of gold and platinum are sufficiently different such that the hot junction mechanical interconnection needs to be flexible to avoid stressing the elements.

The largest concern for substituting Au-Pt thermocouples for the resistance temperature detectors (RTDs) used in LWRs is the increased electromagnetic noise vulnerability due to the smaller signal.

Thermocouple electrical signals are typically around $10 \mathrm{mV}$, whereas industrial RTD signals are at least $100 \mathrm{mV}$. Thus, both better electromagnetic shielding and higher gain, high stability amplifiers are required for thermocouple readout. No standard compensating wire currently exists for $\mathrm{Au}-\mathrm{Pt}$ thermocouples and, as the thermocouple wire is expensive, the thermocouple itself will likely extend only a few centimeters past the exterior of the insulation surrounding the primary circuit. The most likely AuPt measurement configuration in an FHR is to limit the length of the precious metal wires to a 
temperature-monitored junction box located just outside of the piping insulation. Pure copper wires would be used to extend the thermocouple measurement circuit from the junction box to the high-impedance voltage-measurement electronics located in a benign environment. The junction box temperature would be independently measured and compensated for in the liquid salt temperature measurement process. Another performance issue for Au-Pt thermocouples at FHRs is the potential measurement drift due transmutation of their constituent materials by the neutrons produced by the energetic ${ }^{16} \mathrm{~N}$ decay gamma rays impacting the beryllium in the salt. While, the neutron flux is believed to be sufficiently small as to not cause significant drift, this assumption will require validation. Thus, Au-Pt thermocouples have a significant number of technology development issues to overcome before they can be deployed as a primary heat-balance measurement method at FHRs.

The impact of the mechanically and chemically induced changes in RTD electrical resistance with time at high temperature can be avoided by instead basing the measurement on a fundamental property of temperature. Johnson noise is a first-principles representation of temperature. Johnson noise results from the vibration of the electronic field surrounding atoms as they thermally vibrate. Since temperature is merely a convenient representation of the mean kinetic energy of an atomic ensemble, measurement of these electronic vibrations yields the absolute temperature.

As a first-principles temperature measurement, Johnson noise is insensitive to the material condition of the sensor and, consequently, immune to the contamination and thermomechanical response shifts that plague thermocouples and resistance thermometers. Conventional industrial RTD elements are composed of high-purity, well-annealed platinum in order to achieve a repeatable resistance-to-temperature correlation. However, RTDs are restricted to temperatures less than $450^{\circ} \mathrm{C}$ for high-accuracy deployments. As the deployment temperature increases, the CTE mismatch between the platinum element and the support structures exerts progressively greater and greater amounts of stress onto the temperature measurement element, shifting its calibration. This is compounded by the softening of platinum at temperatures over $\sim 650^{\circ} \mathrm{C}$ and the overall increase in impurity atom mobility at higher temperatures.

JNT has three significant sources of potential measurement error that may, in general, be avoided or compensated for by proper design and implementation. However, JNTs being implemented in safety systems will need to assess the design and implementation methodologies selected to overcome the vulnerabilities. While digital implementations of JNT can compensate for some electromagnetic noise pickup, Johnson noise is a small signal phenomenon. Consequently, severe electromagnetic pickup (as would be anticipated from improperly implemented grounding or shielding) would prevent Johnson noise measurement. In addition, JNT relies on high gain $\left(\sim 10^{6}\right)$ wide-bandwidth signal amplification. If the amplifier gain shifts over time or with electronics temperature, the JNT would provide an incorrect RTD recalibration. Consequently, the amplifier gain characteristics need to be verified either online or by periodic maintenance. Finally, the intervening cabling between the sensor and the first-stage signal amplification will cause the higher frequency components of the wideband Johnson noise signal to roll off, restricting the allowed upper measurement frequency. Understanding and compensating for any shifts in the cable properties is required for a successful long-term implementation. Developing a prototype commercial-style JNT is the subject of a current DOE Advanced Small Modular Reactor (AdvSMR) project.

\subsubsection{Primary Coolant Redox Condition and Contamination}

Monitoring the redox condition of the fluoride salts is equivalent to the coolant chemistry monitoring programs of LWRs in that its primary purpose is to ensure that the correct chemical environment is maintained to minimize corrosion. It is also important to ensure that significant amounts of neutron poisons have not been introduced into the primary coolant of an FHR (and compensated for by control 
element withdrawal) as having significant amounts of neutron absorbers in the primary coolant would result in an unacceptably large positive void coefficient.

Electrochemically-based measurements are the most commonly used technique to assess the redox condition of molten fluorides. A general electrical and mechanical configuration for voltammetry based redox measurements in FLiBe was demonstrated in the MSR program. The nickel/nickel (II) couple contained in a boron nitride compartment was demonstrated to be a useful electrode for redox measurements in molten fluorides (Ref. 77). The MSR program also demonstrated in-line electrochemistry-based chemical analysis of molten fluorides (Ref. 78). Additionally, optical absorption spectroscopy was demonstrated as a means to evaluate the redox condition of dissolved species in FLiBe (Ref. 79). Overall, the general framework for redox and impurity monitoring in the FHR primary coolant has been demonstrated. However, few of the engineering details such as the system durability or sensitivity have been determined.

\subsubsection{Level}

Several different level measurement technologies are possible at FHRs. Radar level gauges, bubbler-type level gauges, and heated lance-type level measurements (Ref. 80) are all possible technologies. Radar level gauges have the advantage of not requiring contact with the primary coolant, but they have not been demonstrated for long-term usage over liquid salts. Heated lance type gauges provide only a limited precision of measurement, but are robust and proven. Overall, level gauges are reasonably well-known for FHRs deployment.

\subsubsection{Pressure}

Pressure measurements at FHRs are used primarily as a monitor of structure or component performance. For example, monitoring the primary coolant pump inlet and outlet pressure provides a measure of the pump performance. In addition, observing the change in the pressure drop across heat exchangers provides an indication of tube fouling progression. Differential pressure measurement across a flow obstruction such as a Venturi orifice is also a component of a potential flowmeter.

The most likely pressure measurement technique to be used at FHRs is classical diaphragm deflection based pressure measurement. As with LWRs, the measurement electronics would need to be separated from the primary coolant environment by the use of impulse lines. Sodium-potassium eutectic-based impulse lines are currently commercially available and appear to be technically suitable for FHR implementation. A nickel diaphragm interface between the salt and $\mathrm{NaK}$ eutectic would be suitable to minimize corrosion vulnerability of the measurement.

Gas filled, bubbler-type pressure gauges are also possible. In a bubbler pressure gauge, the gas pressure necessary to cause a small flow (bubbles) of gas into the primary coolant salt is monitored. As inert gases only have small solubility into the salt, the pressure at both ends of the gas line is approximately equal.

\subsection{ISSUES}

The major issue for FHR instrumentation is in maturing the overall concept evaluation to be able to establish specific measurement performance requirements. No fundamental instrumentation hurdles have been identified that would prevent FHR operation. Both normal operating condition performance requirements and accident progression analysis are required to establish the measurement performance requirements and the post-accident in-containment environment that needs to be ensured. Further, the instrumentation architecture, as well as the functional allocation between the operators and control system, remains to be developed. 


\subsection{TASKS}

Only a high-level instrumentation development roadmap for FHRs is currently possible, as FHR concept development remains immature. The instrumentation functional requirements are deeply intertwined with the details of the plant SSCs. Issues, such as, the required number of viewports within the vessel upper flange and the instrumentation for the salt cleanup system, have not yet been addressed. In addition, DBAs have not yet been determined. Consequently, the accident-condition instrumentation performance requirements remain to be determined.

A leading task for the instrumentation system development is thus to mature the overall AHTR and test reactor system design and the plant safety performance requirements. As part of the overall concept maturation effort, a plant I\&C system architecture specification needs to be developed. The system architecture document should include issues such as measurement redundancy and diversity and communications and the ability to maintain/modernize the components over the plant lifetime. A peer review process for both the system architecture and I\&C technology planning effort is recommended. A significant development issue is the overall complexity of the instrumentation system. A peer review process will minimize the potential to overlook development issues and design alternatives.

It is recommended that all of the advanced I\&C technology development projects within the DOE-NE AdvSMR and NEET programs be completed. Key existing projects are (1) advanced I\&C technologies for improved NPP components, for which a canned-rotor, magnetic bearing fluoride salt pump has been selected as the demonstration vehicle; (2) AdvSMR system performance modeling tool development; (3) high-temperature fission chamber development; (4) JNT; and (5) optical access into reactor primary coolant loops. Completion of the existing set of projects will address several of the key instrumentation challenges for FHRs.

Commissioning and operation of the LSTL that has already been constructed at ORNL is also recommended to provide a demonstration platform for the new, nonnuclear instrumentation. Additional liquid salt test facilities are also recommended to provide the specialized demonstration environments required to develop confidence in the reliability and longevity of newly developed instruments. Creation and validation of liquid salt instrumentation calibration facilities and protocols is another underlying development issue. While the liquid salt component and hydraulic test facilities can provide some of the testing capabilities, confirmatory measurement processes and standards will require development.

A portion of the required instrumentation development projects can already be recommended at the present level of FHR concept maturity. Additional instrumentation projects will undoubtedly arise as FHR requirements evaluation progresses. Based upon experience with developing instrumentation of similar complexity, maturing each of the required technologies to the stage of a demonstrated prototype, provided that the testing facilities are available, is anticipated to take roughly three years and cost on the order of \$2M. Creation of specific project plans is, however, recommended as the first task within each project.

Optical liquid salt measurement and diagnostic technologies development is recommended. Developing and demonstrating the technologies necessary to enable optical access into the lower reactor plenum is also recommended. However, the current AdvSMR sponsored project on optical measurement access into primary advanced reactor coolant loops has a broad scope spanning all advanced reactor classes. An FHR focused optical instrumentation project that includes additional assessment of liquid salt measurement capabilities and in-plant implementation issues is recommended. Demonstrating primary loop compatible windows (both immersed and above the pool) and mirror materials will be key development steps.

Developing a periscope for lower plenum observation would be a particularly large improvement in the capability of providing assurance of core coolability. 
Development of a gamma-based flowmeter for primary flow-loop measurements is recommended. The project will include assessing the intensity of the likely background radiation that the instrumentation will be required to withstand and modeling the instrument's capability to compensate for irregularities and instabilities in the flow distribution. The system model will both provide an assessment of the achievable measurement accuracy and support the design process.

Development of primary loop compatible online, electrochemical salt redox-condition measurement instrumentation is recommended. The instrumentation will likely follow the designs developed 40 years ago in the MSR program using a Ni/Ni(II) electrode with a boron nitride sheath. However, both the control electronics and implementation (vibration, fouling, longevity) into a power plant system will require significant design effort.

Demonstration and validation of the ultrasonic flowmeters for both liquid salt loops and reactor operating conditions is also recommended. Ultrasonic flowmeters will likely be the primary flow measurement technology for the intermediate salt loops and may, depending on the environmental tolerance of the components also be implemented on the primary coolant loop. Key tasks will include performance validation and assessment of the measurement uncertainty introduced by nonuniform flow distribution and temporal disturbances such as swirl within the flow. Development of a flow calibration test stand is a key near-term element to the flowmeter validation activity.

Developing an industrial version of the Au-Pt thermocouple and validating its response under chronic low-level neutron irradiation is also recommended. Au-Pt thermocouples would also be useful for primary heat balance measurements around the intermediate and power cycle loops, which will not have the photoneutron issue. As thermocouples are classical temperature measurement instruments, developing an FHR primary loop focused Au-Pt thermocouple is anticipated to require less than half of the resources and time of the more complex instrumentation development projects. 


\section{OPERATIONS AND MAINTENANCE}

\subsection{INTRODUCTION}

O\&M will be conceptually similar between FHRs and other classes of NPPs. The particular equipment used to perform maintenance within containment at FHRs, however, will be distinctive to the reactor class. O\&M is important to consider from the outset of the design process as the operating experience of LWRs has demonstrated that the duration and frequency of maintenance outages is strongly impacted by the plant design and that even plant lifetime can be adversely impacted by the expense and difficulty of component replacement. Also, some plant operational aspects (e.g., the ability to deeply, efficiently, and rapidly load follow) have become more important over time as demand has become more strongly time varying with the introduction of progressively larger amounts of non-dispatchable power onto the grid. Additionally, the current plan for the reactor vessel to remain above the melting point of the primary coolant salt even during outages makes access to component surfaces more challenging for periodic inspection. Consequently, more advanced technologies are required to perform some periodic surveys. For example, checking for heat exchanger tube wall thinning either requires instrumentation compatible with immersion in molten salt or technology to isolate, drain, and cool the heat exchangers with reasonable ease.

NPP maintenance is a broad topic that includes establishing the remaining useful life of SSCs through surveillance, inspections, diagnostics, and prognostics. The purpose for early-phase O\&M planning is to facilitate incorporation of design features that minimize the amount of time and effort required to perform both routine maintenance and component replacement and thereby minimize the LCOE. NPPs' operating history has repeatedly demonstrated that safety, plant availability, and operating costs can be significantly impacted by difficulties with inspection, routine maintenance, repairs, and component replacement. For example, the difficulty in removing the vessel head insulation contributed to the Davis-Besse undetected vessel head corrosion incident (Ref. 81) and the infeasibility of compact heat exchanger inspection makes their inclusion as part of the primary coolant containment more difficult. Conversely, an FHR's thin containment wall, resulting from the lack of internal pressurization sources, makes major component replacement potentially significantly less expensive. As the recent decision to retire Crystal River Unit 3 early, due to the expense of repairing its thick containment as part of SG replacement illustrates (Ref. 82), design for cost minimized repair and replacement is important to long-term economic viability.

Many aspects of O\&M have yet to be considered at FHRs and thus further concept development remains an underlying supporting task. O\&M planning is especially important during concept development as the implications of design choices made in the near-term extend decades into the future. An FHR's lifetime is likely to be roughly a century as lighter weight components and less massive containment facilitate periodic replacement. The buried piping and tritium leakage issues that affect LWRs today are direct consequences of design choices made decades ago. Additionally, the communication network hardware to support O\&M has historically been deeply embedded into the plant structures during construction. Upgrading cabling that is buried within fireproofing and routed through containment penetrations is expensive and time consuming. The limited data communications and storage designed into early generation NPPs prevents applying modern, data intensive diagnostic techniques such as power signature analysis to predict remaining useful life resulting in lower reliability and excessive on-going maintenance costs.

O\&M planning includes the human aspects of NPP operation. Issues such as designing the humanmachine interface so that the plant operators are always aware of the current plant status and properly integrating automation into the plant design to minimize the required staff size are important to plant licensability and operating costs. Further, human performance needs to be considered in the plant layout. 
As full breathing gear and anti-contamination clothing will be required in the inert atmosphere containment of an FHR, mechanically complex tasks within containment needs to be minimized. Thus, the plant design should emphasize locating measurement electronics outside of containment within shielded enclosures that are accessible to maintenance staff during NO. Any electronics that are necessary within containment, in addition to being implemented in a radiation and temperature tolerant format, will likely be periodically replaced during maintenance outages. Designing the electronics to be replaced as a plug-in unit (potentially automatically) would ease the maintenance burden.

The chapter begins with a description of performance objectives for O\&M and then discusses how fulfilling the requirements can be analyzed and documented. The currently identified FHR specific O\&M issues are then listed and followed by a series of tasks recommended to resolve the identified issues. The technologies described reflect the differences between FHR and LWR classes such as the increased incentive for automation within containment at FHRs due to the inert atmosphere and potential for beryllium exposure and the different functional allocation between humans and automated systems due to the anticipated absence of rapidly progressing accidents at FHRs. The focus of the recommended developments is on distinctive FHR O\&M. Common O\&M issues are not addressed in the roadmap and the SSCs themselves are addressed in specific technology chapters (e.g., pumps are addressed in Chapter 8 of this roadmap). Also, the instrumentation used to support O\&M is described in Chapter 9.

\subsection{PERFORMANCE REQUIREMENTS}

O\&M performance requirements arise from a combination of the physical characteristics of the plant and the regulatory framework that must be complied with to obtain and maintain a license to operate the plant. The basis for the O\&M aspects of the regulatory framework is to provide reasonable assurance that the plant staff, as well as its SSCs, remain capable of correctly performing their functions to avoid accidents and properly respond to any accidents that occur in a timely manner to mitigate the accident consequences. Additionally, the exposure of the plant staff and the public to unnecessary radiation is restricted by regulation.

An FHR's physical characteristics and thus its accident initiating events, mitigation systems, containment layers, and consequent emergency procedures are significantly different from those of LWRs.

Understanding initiating events for and the progression of potential FHR accidents is thus necessary to perform a detailed O\&M requirements evaluation. At present, only high-level O\&M performance requirements can be provided.

The organizing principle of the FHR's O\&M is to maximize the net economic benefit of owning and safely operating an FHR. Maximizing the economic benefit includes considerations such as developing the technology to support repairing and replacing components as they wear out over the plant's lifetime and analyzing the plant operational requirements to enable minimizing staffing costs by design. For example, given the slow accident progressions and strong passive safety characteristics of FHRs, can the plant be designed so that the maintenance staff also serves as the normal condition operators with additional staff only brought on-site only as needed? Additionally, what features need to be incorporated into FHR designs so that their below grade location can be most effectively exploited to minimize security costs?

Development of a concept-of-operations plan will be a significant portion of the O\&M planning process. The concept of operations subdivides an FHR's operational goals into specific tasks and explains how they are intended to be accomplished, including the technology infrastructure necessary to achieve the goals. Moreover, a concept-of-operations framework provides a systematic, function-based approach to evaluating the adequacy and completeness of the design of complex systems (Ref. 83). As such, a concept-of-operations document plays a significant role in NRC review of NPPs (Ref. 84). Further, 
creating a baseline concept of operations document supports concept development by providing a means to evaluate the impact of design changes on plant operations. For NO, the concept of operations describes how personnel will interact with the plant systems and components to accomplish their main tasks through normal plant modes such as start-up, power level transitions, full power operation, and shutdown. The concept of operations also includes the functions required for maintenance, refueling, and to respond to accident conditions. Overall, the concept of operations provides the technical basis for ensuring that tasks can be safely and effectively performed.

\subsection{ISSUES}

\subsubsection{Concept Immaturity}

Some FHR support systems have only received minimal to no design effort (coolant cleanup system, cover gas cleanup system, redox control system), and at this point, only modest design efforts have been devoted to even those systems that have undergone preliminary layout (e.g., control rod drives and startup heating system). Hence, several design issues have not yet been resolved, and additional challenges may yet be identified. The impact of known FHR properties has also not yet been fully reflected in maintenance planning. All materials being removed from FHR containment will have a surface contamination of beryllium fluoride, as well as the potential radionuclide contamination issues familiar to other reactors. Beryllium fluoride decontamination procedures will thus need to be incorporated into maintenance planning.

The impact of the environmental conditions within containment on I\&C hardware has not yet been fully assessed. Implementation of digital electronics within containment at LWRs is typically limited by their post-accident monitoring environmental tolerance requirements. The environmental conditions within containment following DBAs at FHRs have not been assessed as of yet, but do not appear to be nearly as harsh as those for LWRs. However, the normal operating condition radiation environment at FHRs will have significantly more gamma dose due mostly to the short half-life isotopes formed by neutron interactions with fluorine. The ability to use modern electronics within containment would significantly simplify the control wiring and ease the implementation of online diagnostics. For example, impressing a digital control signal onto the power bus for the control rod drive motors would avoid the necessity of point-to-point wiring to each motor. However, the radiation and/or temperature environment above the vessel may be too harsh to permit digital electronics directly within the motor housings. The current, very low fidelity estimates do not indicate that a radiation environment harmful to electronics is likely to exist during NO. However, electronics layout should await the results of initial radiation environment simulation. Overall, the reactor concept and technology trade studies require continued advancement.

The technical basis for prognostics and health monitoring and/or equipment condition assessment has not yet been developed. For example, how much intermediate salt leakage into the primary system corresponds to unacceptable heat exchanger tube leakage? What measurements of a control blade motor/drive indicate unacceptable wear? The technical basis for component monitoring will arise from a combination of a detailed performance-requirements evaluation and component endurance testing. Component testing is a sufficient and major portion of FHR development and is addressed in a standalone chapter.

\subsubsection{Incorporating Operations and Maintenance into Concept Development}

A key lesson learned from LWRs is to consider long-term issues such as component replacement, periodic maintenance and inspection, and long-term degradation indicators early in the plant design phase. The nuclear power industry has already established mechanisms and institutions (e.g., the Institute for Nuclear Power Operations and the World Association of Nuclear Operators) for sharing best practices 
in NPP O\&M. As FHR concept development progresses it will, to a progressively larger extent, incorporate the lessons learned by LWRs into the conceptual designs. FHRs, however, are a new reactor class with distinct accident sequences, materials, fuels, instrumentation, and plant layouts from LWRs. Thus, the functions of FHR's O\&M will need to be independently evaluated and resources developed to accomplish the functions.

The technical basis for human performance at FHRs has not yet been developed. Automation will inevitably perform a larger role at FHRs than LWRs due to the combination of the lower safety impact of incorrect actions due to passive safety characteristics, the inert environment within FHR containment (along with toxic beryllium fluoride deposited on surfaces), and the progressive advancement of automated complex control systems. Maintenance activities performed in breathing gear and anticontamination clothing are expensive. Hence, significant consideration needs to be given to minimizing the amount of labor that needs to be performed in containment. Additionally, minimizing the size of pressurized containment has been key to limiting construction costs of LWRs. Maintaining adequate space to efficiently perform maintenance during periodic shutdowns, however, competes directly against containment size minimization. Avoiding too small of a containment to perform maintenance in a first of a kind reactor was a key lesson learned from Fort Saint Vrain. As the cost drivers for low-pressure containment are significantly different from high-pressure containment, an evaluation of specific maintenance tasks will need to be performed as input to determining optimal FHR containment size.

Staffing is the single largest expense incurred in operating NPPs. The basis for staffing levels is to perform required functions over the full plant lifecycle including during potential accidents. The functional allocation between automated systems and plant staff will be different for FHRs than LWRs due to the differences in plant characteristics. A key aspect of FHR concept development, yet to be performed, is the creation of a plant functional assessment, which will serve as input to a concept-ofoperations plan. Development of the accident response portion of the functional assessment will need to await development of an FHR specific set of BDBEs, DBEs and AOOs. The concept-of-operations plan will become progressively more extensive and detailed as FHR concepts are matured.

\subsubsection{Incorporating Plant Security Into Concept Development}

The largest NPP staffing costs are frequently for security. FHRs inherently incorporate a number of security-by-design features. The additional security provided by the plant structures and reactor characteristics will inevitably be reflected in the staffing level required to respond to design basis threats. In contrast to LWRs, the full passive safety of FHRs avoids reliance on control room actions, grid interconnections, or powered equipment to perform safe shutdown or decay heat removal. The practical necessity to locate the reactor core and used fuel decay pool below grade to comply with the NRC directive on resistance to aircraft impact (10CFR50.150) significantly restricts access to in-containment systems. Additionally, used fuel storage within deep, local dry wells substantially mitigates used fuel vulnerability to external assaults. Ease of access for maintenance, however, competes against access restrictions for security. FHR plant security, however, can be enhanced by inclusion of design features to increase the difficulty for an adversary to destroy or disable plant safety structures. For example, simply having heavy shielding blocks over the top of the reactor containment (largely to shield upward gamma flux) would also provide an additional security barrier.

\subsubsection{Accommodating Time Varying Demand}

With the mandated introduction of progressively larger amounts of non-dispatchable power onto the grid, the grid is becoming increasingly less stable and more deeply time variant. Modern LWRs are designed to have maneuvering capabilities, and in France operate in load-following mode participating in frequency control with typical rates of change of 3-5\% of rated power per minute. LWRs, however, are dependent 
upon a generally stable, reliable grid. The Northeast power blackout of 2003 was exacerbated by the loss of offsite power accident initiation potential at LWRs. Nine US and seven Canadian NPPs tripped as a consequence of the outage (Ref. 85). Further, GDC 17 "Electric power systems" of 10CFR50 Appendix A requires a dual connection to a sufficiently reliable grid for plant operation.

In general, the objective for any power generator is to be the lowest cost power producer and then to maximize output. However, in some instances due to the lack of synchronicity of non-dispatchable power with loads (especially during Spring and Autumn nights when demand is at a minimum and winds tend to be at a maximum) wholesale power prices can become below the cost of production or even negative.

Beyond scheduling seasonal refueling and maintenance outages, it will thus be advantageous for FHRs to be able to rapidly transition from generation to motoring mode without damaging components or overburdening their heat sinks while retaining the capability to quickly return to power delivery.

FHRs are anticipated to have a higher degree of power maneuverability than LWRs due to their high degree of passive safety and lack of requirement for highly stable power for their primary coolant pumps. The primary coolant pumps at FHRs will likely be operated on pulse modulated DC power to provide variable speed control. Solid-state DC power supplies are tolerant of significant voltage and frequency variance in their feed power. The ability to passively reject decay heat indefinitely without connection to the grid would essentially obviate GDC 17 for FHRs, and FHRs are anticipated to be able to help restart a black grid. Moreover, an FHR connected to a supercritical steam cycle is anticipated to have more rapid power maneuvering capabilities than a typical NPP steam Rankine cycle. In all operating conditions, an FHR's fuel remains far from damaging thermal or heat flux conditions. Thus, the limitations to the rate of power maneuvering in FHRs lie outside of the core. An FHR's variable speed primary pumps (combined with negative thermal reactivity feedback) would provide rapid power maneuverability over a limited control range. Larger rapid transitions are intended to be managed by combining reactivity and steam flow control. A supercritical steam cycle allows easier, deeper cycling than Rankine cycles as maintaining control of the SG water level in Rankine cycles has historically been a response limiting control problem. However, the power maneuvering capabilities of FHRs have yet to be thoroughly investigated. Overall, several different power cycles, all with different capabilities, are possible for first-generation FHRs. However, the unresolved development issues for FHRs are within containment not in the power cycle. Consequently, evaluating power-maneuvering capabilities will remain a lower priority development item.

\subsubsection{Access to Structures and Components for Inspection}

Reliability is a critical metric for the experimental FHR development program as establishing overall technology credibility is a key hurdle to progressing from test loop, to larger scale demonstrations, to test reactor, to first-generation power plant. Surveillance and inspection are a central part of enabling plant availability as observing component and structure degradation both enable remaining useful lifetime prediction and provide the information necessary to improve future designs. The properties of all components will degrade with time at temperature, and both online and offline inspection and diagnostics will be required. The inspection technologies for FHRs can draw from those developed for LWRs, but the chemical and physical environment differences between the two reactor classes will necessitate a high degree of technological differences. For example, creep is a primary degradation mechanism for HTR vessels, but is not a significant issue at LWRs. The advance of networking technology since most LWRs were constructed will also impact how common inspection technologies are implemented. Power signature analysis at FHRs will closely resemble that developed for LWRs with the notable exception of the potential to integrate the signal wiring into the plant hardware. Most LWRs have significant bandwidth limitations to their online measurements due to the time period of their original instrumentation cabling deployment. FHRs will include ubiquitous high-bandwidth communications to enable extensive online diagnostics to be integrated into NO. 
Visual inspection from above the surface of the salt will be a key technology to assess the condition of salt-wetted components and structures. The low-pressure primary loop will enable observation from above using inert gas filled standpipes to provide optical access. The building block technologies for visual inspection within the salt are already available. Precious metal mirrors and diamond windows are compatible with the primary coolant. The remaining technology challenge is thus to develop inspection tools based upon the building block technologies and to demonstrate their efficacy in monitoring the condition of salt-wetted materials. Diamond windows are also sufficiently expensive that developing alternative, fluoride salt compatible windows, with significant radiation tolerance would be beneficial.

Establishing technical adequacy of protocols for visual inspection of in-vessel structures remains to be performed. For example, visual methods will need to be established to assess whether small surface cracks that develop in service in fluoride salt submerged welds are likely to lead to failure in the nearterm. GDC 30 of 10CFR50 Appendix A requires a high confidence in the overall performance of the reactor coolant boundary. As with other low-pressure reactors, FHRs will use guard vessels as a backup to the primary vessel to limit the safety significance of leaks in the reactor vessel. On the other hand, failure of reactor vessel internals (e.g., mount points for the lower core support plate) would be part of an accident sequence that could lead to loss of core coolability. Thus, high quality materials, design, inspection, and surveillance of the vessel and its internals are all necessary.

FHR primary piping will require heaters and thermal insulation layers to keep the salt liquid during initial start-up and over the course of long outages. Exterior inspection would require removing the outer layers to check for degradation of the coolant boundary. GDC 30 requires that means be identified to detect leaks in the primary coolant boundary. A change in the amount of radionuclides in the gas layer between the primary and guard vessel would provide that indication. However, neither FHR vessel nor primary loop inspection requirements have yet been established. The safety significance of leaks in the primary coolant boundary of FHRs is significantly lower than that of LWRs as loss of pressure does not challenge core coolability. Also, the concept of leakage of a high melt point liquid is not the same as for water. Fluoride salts will solidify as they penetrate into cooler layers of the insulation surrounding the vessel auto-plugging the vessel leak.

Other inspections and maintenance processes will need to be performed with components drained of salt at lower temperatures. A key feature of the AHTR design is the near top access of the primary piping into the reactor vessel. In order to perform maintenance or intensive inspection, the primary loops can be drained and cooled. Both the maintenance cooling system and DRACS loops would remain functional, so the reactor vessel could remain hot and filled with both coolant and fuel. Note the AHTR design currently does not include isolation valves in the primary loops, so a single loop cannot be independently drained. Following shutdown, in order to drain the primary loops to perform maintenance on the pump, piping, and/or heat exchanger, low-point valves will need to be opened and the salt allowed to drain. Minimizing the number of low points within the primary loop will be useful to minimize the complexity of the draining process.

Valves and flanges are central to being able to drain, open, and/or remove components for inspection or maintenance. The MSR program did not achieve an adequate pipe closure mechanical valve. Chapter 8 of this roadmap more extensively discusses valve development and testing issues. Gas-operated valves with an extended valve stem (to provide separation from the high salt temperature) appear to be especially useful as gas pressure can be used to prevent the salt from moving up the valve stem. Using a cannedrotor valve drive is another option. Freeze plugs on piping that extends below the primary loops are another potential approach to enable draining the piping. However, freeze plugs for large diameter pipes have practical challenges such as the stress imparted to the piping walls due to expansion upon melting. Also, the combination of high heat capacity, good natural circulation characteristics, and large phase change energy of fluoride salts makes large size freeze plugs technologically challenging. Mechanically 
advantaged freeze valves in which the melting of the freeze plug releases a mechanical element (flapper or plug) are one potential alternative configuration. Another potential alternative would be braze closures, which, while mechanically reliable, requiring rebrazing following each use. Overall, however, designing and demonstrating a reliable fluoride salt valve remains to be accomplished.

Hydraulic components themselves can either be attached to the primary piping via flanges or welding. As the primary loop piping will be thin-walled, welding is a reasonable possibility. However, mechanical flanges, if possible, would decrease the maintenance effort required. The largest technology challenges for mechanical flanges with fluoride salt piping stem from the large temperature differences across which it is necessary to maintain proper compression on the flange gasket and the limited compression of the available salt and temperature compatible gasket materials. Flange nuts will likely be tightened initially at near room temperature. The high operating temperature means that the interior surfaces of the flange will expand upon heat-up. The temperature of the exterior of the flange will require control and careful specification of the bolting system to maintain proper loading during heat-up. In addition, due to limited gasket compliance the facing surfaces of the flange will require high precision alignment and flatness. A useful technique to minimize the precision required is to use pressurized gas backing of the primary gasket. The pressurized gas prevents small amounts of salt from leaking past the primary gasket. Overall, fluoride salt piping joints are significantly less mature and somewhat more complex than their water counterparts, and effort needs to be expended to developed reasonable joints.

\subsection{TASKS}

\subsubsection{Mature Conceptual Design}

Developing O\&M procedures is dependent upon having all of the required components and systems included in the conceptual design and upon developing the necessary FHR specific O\&M support technologies. Continuing to advance the overall AHTR concept maturity is key to understanding the plant normal and accident condition behavior.

\subsubsection{Safety and Licensing Development}

This task will involve developing and demonstrating online surveillance and periodic offline inspection to provide assurance that the SSCs remain capable of performing their safety functions. This task will depend upon an initial evaluation of the accident initiators and progression to establish the safety significance of the reactor SSCs. This task needs to be closely integrated into the component-testing program. FHR SSC inspections both prior to and during operation will follow existing QA processes and inspection procedures with some adaptation to the higher temperatures (e.g., higher temperature strain gauges and mounting procedures will be required to monitor vessel creep). However, some custom technologies such as under-salt visual inspection and salt contamination monitoring are anticipated to be required. A distinctive aspect of salt contamination monitoring will be ensuring that large amounts of neutron absorbers have not accumulated in the salt (from leaching hafnium from the control blades or a leak developing in the secondary shutdown poison salt injectors) so that the reactor does not develop an unacceptably large positive reactivity void coefficient.

\subsubsection{Develop Concept of Operations}

This task will initially perform a functional evaluation of the AHTR's O\&M over the plant's life cycle. Methods, technologies, and resources to perform the required functions will then be developed and allocated. The functional evaluation will include both necessary safety response actions and routine procedures. An initial functional allocation between automation and plant staff will be performed, and a 
high-level evaluation of means to minimize the impact of maintenance on plant availability through scheduling and prognostics will then be conducted.

\subsubsection{Demonstrate Visual Inspection Technology}

The current plan for the AHTR is to keep the vessel hot and filled with salt throughout its operational life. Hence in-vessel inspections will need to be below the salt surface. Visual inspection is anticipated to be the primary technology adopted. Advanced visual mapping techniques such as optical coherence tomography will likely be used to measure any dimensional changes (due to corrosion, displacement, or creep) over time. The optical access technology for inspections will be similar to that developed for the process control instrumentation. Inspection technology and maintenance tools will be demonstrated using the component testing loops. The developed instrumentation will then be integrated into the overall plant layout as part of the concept development task.

\subsubsection{Develop Surveillance and Testing Methods of Control Mechanisms}

The primary online reactor control mechanisms are the control blades and the primary coolant pump. This task will evaluate and demonstrate technologies necessary to assess degradation of the control mechanisms. The primary coolant pump closely resembles any large, cantilevered, centrifugal pump and as such its diagnostic measurements (e.g., electrical signature evaluation and motor temperature monitoring) are not unique to FHRs. Also, the control blade drive systems are basic rack-and-pinion drives with added mechanical features such as spring loading the pinion gear to release upon loss of power. None of the mechanical features are distinctive to FHRs. However, the reliance upon a CFC $\mathrm{SiC} / \mathrm{SiC}$ rack is distinctive and the overall system design will require validation. Typical functional demonstrations for control blade drives include jogging the control signal and observing the mechanical and neutronic response. As the AHTR core includes 252 control blades and both the temperature and heat transfer characteristics of the core remain far from any fuel damage limits, full insertion of any individual control blade will only result in a small reactivity change. Hence, on line blade drop testing appears to be possible. Demonstrating that each individual blade does indeed fall into the core upon loss of power to its pinion holding solenoid provides strong evidence that the fuel has not warped sufficiently to preclude rapid shutdown. Performing blade-drop testing online would also avoid the necessity of testing each of the drives during maintenance outages. Further, online demonstration of the blade dropping fulfills the GDC 21 requirement of in-service testability of a critical element of the reactor protection system. However, online drop testing has not received analytical scrutiny nor been demonstrated experimentally. Both evaluation and experimental demonstration will be required as part of the control mechanism development and validation process.

\subsubsection{Demonstrate Testing Methods for Secondary Shutdown Mechanisms}

GDC 22 requires a diverse reactor protection system to prevent fuel damage. Fuel is not the most vulnerable component in an FHR. An FHR appropriate GDC will likely specify avoiding unacceptable vessel creep. Vessel creep is not a rapid phenomenon. Hence, the required response time of the secondary shutdown mechanism is not yet known. The AHTR's secondary shutdown mechanism generally consists of poison salt accumulators located in the vessel downcomer, which upon melting of the braze alloy holding their flapper closed inject their load of poison salt into the reactor inlet plenum. The layout for the secondary shutdown salt injectors is described in ORNL/TM-2012/320 (Ref. 1). Monitoring of the secondary shutdown mechanisms will likely consist of (1) monitoring the pressure in the accumulator gas feed lines, (2) monitoring the functionality of the manual actuation power supplies, (3) monitoring the integrity of the electrical heating wires for manual activation, and (4) checking the melt point of the braze alloy batch used to seal the accumulator lid prior to installation. Additionally, the performance of the 
poison salt injectors will need to be demonstrated using the component test loops and performing hydraulic and neutronic modeling and simulation of the salt injection process.

\subsubsection{Demonstrate Operation of Salt Cleanup System}

The general characteristics of the salt cleanup system are described in Chapter 7 of this roadmap. The performance of the salt cleanup system will need to be validated. As only high-level system requirements and a basic process description has yet been developed, creating performance demonstration and maintenance and inspection plans will need to await conceptual design. A key measurement is, however, already known. The liquid bismuth used in the countercurrent liquid-liquid extraction is not compatible with nickel-based alloys. Hence high confidence that the bismuth has been separated from the coolant salt prior to the salt's return to service is required. The quantity of bismuth dissolved in the salt will most likely be measured using optical absorption spectroscopy. Demonstrations of the efficacy of the salt cleanup system can be performed using nonradioactive, non-isotopically selected materials in a FLiBe test facility. A key operational issue remaining to be resolved is integration into the primary coolant loop.

\subsubsection{Demonstrate Operation of Refueling System Monitoring}

The AHTR refueling process is a mechanical transfer process performed using remote-handling equipment under adverse environmental conditions. The AHTR is intended to be refueled hot using standard mechanical components with all of its drive mechanisms located above the salt surface. ORNL/TM-2012/292 (Ref. 66) describes the planned operation of the refueling system.

All of the individual mechanical processes involved use well-known technology. However, the instrumentation system, the virtual reality process visualization to enable the operators to maintain process awareness, and the salt-wetted materials are at lower TRLs. Further, the overall refueling system design is not yet mature enough to have high confidence in any particular component or step. Details such as the dynamic loads on the fuel assemblies and thus the transfer mechanisms due to the coolant flows have not yet been established. Additionally, as the refueling operation involves a series of interrelated steps, the overall system design will require validation.

The most significant instrument component development required to enable the intended optically guided process is the set of telescope optics necessary to observe the mechanical processes. The leading controls challenge for the refueling process is implementing the vision-based feedback into the control algorithm. The design intent is for the plant operators to have an oversight role in the fuel transfer process and be able to override any system actions if incorrect function is observed. In order to allow the operators to maintain situational awareness, a virtual reality-type display of the fuel motion will also need to be developed.

The operators need to maintain situational awareness in order to be able to respond to system malfunctions. As monitoring multiple cameras with multiple different partial views of the refueling process would be complex and confusing, a virtual reality reconstruction of the in-vessel process will need to be provided to improve the ability of the operators to oversee the interrelated series of refueling motions. The virtual reality representation of the fuel motion can also be used in advance to allow plant staff to confirm that the planned control moves match the refueling plan. Since the robots are moving in a structured environment, a robot's current position can be superimposed on a virtual image of the reactor, indicating the robot's desired final location. This process will enable verifying the trajectory taken by the robot and taking any needed corrective actions. 


\section{DESIGN TOOLS AND METHODS}

\subsection{OVERVIEW}

The purpose for this chapter is to describe the modeling and simulation tools and methods intended for use in developing and evaluating a first-generation FHR. The modeling codes are intended to support both design and licensing of both test and commercial power reactors. The data obtained from test reactors will help to validate the modeling tools for use in design and licensing of the commercial-scale systems. Planned code validation experiments are conceptually described in this chapter. Significant portions of the AHTR's SSCs have yet to receive more than a cursory design effort and thus details about code validation requirements are not yet available. Once a functionally complete design has been developed and a set of DBAs have been selected, a more detailed code validation program plan will be required to provide confident cost and schedule estimates.

This roadmap chapter is subdivided into two main areas thermal-hydraulic and reactor physics modeling. The modeling tools described in this chapter are limited to distinctive FHR issues. Mechanical and structural design tools are not included in this chapter, as they do not differ substantially for an FHR from any other large civil structure. Additionally, reactor system engineering tools for non-salt systems are not addressed in this chapter as FHRs are anticipated to rely upon very similar systems engineering and requirements tracking tools as other NPPs. This chapter will need to be updated as the development progresses to include additional tools such as fuel performance evaluation and plant security modeling. While both the reactor physics and the thermal and hydraulic modeling tools described in this chapter are intended to be useful for modeling BDBEs, severe accident modeling is addressed primarily in Chapter 6 of this roadmap.

\subsection{THERMAL AND HYDRAULIC MODELING}

\subsubsection{Purpose and Overview}

Thermal and hydraulic modeling tools serve two purposes in a new reactor design. First, tools are needed to execute analyses that provide confidence in the design's ability to operate safely in order to obtain a DC. These analyses include assessments of the ability to safely remove the heat generated by the core during operation and shutdown conditions and assessments of thermal hydraulic impacts on overall system integrity. Second, analyses are performed to optimize the capital cost and performance of major systems. These analyses consider thermal hydraulic design impacts on plant economic performance such as pumping requirements, sizing of heat exchangers, sizing of system pressure boundaries and coolant inventory requirements.

DC requires demonstration of compliance of a particular design with relevant GDCs. For LWRs these GDCs are defined in 10CFR50 Appendix A. While ANS 54.1 updates the GDCs for SFRs, no such standard currently exists for salt-cooled reactors, but an initial proposal of appropriate GDCs has been developed as part of the FHR program (Ref. 9). These recommendations closely follow the GDCs of 10CFR50 Appendix A with reactor class specific modifications that identify requirements unique to the FHR.

The primary goal of the thermal and hydraulic model development and validation program is to ensure predictions can be made with sufficient fidelity to demonstrate compliance with the relevant GDCs. GDC 10 requires that the reactor core, along with its associated coolant and control systems, be designed with appropriate margin to ensure that fuel design limits are not exceeded. GDC 15 requires the reactor primary cooling system to be designed with sufficient design margin to ensure that the design conditions of the primary reactor coolant boundary are not exceeded during any condition of NO. GDC 34 requires a 
residual heat removal system that includes means to reliably transfer reactor residual heat to an ultimate heat sink under shutdown conditions. GDC 34 also requires that suitable redundancy, independence, and diversity in components and features be provided to protect against common cause failures. GDC 35 requires establishment of emergency core cooling systems, which are likely not needed as a consequence of the fuel form and system design features of the FHR. GDC 38 requires a system to remove heat from the reactor containment during $\mathrm{NO}$ and postulated accidents.

The FHR thermal hydraulic design shares many characteristics with SFRs and other characteristics with HTGRs. As in SFRs, the system operates at low pressure with a high boiling margin that limits opportunities for rapidly evolving hydraulic events and a system design that limits opportunities for significant loss of coolant events. As in HTGRs, the FHR has a substantial heat capacity tied to substantial solid graphite components, which limits opportunities for rapidly evolving thermal events. However, FHRs do have some unique thermal hydraulic features resulting from selection of fuel form and preferred system design, which must be evaluated to ensure compliance with the GDCs. The FHR does operate with sufficient power to exceed thermal limits of the fuel and structural components, so adequate modeling fidelity to ensure performance of the reactor coolant system design is required. The coupling of core thermal hydraulic conditions with reactor physics assessments is also important since the value and sign of the thermal feedback coefficient varies with specific core conditions.

Chapter 5 of NUREG 800 provides specific guidance on specific analyses required to ensure that the relevant GDCs are satisfied in LWR designs. While the specific analyses do not universally translate to FHRs, they do provide general guidance on the fidelity expectations for analyses of system design.

\subsubsection{Methodology}

A thermal hydraulics methodology hierarchy is needed to enable the design team to execute the thermal hydraulic assessments with the level of fidelity needed to demonstrate compliance with the GDCs. A thermal hydraulic design baseline has not yet been established for the FHR, and thermal hydraulic analyses have been limited to conceptual scoping evaluations. As a consequence, it is difficult to make a specific a priori determination of fidelity requirements for GDC assessments and design optimization analyses. Preliminary selections have been made based on flexibility of the code or methodology for application to various coolant types, prior experience applying the code to advanced reactors including HTGRs and SFRs, and current availability of the code, code developers and user support.

A preanalysis code hierarchy is defined in Table 4, with anticipated applications shown for both GDC and design optimization assessments. The table includes thermal hydraulic codes and other codes from other physics domains that may be needed to address coupled multiphysics phenomena and notes the existence of coupling interfaces where relevant. Reactor physics codes are not included and are treated separately below. The table does not include hand calculation assessments, which might be used to extend code results to assessments of additional phenomena, such as estimation of source amplitudes for fluid structure interactions. 
Table 4. Preliminary thermal hydraulics assessment code hierarchy

\begin{tabular}{|c|c|c|c|}
\hline Code & Key capabilities & $\begin{array}{c}\text { Applications and GDC } \\
\text { assessments }\end{array}$ & $\begin{array}{l}\text { Applications and design } \\
\text { optimization studies }\end{array}$ \\
\hline TRACE & $\begin{array}{l}\text { System-scale forced and } \\
\text { free convection heat } \\
\text { transfer, forced and free } \\
\text { convection pressure drops, } \\
\text { forced to free convection } \\
\text { transition, heat loss to } \\
\text { ground/building, stored } \\
\text { energy, residual heat } \\
\text { removal, reactivity } \\
\text { coupling, and system } \\
\text { feedback }\end{array}$ & $\begin{array}{l}\text { Assessments supporting all } \\
\text { fluid system design, core } \\
\text { design, and residual heat } \\
\text { removal system design } \\
\text { GDCs. }\end{array}$ & System level optimization. \\
\hline COMSOL & $\begin{array}{l}\text { Multiphysics, multiscale } \\
\text { analyses of phenomena } \\
\text { such as fluid structure } \\
\text { interaction. } \\
\text { Multidimensional } \\
\text { capabilities for reasonably } \\
\text { sized components or } \\
\text { subassemblies }\end{array}$ & $\begin{array}{l}\text { Supporting analyses, as } \\
\text { required. Potential } \\
\text { applications include fuel } \\
\text { assembly temperature field } \\
\text { assessments. }\end{array}$ & $\begin{array}{l}\text { Fuel subassembly or fuel } \\
\text { element level design } \\
\text { optimization. }\end{array}$ \\
\hline STAR-CCM+ & $\begin{array}{l}\text { 3-D CFD and conjugate } \\
\text { heat transfer analyses using } \\
\text { steady or unsteady } \\
\text { Reynolds-averaged Navier- } \\
\text { Stokes methods }\end{array}$ & $\begin{array}{l}\text { Supporting analyses, as } \\
\text { required. Potential } \\
\text { applications include thermal } \\
\text { striping and stratification } \\
\text { analyses, free-convection } \\
\text { system performance } \\
\text { analyses. }\end{array}$ & $\begin{array}{l}\text { Multicomponent design } \\
\text { optimization, including } \\
\text { integrated multi-fuel } \\
\text { element assessments, inlet } \\
\text { or outlet plena, heat } \\
\text { exchange components or } \\
\text { residual heat removal } \\
\text { system components. }\end{array}$ \\
\hline STAR-CCM+ / ABAQUS & $\begin{array}{l}\text { 3-D CFD capabilities } \\
\text { coupled to 3-D finite } \\
\text { element method structural } \\
\text { mechanics }\end{array}$ & $\begin{array}{l}\text { Supporting analyses, as } \\
\text { required. Potential } \\
\text { applications include thermal } \\
\text { expansion, thermal } \\
\text { cycling/fatigue, and fluid } \\
\text { structure interaction. }\end{array}$ & $\begin{array}{l}\text { Supporting analyses, as } \\
\text { required. Potential } \\
\text { applications include thermal } \\
\text { expansion, thermal } \\
\text { cycling/fatigue, and fluid } \\
\text { structure interaction. }\end{array}$ \\
\hline Nek5000 & $\begin{array}{l}\text { High-fidelity 3-D CFD and } \\
\text { conjugate heat transfer } \\
\text { analyses using large-eddy } \\
\text { simulation or direct } \\
\text { numerical simulation } \\
\text { methods }\end{array}$ & $\begin{array}{l}\text { Supporting analyses, as } \\
\text { required. Potential } \\
\text { applications include thermal } \\
\text { striping in complex } \\
\text { turbulence fields, turbulent } \\
\text { flow stability and natural } \\
\text { convection stability. }\end{array}$ & $\begin{array}{l}\text { Supporting analyses, as } \\
\text { required. Potential } \\
\text { applications include } \\
\text { benchmarking of lower } \\
\text { fidelity methods, turbulent } \\
\text { flow stability, and natural } \\
\text { convection stability. }\end{array}$ \\
\hline Nek5000 / Diablo & $\begin{array}{l}\text { High-fidelity 3-D CFD } \\
\text { coupled to high-fidelity }\end{array}$ & $\begin{array}{l}\text { Supporting analyses, as } \\
\text { required. Potential } \\
\text { applications include fluid } \\
\text { structure interaction in } \\
\text { complex structural } \\
\text { geometries or turbulence } \\
\text { fields. }\end{array}$ & $\begin{array}{l}\text { Supporting analyses, as } \\
\text { required. Potential } \\
\text { applications include fluid } \\
\text { structure interaction in } \\
\text { complex structural } \\
\text { geometries or turbulence } \\
\text { fields. }\end{array}$ \\
\hline
\end{tabular}




\subsection{MODEL VALIDATION}

NRC Regulatory Guide 1.203 provides a systematic process for development of transient and accident evaluation models, the evaluation model development and assessment process (EMDAP), as illustrated in Fig. 8. The process is built on six basic principles.

1. Determine requirements for the evaluations model.

2. Develop an assessment base consistent with the determined requirements.

3. Develop the evaluation model.

4. Assess the adequacy of the evaluation model.

5. Follow an appropriate QA protocol.

6. Provide comprehensive, accurate, up-to-date documentation.

This process builds upon the CSAU methodology described in NUREG/CR-5249.

While most steps in the EMDAP process are design specific and cannot be effectively completed before a baseline thermal hydraulic design is established, some requirements for the evaluation model capability can be defined a priori. The GDCs identified above frame the purpose of the evaluation model. Transient classes, while unique to a class of power plants, are largely common among reactor designs within that class. Figures of merit (FOM), which are derived from the GDCs, are also tied to the class of power plant rather than a specific design. While specific geometries and fields cannot be specified at this point, classes of components to be considered can be identified without a detailed thermal hydraulic design, as they are in Sect. 7-“Component Development." While phenomena that are expected to be common to the class of power plants can also probably be identified on a coarse level, moving beyond these more general steps in the EMDAP and initiating the development of phenomena or process identification and ranking tables to satisfy step 4 of the process requires a detailed thermal hydraulic baseline design that is not yet available.

The development of an assessment base requires access to a significant library of validation data that is relevant for the anticipated design and conditions in the proposed power plant, or access to experimental facilities capable of generating such validation data. Validation data can be classified into a natural hierarchy, as illustrated in Fig. 6, in which data is classified by the complexity of the system, or in most cases, the number of phenomena to be simultaneously considered. Unit test data isolates a single physics phenomenon. In some cases, unit test data may be an exact solution of a simplified equation set, and, in other cases, unit test data may come from carefully designed single phenomena experiments. Benchmark data may come from experiments that integrate a few physical phenomena under conditions similar to those found in the end application. Under some circumstances, extremely high fidelity simulation data, such as direct numerical simulations of fluid flow or $a b$ initio simulations of atomic chemistry may be used to fill gaps in available experimental benchmark data. Subsystem cases integrate phenomena further until all phenomena that occur in a particular component are included. Complete system cases, as the name implies, integrate all of the phenomena that will occur in the complete system. 


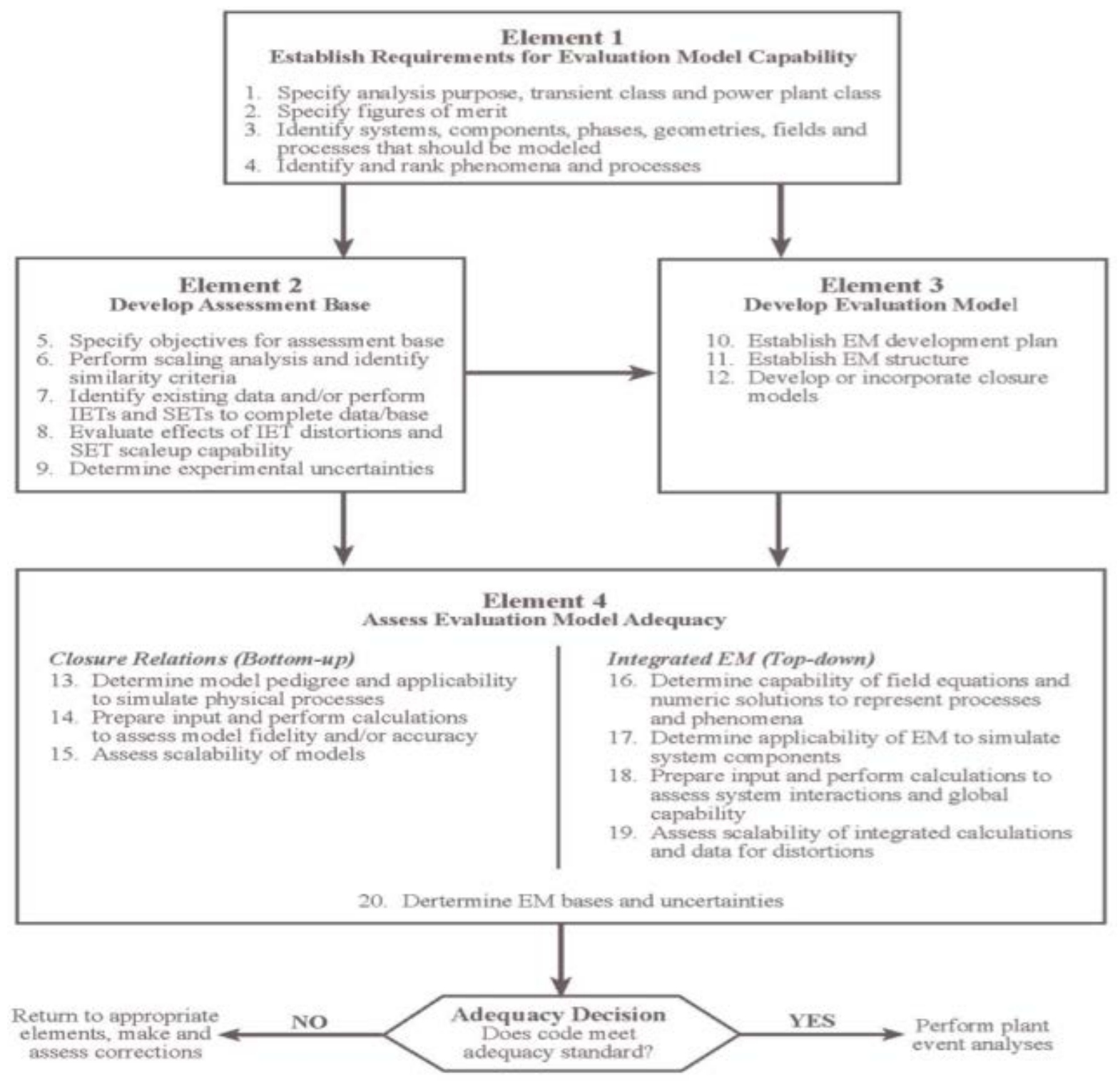

Fig. 8. Graphical flow chart describing the EMDAP.

As a validation program moves up the hierarchy, data associated with a data set becomes courser and, generally, fewer data sets are needed. The validation of a code need only progress up the hierarchy as far as the end application of the code. For example, a CFD code that will be used only for component analysis rather than for full system analysis need only be validated against the unit test, benchmark, and subsystem data relevant to the end application. 


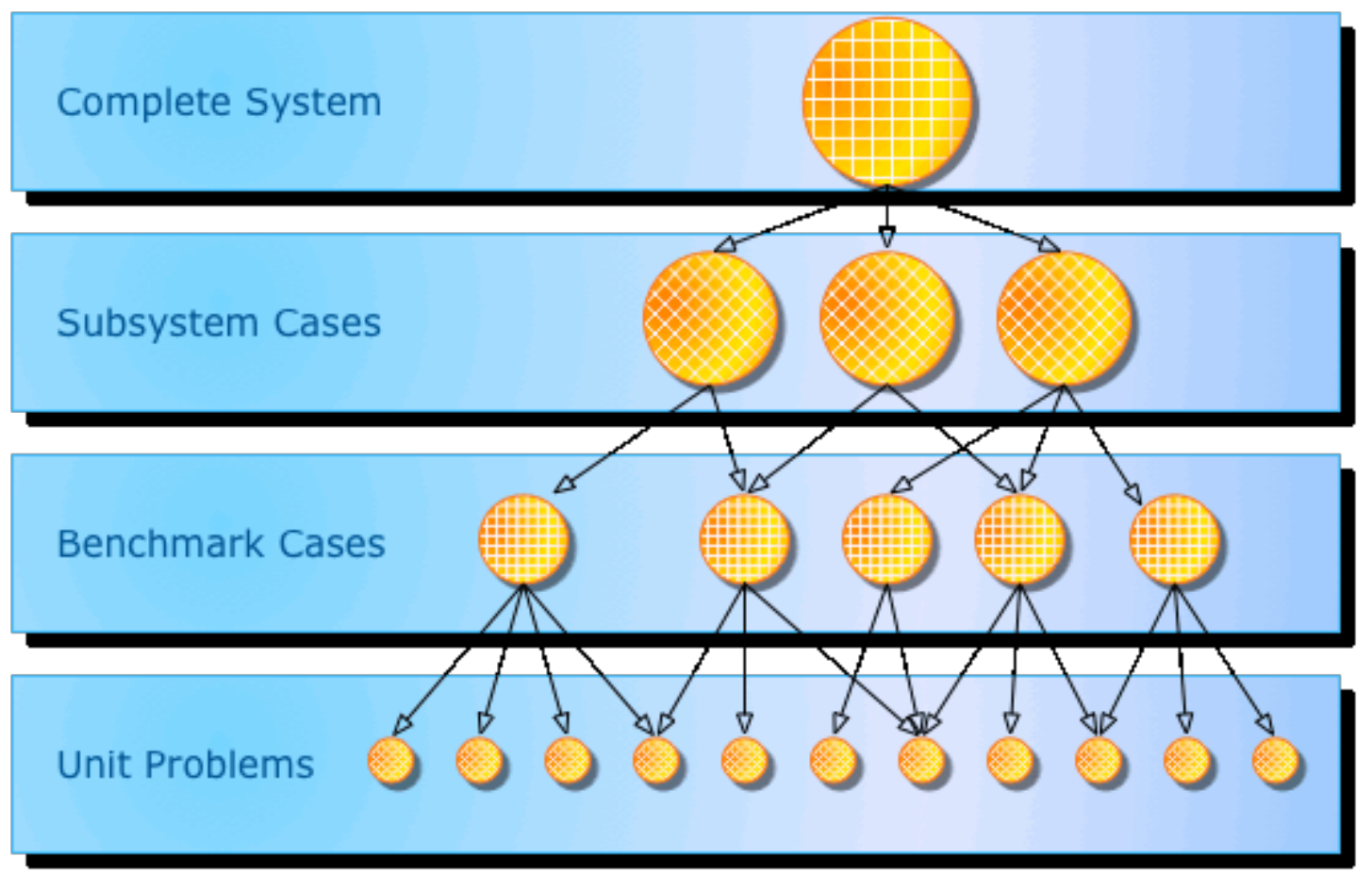

Fig. 9. Illustration of validation data hierarchy.

\subsubsection{Principal Thermal Hydraulic FOM}

The principal FOM for gauging the thermal hydraulic performance of an FHR are very similar to those of other reactor types. An initial list of thermal hydraulic FOM has been identified as part of the series of FHR workshops held in 2012 (Ref. 86).

- Peak fuel element temperature,

- Peak local power density,

- Time at temperature for fuel,

- Peak bulk coolant outlet temperature (e.g., as a simple surrogate for system structural integrity),

- Time at temperature for metallic and ceramic structures,

- Peak thermal gradient induced in metallic and ceramic structures,

- Minimum coolant temperature in the DRACS loop,

- Temperature difference across the DRACS,

- Time at establishment of natural circulation, and

- Time that natural circulation can be sustained.

\subsubsection{Transient Classes}

The following is a list of transient simulations that may be considered when evaluating the performance of a generalized FHR concept during events that it may experience over its lifetime. Some transients may not apply, depending on the details of the system design. The transients have been divided, preliminarily, into the four traditional categories of: NO, AOO, DBA, and BDBA. The placement of transients into these categories is based on the engineering judgment and LWR experience. Future analysis, accounting for a specific FHR design and rigorous probabilistic risk assessment, is required. For AOO, DBA, and 
BDBA transients, key phenomena are identified that may need to be investigated, and specific FOM are provided that may be used in evaluating the FHR design.

Some transients included in this list have been previously identified as part of the AHTR preconceptual design (Ref. 1) and FHR-focused workshops hosted by the Nuclear Energy University ProgramIntegrated Research Project (NEUP-IRP) team led by the Massachusetts Institute of Technology (Ref. 87).

\subsubsection{Normal operation}

- $\quad$ Start-up/heat-up

o Description: Operator controlled increasing of reactor power to rated level. Heat-up of the primary system possibly through auxiliary heating system or through reactor power.

- Shutdown/cool-down

o Description: Operator controlled decrease of reactor power down to shut-down. Possible cooling of the primary system.

- $\quad$ Reactivity insertion/removal (i.e., intended)

o Description: Operator adjustment of reactivity control such as insertion/removal of control rods.

- Refueling

o Description: Normal removal and replacement of fuel assemblies.

- Maintenance

o Description: Normal inspecting components, which may include shutdown/disconnect of systems, removing components, intrusive probing of primary system, and online operations.

- Power oscillations

o Description: Oscillations in the reactor power (e.g., possibly when bringing the core up to power)

\subsubsection{2 $\mathrm{AOO}\left(\geq 10^{-2}\right.$ occurrences per reactor year $)$}

- $\quad$ Overcooling (Refs. 1 and 87)

o Primary side

- Description: From full power, the primary pumps trip, reactor SCRAMs, and the power cycle and intermediate loop pumps remain on removing heat from primary system. DRACS may or may not be assumed to operate.

- Phenomena: Salt freezing

- FOM: Time to freeze

o Secondary side

- Description: From full power, the primary pumps trip, reactor SCRAMs, and the secondary pumps trip but the power cycle remains on removing heat from intermediate loop.

- Phenomena: Salt freezing

- FOM: Time to freeze

- Heat exchanger channel rupture

o Primary side

- Description: From full power, a channel in the P-DRACS HX or the P-IHX fails.

- Phenomena: Salt-salt mixing, salt freezing, salt contamination, radionuclide transport

- FOM: Reactivity, salt cleanup time

o Secondary side 
- Description: A channel fails in the HX from the intermediate loop to power conversion system. This may be evaluated to determine at full power or shutdown conditions.

- $\quad$ Phenomena: Salt-secondary side mixing, salt freezing

- FOM: Heat removal from primary to secondary side

- $\quad$ Pump trip with coast-down (e.g., one pump)

o Description: From full power, a single pump trips and coasts down. The reactor is assumed to SCRAM. This may cause asymmetric flow and salt temperatures in the core region.

o Phenomena: Asymmetric core flow, asymmetric salt temperatures, thermal stresses

o FOM: Peak fuel and vessel temperatures, peak thermal stresses, core flow instabilities

- Loss of grid/load/turbine trip (Ref. 1)

o Description: From full power, the grid goes down, turbine trips, reactor SCRAMs. Auxiliary power remains available.

o Phenomena:

o FOM:

- $\quad$ Fuel plate minor failure (e.g., 'leaker')

o Description: While at full power, minor failure of fuel kernels and release of radionuclides into the primary system.

o Phenomena: RN transport, salt/gas clean-up system performance

o FOM: Time to detection, time to clean salt, worker exposure

- Trip of cover gas system

o Description: While at full power, the cover gas system stops working. The leak-tightness of the cover gas system remains but gas stops flowing.

o Phenomena: Tritium transport, salt vapor deposition, heat up of structures

o FOM: Worker exposure, peak structure temperature, vapor deposit buildup/fouling

- Loss of primary system trace/auxiliary heating

o Description: During shut down, there is a loss of ability to add heat to primary system.

o Phenomena: Local salt freezing, flow blockages, thermal stresses

o FOM: Minimum salt temperature

- Loss of containment heat regulation

o Description: Ability to regulate heat in the containment is lost (i.e., either ability to reject heat or add auxiliary heat).

o Phenomena: Heat-up: component failure (e.g., I\&C, piping, etc.). cool-down: local salt freezing

o FOM: Peak temperatures in safety SSC, containment integrity

- Inadvertent control element movement (Ref. 1)

o Description: With the core at full power or shutdown, the control system inadvertently directs the control blades to be withdrawn improperly.

o Phenomena: Core reactivity/power increase, power oscillation

o FOM: Core reactivity

- Decrease (or increase) of primary salt level (Ref. 87)

o Description: With the core at full power or shutdown, the primary salt level is reduced possibly through moving salt to storage/overflow tank. Other lower probability transients may result in decreased salt level (i.e., loss of coolant accident, primary vessel failure, etc.)

o Phenomena: Decrease in radiation shielding, decrease salt upper plenum residence time, change in system pressures

o $\underline{\text { FOM: }}$ : Worker exposure 


\subsubsection{DBA $\left(10^{-2}-10^{-4}\right.$ occurrences per reactor year $)$}

(All transients below assume reactor successfully SCRAMs except for ATWS scenario.)

- Anticipated Transient Without SCRAM (ATWS) (AOO without SCRAM) (Refs. 1 and 87)

- Flow blockage (Refs. 1 and 87)

o Description: While the reactor is at full power, the entrance to an assembly is assumed to be blocked (e.g., frozen coolant, debris, impurities).

o Phenomena: Local core heat-up, temperature reactivity coefficient

o FOM: Peak fuel temperature, fuel thermal stresses

0 Loss of forced convection (LOFC) protected (Refs. 1 and 87)

o Description: With the reactor initially at full power, all primary pumps trip, unrecoverably and reactor SCRAMs. Heat must be rejected through the DRACS or other available cooling systems.

o Phenomena: DRACS performance [e.g., passive decay heat removal (flow reversal, HX performance, flow diode performance)]

o FOM: Peak fuel and vessel temperature

- LOCA (Refs. 1 and 87)

o Description: With the reactor starting at full power, a failure in the primary piping is assumed to occur resulting in outflow of reactor coolant with possible ingress of gas.

o Phenomena: Break flow, possible freezing/self-sealing effects, gas ingress into primary system

o FOM: Salt level, containment integrity

- Pump locked rotor

o Description: With the reactor initially at full power, a single pump rotor is assumed to seize and stop instantly (e.g., bearing seize) and reactor SCRAMs. This may cause dynamic loadings due to pressure waves and asymmetric core conditions.

o Phenomena: Dynamic pressure-structural loading response, asymmetric core flow and temperatures

o FOM: Margin to component failure

- $\quad$ Earthquake (DB)

o Description: Design basis earthquake occurs with reactor initially at power. Reactor is assumed to successfully SCRAM.

o Phenomena: Structural mechanics and dynamics (e.g., vibrations, stress, wear), salt sloshing, pump stability

o $\quad$ FOM: Structural loading (e.g., fuel, vessel, DRACS)

- Flood (DB)

o Description: Design basis flood of the plant assuming the plant has been shut down for a predetermined time.

o Phenomena: Structural loading, DRACS performance

o FOM: Possible structural loading, electrical system integrity, water ingress

- Fuel plate failure

o Description: A fuel plate is assumed to fail in the core region (i.e., due to a manufacture defect). The accident should not be shown to propagate to other fuel. Any releases from the failed fuel need to be mitigated. This scenario may challenge removal by the refueling arm.

o Phenomena:

o $\underline{\text { FOM: }}$ : Peak temperature and stress level of neighboring fuel

- Break of cover gas line 
o Description: An in-containment component of the cover gas system is assumed to fail and results in primary-to-containment releases. Scenarios could include cover gas losses in the reactor upper plenum, pump gas space, or other space.

o Phenomena: Radionuclide release/mitigation, salt level, pipe whip (i.e., if pressurized)

o FOM:

- $\quad$ Station black out (e.g., external power) (Refs. 1 and 87)

o Description: All external AC power to the plant is lost. Reactor must cope with battery backup or other onsite power sources.

o Phenomena: DRACS performance, auxiliary power performance

o FOM: Peak fuel temperature, peak vessel temperature, coping time, battery/other power supply duration

- Tritium removal system failure

o Description: The tritium removal system is assumed to fail. The failure could result in residual tritium in piping to be released.

o Phenomena: Tritium transport, tritium production/decay

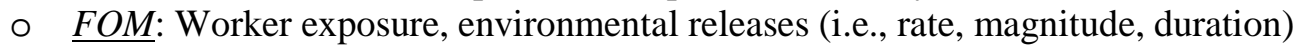

- Civilian aircraft impact (Ref. 1)

o Description: With the reactor initially at full power, a large civilian aircraft impacts AHTR building severing one of the DRACS. The reactor is assumed to successfully SCRAM.

o Phenomena: Core decay heat rejection, core heat up

o FOM: Peak fuel/vessel temperature, time at temperature, environmental releases i.e. tritium (e.g., rate, magnitude, duration)

\subsubsection{4 $\mathrm{BDBA}\left(\leq 10^{-4}\right.$ occurrences per reactor year $)$}

- $\quad$ LOFC unprotected (Refs. 1 and 87)

o Description: All primary pumps trip, un-recoverably, and reactor cannot be successfully in SCRAM. Heat must be rejected through the DRACS or other available cooling systems.

o Phenomena: DRACS performance [i.e., passive decay heat removal (flow reversal, HX performance, flow diode performance)], parasitic heat losses

o FOM: Coping time, peak fuel and vessel temperatures, environmental releases

- $\quad$ Reactor vessel breach (Refs. 1 and 87)

o Description: The primary vessel is assumed to fail while the reactor is at full power. One could assume the leak is detected and the reactor is scrammed or the leak remains undetected and reactor remains at power for some time. The location and size of the break should encompass a range of possible scenarios.

o Phenomena: Break flow, possible freezing/self-sealing effects, gas ingress into primary system

o FOM: salt level in primary system, containment integrity, environmental releases

- Failure reactor internals (Refs. 1 and 87)

o Description: From full power, assembly support (i.e., hold-down) or reflector, etc., is assumed to fail. (e.g., caused by structural defect, earthquake, etc.)

o Phenomena: Core realignment, channel blockage, reactivity, safe shutdown (e.g., poison salt)

o FOM: Criticality (e.g., ability to shutdown), Coolability (e.g., peak fuel and vessel temperature), environmental releases 
- Loss ultimate heat sink (Refs. 1 and 87)

o Description: From full power, all DRACS systems are lost, possibly severed above ground, and heat removal via the intermediate loop is halted. Maintenance cooling loop may or may not be assumed to be available.

o Phenomena: Primary-cavity cavity-outside heat loss (e.g., 'parasitic' system heat losses)

o FOM: Coping time, peak fuel and vessel temperatures, environmental releases

- Air/steam/water ingress (Ref. 1)

o Description: Air, steam, or water is able to find its way into the primary system. Analysis should be performed for the reactor at shutdown and full power conditions.

o Phenomena: Local salt freezing, reactions, 'rapid' corrosion, cleanup system performance, ingress detection.

o FOM: Criticality, environmental releases, corrosion rate/location

- $\quad$ Earthquake (BDB) (Ref. 87)

o Description: With the reactor initially at full power, a beyond-design basis earthquake occurs.

o Phenomena: Coolant boundary rupture, pump rotor energetic lock-up, multiple system failures.

o $\quad$ FOM: Primary system (i.e., fuel, vessel) margin to failure, environmental releases

- Flood (BDB) (Ref. 87)

o Description: A beyond-design basis flood occurs. Reactor is assumed to be shutdown for a predetermined time before flooding.

o Phenomena: Water ingression, multiple system failures, margin to failure

o FOM: Environmental releases

- Refueling accident

o Description: While reactor is shutdown, an accident is assumed to occur during refueling. This could include dropping an assembly, removal/placing an assembly in the wrong core location, hang-up of the assembly, etc.

o Phenomena: Passive cooling of assemblies, reactivity of assembly miss-load, impact/failure of assembly (e.g., dynamics, structural mechanics)

o FOM: Criticality, environmental releases

\subsubsection{Phenomena Identification}

A preliminary unranked phenomena list has been developed based on the potential FHR transients and conditions listed above. However, a full PIRT analysis cannot be completed without a specific baseline thermal hydraulic design.

- Flow distribution

- Forced convection heat transfer

- Forced to free conv. Transition

- Mixed convection

- Free convection heat transfer

- Radiation heat transfer

- Multidimensional heat conduction

- Salt conduction

- Heat loss to building/ground

- Buoyancy driven flow

- Forced convection pressure drop

- Free convection pressure drop

- Thermal striping
- Flow reversal

- Flow induced vibration

- Pressure induced stresses

- Thermal stresses

- Stored energy

- Power distribution

- Decay heat

- Hydrolysis

- Tritium production

- Tritium transport

- Graphite/structural swelling + fluence

- Salt freeze/thaw

- Fuel/reflector conductivity 
- Heat exchanger performance

- Two phase flow (solids particles)

- Thermal plumes

- Tube leak flow regime

- Back pressure in water circuit

- Thermal mixing and stratification

- Pressure waves
- Salt physical properties

- Salt chemical properties

- Impurity vapor partial press

- Salt reactions with other materials

- Reactivity coupling/feedback

- Core degradation

\subsubsection{Surrogate Fluid Testing}

A series of experiments using surrogate fluids will be required to fill gaps in available experimental data at all levels of the validation hierarchy. Data requirements are specific to a particular thermal hydraulic design and should be identified as part of the preliminary thermal hydraulic design analyses. For a specific plant design, additional surrogate fluid testing to confirm hydraulic predictions, including pressure loss, turbulence development, turbulent diffusion and flow induced vibration, in specific geometric configurations that have not appeared in prior relevant experience should be expected. Existing facilities that may be used to support such testing and anticipated new facilities that may be needed are identified in Chapter 14 of this roadmap.

\subsubsection{Prototypic Material Testing}

A series of experiments using prototypic materials will also be required to fill gaps in available experimental data at all levels of the validation hierarchy. For a generalized FHR design, new prototypic material testing is likely to be needed to qualify material property models, predictions of heat transfer in the various systems, and predictions of material interactions under prototypic conditions. Existing facilities that may be used to support such testing and anticipated new facilities that may be needed are identified in Chapter 14 of this roadmap.

\subsection{TASKS}

First, a preliminary thermal-hydraulic design will be developed for the AHTR based on recent core design studies. This will entail using TRACE for system analysis and sizing and higher resolution modeling using codes such as STAR-CCM+ for more detailed designs of select subsystems and components such as the core subassembly. In preparation for this work, a standardized set of salt properties will be defined and integrated into the codes.

The design will then be refined based on a set of FOM (see Sect. 11.3.1) for performance during select transient scenarios (see Sect. 11.3.2) and economics.

After a preliminary thermal design is developed, a PIRT will be generated to identify areas requiring further study. The PIRT will be used to guide what experimental and modeling validation efforts are needed to fulfill the requirements to obtain DC.

Updating and optimizing TRACE for FHR applications is a supplementary thermal hydraulic task that is essential to completion of the thermal hydraulics design. Best practices will also be defined for the use of higher resolution codes such as COMSOL and STAR-CCM+. 


\subsection{REACTOR PHYSICS MODELING}

\subsubsection{Purpose and Overview}

The two major purposes for the reactor physics modeling chapter are to provide assurance that the core can be operated without undue risk to facilitate obtaining a DC and to optimize the core design. Reactor physics modeling provides assurance that the reactor core will function as intended for both NO and in accident scenarios. Reactor physics modeling also enables optimizing the core design to maximize the plant economic performance through evaluating the impact of design variants on items such as: enrichment resource requirements, fuel configuration, fuel cycle length, radiation damage to surrounding structures, and power peaking.

To obtain a DC, the reactor physics of a particular design must be shown to be compliant with the relevant GDCs. While the GDCs provided in Appendix A of 10CFR50 formally only apply to LWRs, they express general design principles and are thus anticipated to apply, albeit likely with reactor class modifications specific to FHRs. Demonstrating sufficient core performance modeling fidelity to enable GDC compliance demonstration for specific core designs is thus the primary issue for validating reactor physics modeling tools. GDC 10 requires that the reactor core be designed with appropriate margin to ensure that fuel design limits are not exceeded. GDC 11 requires that the net effect of the reactor prompt inherent feedback characteristics, during power range operations, tend to compensate for rapid increases in reactivity. GDC 12 requires that power oscillations that can result in conditions exceeding fuel design limits are reliably and readily detected and suppressed. GDC 20 requires automatic reactivity control systems to ensure that fuel design limits are not exceeded. GDC 25 requires that fuel design limits not be exceeded for a single malfunction of the reactivity control system (e.g., control blade withdrawal). GDC 26 requires both that reactivity changes due to NO with appropriate margins for failed systems not result in fuel damage and that the reactivity worth of one of the reactivity control mechanisms be sufficient to hold the reactor core subcritical under cold conditions. GDC 27 requires that even under accident conditions the core reactivity remains controlled sufficiently to maintain core coolability. GDC 28 requires that the ability to change the core reactivity be limited such that under both normal and accident conditions reactivity accidents can neither result in damage to the reactor coolant boundary beyond limited local yielding nor sufficiently disturb the core to impair core coolability.

FHR reactor physics design issues have significant overlap with those of both LWRs and HTGRs in that all are thermal spectrum reactors intended to operate using LEU fuel. In LWRs, core design is intimately related to avoiding fuel damage during power range operation and ensuring sufficiently rapid protection system response under accident conditions. Much as in HTGRs, the large thermal margin to coolant boiling combined with the lower core power density makes rapid thermal- and reactivity-transient-caused fuel damage accidents not credible in FHRs. Thus, as with HTGRs, an FHR's reactor protection system negative reactivity insertion speed is not a significant design concern. Nevertheless, FHRs do have significant reactor physics design issues that must be addressed to produce a licensable core design. The power density of FHRs will be roughly $15 \mathrm{MW} / \mathrm{m}^{3}$. The FHR core power density is sufficiently high that the TRISO particle maximum allowable normal operating condition temperature can be exceeded if the fuel particles are not effectively thermally coupled to the coolant. Similarly, the maximum allowable accident condition fuel temperature can be exceeded during loss of forced flow accidents if the fuel particles are not effectively thermally coupled to the coolant. Thus, an adequate precision core power distribution model will be necessary.

In any nuclear reactor the central safety assessment provided through the reactor physics modeling is the quantification of the core reactivity and the impact of the inherent feedback mechanisms and control responses. In FHRs, the value and sign of the coolant temperature feedback coefficient varies with the ratio of the amounts of carbon to heavy metal within the core. The magnitude of the coolant temperature 
feedback coefficient also depends on core coolant volumetric fraction. Demonstrating that neither control system malfunctions nor other DBAs can result in positive reactivity transients sufficiently large to damage the fuel or coolant boundary necessitates adequate overall core temperature reactivity feedback models throughout the fuel cycle. Demonstrating that the core can be brought and maintained subcritical at any point in the fuel cycle also necessitates reactor physics models for the control blades, implanted burnable poisons, the coolant salt composition, and the secondary shutdown poison salt.

Section 4.3 of NUREG 0800 (Ref. 11) provides guidance on acceptable methods for demonstrating that an LWR's nuclear design conforms to the reactivity GDCs. In particular, Sect. 4.3 provides AC for LWR nuclear design of the fuel assemblies, control systems, and reactor core such that fuel design limits will not be exceeded during NO or anticipated operational transients and that the effects of postulated reactivity accidents will not cause significant damage to the reactor coolant pressure boundary or impair the capability to cool the core.

NUREG 0800 provides the following specific guidance on calculation of reactivity coefficients.
4.3.I.3.A-The applicant's presentation of calculated nominal values for the reactivity coefficients, such as the moderator coefficient, which involves primarily effects from density changes and takes the form of temperature, void, or density coefficients; the Doppler coefficient; and power coefficients. The range of reactor states to be covered includes the entire operating range from cold shutdown through full power and the extremes reached in transient and accident analyses. It includes the extremes of time in cycle and an appropriate range of control rod insertions for the reactor states. The applicant needs to demonstrate that the coefficients used are conservative.

\subsubsection{Methodology}

Reactor physics modeling begins with creating simplified system computational models. Progressively more details and features are then added to the reactor model to improve the modeling fidelity and increase the simulation realism. The applicability of the modeling tools to the specific core design is assessed both by comparing the predictions of the tools to experimental benchmark experiments at critical facilities and test reactors and by comparing the modeling predictions with those obtained through other computational methods.

FHR reactor physics modeling is based upon the tools and technologies developed for other reactor classes. FHR core physics are most closely related to those of HTGRs due to the high degree of commonality in the core materials and fuel. A number of experiments have been performed internationally since the early 1960s to confirm data and validate HTGR design tools (Ref. 88). The use of fluoride salt as the primary coolant is the principal difference between HTGR and FHR cores. Additionally, the fuel configuration and core power density of FHRs are significantly different from HTGRs. However, the neutron cross-sections of the light isotopes that comprise the primary coolant are reasonably well-known. The existing experience base with HTGR reactor physics modeling combined with the limited uncertainty of FLiBe isotope cross-sections provides confidence that reasonable modeling results can be obtained for FHRs using similar computational tools and methods.

The primary neutronic modeling toolset for the AHTR has been and is anticipated to remain the SCALE code suite (Ref. 89). Standardized Computer Analyses for Licensing Evaluation (SCALE) is a comprehensive modeling and simulation suite for nuclear safety analysis and design. SCALE has been recently updated to support modeling of HTGRs (Ref. 90). The applicability of SCALE to HGTR design has been validated by comparing its predictions to from the HTTR and HTR-10 start-up and initial criticality experiments. The primary coolant salt in FHRs is both a neutron moderator and absorber. 
Validating the use of SCALE for modeling the AHTR core, thus, needs to address assessing the ability of SCALE to accurately simulate the impact of the presence FLiBe and its impurities on the reactor physics. Additionally, SCALE validation needs to ensure that unacceptable amounts of modeling error are not introduced due to the layout differences between HTGR cores and the AHTR.

While values of FLiBe reactivity worth as a function of temperature can be calculated using existing neutronic toolsets, the fluoride salt is a major core component and its reactivity worth (due to actual impurity levels) as a function of temperature has sufficient remaining uncertainty so as to impact the reactor design and licensing. Further, since fuel is generally used until the core excess reactivity, at operating temperature, reaches zero and the fuel reactivity decreases slowly with use, having an accurate value of the fuel temperature feedback coefficient is also key to establishing the reactor cycle length.

\subsubsection{Validation}

Reactor physics modeling tool validation is performed through comparing calculated and measured parameters obtained from critical facilities and test reactors with adequate similarity to the reactor being licensed. NUREG 0800 (Ref. 11) indicates that benchmarking reactor physics modeling tools against critical systems and operating reactors remains the preferred method for establishing their usability for application in licensing.

4.3.I.3.B-The applicant's presentation of uncertainty analyses for nominal values, including the magnitude of the uncertainty and the justification of the magnitude by examination of the accuracy of the methods used in calculations (safety analysis report-Chapt. 4.3.3), and comparison where possible with reactor experiments. For comparisons to experiments, it is important for the applicant to show that the experiments are applicable and relevant.

4.3.III.7.F-Verification of the database, computer codes, and analysis procedures has been made by comparing calculated results with measurements obtained from critical experiments and operating reactors.

A series of critical facility and test reactor benchmarking activities are planned to validate the use of SCALE for both design and reactor physics licensing activities for the AHTR. The first validation experiments are under preparation at the LR-0 critical facility at the Nuclear Research Institute at Řež in the Czech Republic. SCALE validation for commercial power reactor licensing will continue at the both the first (0-2 MW) and second (10-20 MW) FHR test reactors currently being planned by SINAP for construction near Shanghai. The specific code validation experimental program has yet to be determined for the SINAP test reactors. However, it is anticipated that all three of the critical facility demonstrations will be published in the International Handbook of Evaluated Reactor Physics Benchmark Experiments. (Ref. 91).

Note, that while a series of reactor physics modeling benchmark experiments are planned to increase the confidence in the ability of SCALE to model the AHTR's core with adequate accuracy, the robust fuel and large flux and temperature margins to failure allow for relatively large uncertainty in the reactor physics parameters. The liquid cooling and mitigates the impact of unanticipated flux peaking and the strong negative Doppler feedback provides large negative reactivity insertion before fuel damage occurs.

\subsubsection{Core design optimization}

Core design optimization is also a primary purpose for reactor physics modeling. FHRs are less mature than HTGRs with significant unexplored design options. Further, the large margin to fuel damage and large number of control elements in the AHTR potentially enables nontraditional operational concepts ranging from pump speed based control to power distribution control at the fuel assembly level (withdraw 
blades within assemblies that are being replaced at the next refueling outage first) to maximize the achievable burnup for a particular fuel enrichment. SCALE is not currently optimized to rapidly evaluate the multiscale heterogeneous core configurations characteristic of TRISO fuel particles configured into layers within carbon fuel elements. Additionally, evaluating the impacts of repositioning control blades over the course of a fuel cycle on the power distribution, radiation damage, and core exit coolant temperature distribution is both computationally difficult and laborious. Further, SCALE continues to require significant effort to evaluate the impact of core materials or fuel assembly structure changes and is currently not capable of reading in its core geometry definition from mechanical modeling tools.

One example of an as yet unexplored, nontraditional core design option would be to use the AHTR control blades to provide shutdown, reactivity control, and burnup compensation to reduce fuel cycle cost. Avoiding the use of burnable poison would both simplify the fuel plate manufacturing and avoid the reactivity penalty associated with unused burnable poison at the end of cycle. The AHTR design includes 252 control blades (one for each fuel assembly). Each is independently controlled. The blades are formed from a MHC alloy. The amount of hafnium within the control blades will be selected to obtain sufficient neutron absorption to achieve and maintain cold reactor shutdown. PWRs commonly dissolve boron into their primary coolant to decrease the core reactivity at the beginning of the fuel cycle. The current AHTR design uses burnable poison particles within the fuel plates to accomplish the same objective. PWRs are required to globally reduce the core reactivity as using shutdown rods results in undesirable power distributions that can violate the core heat flux restrictions. FHRs, in contrast, are significantly more tolerant of nonuniform power distributions and, moreover, can provide relatively fine spatial control over the power distribution due to the larger number of control blades.

Increasing the AHTR's core power density from its current $12.9 \mathrm{MW} / \mathrm{m}^{3}$ to $15-20 \mathrm{MW} / \mathrm{m}^{3}$ may also be possible through shifting the core design parameters. Increasing the core power density would be desirable to reduce the core size and overall reactor vessel diameter. The principle restriction to more thoroughly exploring the AHTR core design options is the computational requirements of the reactor physics simulations. Continuing to improve the speed and ease of the reactor physics variational analysis would enable design option analysis to be performed with less time and effort.

\subsubsection{Tasks}

Neutronic design optimization is part of the overall AHTR concept evaluation and optimization process. Understanding developed in each area of concept development will impact the requirements of the remainder of the plant. Thus, each aspect of the plant design should progress to roughly equivalent maturity levels as the overall concept is developed.

The major reactor physics modeling tool development task is to assess and validate the fidelity of the SCALE modeling package for FHR core designs. The principle means for validating SCALE performance will be to compare its reactor parameter predictions with those obtained from the FHR critical facility and test reactor experiments that will be performed over the next few years. Designing the benchmarking experiments and measurements will be key to ensuring that the experiments are relevant and applicable to reactor physics model validation.

Optimizing SCALE for FHR cores is a supportive reactor physics modeling task. This involves improvements for modeling FHR geometries, particle-based fuels, and depletion. A parallel version of SCALE is currently under development as part of the SCALE maintenance and upgrading process. Implementation of the AHTR model into a parallel version of SCALE would decrease the time and effort required to evaluate FHR core design options. Further, automating multiscale core heterogeneity evaluation and core geometry definition would improve the ability to evaluate potential core design options. 


\section{ECONOMICS AND COMMERCIALIZATION}

\subsection{INTRODUCTION}

The objectives for this chapter are to (1) describe the technical challenges that must be addressed to develop adequate confidence that FHRs will be operated both safely and profitably and (2) illustrate how a focused technology development program can decrease the costs and time to deploy an FHR. The technical developments described throughout this roadmap address the technical challenges identified in this chapter. The overall purpose of FHRs is to safely and cost-effectively generate power. If FHRs can be shown highly likely to be a profitable means to generate electricity, then FHRs will be commercially deployed. A key element in ensuring FHRs provide power economically is minimizing the risk premium element of the interest rate paid on funds borrowed to construct plants. The interest rate risk premium is determined based upon how confident a lender is that an FHR plant (1) will be constructed at planned cost and schedule, (2) will obtain regulatory approval to operate, and (3) will operate reliably for many years. All of the risk factors have major technology aspects.

The chapter begins with a description of the roles and motivations of the entities necessary for FHRs to transition to commercial deployment. It then discusses the risks and challenges of commercialization. Lessons learned from prior non-water-cooled reactor programs and advanced LWRs are then presented. The roadmap is limited to technology aspects of plant economics and commercialization. Many aspects of national policy, market integration, and both utility and reactor vendor decision processes are beyond the scope of a technology-focused roadmap. Further, many of the societal benefits of FHRs are nonmonetary. Cleaner air, decreased greenhouse gas emissions, a stable and reliable grid, high-skill domestic jobs, improved balance of trade, influence over international trade in nuclear technologies, low-proliferation potential, and decreased dependence on unstable, and non-market-oriented sources for strategically important resources are all positive, intangible attributes of FHR development.

\subsection{ROLES AND INCENTIVES}

FHR commercialization requires support from a number of cooperating entities all of which must perceive significant benefits to be willing to invest the necessary resources. Introducing a new reactor class will require cooperation and support from national governments, reactor vendors, specialized suppliers, and plant owner/operators. National governments are needed to develop the foundational technologies and set the necessary standards to enable commercial FHR development and deployment. Support from national governments is also necessary to develop the regulatory structures to provide assurance that FHRs are constructed and operated without undue risk to the public or the environment. Obtaining support for FHR development from suppliers and utilities requires that FHR foundational technologies be demonstrated as practical and reliable. Reactor vendors, material and component suppliers, and utilities will only invest their resources in reactors that they believe are likely to be built and operated. The primary motivating factors for utility support for FHRs will be the potential for lower cost electricity generation, with continuing potential for additional cost reductions in future deployments, and the ability to serve the high-temperature process heat markets that LWRs cannot reach. As the foundational technology for FHRs advances, technology vendors and utilities can both provide insight into specific plant features and review how the overall system can best be configured to meet their needs.

The private sector tends to systematically underinvest in $R \& D$ relative to the potential gains to society, even when a market for the desired technology exists because it is difficult for any individual firm to monetize all the benefits from its investments (Ref. 92).

FHR deployment, thus, depends on national government investment in the necessary foundational RD\&D. The United States has been pursuing FHR technology development on a small scale for the past 
decade. The Chinese government, through its academy of sciences, has recently begun aggressively pursuing FHR development. FHR development is also under early-phase consideration by other governments (e.g., India, Japan, and the Czech Republic). The United States currently has the most experience with FHR technologies as a result of its historic and long-term investments in advanced nuclear reactors (in particular MSRs), advanced materials, and coated particle fuel. However, the rapidly progressing Chinese program will soon surpass US capabilities. SINAP's leadership has expressed strong interest in partnering with the United States during the precommercial phase to minimize the development costs and risks. Given the resources already committed, the CAS program will almost certainly succeed in bringing FHRs to market independent of external partnering. Thus, the remaining question for the United States is whether to partner with China, helping to direct a joint development path; to fund a competing development program; or to back away from FHR technology and eventually become dependent on imported technology for key aspects of the US energy infrastructure.

One of the key remaining areas to address for FHR deployment is NRC licensability. If a reactor vendor were to submit a 10CFR52 DC application in the near-term, it is not clear that NRC has the tools and staff familiar with FHRs necessary to judge whether operating the plant meets acceptable levels of safety and does not pose an undue risk to the public or the environment. It is now commonplace in the United States for commercial applicants to pay the full cost of evaluating licensing submissions in regulated industries. However, no regulated industry has paid the cost to develop the regulations it is subjected to.

Furthermore, even the evaluation costs of especially innovative technologies have generally been waived. For example, under Sect. 736(d)(1)(B) of the Federal Food, Drug, and Cosmetic Act, if the regulatory fees would represent a significant barrier to the applicant's ability to develop, manufacture, or market innovative products or pursue innovative technology, they may be waived. It is, thus, reasonable that NRC be funded to develop the procedures and tools necessary to evaluate the acceptability of FHR plants and technologies.

Another key element in developing reactor vendor interest in FHRs is first establishing utility interest. The primary impediments to developing utility interest in advanced nuclear power have been (1) the high up-front capital costs, (2) the potential for delays in construction and hence escalation of costs, and (3) the potential low-reliability of new technology. Low construction cost and high availability are both required for FHRs to succeed in the market. Much of the cost escalation seen in deploying LWRs over the past several decades stems from increased system complexity and the scale of specialized structures required. In contrast, the passive safety of FHRs avoids the requirement for active safety systems, while their low pressure obviates the necessity for high-pressure vessel, piping, and containment structures.

Material and component suppliers will also contribute significantly to FHR commercialization. A significant amount of intellectual property supporting nuclear reactors lies with the material and component suppliers. For example, nuclear grade graphite is a specialized product with a distinctive microstructure sold by a narrow group of qualified suppliers to multiple reactor vendors. While material composition, structure, and performance details are extensively documented to support reactor safety and performance evaluation, the specific manufacturing steps are proprietary. A similar situation is envisioned for FHRs in which material or component suppliers profit from unique manufacturing skills for qualified products.

\subsection{CHALLENGES}

\subsubsection{Perceived Impracticality}

The United States has attempted to develop non-water-cooled reactors since the 1950s. None have succeeded in the commercial market despite long-term, substantial government funding. A central challenge for FHRs gaining sufficient development support is, thus, demonstrating how FHRs are more 
advantageous for commercial deployment than other advanced reactors. The key distinction in developing FHRs is that minimizing overall energy generation cost while maintaining passive safety has been the principal focus throughout their history. Fast spectrum reactors introduce additional goals of fissile resource sustainability or transuranic waste consumption. HTGRs are low-power-density high-pressure reactors that are limited to less than $600 \mathrm{MW}$ (th) to maintain passive safety due to their inability to effectively use natural circulation to reject decay during loss of forced flow accidents. FHRs, in contrast, can generate large quantities of power and provide high-temperature process heat while maintaining full passive safety.

Developing a thorough, detailed understanding of the plant materials, fuel, accident initiation and progression, system technologies, and operations is the single most important overall program task. However, FHRs build upon established technology from existing power reactor plants and while requiring substantial RD\&D effort, do not appear to depend on any technology breakthroughs. This technical roadmap provides more detail about the scale of effort and time frame required for FHR development than has heretofore been available. Also, the CAS program plan to achieve initial criticality in a test reactor in only a few years shows that others have concluded that FHRs can be a near-term reactor class.

The fundamental requirement for FHRs to enter commercial service is to become a high-reliability, lowcost producer of energy. Mission creep into a flexible, multipurpose power plant is a risk to successfully developing FHRs as practical systems. Introducing noncritical functions into FHRs, thus, needs to be avoided as all additional features introduce additional risks to the plant reliability. Items such as online refueling, multi-fuel power cycles, and nontraditional licensing strategies, thus, are not recommended in first-generation FHRs.

\subsubsection{Licensing}

The United States has an established licensing process for NPPs. The Fort Saint Vrain HTGR was successfully licensed through this system and the SFRs of the 1980s had largely been evaluated using the existing process when these programs were cancelled. It is expected that the licensing experience with previously reviewed/licensed non-LWRs that have design aspects similar to FHRs will be leveraged to reduce some of the licensing risk. Nevertheless, FHRs are a new reactor class and thus substantial risk remains in being able to successfully obtain a design certification from NRC in a timely manner. (Chapter 6 of this roadmap describes the proposed pathway to minimize this risk.)

\subsubsection{Low Reliability}

Developing confidence in the likelihood of FHRs to reliably and profitably operate is the single largest challenge to commercial deployment. Advanced reactors have historically had low capacity factors making them highly uneconomical. No market economy has succeeded in introducing non-water-cooled reactors. Despite more than 50 years of development, SFRs are only operating for power production with Russian state support. The Fort Saint Vrain HTGR had several design and operational problems that prevented it from reliably operating. More recently, the NGNP Industry Alliance has concluded that there is a strong economic case for HTGRs supplying industrial process heat, but that they are only competitive for electricity production in the United States for locations with unique siting constraints such as a need for close locations to load centers (Ref. 93). Even LWRs took decades of focused effort to transition from the $60 \%-70 \%$ availability characteristic of the 1970 s to the roughly $90 \%$ availability of today. The combination of low-pressure, high thermal efficiency, passive safety characteristics, and potential for large size offers the potential for FHRs to profitably compete against LWRs for electricity generation and HTGRs for high-temperature process heat applications. 
Steam-based systems are the most widely deployed and extensively studied power cycles, with wellknown performance and reliability characteristics. Supercritical water power cycles have been selected for both advanced coal fired power plants and the United States and Chinese HTGR development efforts. Using a supercritical steam cycle is, thus, recommended as the power cycle for first-generation FHRs. Integrating the nuclear generated heat with natural gas to create a nuclear air Brayton combined cycle to provide surge capacity to respond to wholesale power price spikes is not recommended for a firstgeneration plant. Not integrating natural gas into an FHR's power cycle results in a simpler and thus higher reliability power cycle. Further, not introducing large quantities of natural gas near the reactor also avoids introducing a unique, unevaluated licensing issue. Simple, high reliability systems are critical to successful commercialization.

\subsubsection{Materials and Fuels}

FHRs shift costs from capital expenses for large, complex structures to manufacturing costs for specialized materials and fuel. Coated-particle fuel will cost more than fuel pellets, and isotopically selected FLiBe will cost much more than water. Costs for lithium isotope separation and layered fuel fabrication are discussed in Chapter 13. Chapters 4 and 7 discuss the manufacturing and qualification technology challenges. Neither the cost of the primary coolant nor the production costs for layered TRISO fuels appear to be so large as to prevent FHRs from being economically attractive.

The primary coolant would be purchased (or leased) only as needed, transferring production risks to the coolant vendor. FLiBe is only consumed to a trivial extent in an FHR, and its primary coolant would, thus, remain available for a future generation FHR. Only the first fuel load is an up-front cost. Once fuel certification is obtained, the majority of the fuel production risk rests with the fuel manufacturer, not the utility. Fuel fabrication cost differences between LWRs and FHRs are significantly influenced by the maturity and scale of the manufacturing processes involved. It is anticipated that over time, as more FHRs are built, LWR and FHR fuel cost differences will become progressively smaller. Developing and validating the technology for manufacturing specialized materials and components will precede plant construction by several years. Hence, component and material supplier manufacturing and development costs will accrue well before a large-scale return on investment is received. Particular emphasis, thus, needs to be placed on material and component technologies as part of early-phase RD\&D to minimize barriers to entry into commercial production.

\subsubsection{Long Time Frame}

The long lead time between base technology development and commercial deployment presents a challenge for FHR technology developers. FHR development has been under way at low level for more than a decade already, yet large-scale commercial deployment remains at least 15 years in the future. Thus, patents on key technologies will expire before commercial deployment. The lack of ability to protect intellectual property over the development time frame of reactors encourages using technologies that have nonreactor uses wherever possible to spread the development costs. CFCs and advanced alloys will be useful throughout high-temperature industrial processes, and liquid salt heat transfer technologies are broadly applicable to high-temperature process industries. Material qualification for reactor use and reactor specific components, however, will require government incentives or support to develop into commercial technologies.

\subsection{LWR PATH}

LWRs (and to a lesser extent heavy-water reactors) are the only nuclear reactor class that has successfully entered the market. Therefore, first-generation FHRs are intended to follow the example set by LWRs and only deviate where their inherent characteristics enable a level of performance that has been unattainable 
by LWRs. The evolution of commercial LWR power plants has resulted in designs with progressively larger power output, taking advantage of the substantial economies of scale for larger unit capacities (Ref. 94). Even as recently at the mid-1990s, Westinghouse realized that its AP-600 plant did not have a market and proceeded to develop the AP-1000, which actually produces 1117 MWe. FHR concept development follows this logic, basing technology development plans on the 1,500 MWe AHTR.

Developing an advanced reactor is a costly, time consuming activity. A reactor vendor, thus, needs to judge that the potential for profit substantially exceeds its risks and expenses to initiate commercial development. While many of the steps of power plant development are common to FHRs and LWRs, more time and funding will be required for the first-generation of any new reactor class. The full passive safety of FHRs is appealing but is insufficient motivation to depart from modern, acceptably safe, and highly reliable LWRs. Lower costs with the potential for further cost reductions and large additional markets (transportation fuel and industrial process heat enabled by high process temperatures) that cannot effectively be served by LWRs provide potentially key motivating factors for industry. A reasonable metric, thus, for assessing when FHRs are sufficiently mature to transition away from primarily government support occurs when multiple reactor vendors initiate competing FHR developments.

Some modern LWR designs mitigate cost escalation by either increasing their passive safety (Gen III+ designs with enhanced passive safety) or decreasing their scale (small modular reactors). FHRs represent a much larger opportunity for lowering costs than incrementally improved LWRs. This is accomplished by not using high pressures in the reactor building, thus avoiding long lead time; expensive, specialized structures such as a high-pressure vessel; high-pressure piping; and high-pressure containment. Moreover, the full passive safety of FHRs allows them to realize the cost advantages provided by economies of scale without the complexity and unattractive economies of scale for multiple, redundant safety systems associated with large LWRs. For example, passive decay heat rejection of FHRs is provided by several smaller natural-circulation-based systems operating in parallel. The decay heat rejection capability of the reactor can therefore be increased incrementally as the design output power is increased. Further, the radioactive release source term remains small for any size FHR since fuel failure only results in noble gas release into the cover gas with the remainder of the fission products chemically bound into the lowpressure coolant. Additionally, the large amount of time afforded by FHR passive safety characteristics to respond to transients avoids the requirement for expensive, rapidly responding instruments and components. The dramatic lowering of the radionuclide release potential inherently provided by FHRs, thus, also offers the potential for more directly meeting regulatory requirements and thus lowering the costs for DC.

The siting requirements for FHRs and their land acquisition costs remain substantially unknown. If barge transportation is not required, FHRs can more easily be located away from water resources than LWRs. The higher temperature of FHRs inherently makes them more compatible than LWRs with dry cooling. Also, an FHR's passive safety features may make reducing the emergency-planning zone to the site boundary potentially possible. Further, the fully passive decay heat rejection of FHRs avoids the necessity for dual grid connection, which can facilitate locating FHRs near demand centers minimizing the grid connection costs.

Like LWRs, FHRs will be thermal spectrum reactors that are optimized for a once-through, uraniumbased fuel cycle. The once through cycle has advantages in cost, proliferation, and fuel cycle safety and is disadvantageous only in respect to long-term waste disposal (Ref. 95). All forms of breeder reactors (whether thorium- or uranium-based) introduce unnecessary (as demonstrated by the successful deployment of LWRs) complications into reactor operations. Uranium resources do not appear likely to become a significant nuclear power cost driver over the next few centuries even with aggressive expansion worldwide (Ref. 96) — especially considering the improving capabilities to extract uranium from seawater at an acceptable price. 
The used fuel disposition path for FHRs will be similar to that for LWRs. However, due to the lower heavy metal loading in the fuel, FHR fuel will require liquid cooling for only about a year following removal from the core, enabling earlier transition to less expensive dry storage. Also, TRISO fuel is more chemically and thermally robust than LWR fuel rods. In particular, the carbon structure is not watersoluble. FHR used fuel is thus well suited for indefinite storage in dry wells located on the reactor site. Subsurface storage is recommended to comply with NRC directives on aircraft impact. For long-term used fuel disposal, the 1957 National Academy of Sciences Report on Disposal of Radioactive Waste on Land indicated that disposal of used fuel in cavities in underground salt beds was "the most practical immediate solution to the problem” (Ref. 97). The operating Waste Isolation Pilot Plant is based on emplacing nuclear waste in just such cavities in underground salt beds. The potential geologic storage volumes in underground salt beds greatly exceed any potential FHR waste generation volumes even for extensive deployment. Note, as geologic timescales are orders of magnitude larger than the radioactive decay times of either the actinides or fission products, little benefit accrues from the limited term (few thousand years) radiotoxicity differences between the uranium and thorium fuel cycles.

\subsection{TASKS}

The technical development tasks outlined throughout this roadmap address the technical challenges to commercialization. Commercialization is the step where advanced reactors, apart from progressively improved LWRs, have failed. Thus, economic and commercialization strategies for FHRs will be based upon the course taken for LWRs. The economics and commercialization development tasks are focused on reducing the risks to commercial FHR participants and ensuring that the FHR program communicates with and focuses on the needs of the eventual reactor owners/operators.

\subsubsection{International Collaboration}

The large and rapidly progressing CAS FHR development program could radically change the near-term commercialization potential for FHRs. Building and operating FHR test reactors will be the single most expensive step in the commercialization of FHRs. Development of FHRs for the US market can rapidly advance if knowledge and information developed by the Chinese program is available to researchers, designers, and regulators. Further, many FHR system reliability issues can be addressed through a combination of the required materials, components, and fuels development tasks that need to be resolved to operate a test reactor. CAS has expressed strong interest in partnering with the US to develop precommercial-phase FHR technologies. The principle focus of this task is thus to develop and maintain a strong working relationship with CAS and the CAS FHR program. The first step in this process is to obtain DOE approval on a cooperative R\&D program to enable the US and Chinese programs to jointly develop technologies.

\subsubsection{Economic Model Development}

During 2011 the FHR R\&D development program applied the GenIV economic model to the AHTR (Ref. 2). While the modeling results confirm that FHRs have the potential to be economically advantageous, the model contains a sufficient amount of conjecture so as to greatly increase the uncertainty in the numerical output. Nevertheless, the economic model does identify key areas to focus development resources on both to lower the actual cost through technology improvement and to decrease the modeling uncertainty. This task will integrate improved FHR technology understanding into the AHTR economic model as the technology understanding is improved. 


\subsubsection{Utility Guidance}

US deployment of FHRs will be influenced by both technology readiness and customer interest. To-date, the technology development has proceeded largely without input from utility customers. This task will seek to inform utilities about this developing reactor class and seek guidance about specific FHR design features, much as utility guidance documents have provided input to LWR developments.

\subsubsection{FHR Technology Maturation}

The concept and technology development tasks, as well as the safety and licensing tasks, are aimed at reducing the risk for commercial deployment of FHRs through developing and demonstrating the viability of FHR related technologies. Developing the capability to evaluate FHR accident progression is key to establishing the capability to license FHRs and to assessing the potential to reduce the emergency planning zone to the site boundary. 


\section{CONSTRUCTION AND MANUFACTURING}

\subsection{BACKGROUND}

Controlling construction and manufacturing costs and schedules is key to the economic viability of NPPs. The upfront costs of NPPs are significant while their fuel costs are much smaller compared to fossil-fuelbased power plants. The same general cost distribution will hold true for FHRs. The overall similarity among NPP inherent costs allows making reasonable comparisons between FHR and LWR manufacturing and construction. However, the cost distribution among different facets of construction and manufacturing will differ between FHRs and LWRs due to their distinctive physical characteristics. The most significant cost differences between LWR and FHR construction and manufacturing arise from an FHR's low-pressure primary coolant and its use of specialized coolant and fuel. The low operating pressure of the FHR primary coolant and the lack of potential for pressurizing the containment during accidents can significantly decrease the cost for plant structures. Conversely, using isotopically selected ${ }^{7} \mathrm{Li}$ as a principal constituent in the primary coolant and using a fuel type with which there is no established, large-scale fabrication experience can significantly increase the manufacturing costs.

Construction and manufacturing are major aspects of the concept development process. Planning how the SSCs will be manufactured, brought on site, and assembled impacts the overall design. The additional time, difficulty, and expense of performing work in the reactor buildings while they are under construction (due to weather exposure, confined spaces, competing tasks, and lack of existing services) has resulted in modern LWR construction being configured into large modules that are factory-assembled and inspected and then assembled at the worksite. Anticipated manufacturing technical capabilities and costs also feed back into the design process. For example, the technology for manufacturing large CFC structures is critical to being able to use them as FHR reactor vessel internals. Important design issues such as the mechanical interface between the control blade drive motor and the control blade leader rod, as well as the core flow inlet orifice shape, are intimately associated with CFC manufacturing capabilities. Additionally, the expense of lithium isotope separation influences the primary coolant circuit design. Ideally, from a safety perspective, an FHR's vessel should contain a large amount of primary coolant to serve as a thermal buffer in case of loss of forced flow events. On the other hand, ${ }^{7} \mathrm{Li}$ is currently expensive and its use should be minimized. Improving industrial-scale lithium isotope separation technology is thus key to keeping costs down while maintaining a large safety margin.

This chapter begins with a discussion of major lessons learned in prior NPP construction and manufacturing and how they apply to FHRs. Next, distinctive construction and manufacturing issues for FHRs and the related licensing issues that have the potential to impact construction or manufacturing costs or schedules are described. A series of tasks is then listed to address the identified issues. However, most of the construction and manufacturing tasks depend on additional developments within technology areas and thus cannot yet be described in detail.

\subsection{LIGHT-WATER REACTOR LESSONS LEARNED}

Most aspects of FHR construction will be nearly identical to those performed for LWRs. Items such as site preparation, rail spur and switchyard construction, and materials inspections and site security will not differ substantially for FHR construction. Open-top and modular construction processes are especially important technologies to reduce construction time and overall costs. Also, using steel plate form walls instead of locally installed rebar cast into concrete within removable forms reduces plant construction time. Open-top construction enables assembling the reactor systems into large modules and then lifting them into place using heavy-lift cranes. Being able to assemble modules in locations with a controlled 
environment, having support services available and using modules that are designed to enable access can significantly decrease the manufacturing time and effort and allow SSC inspection and approval with minimal interference. TVA's evaluation of the construction delays that have occurred at Watts Bar Unit 2 notes the decrease in productivity and challenges of working in cramped spaces (Ref. 98). With open-top construction, any scale of reactor can thus take advantage of modular factory fabrication and learning during the manufacturing process. Even sites without barge access can use modular construction by assembling large reactor modules in a local workshop using specialized assembly jigs, which could be transported to the next construction site after use.

Integrating inspections and testing with construction (rather than as an add-on following construction) is another key lesson learned from recent LWR construction. The high water content of the concrete at Oikiluoto Unit 3 was not recognized until after the concrete had been cast, resulting in months of delay. Performance-based testing of all critical materials and components needs to be integrated with the construction planning process. As technologies for making the required measurements are largely already available, the key remaining issues appear to be integrating the required testing with the manufacturing and construction practice and automatically reporting the testing results. Task-focused project software that enables external evaluation of the status and details of the construction and manufacturing plans, thus, will be recommended for FHRs.

In 2012, construction on Vogtle Unit 3 was delayed for several months while a license amendment was applied for, evaluated, and eventually granted following an NRC ruling that a design for the installation of floor rebar did not conform to the DC. Thus, it will be important to ensure that FHR DC requirements and AC are clearly stated, performance based, and fully reflected in construction contracting language. Using modern systems engineering and requirements-tracking tools (e.g., ISO 10303 AP-233) in the plant design specifications can mitigate the difficulty in transferring requirements and AC into the design and manufacturing of SSCs. Because NRC has never reviewed a license application for an FHR, to avoid possible delays in the inspections, testing, analysis, and AC process, a DC that includes more extensive explanatory information on FHR SSCs and plant operation than has been the case for LWRs will be necessary.

\subsection{MODULAR MANUFACTURING}

The low-pressure and resulting thinner walls of both an FHR's primary coolant boundary and containment enable modular manufacturing to have a comparatively larger impact on FHRs than in LWRs. The AHTR's primary reactor vessel will be a thin-walled, ribbed structure designed to be factoryfabricated in sections, brought to the site by rail, and welded together in a local workshop. Alternatively, for sites with good barge access, the entire vessel may be factory assembled and shipped to site as a unit. Similarly, an FHR's containment shell will be a thin stainless steel truss structure that is primarily fabricated off-site and then welded together in a local workshop and as needed in-position.

Transportation costs for large, heavy items such as the reactor vessel and SGs can be significant but are highly site dependent. Large, heavy components can readily be transported by barge. However, the ability to locate FHRs away from navigable waterways greatly increases their potential deployment locations and reduces their land acquisition cost. Consequently, the AHTR is designed not to rely on any individual components that cannot be transported by rail. All larger, heavier components are intended to be assembled on-site from smaller components. Note, however, that the ongoing development of heavy-lift hybrid aircraft may eventually enable worldwide transport even of items as heavy as LWR vessels, accommodating transport to otherwise inaccessible sites.

As with LWRs, entire building compartments for FHRs are intended to be factory- (or workshop-) assembled, lifted into place, and welded to adjoining systems after being moved into position. Note that 
modular style construction increases the cost significance of cable drawing in the construction process as cables are required to cross module boundaries. Automated cable drawing and, as necessary, fireproofing are thus comparatively more important for FHRs. As discussed in Chapter 9, the passive safety characteristics of FHRs appear likely to significantly relax the timing requirements for accident response. Thus, the communications system architecture at FHRs will likely include less point-to-point wiring and greater amounts of wireless communication than at LWRs. Also, high-temperature-tolerant metal-clad optical fiber provides an advantageous combination of fire resistance and long life and will thus be more extensively deployed at new NPPs.

Dividing the reactor into modules and using factory fabrication transforms much of the building of FHRs from a construction into a manufacturing effort. The same factory can manufacture modules for subsequent FHRs. Because of this, FHRs will benefit from learning during manufacturing, decreasing the cost for subsequent units. Even the specialized workshop assembly jigs can be transferred from one construction site to the next, transferring capabilities and decreasing costs for subsequent construction.

\subsection{SAFETY CLASSIFICATION}

The high degree of passive safety of FHRs will reduce the number of required safety-related SSCs. The QA and qualification requirements for safety-related SSCs directly and significantly increase cost. Further, the number of component vendors holding nuclear safety certifications is limited. Much of the regulatory design evaluation process is focused on demonstrating the adequacy of safety-related SSCs. GDC 1 of 10CFR50 Appendix A specifies that the quality of safety-related NPP SSCs shall be commensurate with the importance of the safety functions to be performed. The purpose for 10CFR50 Appendix B is to provide additional guidance on the QA for SSCs that prevents or mitigates the consequences of postulated accidents that could cause undue risk to the health and safety of the public. Furthermore, 10CFR50.65(b) requires monitoring of non-safety-related SSCs to verify that failures of non-safety-related systems will not prevent the fulfillment of safety-related functions and that failures resulting in SCRAMs or unnecessary actuations of safety-related systems are minimized. Thus, if the number and complexity of safety-related SSCs can be minimized by design, the corresponding cost of the resultant QA and qualification requirements will be minimized as well.

Only preliminary classification of SSCs can be made at this time since DBAs have not yet been identified for FHRs nor have evaluations of accident initiators and accident progression been performed.

Furthermore, some SSCs, while not directly preventing or mitigating the consequences of DBEs, perform supporting roles in providing confidence that AOOs will not escalate and require scramming the plant or activation of safety-related SSCs. For example, the circulating activity monitors may not be safety-related due to the radionuclide retention properties of the primary coolant. Nevertheless, monitoring the coolant circulating activity provides information useful to preventing fuel leakage from evolving into a more serious event. Thus, some SSCs will be subjected to intermediate levels of regulated QA. Developing performance-based QA metrics for both passive safety and nonsafety special treatment SSCs will become important as FHR conceptual development progresses.

A key issue in being able to widely use commercial grade parts is reflecting the passive safety characteristics of the AHTR into SSC safety classification. The different safety classifications of SSCs is a key difference between LWRs and FHRs. Even items such as control blade drive motors may not be classified as safety-related at the AHTR. The ability of the fuel and primary circuit to tolerate a transient (many hours) temperature rise of more than $10 \mathrm{~K}$ enables the use of thermal fuses in the reactivity control mechanisms. Using passive thermal fuses to activate both the primary and secondary (set a few degrees higher) shutdown mechanisms decreases the safety significance of several systems from core outlet temperature sensors to reactivity insertion controls. The ability to use commercial grade parts would greatly diversify the potential supplier base and lower system costs. Proving safe operation of complex 
digital systems is both technically challenging and required to allow their use in safety-related systems. The passive safety characteristics of FHRs combined with the passive safety design features of the AHTR may decrease the safety classification of the digital systems enabling use of industrial grade digital components, significantly decreasing their cost. Understanding and modeling DBEs and AOOs is thus a key task in developing a component sourcing strategy for first-generation FHRs.

\subsection{FUEL FABRICATION}

The initial fuel loads for first-generation FHRs will cost substantially more than for LWRs. TRISO fuel is not currently manufactured at commercial scale. Consequently, the cost savings resulting from manufacturing scale-up and automation cannot currently be reliably estimated (Ref. 99). The TRISO fuel manufacturing process is different from the LWR fuel pellet manufacturing process. Further, the layered TRISO fuel element manufacturing process is different than that of fuel pin manufacturing. Hence, only limited comparison can be made between LWR and FHR fuel manufacturing. FHRs like LWRs, however, are thermal spectrum reactors intended to run on a once-through low enrichment uranium fuel cycle. Thus, the nonmanufacturing fuel costs for FHR TRISO are expected to be similar to those for LWR pellets. Also, the current AHTR reactor physics model indicates that the improved moderating ratio provided by carbon (compared to water) results in only slightly improved fuel use, implying similar uranium mining and enrichment cost impacts on the overall fuel cycle cost.

A previous ORNL report on evaluating fuel manufacturing costs provides an estimate for manufacturing TRISO fuel compared to PWR fuel (Ref. 100). In this study the same group of fuels R\&D experts, design engineers, and cost estimators prepared early-phase estimates for the costs of large, mature fuel fabrication facilities. An interest rate typical of privately financed nuclear projects was used in the analysis. Given that the life-cycle cost estimates were all prepared with level playing field assumptions by the same individuals, the ratio of TRISO's unit manufacturing cost to that of typical PWR fuel at that time yields an indication of the comparative technical complexity of manufacturing these fuels. A unit fuel fabrication cost ratio of 6.09 between HTGR TRISO and PWR fuel pellets was calculated in the earlier cost estimation report. The fuel fabrication costs, however, are only estimated to be roughly $20 \%$ of the total fuel cycle costs (Ref. 2), decreasing the impact of the uncertainty in the fuel fabrication cost estimate on the overall fuel cycle cost estimate. Several factors may shift the TRISO manufacturing cost estimate ratio from the 1979 estimate. The revolutionary improvements in process automation over the past few decades will have a comparatively higher impact on more complex manufacturing processes. Also, the higher tolerance of fuel leakage in FHR TRISO as compared to the evaluated HTGR TRISO may decrease the QA component of the manufacturing cost.

\subsection{COOLANT MANUFACTURING}

An FHR's primary coolant will cost much more than water. The largest cost to produce the isotopically selected FLiBe will be to separate the ${ }^{7} \mathrm{Li}$. Lithium isotope separation technologies are discussed in Chapter 7 of this roadmap. Cost and scalability are key issues for development of lithium isotope separation technology. A confident cost estimate for large-scale production of high purity ${ }^{7} \mathrm{Li}$ is not currently available as the preferred technology for separation has not yet been selected. However, lithium isotopic separations that are based on classical chemical processes have well-understood cost versus production volume scaling relationships. The capital costs per unit of production decrease as the scale of the operation increases by the production amount raised to the 0.6 to 0.7 power (Ref. 101). The COLEX process was deployed at commercial scale from the 1950s to the 1960s. Consequently, the historic MSR project developed cost estimates based on the lower separation efficiency (as compared to its likely successors) COLEX process. Alvin Weinberg reported to the Atomic Energy Commission in a letter dated January 3, 1969, that ${ }^{7} \mathrm{Li}$ could be produced for $\$ 120 / \mathrm{kg}$. The proper inflation and technology shift adjustments that need to be applied to the earlier estimate are unknown. Overall, ${ }^{7} \mathrm{Li}$ separation appears to 
be an expensive but not dominant cost for an FHR. Evaluating the cost will, therefore, be a significant factor in selecting the preferred lithium isotope separation technique.

Beryllium is a relatively expensive material (2012 price $\sim \$ 450 / \mathrm{kg}$ according to US Geological Survey commodity pricing). Also of concern is the limited industrial production of beryllium. Only about 220 tons of beryllium was consumed in the United States in 2012. A single large FHR will require more than 100 tons of beryllium, thus consuming a significant fraction of the market. While extensive world reserves of beryllium do exist, large-scale FHR deployment will necessitate additional mining and processing plant construction.

\subsection{COMPONENT MANUFACTURING}

Component testing and qualification issues are addressed in Chapter 8 of this roadmap. FHRs will require a number of specialized components from pumps, to piping, to instrumentation, to motors. Many of these will only have limited variance from existing commercial systems, and normal market forces would be anticipated to develop a source of supply for the components. For example, custom seat and plug materials for industrial valves can be specified from some manufacturers during the purchase process. Many modern components have embedded digital electronics to provide health monitoring or to enable direct interfacing to digital communications systems. Understanding the component safety functions and post-DBA containment environment is key to being able to specify component performance and environmental tolerance requirements.

Heat exchangers will be the most expensive component class as FHRs contain a number of heat exchangers in the power generation, maintenance, and DRACS heat removal paths. Materials and overall design issues for heat exchangers are discussed in Chapter 5 of this roadmap. Advanced heat exchanger materials are recommended for development, and the performance and joining techniques of the new materials are not yet well known. First-generation FHRs, however, will use well-known tube-and-shell configurations. Large, complex heat exchangers are commercially available for industrial process heat transfer. Thus, first-generation FHR heat exchangers do not appear to require manufacturing technology development.

\subsection{SEISMIC TOLERANCE AND AIRCRAFT IMPACT RESISTANCE}

The recent NRC directive on aircraft impact resistance (10CFR50.150) effectively means that any new NPP designs will have significant portions of the plant located below grade. Below grade construction implies watertight construction for even noncontainment structures. Below grade construction is not new and hence no new technologies appear to be required.

Recent events have also increased the focus on seismic design considerations for NPPs. The precise seismic requirements are highly site dependent. However, as the recent earthquake impacting the North Anna plant shows, seismic isolation may be a useful protective measure even in less geologically active regions. The AHTR's nuclear island is designed to be supportable on seismic isolation pillars. In geologically stable areas, seismic isolation may be an unnecessary expense. Supporting the nuclear island on seismic isolation pillars enables external surveillance of the containment outer wall for long-term degradation and thus may be an acceptable expense even in non-seismically active zones. Seismic isolation pillars are not unique to FHRs and thus no specific technology development tasks are required.

FHRs will have large, thin-walled reactor vessels that are supported from the top rim. Seismic shaking will cause vessel stresses due to the hydraulic loads. The AHTR features a dashpot/spring type vibration damping system pressing against its ribs two-thirds of the vessel depth below its flange. While vessel vibration damping systems are not typically used in LWRs, the technology is well known. The DRACS 
cooling towers will extend up from the reactor building to enable developing a chimney effect to reject heat to the ambient air. The DRACS towers are required to be seismically tolerant and will be constructed of high tensile strength materials. Since the DRACS are safety-related components, the specific system design will require extensive validation. However, seismically tolerant chimney stacks are not new and thus no technology development tasks are required.

The mechanical support for specific portions of the intermediate loop piping depends upon the particular pipe segment location. The intermediate loop piping located in the reactor building will be supported by the reactor-building base. Similarly, intermediate piping in the trench between the reactor building and the turbine building will be supported by the trench foundation. Significant forces may occur during earthquakes where the intermediate piping connects between the trench and the seismically isolated reactor building. To accommodate the forces the intermediate loops include shielded bellows within the piping. The AHTR design also includes large catch basins below the bellows so that if the bellows were to fail, it would be preferable to capture the intermediate salt to enable more rapid plant restart. Again, none of the FHR seismic tolerance technology is new, but it has been used for new applications.

\subsection{TASKS}

The construction and manufacturing tasks are closely related to other development areas but are addressed separately given their potential for significantly impacting the economic viability of NPPs. The construction and manufacturing tasks thus emphasize the economic impact of technology choices whereas the technical-area-focused tasks emphasize maturing specific technologies.

The first construction and manufacturing related task is to perform SSC safety classification to advance the safety and licensing of FHRs. The next task is to perform a more detailed construction and manufacturing breakdown of the AHTR to begin to evaluate bottlenecks and unresolved issues in FHR manufacturing and construction. Assembly and inspection requirements also need to be brought into the concept development activity to gain improved understanding of additional FHR-specific construction issues. Further, a trade study to evaluate systems engineering tools for FHR requirements tracking and inspections during construction appears useful to minimize the potential for problems similar to those that have recently been experienced in LWR construction.

The fuel and primary coolant costs are the only FHR plant costs that appear to be significantly larger than the equivalent costs for LWRs. It is thus recommended that more detailed economic assessments of fuel and coolant manufacturing costs be performed to provide additional confidence in the economic viability of FHRs. Also, it is currently unknown to what extent the lower consequences of fuel leakage (as discussed in Chapter 4 of this roadmap) at an FHR compared to an HTGR will lower the costs for TRISO fuel fabrication. Performing a technical and economic evaluation of the cost issues associated with scaleup and automation of TRISO fuel fabrication and comparing the costs of HTGR versus FHR fuel kernels are thus recommended. Additionally, a modern bottom-up cost evaluation of lithium isotope separation costs is also recommended once a preferred isotope separation technique is selected. 


\section{DEMONSTRATION AND VALIDATION FACILITIES}

\subsection{INTRODUCTION}

The purpose for this chapter is to describe the necessary performance validation facilities for a firstgeneration FHR from a requirements fulfillment perspective. FHR demonstration facilities will have two central missions (1) decreasing an FHR's LCOE by facilitating design of reliable, maintainable SSCs and (2) developing information necessary to obtain DC. To a large extent the requirements for a licensable plant coincide with those for a cost effective plant, as reliability is key to both safety and power production. The misalignment between ensuring safety and lowering costs is less in FHRs than in LWRs due to the reduction in scale and complexity of an FHR's safety-related SSCs arising from the low coolant pressure and passive safety characteristics. The recommended experimental facilities are based upon developing and demonstrating acceptable (as opposed to optimal) solutions to functional and licensing requirements to minimize the experimental program cost and duration.

This roadmap chapter only addresses a subset of the overall performance validation facilities. Reactor physics and a thermal and hydraulic code discussion are in Chapter 11 of this roadmap. Material testing is primarily based upon qualifying both the materials and their specific use within the ASME BPVC (e.g., CFCs for core support applications within Sect. III, Division 5, Subsection HH - Class A Non-Metallic Core Support Structures) as described in Chapter 5 of this roadmap. Fuel qualification is discussed in Chapter 4 of the roadmap. Also, salt property assessment and instrumentation developmental facilities are discussed in their respective chapters. This chapter is also limited to those demonstration facilities that differ substantially from those for other reactor classes (e.g., weld inspection methodologies are largely independent of reactor type). Also, demonstration of systems that have long industrial heritage, but may require minor modifications for adaption to FHR use such as hydrogen (tritium) removal from an inert gas environment is not addressed.

Significant portions of the AHTR's SSC have yet to receive more than a cursory design effort and thus the performance validation program can only be described at a high level at present. Once a functionally complete design has been developed and a set of DBAs has been selected, a more detailed FHR development and validation program plan will be required to provide confident cost and schedule estimates. Moreover, each of the individual test facilities will require an individual planning effort to develop a realistic cost and schedule.

The distinctive characteristics of FHRs cause their required safety phenomenon demonstrations to differ substantially from that for other reactor classes. In contrast, an FHR's SSC reliability demonstrations will closely resemble that for other passively safe reactors. For example, the most thermally vulnerable component of an FHR is not its fuel and the design-limiting phenomenon is not the heat transfer rate between the fuel and coolant. Consequently, FHR safety phenomenon demonstrations do not center on ensuring adequate margin from departure from nucleate boiling in the core or preventing fuel melting. Further, an FHR's low-pressure liquid phase cooling enables a higher degree of similarity between less expensive, low-pressure, lower-temperature simulant-coolant based physical models than is possible with LWRs. However, the reliability of an FHR's SSC are equally important to those for other passively safe NPPs. Thus, an FHR's primary pump reliability demonstration requirements resemble those for an HTGR gas circulator or an SFR's primary pump.

A key element to limiting the number and expense of required demonstration facilities is developing an understanding of which tests can be combined and where prior experience provides an adequate design basis. For example, once the P-IHX is drained of salt, its inspection and/or tube plugging process becomes similar to that used for other double-walled heat exchangers. Thus, the demonstration should 
focus on the process and components for draining the salt and not on evaluating eddy current probes. The historic MSR program provides extensive molten salt SSC reliability and performance data, such as the general viability of core length graphite pieces in molten salt flows and redox condition restrictions on alloy compatibility with fluoride salts, that need to be reflected in the FHR experimental program to avoid repeating costly demonstrations.

Cost minimization is not considered in the NRC requirements for safety demonstrations beyond allowing demonstrations to be performed in the least burdensome manner. Thus, to minimize cost, the testing necessary to obtain a DC should include evaluation of cost-effective alternatives for performing required functions. For example, inspecting heat exchanger tubing for leaks may be more rapidly performed using mechanical valves and flanges to isolate and drain the component. However, cutting and eventually rewelding the piping along with using freeze valves would likely be acceptable from a regulatory perspective. Development and demonstration of mechanical valves and flanges, thus, primarily supports cost minimization but would be part of an FHR demonstration program.

As DBAs have not yet been established, accident performance test facilities remain largely undefined. Design issues such as validating modeling tools to assess accident progression (e.g., ensuring that stresses on the core internals remain below design limits following an undetected failure of a single primary coolant pump) remain to be resolved. Further, the design bases for the technical specifications have yet to be set. Issues such as how much P-IHX leakage can be tolerated before requiring the plant to shut down, how such leakage can be quantified online, and the required sensitivity of the subcriticality monitoring instrumentation need to await further concept maturation.

This roadmap chapter begins by presenting the regulatory basis for the recommended demonstration facilities. Specific test facilities are then conceptually described. All of the validation testing is envisioned to be limited to the large laboratory scale. None of the key phenomena have such scale dependence as to require full-size testing (apart from full-height testing of gravity-driven phenomena) before transitioning to a commercial development program. Also, while (3-7 years of development efforts will be required for each of the individual systems, nearly all of the testing can be performed in parallel, resulting in a resource- as opposed to schedule-constrained development program.

\subsection{REQUIRED DEMONSTRATIONS}

\subsubsection{Requirements Evaluation}

Previous advanced reactor development efforts provide insight into the required demonstrations. In particular, the NRC "Process for Determining Testing Needs" within the policy letter on Prototype Decisions for Advanced Reactor Designs provides a path for determining safety-testing requirements (Ref. 102). Assessing the required experimental facilities begins with developing a functionally complete preconceptual design for an FHR power plant. The plant design is then logically decomposed into SSCs and the required performance of each is documented for all parts of its operational life cycle including AOOs, DBEs, and post-accident environments. The functional requirements also need to be evaluated at an overall plant level to ensure that interdependent effects among subsystems are considered in the design.

HTGR technology demonstrations also provide insight into FHR demonstration requirements. HTGRs are particularly challenged by poor primary coolant mixing in their outlet plenum resulting in thermal striping that can damage their hot ducts. The AHTR's design calls for a large volume of salt above core resulting in an average upper plenum primary coolant residence time of about 40 seconds. While the large mixing time and comparatively small flow volume is anticipated to reduce the potential for thermal striping, AHTR upper plenum flow modeling and demonstrations will be required to bound the potential hot leg 
performance issue. HTGR performance demonstrations have also focused on quantifying and limiting bypass flow to minimize hot spots in the core. The combination of the AHTR's fuel assembly channel boxes and the decrease in primary coolant viscosity with increasing temperature is anticipated to minimize hot spot development. Moreover, the large amount of margin between the fuel operating temperature and damage initiation reduces the required modeling precision. Nevertheless, flow distribution modeling and demonstration throughout the reactor vessel, not just within core, is required to develop confidence in the fuel performance.

\subsubsection{DCD Demonstration Requirements}

The advanced NPPs demonstration requirements for obtaining a DC are specified in 10CFR50.43(e).

(e) Applications for a design certification, combined license, manufacturing license, or operating license that propose nuclear reactor designs which differ significantly from light-water reactor designs that were licensed before 1997, or use simplified, inherent, passive, or other innovative means to accomplish their safety functions, will be approved only if:

(1) (i) The performance of each safety feature of the design has been demonstrated through either analysis, appropriate test programs, experience, or a combination thereof;

(ii) Interdependent effects among the safety features of the design are acceptable, as demonstrated by analysis, appropriate test programs, experience, or a combination thereof; and

(iii) Sufficient data exist on the safety features of the design to assess the analytical tools used for safety analyses over a sufficient range of normal operating conditions, transient conditions, and specified accident sequences, including equilibrium core conditions; or

(2) There has been acceptable testing of a prototype plant over a sufficient range of normal operating conditions, transient conditions, and specified accident sequences, including equilibrium core conditions. If a prototype plant is used to comply with the testing requirements, then the NRC may impose additional requirements on siting, safety features, or operational conditions for the prototype plant to protect the public and the plant staff from the possible consequences of accidents during the testing period.

\subsubsection{GDC-Required Safety Performance Demonstrations}

The initial, candidate set of safety performance demonstrations recommended is based upon obtaining the information necessary to fulfill the "General Design Requirements for Nuclear Power Plants" that NRC has stipulated to obtain DC (e.g., 10CFR50 Appendix A). More specifically, proposed FHR oriented modifications to the LWR oriented Appendix A criteria are used to as the basis for the required information (Ref. 9). Chapter 4 of NUREG 0800 (Ref. 11) provides for the guidance to the level of detail necessary in the licensing information. An initial candidate demonstration set that has been developed by assessing each GDC in-turn is presented next. Only GDCs that necessitate specific demonstrations are listed. A paraphrase of the validation requirement of each GDC is first presented and then demonstrations to fulfill the requirement are described. The AHTR is used as a template for the demonstration requirements. 


\section{Criterion 4-Environmental qualification}

SSCs are required to be compatible with and accommodate the effects of the environmental conditions associated with NO, AOOs, maintenance, testing, DBEs, and post-accident environments.

The first task necessary to comply with Criterion 4 is to determine the environments that the plant SSCs must tolerate throughout the plant lifecycle. Most of the testing requirements to comply with environmental qualification are addressed by material qualification. In addition to the normal operating and post-accident environments, emphasis will need to be placed on transitions during NO. For example, the AHTR's control blade leader rod is partially immersed in the salt and partially in the cooler cover gas when the blade is withdrawn from the core. If the rod is inserted rapidly it will experience thermal stress. Thus, the ability of CFCs to withstand repeated thermal cycles needs to be demonstrated. Establishing post DBE environmental conditions is key to technology selection for post accident monitoring. The currently available, very preliminary estimates of the post accident, in-containment environments indicate much less severe conditions than an LWR.

\section{Criterion 10-Reactor design}

Criterion 10 requires that acceptable core design limits not be exceeded during any condition of NO or AOO.

The key SSC validation demonstration necessitated by Criterion 10 is demonstration that neither full power flow, nor flow transitions cause unacceptable vibration of any of the core structures. To a large extent, neutronic and thermal TRISO fuel qualification addresses fuel viability from a radionuclide retention perspective. However, the AHTR design uses fuel plates. Structural performance aspects of AHTR fuel plates and/or fuel assemblies are not addressed by the fuel kernel qualification. Flow-induced vibration of complex structures is difficult to computationally model. However, a low-temperature waterbased [or aqueous KOH-based - the United States and Japan have been jointly studying the fluid mechanics and heat transfer properties of FLiBe simulants since 2001 (Ref. 103)] hydraulic model of the core flow coupled with evaluation of the relationship between the at temperature fuel assembly mechanical properties and the coolant properties to the model system can provide high confidence that the fuel assemblies will not chatter in practice.

\section{Criterion 13-I\&C}

Instrumentation is required to monitor the variables and systems including variables that can affect the fission process, the integrity of the reactor core, the primary coolant boundary, or the containment integrity.

The particular variables and systems that need to be monitored to comply with Criterion 13 will depend the physical characteristics of FHRs and the accident progression evaluation of a particular design. Unlike LWRs, the very high-temperature tolerance of the FHR core materials combined with the negative fuel thermal feedback avoids either normal or accident condition core temperature having a significant impact on the integrity of the reactor core. Thus, core exit thermometry at FHRs appears to be a nonsafety-related control measurement. Temperature in the hot-leg and the downcomer, however, directly impacts the integrity of the primary coolant boundary and would be safety-related measurements. Furthermore, the seal between the reactor vessel and the vessel flange is part of a containment layer. The high salt temperature will result in the vessel expanding substantially during initial heat-up. The upper vessel flange will be maintained at a lower temperature and will thus not expand as much. Monitoring the seal integrity is required to comply with GDC 13. Likely the seal will have a higher pressure gas-backing ring to cause the preferential leak direction to be inwards and to provide flange cooling. Thus, the required flange seal integrity monitoring will likely consist of a seal gas flow and pressure monitoring system. The 
electrical power to the control blade engagement mechanism (the solenoid that causes the pinion gear to engage with the rack on the control blade leader rod) will be thermally fused and coupled to the upper vessel flange automatically inserting all of the control blades in the event that the upper vessel flange exceeds its design temperature.

If neutron poisons were inadvertently added to the primary coolant (for example by the secondary shutdown system developing a leak) and this addition went undetected, the reactor core could remain critical by additionally withdrawing the control blades. In this event decreasing the coolant density due to increasing its temperature would remove neutron poison from the core resulting in a positive reactivity insertion. Either tracking the intended position of the control blades against the scheduled withdrawal during the fuel cycle or monitoring the salt chemical composition would enable corrective action to be taken. Demonstrating that the salt cleanup system effectively removes neutron poisons from the primary coolant and effectively monitors the composition of the primary coolant is, therefore, necessary to comply with GCD 13.

\section{Criterion 15-Reactor primary coolant system design}

Criterion 15 requires that sufficient design margin be provided such that the reactor coolant boundary technical specifications are not exceeded by NO or AOOs.

The primary coolant boundary is an FHR's most thermally vulnerable component. Creep is the dominant phenomenon through which an FHR's vessel could fail. Creep, however, is a progressive as opposed to threshold phenomenon. An FHR's vessel will, therefore, creep very slowly even during NO. Thus, the method to ensure that performance limits for the reactor primary coolant boundary are not exceeded is to assign a creep budget (typically 1\% deformation) and monitor the components to ensure that they have not exceeded their creep budget. Demonstration of the component creep monitoring system will, thus, be required to meet GDC 15. Creep can be monitored by technologies such as high-temperature strain gauges and/or optical mapping of the reactor vessel dimensions from the interior. Creep monitoring technology demonstration will, thus, need to be included within other multipurpose FHR demonstration facilities.

\section{Criterion 17-Electric power systems}

GDC 17 requires that reliable electric power be provided to permit function of safety-related SSC under normal conditions, AOOs, and DBE.

A key safety feature of FHRs is to have an unlimited coping time, not requiring off-site electric power to perform any safety-related action. In the event of grid disconnection, the design intent of FHRs is to runback power to the minimum level necessary for NO and to remain available to help restart the grid. However, the reactor decay heat rejection and used fuel cooling heat rejection functions performed by active systems at LWRs require passive alternatives at FHRs that must be demonstrated.

An FHR's used fuel cooling pool will have diverse lines of cooling defense that do not require external electrical power. Under NO, the used fuel cooling pool will reject heat using multiple-redundant pumped heat transfer loops potentially auto-powered by Stirling cycle generators with their hot element immersed in the decay pool and their cold elements connected to natural draft cooled heat exchangers. While the cooling loops are electrically powered, the power is not derived from the grid. Moreover, these are normally operating systems and so do not have start-up transients associated with a grid disconnection event. Additionally, the cooling systems are inherently self-regulating in that increased pumping power (and thus more heat rejection) is caused by pool temperature increases. A backup for the used fuel pool cooling system has not yet received significant design effort. However, the high-temperature tolerance of fluoride salts and TRISO fuel appears to enable a natural, passive backup used fuel cooling pool heat 
rejection system. Under long-term loss of forced flow conditions, the pool could reject its heat through natural draft cooling of an air tube bank (similar to an RCCS) dipped into the used fuel pool.

Alternatively, evaporation and natural convection would inherently increase from the used fuel pool as its temperature rises. The used fuel pool would thus be thermally connected to the containment stainless steel roof. The roof would directly radiate and convect the decay heat to the atmosphere.

Control room and post-accident monitoring power at FHRs is intended to be derived from Stirling cycle generators powered by the fuel decay heat. Backup to the auto generated power is intended to be provided by local batteries.

\section{Criterion 20-Protection system functions}

Criterion 20 requires that the protection automatically initiate protective functions in the event of an accident to prevent operational limits being exceeded.

The AHTR features two independent means to insert negative reactivity in the event that the primary coolant temperature rises beyond normal operating conditions. Melt point fuses will be included in both the control blade connection system and the poison salt injector system (set to trigger under more severe accident conditions). The DRACS will always reject decay heat representing a small parasitic heat loss during operation. However, if the primary coolant pumps were to remain running following a loss of ultimate heat sink accident, their operation would prevent the DRACS from establishing a natural circulation loop within the vessel and thereby rejecting adequate decay heat. Thus, during NO the primary pump power should be derived from locally generated power. Note, that during start-up plant power will be derived from the grid and manual action will need to be taken to enable the primary cooling pumps to derive power from local sources.

Thermal fuses are distinctive FHR features, and the control blade release mechanisms, the poison salt injectors, and the poison salt dissolution and mixing in the lower plenum will require demonstration.

\section{Criterion 21-Protection system reliability and testability}

Criterion 21 requires that the protection system be highly reliable and testable in-service.

Both the control blade release mechanism and the blade insertion into the core will require demonstration. The protection system release mechanism will be tested whenever new fuses are acquired or whenever existing fuses may have been altered in service by demonstrating the melting of sample fuses. In LWRs, rod drop timing and functionality are tested during refueling outages. The larger number of independent control blades in FHRs enables blade dropping to be tested during operation. Dropping a single element (by disengaging the pinion gear) only introduces a small negative reactivity that will largely be inherently compensated for by the thermal feedback of the other assemblies. Inserting the control blades provides confidence that the blades have not become stuck and that the guide structures have not warped sufficiently to prevent controlled shutdown.

\section{Criterion 22-Protection system independence}

Criterion 22 requires that the protection system not be disabled under normal, maintenance, testing, or accident conditions. Additionally, criterion 22 requires that functional diversity be used to the extent practical between the negative reactivity insertion systems.

FHRs apply functional diversity in their protection systems by using both a pressure- (accumulator-) driven poison salt injection system and a mechanical, gravity-driven, control-blade-based shutdown mechanism. Melt point fuses are independent of each other and cannot be disabled. The control system 
provides diversity in the ability to activate the protection functions. The poison salt injectors can be triggered via manually triggered electrical heating and the control blades can be driven in by the control system or released by depowering the pinion gear engagement circuitry. The manual activation of the protection functions by the control system will also require demonstration as part of the protection system functional demonstration.

\section{Criterion 24-Separation of control and protection functions}

Criterion 24 requires that the failure of any single protection component or channel leaves intact a fully functional protection system. Criterion 24 also requires minimizing any interconnection between the protection and control systems.

FHR protection melt point triggers are passive and cannot be removed from service. All of the thermal fuses are independent; the failure of any one trigger will not impact the functionality of any of the others. Also, the protection system is nonelectrical. Consequently, it is not interconnected to the control system. The functionality of a local energy storage system (battery) to melt the poison salt injector release fuse, however, will require monitoring and demonstration.

\section{Criterion 25-Protection system requirements for reactivity control malfunctions}

Criterion 25 requires that the protection system be designed to ensure that the malfunctioning of any single element of the control system does not result in exceeding operational limits.

The control logic is a common element to the control system. If the control logic were to be incorrectly implemented, all of the control blades could be directed to withdraw at the maximum rate physically possible. The protection system thus needs to be designed to be sufficiently sensitive to trigger (melt fuses and drop blades) sufficiently rapidly to avoid exceeding any operational limits. The maximum potential blade withdrawal rate will thus need to be demonstrated, as well as the speed of the thermal fuse response.

\section{Criterion 28 - Reactivity limits}

Criterion 28 requires that the potential positive reactivity insertion rate not be sufficiently high as to damage or impair the reactor's safety functions.

FHRs can only add positive reactivity by increasing the pump speed or withdrawing the control blades (as well as slowly removing neutron poisons from the primary coolant via the cleanup system). The available rate of change from both the pump and control blades will need to be demonstrated and fed back into the reactor evaluation models to demonstrate lack of safety-adverse impact.

\section{Criterion 32-Inspection and surveillance of reactor coolant boundary}

Criterion 32 requires that the reactor coolant boundary permit inspection and surveillance and provide the means to detect and to the extent practical locate the source of reactor coolant leakage.

The primary means to inspect the reactor vessel and primary piping boundary will be visual inspection from the interior. The P-IHX will be designed to be periodically drained and inspected using conventional eddy current probes. Monitoring the buildup of corrosion products and checking for ingress of intermediate loop salt into the primary coolant will provide online surveillance of the primary coolant boundary. The functionality of the online primary coolant contamination evaluation instrumentation (likely via optical absorption spectroscopy) will also need to be demonstrated. 


\section{Criterion 34-Residual heat removal}

Criterion 34 requires redundant, independent, diverse means for removing the core's decay heat sufficiently such that the reactor coolant boundary and fuel integrity are not compromised.

The DRACS are redundant to, and diverse and independent from the primary heat removal path. For instances when the primary heat removal path has been disabled (for example when the power cycle is shut down for maintenance). The AHTR includes a maintenance cooling system separate and diverse from the primary cooling system. The DRACS are sized to perform their safety function with a single unit out of service. DRACS are safety-related systems. Consequently, extensive demonstrations of their functionality will be required. The tools needed to perform design basis analysis showing DRACS adequacy is discussed in Chapter 11 of this roadmap. The maintenance cooling system can prevent AOOs from escalating into larger accidents and thus will require special regulatory treatment. The maintenance cooling system is intended to be either normally powered by the grid or auto-powered by Stirling cycle generators whose energy derives from the heat of the primary coolant loop. The tools needed to show the design basis cooling system adequacy are discussed in Chapter 11 of this roadmap.

\section{Criterion 35-Inspection and testing of residual heat removal}

Criterion 35 requires that the functionality of the residual heat removal systems be periodically tested.

The DRACS systems are always on and represent a small parasitic heat load. Thus, the systems are continuously being demonstrated to be functional. However, natural circulation within the reactor vessel is required for either the DRACS or the maintenance cooling systems to reject decay heat. Periodically measuring the pressure drop across the core provides assurance that natural circulation will occur if forced flow is stopped. The AHTR's NDHX at the base of their external cooling towers are also normally contained to facilitate tritium capture. Thermal triggers are used to enable airflow across the NDHX under accident conditions. The thermal trigger functionality, thus, needs to be periodically tested. The DRACS demonstration facilities will, therefore, include the thermal triggers and NDHX and mechanical functionality of containment.

\section{Criterion 38-Containment heat removal}

Criterion 38 requires that a system be provided to maintain containment at acceptable temperature during NO, AOOs, and DBEs.

The AHTR uses a primary coolant loop that is well insulated thermally. The AHTR's containment environment will be kept cool during NO by an active cooling system that chills the operating atmosphere and removes heat from the energized components. The AHTR design intent is to provide adequate margin during NO so that the containment temperatures not exceed allowable limits during accidents. Both the insulation attachment and the normal operating condition heat load to the containment will need to be demonstrated to provide assurance that an additional accident condition cooling will not be required.

\section{Criterion 41-Containment atmosphere control}

Criterion 41 requires that a system be provided to reduce the concentration of fission products and other gases released during accidents.

Minimal additional fission products are anticipated to be released from FHRs under accident conditions due to the retention of fission products in the coolant salt. Tritium will be stripped from the inert containment atmosphere by passing it through a heated metal bed (likely a titanium sponge) to form a metal hydride. Additionally, the containment atmosphere will require active cooling to maintain the containment temperature at a sufficiently low normal operational temperature to withstand a loss of 
containment cooling accident. As part of the containment atmosphere and cover gas cooling systems, fission gases would be cryogenically cold trapped out of the inert environment using existing industrial technology.

\section{Criterion 60-Control of releases of radioactive materials to the environment}

Criterion 60 requires that suitable means be provided to control the release of radionuclides into the environment during NO.

FHRs have limited potential for radionuclide release into the environment during NO. Fission gases (primarily krypton and xenon) from leaking fuel, however, can evolve into the reactor vessel cover gas where they would be trapped by the cover gas cleanup system using cryogenic cold trapping. Tritium, however, is the most potentially problematic radionuclide release from FHRs. The cover gas cleanup system, the containment cleanup system, and the NDHX fill gas cleanup systems will require tritium traps (reaction with a heated metal to form a hydride). However, a primary potential tritium release vector is through the P-IHX. The initial candidate tritium trapping mechanism is into a yttrium hydride between the walls of a double-walled heat exchanger. A discussion of double-walled P-IHX tritium trapping issues is provided in Chapter 5 of this roadmap. Tritium trapping performance and double-walled salt-to-salt heat exchanger design will require demonstration.

\section{Criterion 61—Fuel storage and handling and radioactivity control}

Criterion 61 requires that the fuel storage and handling system be designed to ensure adequate safety under normal and accident conditions.

While entirely based on known industrial technologies, the AHTR's overall fuel assembly loading and handling procedures are distinctive and will require both extensive modeling and demonstration. In particular, the optical instrumentation used to provide confirmation of the mechanical actions has not been used for nuclear fuel handling previously. Furthermore, the integrated, multi-camera visualization system used to enable the plant operators to provide oversight of the reloading process is substantially more complex than the direct observation of fuel motion through a flood channel used in an LWR.

\subsection{PERFORMANCE VALIDATION FACILITIES}

FHR performance and reliability validation testing requirements derive from functionally decomposing the plant and assessing the individual demonstrations required to provide confidence that the SSCs will perform as intended. The performance demonstrations need to include all phases of the plant life cycle. Plant state transitions, as well as maintenance and refueling activities, have been significant sources of operational issues at both LWRs and advanced reactors.

The performance validation facilities described in this chapter are limited to those that have a specific relationship to GDC fulfillment and are not directly addressed by the technology focused roadmap chapters. Other important validation facilities such as fuel fabrication, core flow simulation, material qualification, and/or component reliability demonstrations are described in the roadmap chapters devoted to the specific technologies. To the extent possible, the validation facilities will support multiple requirements demonstrations. For example, the core flow validation facility will also support validation of the maintenance cooling system adequacy and provide information on the DRACS in-vessel loop performance.

The experimental program needed to develop the FHR relies on several interrelated experimental steps. Initially, it is expected that many small experimental efforts will be used to establish the technologies needed for FHRs. These will include small-scale liquid salt tests, surrogate fluid testing, and 
subcomponent level testing. A wide variety of small-scale salt testing equipment and facilities have already been constructed at US universities to support FHR technology development The testing capabilities have largely been developed in an ad hoc manner without an integrated plan of the roles of each facility and/or piece of equipment. While only loose coordination is appropriate in early phase research, this roadmap is intended to help identifying the purpose for future development activities.

This chapter, however, does not attempt to catalog all of the existing or planned small-scale test facilities with capabilities relevant to FHR development. Indeed, FHRs will rely upon sufficiently common fluid flow, heat transport, and materials technologies that describing each potentially applicable laboratoryscale system is not possible. An additional value of the widespread initial testing programs is to begin to reestablish experience across the US university system with the technologies needed to work with fluoride salts. As the FHR program matures, testing will become more focused, and test facilities will be developed both for testing specific components and for more integrated testing. The test reactors (described in Chapter 15) will also be used to continue the experimental program. In particular, test reactor data will be used to validate codes used for safety and design analysis, and confirm the FHR design basis.

A significant amount of uncertainty remains in the future test program that will be needed to validate an FHR's design basis due to the limited analysis that has yet been performed and lack of a complete preconceptual design. The discussion is therefore not intended identify every experiment that will be needed during execution of the FHR program nor to provide specific details for those that are presently envisioned, but rather to describe those areas that have already been identified as needing experimentation, and in some cases to outline some of the salient features of that testing. This chapter does not discuss either fuels nor materials irradiation testing that will be needed to support FHR development.

This chapter is organized into four subdivisions. The first subdivision describes university-based surrogate fluid test equipment/facilities that are intended to support validating FHR hydraulic design codes. The second subdivision identifies test facilities needed to confirm performance of specific FHR components. The third subdivision discusses multi use facilities that will be used to test a variety of scaled components. The fourth subdivision discusses testing and equipment that will be used in multiple experimental facilities, with the expectation that this equipment will become more sophisticated and prototypic as the program progresses.

\subsubsection{University-Based Surrogate Fluid Test Facilities}

Surrogate fluid testing will be used for multiple purposes in the FHR development process. Due to the single phase, low-pressure salt coolant, surrogate fluids can provide a closer thermal and hydraulic match

to FHR conditions than is readily achievable for water-cooled reactors. Further, the use of surrogate fluids offers a relatively inexpensive method of providing reasonable fidelity experimental validation of design concepts and thus the potential to significantly reduce experimental costs compared to performing all experiments with high-temperature, beryllium bearing salts. Surrogate fluid experiments also are useful for developing benchmark data that can be used to validate the performance of design and safety codes used for both reactor design and establishing the reactor licensing basis.

Similar to geometrically scaled testing, surrogate fluid experimentation must be developed using scaling analysis to ensure that all pertinent phenomena and physical behavior that would occur in the reactor design are captured in the experiment. NRC's EMDAP process, discussed in Chapter 11 of this roadmap, ensures that the codes (and associated benchmarking) that are intended for use in safety analysis have been benchmarked against appropriate experiments. Because of the advantages of using surrogate fluids it is expected that they will play a substantial role in the FHR development program. 


\section{Compact Integral Effects Test (CIET)—UCB}

The CIET facility is designed to simulate the integral transient response of pebble bed type FHRs in forced and natural circulation operation, with a specific focus on the performance of the DRACS. The facility is currently under construction at UCB under DOE-NE sponsorship. The planned testing program will include simulating start-up and shutdown, loss of forced circulation with scram, and passive insertion of a buoyant shutdown rod in a bypass channel. Facility consists of two flow loops of Dowtherm A, an electric heater, a pump, a Coriolis type flow meter, a fluidic diode, an oil-to-oil heat exchanger, and an oil-to-air heat exchanger.

\section{Low temperature DRACS loop-OSU}

The purpose of this integral facility is to assess the performance of a DRACS and the performance and viability of its components. The facility is intended to support thermal-hydraulic code benchmarking. The primary loop uses pressurized water at 10 atmospheres and the DRACS loop uses water at near ambient pressure. The facility includes an electrically heated core, DHX, NDHX, diode, pump, and various expansion tanks. This facility is also under construction under DOE-NE sponsorship.

\section{Salt-salt DHX - University of New Mexico (UNM)}

UNM recently started developing a small-scale Dowtherm A facility to test heat exchanger designs, specifically the DRACS salt-to-salt heat exchanger.

\section{Tritium stripping loop-UNM}

This water loop is to serve as a testing platform to investigate bubble generation and separation technology relevant to tritium stripping for FHRs.

\subsubsection{Component Specific Facilities}

\subsubsection{Reactivity control system test facilities}

\section{Control blade performance and endurance test stands}

A control blade test stand will be necessary to comply with Criterions 4 and 28 . The performance test stand will consist of a single full-height fuel assembly cylindrical segment of the AHTR reactor vessel. The test facility will be designed to demonstrate all of the features of the control system performance apart from the neutronic response. As $\mathrm{KF}-\mathrm{ZrF}_{4}$ has an even higher vapor pressure than FLiBe at a given temperature, the much less toxic salt will be used in the experiment to provide a conservative demonstration of the impact of fluoride salt precipitation onto the pump mechanisms. The test will be at prototypic temperatures to demonstrate that the cover gas sweep rate is sufficient to cool the upper vessel structures. The fuel assembly will be an electrically heated mock-up.

Control blade drive mechanisms will also be tested for endurance in a warm gas environment. The fusible link design will be included as part of the endurance test package. The ability to inspect, test, and maintain these drives will also be demonstrated using the control blade endurance test rig.

\section{Secondary shutdown mechanism demonstration}

The secondary shutdown mechanism demonstration will generate information necessary to comply with GDCs 20, 21, and 24. The demonstration facility will consist of a single, scaled fluoride salt accumulator, immersed in a fluoride salt melt that upon release injects its poison salt load into an instrumented salt volume. The testing will most likely be performed using a multipurpose salt pool test facility. Demonstration scale will likely be $\sim 1 / 10$ of full size as the critical phenomena being demonstrated are not 
highly scale dependent. Repeated demonstrations will be performed to establish performance time variance and to validate the reliability of the release mechanism. The test facility will enable demonstration of both manual and automatic actuation of the poison salt injectors and the rate of dissolution of the poison salt powder in the lower plenum. $\mathrm{KF}_{\mathrm{ZrF}} \mathrm{Zrill}_{4}$ be used as surrogate salt for $\mathrm{FLiBe}$ to avoid the expense of the additional safety requirements for $\mathrm{BeF}_{2}$. The solubility of lanthanide fluorides in both FLiBe and $\mathrm{KF}_{-} \mathrm{ZrF}_{4}$ is well above that resulting from a single accumulator injection into the AHTR lower plenum.

\subsubsection{Tritium control system testing}

\section{Double-walled heat exchanger tritium trapping}

Tritium trapping demonstration is required to comply with GDC 60. A series of successively more complex and realistic tritium trapping and double-walled heat exchanger tube demonstrations will need to be performed. Initial testing will focus on supporting design of the trapping system and integrating it into the heat exchanger design. The use of palladium-coated yttrium structures as a direct trapping mechanism in the primary coolant loop will also require design and testing. Validation testing will not start until a candidate tube and trap design has been selected. Note, if a yttrium foil barrier can be directly sandwiched between two tube walls (likely via co-extrusion or explosion bonding), then the heat exchanger reverts to a single-walled design.

\section{DRACS air cooler isolation}

Tritium isolation will be required to avoid tritium release from the DRACS air cooler system. Presently, the air cooler design mechanically isolated and uses fusible links in order to use the DRACS for decay heat removal. This system will have to be tested in order to both prove that tritium will not escape during NO, and to prove that the fusible links are effective in allowing the DRACS to remove decay heat when required.

\subsubsection{Refueling mechanisms demonstration}

Validation of the performance and reliability of the refueling mechanisms and instrumentation are required by GDCs 13 and 61. Further, GDC 34 requires demonstration of the adequacy of the maintenance cooling system if it is to be relied upon during outages. While the AHTR refueling process is based upon simple mechanical transfers using common industrial mechanisms, fully automated, remotely observed fuel transfer under the surface of a fluoride salt is substantially different than common LWR practice.

Shortly following shutdown, the AHTR's fuel assemblies will each produce roughly 1 MW of decay heat. The adequacy of natural circulation cooling of an individual fuel assembly shortly following shutdown will need to be demonstrated to show that stopping the fuel transfer process (likely due to mechanical failure) while a fuel assembly remains immersed in salt does not lead to fuel damage. The consequences of dropping a fuel assembly will also need to be assessed. The small negative buoyancy of the fuel assemblies with their control blade inserted indicates that in such an event the dropped fuel assembly would slowly come to rest (likely on its side) at the bottom of the vessel. The adequacy of natural circulation cooling of individual fuel assemblies in nearly horizontal configurations thus also needs to be validated. A key step in the fuel transfer process is transferring individual fuel assemblies across a transfer weir into the storage salt. During the transfer process the fuel assemblies will heat up. A thermal fuse will be relied upon to allow the fuel assemblies to slide back into liquid cooling if the refueling process is stopped for too long during the transfer. Both the sliding process and the thermal fuse will require demonstration. 
The refueling demonstrations will consist of progressively more realistic mock-ups of the refueling process. A virtual reality simulation of the process will also need to be developed to overlay against the observed performance. Keeping the plant operators aware of the current transfer status will be key to enabling them to respond to any faults in the fuel handling.

Additionally, the adequacy of the maintenance cooling system to remove decay heat needs to be demonstrated to enable the primary cooling loops to be disabled during maintenance and/or refueling outages. The design of the AHTR's maintenance cooling system remains immature. In particular, the time period following shutdown when the core decay heat will be reduced sufficiently so that the natural circulation driven in-vessel portion of the maintenance cooling system will become able to provide adequate cooling.

\subsubsection{Passive reactor decay heat removal demonstration}

Decay heat removal capability demonstration is required to fulfill GDC 35. Both the surrogate fluid DRACS demonstration facility at UCB and the prototypic fluid DRACS loop being constructed at OSU will produce performance data. The OSU facility is currently under construction. The primary loop includes an electrically heated core cooled by a FLiNaK, a primary to DHX, a cantilever pump, and a

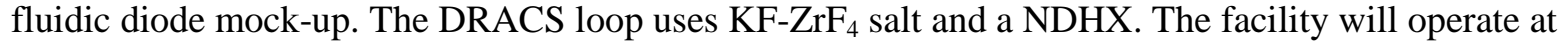
prototypic temperatures, is designed for $10-70 \mathrm{~kW}$ of duty, and is made primarily of stainless steel.

Further, the general functionality of the DRACS loops will be demonstrated using a modified version of the existing ORNL LSTL. These facilities are to provide integral data for code validation and future DRACS design and to provide a development platform for individual components (heat exchangers, etc.). The facilities will provide information such as the recirculating salt flow rates, heat exchanger and diode performance, and the possibility for salt freezing.

The core flow simulation facility will provide additional information to validate the in-vessel natural circulation flows. The planned hydraulic and heat transfer validation facilities and the modeling tool development effort are described in the Chapter 11 of this roadmap. Demonstration testing of a particular FHR DRACS design would be performed in a larger scale DRACS demonstration facility.

\subsubsection{Passive used fuel pool decay heat rejection demonstration}

Demonstration of the used fuel pool decay heat rejection system is required in order to maintain the containment at an acceptable temperature as required by GDC 38. Proper function of the passive used fuel decay heat rejection system is also relied upon to meet the fuel storage requirements of GDC 61 . The normal used fuel cooling power system is also required to be demonstrated to meet GDC 17 on electric power systems. The Stirling cycle power generators are innovative and will require demonstration and their functionality in post-accident containment environments must be demonstrated to meet GDC 4. Initial demonstration of the Stirling cycle electricity generation system will be performed using the LSTL.

\subsubsection{Salt fission product and absorber clean-up system demonstration}

Complying with GDCs 60 and 41 requires either non-leaking fuel or a fuel leak cleanup system. Additionally, the ability to remove neutron absorbers is economically required so that activation of the poison injection system is not prohibitively expensive. The primary salt cleanup system materials and functionality are discussed in Chapter 7 of this roadmap. While the underlying technology for the salt cleanup system was demonstrated under the MSR program, engineering development remains to be performed. The design validation program cannot be specified until the design has been completed. 


\subsubsection{Reactor cavity and component cooling system demonstration}

A model for the normal operating condition reactor cavity and component cooling system, as well as the heat loads within containment, will need to be developed and validated to comply with GDC 38 on postaccident containment cooling. (See Chapter 11 of the roadmap for a discussion on the development and validation of thermal models.)

\subsubsection{Multiple Use Facilities}

\subsubsection{LSTL-ORNL}

This versatile test facility consists of a test section region, salt-air heat exchanger, pump, surge tank, and two $\sim 1.5 \mathrm{~m}$ straight piping segments. The facility is primarily constructed of Inconel 600 . The LSTL suite of instruments includes salt flow, pressure, level and temperature. The loop is capable of $700^{\circ} \mathrm{C}$ operation with FLiNaK or other salts (Ref. 104).

Development testing to be performed includes, instrumentation (flow meter, level, and pressure), flange, and bellows. Performance testing of the pump and air cooled heat exchanger will also be conducted. Small-scale, inductively heated, core simulation is also possible with this facility.

\subsubsection{In-Line Test Facility}

The In-Line Test Facility (ILTF) provides a versatile testing platform for in-line component testing in high-temperature flowing salt. Testing would include performance, endurance, and demonstration testing. This facility is intended to be a step larger in scale than the LSTL. The loop would use $\mathrm{KF} \mathrm{ZrF}_{4}$ and/or FLiNaK.

A preconceptual design for the loop is sized to test full-size components for a 10-20 MW(th) test reactor or scaled components for a utility-scale FHR. At this scale the variable speed pump would be sized for $40-50 \mathrm{~L} / \mathrm{s}$ at a to-be-determined head, the piping would be $12 \mathrm{~cm} \mathrm{ID}$, the salt capacity would be on the order of $200 \mathrm{~L}$, and auxiliary heating and cooling might be on the order of $1 \mathrm{MW}$. Upon successful development of flanges, the facility would be designed to include a few component testing positions either in series or parallel (depending on the development path for valves).

A water loop, for which a low temperature version currently exists, similar in scale to the ILTF would perform component testing in water prior to salt loop testing.

The ILTF would be developed in stages based on the component development and testing needs of the program. One progressive testing campaign may be as follows:

Stage 1-Testing of basic loop components consisting of pump, salt storage tank, flow meter, trace heating, simple air-cooled heat exchanger, and flanges;

Stage 2-Testing of components of flanges, isolation valves, bellows, and flow diodes;

Stage 3-Testing of components of forced flow salt-salt heat exchanger in recuperator configuration and air-cooled heat exchanger;

Stage 4-Testing of an incorporation and performance of continuous process salt clean-up system and redox control; and

Stage 5-Tests of integral coupling to the integral pool test facility (IPTF). 


\subsubsection{Integral Pool Test Facility}

The IPTF will be a scaled version of the core and vessel. It will include the major components of the reactor, including an electrically heated core region, a reactor vessel, guard vessel, upper vessel flange, etc. The facility will initially use $\mathrm{KF}_{-} \mathrm{ZrF}_{4}$ and be at prototypic temperature. The pool facility will be used in satisfying a number of GDCs, including GDCs 4, 15, 20, 21, 24, 28, and 32.

Component testing includes the DHX, core components, vessel gas seal and insulation, and instrumentation and inspection technology. Subsystem testing includes the cover gas system, poison salt injection system, redox control, and possibly the continuous salt cleanup system. The system may also be used for some refueling technology demonstrations.

Code validation tests include validating convection flow rates, core pressure drop, forced to free flow transition, etc.

\subsubsection{Test Programs Performed in Multiple Facilities}

\subsubsection{Component maintenance demonstrations}

The ability to effectively service and maintain an FHR's SSCs is critical to overall system viability. However, much of the technology used in FHRs is closely analogous to existing industrial technologies. Hence, inspection technologies are reasonably well known. The demonstrations necessary for an FHR, thus, need to focus on obtaining access to the SSCs. The technology demonstrations will thus concentrate on demonstrating salt compatible flanges and valves to isolate, drain, and subsequently return SSCs to service. The valve and flange testing will be performed using the liquid salt testing infrastructure constructed for component testing.

\subsubsection{Optical instrumentation demonstration}

Optical instruments will be much more widely deployed at FHRs than in other reactor classes and thus they are key to complying with several GDCs $(13,15,32$, and 61$)$. The functioning and reliability of the fuel leakage monitoring (optical absorption spectroscopy), reactor power level (Cerenkov intensity), primary coolant boundary condition (corrosion and creep), void reactivity coefficient (optical absorption spectroscopy for contaminants), and the visually based automated refueling will need to be verified and validated. The instrumentation demonstration will be integrated into the system test facilities.

\subsubsection{Salt purification system demonstration}

Chapter 7 of the roadmap describes the purpose and mechanisms for salt purification in an FHR. Purification systems with specific capabilities will be needed for all facilities that use fluoride salts and that need to ensure facility longevity. These systems are expected to become larger, more sophisticated, and more automated as the test facility size increases. Purification system equipment will also most probably be shared between experiments as the program develops.

In a reactor system, a continuous salt cleanup system will need to be developed and demonstrated. The demonstration can be accomplished in increasing steps of complexity. Different cleanup requirements and therefore system capabilities may be required for the primary and secondary systems and the auxiliary cooling systems.

The LSTL is currently coupled with an $\mathrm{HF}-\mathrm{H}_{2}$ bubbling-based salt cleanup system. The system is capable of cleaning $150 \mathrm{~kg}$ of fluoride salt in 1 week. The facility consists of a $2 \mathrm{~m}$ tall nickel crucible, gas system 
(HF, $\mathrm{H}_{2}$, and Ar), and off-gas cleanup. The heated crucible is used to remove moisture and oxides from the salt.

\subsubsection{Redox control demonstration}

Maintaining the salt redox condition as slightly reducing is key to avoiding primary coolant boundary corrosion and thereby enabling compliance with GDC 15. A series of redox control technology development oriented demonstrations will be required to develop a redox control system design. An overview of redox based corrosion control is provided in Chapter 7 of the roadmap. The design validation program cannot be specified until the design has been completed.

\subsubsection{Cover gas cooling and cleanup demonstration}

The cover gas cooling system will be required to comply with GDC 15 on primary containment boundary integrity and GDC 4 on maintaining a normal operating condition that the control blade drive motors can withstand. The cover gas cooling system will cool both the reactor vessel upper flange that the control blade drive motors are located above and that seals to the reactor vessel to provide a containment boundary. The cover gas cooling and cleanup systems will consist of conventional technologies. However, a thermal model for the upper vessel structures will need to be developed and validated to develop confidence in the adequacy of the system.

\subsection{PRELIMINARY EXPERIMENTAL FACILITIES PLAN}

Table 5 provides a preliminary listing and status summary of the proposed experimental test facilities as the text in Section 14.4.

Table 5. Preliminary test facility summary

\begin{tabular}{lll}
\hline \multicolumn{1}{c}{ Test facilities and infrastructures } & \multicolumn{1}{c}{ Status } & ID \\
\hline Enabling facilities & Building & SCUS-B \\
$\begin{array}{l}\text { Salt Cleanup System—batch } \\
\text { Salt Flow Calibration Stand } \\
\text { Versatile testing platforms }\end{array}$ & Preconceptual & SFCS \\
Liquid Salt Test Loop & Built & LSTL \\
In-Line Test Facility & Preconceptual & ILTF \\
\hline Integral Pool Test Facility & Preconceptual & IPTF \\
Full-Height Pool Facility—blade test stand & Preconceptual & FHPF \\
Specialized test facilities and systems & & \\
Cover gas system & Preconceptual & \\
Salt Cleanup System—continuous & Preconceptual & SCUS-C \\
Poison Salt Injection System & Preconceptual & \\
Scaled DRACS Demonstration Facility & Preconceptual & SDDF \\
\hline
\end{tabular}




\section{TEST REACTORS}

\subsection{INTRODUCTION}

The purpose for this chapter is to describe the role of critical facilities and test reactors in supporting development of FHR NPPs. To a large extent, a test reactor is simply the most expensive experiment in an FHR development and demonstration program with a primary mission to produce information necessary to design, license, construct, and operate FHR NPPs. While component, separate effects, and some combined effects testing can be more readily performed using nonnuclear test facilities, full-scope, integrated system testing requires a test reactor.

The United States has not made any commitment to develop an FHR test reactor. However, critical facility testing is currently planned to take place in the Czech Republic, and SINAP has plans for both a first [0-2 MW(th)] and second [10-20 MW(th)] FHR test reactor near Shanghai. Obtaining access to the information generated by the critical facility and test reactors will be key to FHR development and licensing in the United States. Additional reactor testing will also be performed in LWR materials test reactors to qualify FHR core materials and fuel. More information on the TRISO fuel qualification and the graphite and ceramic composite radiation testing programs are available in Chapters 4 and 5 of this roadmap.

Higher power test reactors (e.g., the second SINAP FHR test reactor) will require many of the same systems as an FHR NPP. As some of the required SSCs have not received more than a cursory examination to date, test reactor development issues can currently only be described at a conceptual level. This chapter begins with an explanation of the purposes for FHR test reactors. It then describes the current international plans for critical facility testing and FHR test reactor development. Finally, early phase tasks in test reactor development are described.

\subsection{PURPOSES}

The purposes for FHR test reactors are to:

1. Demonstrate the integrated set of FHR technologies reliably functioning together,

2. Demonstrate acceptable performance of the safety features of the reactor class,

3. Demonstrate acceptable performance of the computational tools used in the plant design and analysis over a broad range of operating and accident conditions, and

4. Initiate supply chain development of specialized components and materials.

As discussed in Chapter 14, NRC has provided an acceptance methodology for advanced reactor safety features in 10CFR50.43(e). The licensing purpose of an FHR test reactor is to experimentally demonstrate the reactor class characteristics to generate the information necessary to license larger scale FHR NPPs. The first FHR NPP will likely initially operate as a prototype plant. The experience derived from the test reactors will decrease the amount of time and operating limitations prior to transitioning to a commercial operating license. The key challenge in using a smaller scale test reactor to obtain the information necessary to ascertain acceptable performance of a larger scale reactor is whether the smaller scale of a test reactor significantly changes the performance characteristics of the reactor class. Thus, a principal objective of a test reactor design is to exhibit adequate similarity to larger scale NPPs. A description of hydraulic code scaling for FHRs is presented in the "thermal and hydraulic methods" subdivision of Chapter 11 of this roadmap.

Both SFRs and LWRs used reduced-scale test reactors to obtain safety performance data, which were then extrapolated to larger reactor systems. The Experimental Breeder Reactor-II project extrapolated its 
60 MW(th) passive safety testing to “a wide range of sizes of LMRs of commercial interest” (Ref. 105). The EBR-II demonstration of lack of core damage from an unprotected loss of flow accident undergirds many of the safety claims made for SFRs today. Much of the data used to demonstrate the adequacy of the PWR thermal-hydraulic modeling tools was obtained from the loss of fluid test (LOFT) reactor. While FHRs do not have an equivalent accident, the scaling analysis used in the LOFT program provides guidance on acceptable extrapolation from small-scale reactor experiments to larger scale power plants. LOFT was a $50 \mathrm{MW}$ (th) PWR designed on the principal of volume scaling to simulate the major components and system responses of a four-loop [3,540 MW(th)] commercial PWR (Ref. 106).

An FHR's single phase, low pressure primary coolant and lower power density increases the potential fidelity of a test reactor to a commercial-scale system. Further, the modularity of an FHR's DRACS decay heat rejection system enables essentially full-scale testing of a DRACS loops in a test reactor. However, unlike LWRs (and to a lesser extent SFRs) the most vulnerable component of an FHR is the reactor vessel, not the fuel. Consequently, an FHR test reactor serves primarily to demonstrate integrated material, SSC, and reactor physics performance instead of primarily demonstrating hydraulic and heat transfer performance. However, much like the EBR-II safety testing experiments, demonstrating that a properly designed FHR will withstand even severe transients without core damage or reactor vessel yielding will provide stronger evidence for a licensing case than is possible via computational modeling. However, validating computational toolsets is a primary purpose of the overall experimental program. Thus, all of the planned experiments will include both a modeling prediction and experimental variance evaluation phase.

Integrated technology demonstration is key to ensuring that interdependent effects have been properly accounted for. Developing confidence in the reactor system working reliably is a key element in minimizing the risk premium component of financing a first commercial FHR NPP. System reliability is the dominant factor in maximizing plant availability. Finding and resolving any previously unidentified performance issues is, therefore, a key mission of FHR test reactor construction and operation.

To maximize the utility of a test reactor to generate design and licensing validation data, the experimental program plan will need to be central to the test reactor design requirements. Most safety and performance data can and thus should be obtained using simpler, cheaper experiments or models. The test reactor experimental program will be based upon demonstrating the validity of the plant safety and performance claims. Demonstrating compliance with the GDCs under normal, transient, and accident conditions will be the organizing principle for the overall program. However, the economic performance of an FHR would be improved by using commercial grade components for as many SSCs as possible. Demonstrating adequate safety performance with safety features bypassed provides evidence to decrease the safety classification of particular SSCs.

Initiating the FHR component and material supply chain is another purpose for the test reactor program. FHRs will use both components and materials that are not currently in widespread usage. A supplier base will be required in order to proceed into commercial deployment. Demonstration of component performance under realistic, integrated operating conditions will assist suppliers in developing and improving specific component designs. Further, by providing an initial market for the components the test reactor will provide incentive for suppliers to make the investment necessary to develop and gain approval of their specific components for use in nuclear power applications.

\subsection{INTERNATIONAL CRITICALITY TESTING AND TEST REACTOR DEVELOPMENT}

Both China and the Czech Republic have FHR test reactor and/or critical facility demonstration plans. The United States has not committed to any FHR test reactor development. The Czech criticality testing will take place using the SPHINX test facility at their existing experimental, light-water zero-power, pool- 
type reactor designated as LR-0 (Ref. 107). The SPHINX facility features a reconfigurable central region intended to accommodate graphite and fluoride salt configurations. The SPHINX central region is surrounded by reduced height LWR driver fuel to create a critical configuration. Czech researchers are currently planning their experimental program. Under the Memorandum of Understanding between DOE and the Ministry of Industry and Trade of the Czech Republic, the United States provided a portion of the MSRE intermediate loop salt to enable reactor physics measurements at the LR-0 facility. In return, the United States will have access to all of the data generated in the experiments. The joint intent is to publish the measurements as an international reactor physics benchmark experiment enabling the Chinese FHR development program to also benefit from the reactor physics measurements (Ref. 108).

SINAP currently has two FHR test reactors planned for construction near Shanghai. The first reactor will be limited to $2 \mathrm{MW}$ of thermal power. The first reactor is scheduled to achieve first criticality by the end of 2015 and ascend to power over the next two years. The principal mission of the first reactor is to understand integrated FHR performance issues and thereby increase confidence in FHRs as a viable reactor class. The second test reactor design is planned to have a power level between 10 and $20 \mathrm{MW}$ (th). The second test reactor design will depend significantly on the information developed by the first unit. As such only an approximate schedule of five years following completion of the first reactor is currently available. SINAP's current plans also call for a follow on first-of-a-kind FHR power plant roughly five years following the second test reactor. However, Chinese government approval for the FHR power plant has not yet been announced.

\subsection{TASKS}

\subsubsection{Establish SINAP-ORNL Cooperative R\&D Agreement (CRADA)}

The first step in the US FHR test reactor development support effort is to initiate a CRADA between the ORNL and SINAP on FHRs under the aegis of the Memorandum of Understanding on between DOE and the CAS on nuclear energy sciences and technologies signed in December 2011.

While ORNL and SINAP would be the lead US and Chinese organizations for FHR collaboration, it is intended that the CRADA would serve as a vehicle for other US and Chinese organizations to participate in the collaboration. The CRADA would enable Chinese access to US expertise on the broad set of technologies necessary to design and operate an FHR test reactor while the United States would gain access to the information generated by the extensive, ongoing and planned FHR materials, components, and systems R\&D efforts.

\subsubsection{Collaborate on SPHINX FHR Reactor Physics Benchmark Experiments}

Another near term task in the FHR test reactor development program is to work with Czech researchers to ensure that the reactor physics data obtained from LR-0 testing supports FHR reactor physics model validation. While Czech researchers are expected to lead the experimental and model validation efforts, US researchers will perform independent reactor physics modeling and assist in formulating the experimental plan and analyzing the data.

\subsubsection{Develop Test Reactor Experimental Plan}

This task will develop experimental plans for the envisioned FHR test reactors to ensure that desired capabilities are included from the design stage. The experiments to be performed will be informed by the HTR-10 and EBR-II experimental programs, as well as an analysis of the evidence required for NRC to be able to certify that the design features of FHRs will allow compliance with an FHR specific version of the GDCs. 
FHRs have a large set of test reactor design options. Much of the design for the first SINAP FHR test reactor will be set by the availability of fuel and materials due to the short time frame for initial criticality. However, to the extent possible, the reactor design should reflect the intended experimental program. A principal purpose for the test reactors is to verify safe operation under accident conditions. Safely simulating accidents, as well as monitoring the accident progression, to enable extrapolating the performance to larger scale FHRs, significantly influences the test reactor design. Lack of such considerations (as well as the decision to perform safety testing on a full-scale reactor) was one of the causes of the Chernobyl disaster. The ability to safety simulate accidents, thus, needs to be incorporated into the test reactor from the design stage.

Specific design features will need to be incorporated into the test reactor to simulate system and component failures in order to demonstrate achievement of safety goals when subjected to failures. For example, the melt point fuses in the control blade linkage would not be bypassable in a commercial plant. However, in order to demonstrate that neither fuel damage nor vessel yielding occurs for an unprotected loss of flow accident (matching the EBR-II demonstration), the melt point links in the control blades and the secondary poison salt injectors would need to be defeated. Demonstrating that adequate reactivity control is provided by the inherent thermal feedback mechanisms demonstrates compliance with the GDCs within Sect. III Protection and Reactivity Control Systems of 10CFR50 Appendix A under loss of forced flow accident conditions. Further, demonstrating that adequate reactivity control to achieve cold shutdown is provided through the control blade melt point fuses provides evidence to support the control blade drive motors being classified as part of the control system lowering their cost. 


\section{FHR TECHNOLOGY READINESS LEVEL ASSESSMENT}

This chapter provides a TRL assessment for the major SSCs of an FHR. The results from this TRL assessment were used as input to the development of other chapters of this FHR roadmap report. No FHR has yet reached the point of a complete preconceptual design. Hence, the level of precision in this TRL assessment is not as high as that performed for more mature reactor classes. The TRL of yet undesigned SSCs cannot be specified beyond providing general bounding information.

This evaluation follows the format of prior advanced reactor TRL assessments, beginning with an explanatory background on the TRL assessment process and the limitations to focusing solely on technology readiness when evaluating the readiness and maturity of reactor concepts. The chapter then discusses the limits on the precision of the TRL assessment arising from the lack of a completed preconceptual design, followed by a piecewise TRL assessment of the AHTR, which is the most mature FHR concept currently available. Finally, a summary table of the AHTR TRL assessment scores is presented in Sect. 16.3.

While TRL assessments have known limitations for estimating the required development effort level and time frame, as described later in this chapter, this initial assessment assists with evaluating the scope of the development effort. The TRL assessment also supports minimization of the development risk by identifying the current technological state of the art across the diverse set of required FHR technologies and in developing a more logical pathway for maturing the required technologies.

The TRL of an FHR is greatly influenced by the core outlet temperature, as higher temperature technologies are significantly more technically challenging. The AHTR is a design concept for a large, central-station-type first-generation FHR focused on maximizing system reliability and economic performance. The AHTR deliberately minimizes technology introduction into a first-of-a-kind system to maximize system reliability while minimizing development risk, even at some cost to the potential plant performance. The AHTR design team has selected $700^{\circ} \mathrm{C}$ as its baseline core outlet temperature with a fallback position of $650^{\circ} \mathrm{C}$. For a $700^{\circ} \mathrm{C}$ core outlet temperature, a supercritical steam cycle (with a peak steam temperature of $650^{\circ} \mathrm{C}$ ) provides the highest plant thermal efficiency along with a mature commercial pedigree. This TRL assessment is limited to the reactor and intermediate loop portions of the AHTR. Further, the TRL assessment is limited to FHR-specific technologies and does not address supporting technologies such as steel form concrete construction or seismic base isolation that are common across modern advanced reactors.

\subsection{BACKGROUND ON TECHNOLOGY READINESS LEVELS}

TRL assessments are a means to document the maturity of individual technology elements that together make up complex systems. Both the US Department of Defense and the US Government Accountability Office have recently provided guidance on how to perform TRL assessments (Refs. 109 and 110). This early-phase assessment follows the process outlined in the guidance documents with a lower degree of formality and depth-of-analysis than would be used for larger projects further along their development paths.

The overall goal of a TRL assessment is to assist in the determination of whether the required technologies have acceptable levels of risk based largely on the degree to which they have been demonstrated. TRL numbers provide a standardized knowledge-based shorthand for evaluating technology maturity. Formal TRL assessments should be performed by an independent team of subject matter experts with demonstrated, current expertise. However, due to the relative system immaturity, this early-phase TRL assessment has been performed internally. 
Table 6 provides an overview of the TRL categories, a description of each TRL, and examples of FHR relevant technologies at each level.

Table 6. Technology readiness level (TRL) categories, description, definition, and examples

\begin{tabular}{|c|c|c|c|}
\hline TRL & Category & Description & Advanced reactor definition and examples \\
\hline 1 & & $\begin{array}{l}\text { Lowest level of technology readiness. } \\
\text { Scientific research begins to be } \\
\text { translated into applied R\&D. }\end{array}$ & $\begin{array}{l}\text { New discoveries that may lead to performance } \\
\text { improvement or cost reductions. At this TRL, the } \\
\text { basic properties of advanced materials might be } \\
\text { studied (e.g., tensile strength as a function of } \\
\text { temperature and compatibility with fluoride salt), } \\
\text { and once it is demonstrated that these } \\
\text { fundamental properties are understood, the } \\
\text { advanced material would mature to the next } \\
\text { TRL. }\end{array}$ \\
\hline \multirow[t]{2}{*}{2} & & \multirow{2}{*}{$\begin{array}{l}\text { Application begins once basic } \\
\text { principles are observed; practical } \\
\text { applications can be invented. } \\
\text { Applications are speculative and no } \\
\text { proof or detailed analysis to support the } \\
\text { assumptions may yet exist. }\end{array}$} & $\begin{array}{l}\text { New discoveries may result in performance } \\
\text { improvements or cost reductions in future plants. }\end{array}$ \\
\hline & $\begin{array}{l}\text { Concept } \\
\text { development }\end{array}$ & & $\begin{array}{l}\text { For example, following the observation of } \\
\text { advanced materials properties at TRL } 1 \text {, the } \\
\text { potential applications of the new materials for } \\
\text { structural materials applications can be defined. } \\
\text { At this level, the application is still speculative; } \\
\text { there is no experimental proof or detailed } \\
\text { analysis to support the conjecture. }\end{array}$ \\
\hline 3 & & $\begin{array}{l}\text { Active R\&D is initiated. This includes } \\
\text { analytical studies and laboratory studies } \\
\text { to physically validate analytical } \\
\text { predictions of separate elements of the } \\
\text { technology. }\end{array}$ & $\begin{array}{l}\text { Analysis of the performance of SSCs produces } \\
\text { favorable results, but testing is needed to } \\
\text { validate the prediction and provide data } \\
\text { supporting key features. Examples would } \\
\text { include testing of carbon-sacrificial-electrode- } \\
\text { based redox oxygen removal and redox control } \\
\text { in FLiBe and confirming performance of new } \\
\text { optical access concepts for in-service inspection } \\
\text { of components and structures. In addition, CFCs } \\
\text { are key new materials for FHRs. The AHTR } \\
\text { depends on the irradiation and thermophysical } \\
\text { properties of both SiC-SiC and C-C CFCs- } \\
\text { TRL } 3 \text { would be attained when these materials } \\
\text { had undergone irradiation with subsequent PIE } \\
\text { and their post-irradiation thermophysical } \\
\text { properties were defined and known. }\end{array}$ \\
\hline 4 & $\begin{array}{l}\text { Proof-of- } \\
\text { principle }\end{array}$ & $\begin{array}{l}\text { Integration of basic technological } \\
\text { components for testing in laboratory } \\
\text { environment. Includes integration of ad } \\
\text { hoc hardware in the laboratory. }\end{array}$ & $\begin{array}{l}\text { Laboratory testing of individual components or } \\
\text { portions of systems has been completed } \\
\text { successfully. Examples would include separate } \\
\text { effects testing of component performance such } \\
\text { as ultrasonic flowmeter mounting onto nickel } \\
\text { alloy piping or fluidic diode performance testing } \\
\text { with water. }\end{array}$ \\
\hline
\end{tabular}


Table 6. Technology readiness level (TRL) categories, description, definition, and examples (continued)

\begin{tabular}{|c|c|c|c|}
\hline TRL & Category & Description & Advanced reactor definition and examples \\
\hline 5 & $\begin{array}{l}\text { Proof-of- } \\
\text { principle } \\
\text { (continued) }\end{array}$ & $\begin{array}{l}\text { Integration of basic technological } \\
\text { components with realistic supporting } \\
\text { elements for testing in relevant } \\
\text { environment. }\end{array}$ & $\begin{array}{l}\text { Individual components or portions of systems } \\
\text { have been successfully tested at less than full } \\
\text { scale in a test reactor, out-of-pile test facility, or } \\
\text { in another application. Examples would include } \\
\text { successful testing of a section of a fuel element } \\
\text { in a test reactor or successful testing of } \\
\text { individual hydraulic components of a molten salt } \\
\text { system in a molten salt loop. For example, a } \\
\text { reduced-size canned-rotor, magnetic bearing } \\
\text { pump promising a more robust primary plant } \\
\text { system design will be built and tested with a } \\
\text { fully-immersed FLiNaK environment and tested } \\
\text { with its power supply and control system. }\end{array}$ \\
\hline 6 & & $\begin{array}{l}\text { Model or prototype system testing in } \\
\text { relevant environment. }\end{array}$ & $\begin{array}{l}\text { Systems, subsystems, or components have been } \\
\text { demonstrated at less than full scale in a test } \\
\text { reactor, in an out-of-pile test facility, or in } \\
\text { another application. Examples would include } \\
\text { successful demonstration of individual fuel } \\
\text { elements in a test reactor or successful operation } \\
\text { of a section of a steam generator connected to a } \\
\text { salt loop. }\end{array}$ \\
\hline 7 & & $\begin{array}{l}\text { Demonstration of prototype system in } \\
\text { an operational environment at } \\
\text { engineering scale. }\end{array}$ & $\begin{array}{l}\text { The SSC or system behavior has been } \\
\text { successfully demonstrated under prototypic } \\
\text { conditions in a test reactor or in an out-of-pile } \\
\text { test facility if the SSC or system will never see a } \\
\text { radiation environment during anticipated } \\
\text { deployment operations. Examples would include } \\
\text { successful testing of a tritium-trapping heat } \\
\text { exchanger at a test reactor or demonstration of } \\
\text { redox control in a large test loop. }\end{array}$ \\
\hline 8 & $\begin{array}{l}\text { Proof-of- } \\
\text { performance }\end{array}$ & $\begin{array}{l}\text { End of system development. } \\
\text { Technology proven to work in } \\
\text { operational environment at engineering } \\
\text { to full scale. }\end{array}$ & $\begin{array}{l}\text { The SSC has been successfully deployed in } \\
\text { operations of a test reactor or a prototype of the } \\
\text { SSC has been successfully deployed in power } \\
\text { reactor operations, or a system characteristic has } \\
\text { been demonstrated in an experiment (i.e., loss of } \\
\text { forced flow passive safety demonstration). }\end{array}$ \\
\hline 9 & & $\begin{array}{l}\text { Full-scale application of technology in } \\
\text { its final form at mission conditions. }\end{array}$ & $\begin{array}{l}\text { The system, structure or component has been } \\
\text { successfully deployed in operations of a } \\
\text { commercial FHR (or another commercial power } \\
\text { reactor if the SSC is not liquid salt related, such } \\
\text { as containment structures), or a relevant system } \\
\text { behavior has been demonstrated in such a } \\
\text { reactor. }\end{array}$ \\
\hline
\end{tabular}

\subsubsection{Technology Readiness Level Limitations}

While potentially a useful planning support tool, TRL assessments have shown limitations. NPPs are not simply agglomerations of technologies. A reactor's licensability, its economic potential, and its environmental considerations have significant components outside of the scope of technology readiness. 
Additionally, TRL assessment presumes a continuous, linear development model starting with fundamental principles at a small scale and extending to a larger scale. The TRL-based development model poorly captures the issues of adapting proven technology to a new mission/environment and does not address technology obsolescence. Furthermore, while the level criteria are objective, the assessments are subjective. TRLs also, by applying the same scale to all technologies, do not address the difference in the degree of risk/difficulty in maturing distinct technologies. In general, TRL assessments are vulnerable to providing a deceptively simplistic portrait of the issues associated with reactor development/deployment.

A key development issue not well addressed by the TRL assessment process is the necessity to adapt the proven NRC, LWR-centric, licensing framework to FHRs. Important development issues such as development of a consensus set of accident initiators are not addressed through a TRL assessment process. The obsolescence of the prior, proven lithium isotope separation technology is also not recognized in the TRL assessment. The mercury-based COLEX process was developed into a mature, industrial-scale separated lithium isotope production process (TRL 9). However, processes that make large-scale use of mercury are no longer environmentally acceptable, and replacement technology will need to be matured. Moreover, FHRs must provide significant economic advantage over proven, acceptably safe LWR technologies to merit a large-scale development effort. The TRL assessment process does not address deciding on which ensemble of potential FHR technologies constitutes a sufficiently advantageous design to merit system development.

In a technology adaptation process, previously developed technology is applied to a different, but related, use that may introduce additional performance issues. For example, FHR SGs are functionally similar to those for MSRs or SFRs. Once the high-temperature material environmental tolerance issues for FHR SGs are resolved, much of the existing knowledgebase can be directly applied, markedly shortening the development process from the TRL-staged approach. Overall, FHRs are an amalgamation of technologies from prior reactors, development programs, and other industries. Thus, technology adaptation issues are especially key for FHRs, and their development path will include nonlinear maturity progression.

TRL assessments do not address the full spectrum of issues associated with reactor development/deployment. For example, a 2008 TRL assessment of lead-bismuth eutectic technology and materials for high-temperature advanced reactors gave a conservative evaluation of number seven, which would tend to give the impression that the reactor class was nearly ready for commercial deployment (Ref. 111). However, at the time of the TRL assessment (1) no licensing framework was under development, (2) no conceptual reactor design had been completed, and (3) no significant structural alloy code case (ASME BPVC Sect. III, Subsection NH) development effort was under way.

\subsubsection{Application of Technology Readiness Level Assessment Process to FHR Development}

Most aspects of FHR viability have been demonstrated. However, significant system integration and technology advancement remains before development of an economically viable, licensable system. The most significant overall FHR development issue is determining the integrated suite of technologies with minimum development cost/risk that can readily be licensed and will perform sufficiently, efficiently, and reliably for plant profitability. TRL assessment is primarily supportive of this overall goal by providing a consistent means to document the current FHR technology state of the art. FHRs, more than other reactor classes, depend on technologies that have been developed and demonstrated in other reactor technology programs, in some instances decades ago. Dependence on disparate technology antecedents makes constructing an integrated, consistent portrait of the remaining technology hurdles especially challenging. Equally important with respect to FHRs is that their technological readiness can easily be misinterpreted by either not accounting for historic precedent or not appreciating the full suite of remaining technology hurdles for a reliable, licensable, and economic NPP. 
A precise, confident FHR TRL assessment is not yet possible as the assessment process relies on a completed preconceptual design. While the AHTR has selected candidate technologies to fulfill each of the required plant functions, several component and system designs have yet to be completed. For example, it will need to be possible to remove fission products from failed fuel dissolved in the salt of an FHR's primary loop. The basic bismuth-lithium-alloy-based reductive extraction technology for removing both dissolved fuel and fission products from liquid fluoride salt was demonstrated during the MSR program. However, neither the mechanisms to interconnect the salt cleanup system to the primary coolant system (batch process versus an auxiliary loop), the necessary structural materials, nor the overall system performance requirements have yet been determined/developed. The allowable circulating activity depends on both accident progression analysis (potential dose to the public) and likely dose to the plant staff during maintenance activities. The salt cleanup system is also intended to remove the secondary poison salt if the secondary shutdown system is ever activated. FHRs do not yet have agreed upon DBAs nor validated modeling tools to evaluate accident progression. Note, as with most design issues, a reasonable preconceptual system design could be generated using a combination of highly simplified system models, precedent, and engineering judgment. The technologies selected for the initial design of the salt cleanup system may have a wide range of maturities. However, until an initial design of the primary salt cleanup system is performed, a TRL assessment would neither be especially informative to an external audience nor of significant use to the design team.

The principal intended use for the TRL assessment is as a design support tool. TRL assessment of different design options is a key portion of the trade studies necessary to assess the current state of the art in the specialized technologies necessary for FHR design, construction, evaluation, and operation. The TRL assessment would support refinement of an initial preconceptual design by providing a consistent assessment of the development stages of various technology options. The TRL assessment in conjunction with the technology roadmap promotes developing an understanding of the costs versus benefits, and likely timescale, of pursuing particular advanced technologies with an intention of deployment in a firstgeneration FHR power plant.

FHR SSC TRL assessments can vary widely based upon design assumptions and understanding of the diverse prior development efforts. INL recently published a TRL assessment of a SG for the AHTR that concludes that the TRL of the AHTR SG is three (Ref. 112). However, the INL evaluation does not reference the MSBR SG design performed in the 1970s for very similar conditions (Ref. 4). The MSBR SG design was both detailed (designed as a Class 1 vessel in accordance with Sect. III of the 1971 edition of the ASME BPVC) and mature, relying on the large amount of Alloy N property (Refs. 5 and 113), performance (Refs. 114 and 115), and fabrication (Refs. 116 and 117) data generated for the MSR program, most of which was not referenced in the INL report. However, as the core outlet temperature increases, the knowledgebase for FHR SG design becomes much more sparse, and the INL TRL assessment is more nearly correct since the SG remains in the concept development phase.

FHRs use an amalgam of technologies from other reactor classes (e.g., fuel from the AGR program and an SG combining elements from the MSR, SFR, and HTGR programs) making TRL assessment more complex than for other advanced reactors. Also increasing the difficulty of making a useful assessment is the combination of relatively simple operations in a high-temperature liquid salt environment. Similar machines to those that would be used to manipulate the AHTR's fuel assemblies are in widespread industrial use. However, the specific application of the mechanisms to an FHR environment has not been addressed, leading to the conundrum, "Should the refueling mechanism TRL be assessed as nearly ready for full-scale testing with an explanatory asterisk, or as at early phase proof-of-concept with a potential for very rapid advancement?" Therefore in the following section, rather than attempting to justify a specific TRL for the various components evaluated, a TRL range is provided for each, along with a description of the major issues involved with developing mature, reliable FHR technologies. 
The TRL of technologies for a test reactor is not necessarily the same as that of a commercial power plant. The lower risk to the public, smaller size, potential for enhanced monitoring, and smaller cost increase the TRL of many of the key technologies for test reactor deployment. In fact, the test reactor is in itself an element in the development process for commercial FHRs. Minimizing technology development for a test reactor is especially important as establishing the reliability of FHR technology is a key component to transitioning FHRs into commercial deployment.

\subsection{FHR SYSTEMS, STRUCTURES, AND COMPONENTS TRL ASSESSMENT}

The TRL assessment is subdivided by system, structure, or component. The subdivision is based upon a traditional reactor breakdown structure. Each evaluated element is first listed, a score presented, and then a brief discussion of the ranking rationale provided. Current descriptions of the AHTR SSCs are available in the recent design report (Ref. 114).

\section{Fuel particles-5-7}

Identical fuel particles (with potentially different enrichment) to those currently being qualified under the AGR program are intended for the AHTR. The scale issue for TRL advancement is not in the particles themselves but in the increase in the scale of fabrication equipment. The operational temperatures of FHR fuel particles are likely to be somewhat lower than HTGRs.

\section{Fuel plate-3-4}

Fabrication processes and performance of fuel compacts for HGTRs provide basic production information. The fuel plate production steps are mechanically simple and well known. Issues involving larger scale fuel elements and integration into fuel assemblies remain largely unexplored.

\section{Reactor core structure-3-5}

All of the core materials have had basic performance demonstrations (e.g., general principles of the radiation response of $\mathrm{C}-\mathrm{C}$ composites are established, the compatibility of fluoride salts with carbon is well-known, heat transfer correlations for FLiBe have been established). No integration evaluations have been performed, nor has an initial hydraulic design of the AHTR core been performed.

\section{Reactor vessel internals-4-5}

Mechanical performance and general radiation response of both SiC-SiC and C-C CFCs have been established. Specific design for the AHTR remains to be performed. An adequate material specification for C-C composites (different feedstock, different fabrication methods) has yet to be established. Environmental compatibility of the selected C-C CFC with fluoride salt remains to be established.

\section{Control blades-5}

Both the radiation performance and chemical compatibility of molybdenum with fluoride salts has been established. The impact of the hafnium alloying addition remains to be demonstrated. Fabrication properties of molybdenum alloys are well established.

\section{Thermal release mechanisms $-3-4$}

Melt point alloys are a proven, commercial technology. However, use in a near core environment along with the specific chemical environment of the AHTR primary loop is unproven. Also, acceptable methods for acceptance testing and periodic surveillance will need to be developed, as the releases are a safety feature. Note, this technology is likely to have a nonlinear TRL advancement, as the release mechanisms are not highly scale dependent. 


\section{Secondary shutdown poison salt injectors-3-4}

The concept of an accumulator injecting material is an established commercial technology. The solubility of rare earth fluorides in FLiBe is known. Operation at temperature, in a near-core environment remains to be proven. Also, the rate of dissolution of the poison salt and its introduction into the core remain to be demonstrated. For example, if the secondary salt were to agglomerate in the accumulator before use, the poison salt could become a slowly dissolving plug in the lower reactor plenum rather than being rapidly incorporated in the primary coolant.

\section{Fluidic diodes-3-7}

Fluidic diodes themselves are a known, commercial technology. Neither, the scale nor the operating conditions are outside of normal practice. However, a specific design that integrates the diode into the downcomer flow stream and the lower outlet of the DRACS in-vessel heat exchanger has yet to be designed. Further, the integration issues involving mounting the fluidic diode within the vessel to minimize bypass flow are complex.

\section{DRACS in-vessel heat exchanger-3-8}

The DRACS in-vessel heat exchanger is likely to be a tube bundle type heat exchanger similar in size to the MSRE primary-to-intermediate heat exchanger. Tube-bundle-type heat exchangers are the most widely used industrial format. However, a specific design for the AHTR has not yet been developed.

\section{Reactor vessel-3-8}

Fabrication methods for thin-walled vessels from proposed AHTR alloys are well-known, commercial technologies. Further, the MSRE reactor vessel provided a demonstration of the vessel performance. However, the long-term high-temperature alloy degradation mechanisms in a molten salt environment are not well known. The variation in the TRL is thus principally based upon vessel lifetime specification.

\section{Primary piping-3-8}

Methods for fabricating piping from the proposed AHTR alloys are well-known. The AHTR design has been selected to minimize hydraulic stresses on piping. However, the long-term high-temperature alloy degradation mechanisms in a molten salt environment are not well known. The variation in the TRL is thus principally based upon the lifetime specification.

\section{DRACS piping-3-8}

Methods for fabricating piping from the proposed AHTR alloys are well-known. The AHTR design has been selected to minimize hydraulic stresses on piping. The DRACS loop introduces the additional challenge of ensuring sufficient heating to avoid freeze-up while preserving the low-pressure drop necessary for natural circulation flow. However, the long-term high-temperature alloy degradation mechanisms in a molten salt environment are not well known. The variation in the TRL is thus principally based upon the lifetime specification.

\section{Primary coolant pump-4-7}

An overhung cantilever pump would be similar to that used at the MSRE. However, modern seals and bearings were not demonstrated at the MSRE and appear to be important to long, maintenance-free intervals. The AHTR's primary coolant pumps will also be significantly larger than those demonstrated to date. 


\section{P-IHX-3-7}

The P-IHX represents a blend of double-walled heat exchanger technology and yttrium-based tritium trapping in a liquid salt shell-and-tube style heat exchanger. The MSRE demonstrated liquid salt shelland-tube heat exchangers. Other industries have demonstrated double-walled heat exchangers. However, an AHTR design that includes a tritium-trapping layer has yet to be designed.

\section{Primary loop redox control system-3-5}

The use of sacrificial carbon electrodes in fluoride salts is the basis for aluminum electrowinning from molten cryolite. Beryllium contacting as a mechanism to cause FLiBe to become more reducing was demonstrated in the MSR program. However, a specific design of the overall system has yet to be created.

\section{Primary loop salt cleanup system-4}

Bismuth-lithium alloy-based reductive extraction technology development was a significant development focus for the MSR program. However, integration issues with introducing the technology into a reactor were largely unaddressed. Also, the materials issues associated with long-term operation of liquid bismuth containing vessels remain unresolved.

\section{Instrumentation-4-9}

Much of the instrumentation for an FHR is classical and thus commercial. However, several instruments such as the in-vessel optical measurements have significant unresolved integration issues. Further, developing sensitive neutron flux measuring instruments that are capable of operating at FHR temperatures is only at early-phase experimentation.

\section{DRACS NDHX -5-7}

NDHXs are a well-known commercial technology. However, a specific design for the AHTR has not yet been performed leaving system integration issues such as developing a compliant mounting system to accommodate thermal expansion unresolved. Further, integrating tritium trapping into the NDHX design may introduce unforeseen complications.

\section{Maintenance heat transfer system-5-8}

The maintenance heat exchange system is essentially a pumped liquid salt loop. Its smaller scale increases its correspondence to previous laboratory demonstrations and the MSRE intermediate loop. However, an initial design for the AHTR maintenance heat exchange loop has not yet been generated.

\section{Intermediate loop piping-5-8}

Piping for molten salts is reasonably mature. However, the long-term high-temperature alloy degradation mechanisms in a molten salt environment are not well known. The intermediate loop may experience more frequent transients than the primary loop due to maintenance shutdowns of the power cycle.

\section{Intermediate loop components-4-7}

The intermediate loop incorporates hydraulic components such as bellows, rupture disks, a pump, a redox control system, and a salt impurity removal system. The basic technology underlying these items has been demonstrated in related but nonidentical systems.

\section{Steam generator-4-7}

The MSBR program generated an SG design that would be appropriate for a $650^{\circ} \mathrm{C}$ core outlet temperature. At this lower temperature the FHR development requirements also merge with those of 
SFRs. A steam temperature of $650^{\circ} \mathrm{C}$ is commercial state of the art in the fossil industry. Use of Sect. I (power boilers) of the ASME BPVC for the AHTR SG increases the ability to introduce innovative technology. However, a specific SG design for the AHTR has not yet been created.

\section{Lithium isotope separation-4-6}

Displacement band chromatography and electrophoresis-based separation technologies have been demonstrated in the laboratory for the fusion program. Closely related separation technologies are available at commercial scale. However, the specific requirements for FHRs in terms of throughput and feedstock purity have not yet been addressed.

\section{Refueling mechanisms - 5-8}

The refueling mechanisms themselves are classical. However, integration issues with the control system and the hydraulic design have not been completed. Even an initial water mock-up model has yet to be created to ensure that the hydraulic and access issues have been appropriately considered.

\section{Safety assessment tools-3-6}

No accident initiators or DBAs have yet been developed, so the modeling tool requirements have not yet been developed. However, single-phase heat transfer and coolant flow are comparatively simple to model. Also, the lower core power density and large mass of primary coolant decreases the modeling fidelity required.

\section{Containment-8}

The containment is almost entirely classical and low pressure. However, preserving the capability to remove the roof for long-term maintenance introduces an unproven design element.

\subsection{TRL SUMMARY AND CONCLUSIONS}

Performing this early phase TRL assessment documents the current state of the art in FHR technologies and provides both a reference for evaluating development tasks and an integrated reference to earlier related development work. This early-phase TRL assessment will also serve as a straw man to facilitate introducing currently unrecognized technology to the FHR program staff. Finally, this early phase TRL assessment will serve as a benchmark to gauge future development progress against. Table 7 presents a summary of the AHTR TRL assessment scores. 
Table 7. AHTR TRL assessment scores

\begin{tabular}{lr}
\hline \multicolumn{1}{c}{ SSC } & TRL \\
\hline Fuel particles & $5-7$ \\
Fuel plates & $3-4$ \\
Reactor core structures & $3-5$ \\
Reactor vessel internals & $4-5$ \\
Control blades & 5 \\
Thermal release mechanisms & $3-4$ \\
Secondary shutdown poison salt injectors & $3-4$ \\
Fluidic diodes & $3-7$ \\
DRACS in-vessel heat exchangers & $3-8$ \\
Maintenance heat transfer systems & $5-8$ \\
Intermediate loop pipings & $5-8$ \\
Intermediate loop components & $4-7$ \\
Steam generators & $4-7$ \\
Lithium isotope separations & $4-6$ \\
Refueling mechanisms & $5-8$ \\
Safety assessment tools & $3-6$ \\
Containment & 8 \\
\hline
\end{tabular}

FHRs are largely at an engineering development phase of maturity. No AHTR TRL is below two, where a proof-of-concept has been established. The only potentially conceptually limiting technology still at early phase development is tritium trapping in the P-IHX. However, all aspects of FHRs (including the nontechnological licensing, commercialization, and concept evaluation areas) require significant further development. Concept and technology development need to be pursued in parallel as each informs the other. Safety and licensing, as well as economic performance evaluation, need to be considered independently of technology evaluation.

The TRL scores only indicate current technology maturity; they do not indicate the difficulty, risk, or time required for developing any particular technology to commercial readiness. The scores presented in this chapter are a subjective evaluation and have not been submitted for independent peer review. The combination of the subjective nature of the evaluation and the nonlinearity of the maturity scale limits the utility of the TRL scores for extrapolation of required system development effort or time. 


\section{FHR RD\&D TASK INTEGRATION AND COMPILATION}

This chapter has two primary purposes: (1) to compile a list of RD\&D tasks as a guide to where in the roadmap the topic is primarily addressed and other locations where closely related RD\&D issues are described and (2) to show a somewhat more detailed breakdown of the key elements of the RD\&D of two example topic areas: tritium control and structural materials development. Successfully maturing each of the FHR technology areas requires completion of a number of interrelated tasks. However, FHRs are not yet sufficiently mature to permit developing a complete work breakdown structure. Moreover, creation of a detailed task plan will need to be a collaborative effort between the United States and China. Two of the key FHR technology areas have been selected to illustrate the currently identified development subtasks. The RD\&D necessary for tritium management and structural material development are graphically presented in Fig. 10 and Fig. 11.

Figure 8 illustrates the relative progression and relationships of individual development activities necessary to provide the capability to contain and capture tritium for first-generation FHRs. The current design intent is not to actively strip tritium from the primary coolant but to chemically capture tritium as it emerges from the primary coolant. This approach avoids the issue of effectively separating a low concentration of dissolved gas from a high-temperature liquid, instead relying on the ability to strip hydrogen isotopes from inert gases and to chemically trap tritium as stable metal hydride using yttrium. Developing a doubled-walled P-IHX that includes a tritium-trapping layer thus becomes a key task. Technologies for trapping and blocking tritium escape are discussed in both Chapters 5 and 14 of this roadmap. A logical task progression is to conduct initial testing using nonradioactive hydrogen isotopes as a surrogate for tritium and then moving forward to a laboratory-scale, double-walled fluoride salt PIHX, and finally to a demonstration system including both beryllium bearing salts and tritium to demonstrate system performance and thereby to meet GDC 60.

Fig. 11 provides a comparable breakdown of the principal activities required for FHR-focused materials development. The materials RD\&D activities align with the list of materials development tasks from Chapter 5 and are illustrated showing the sequence of activities to be performed rather than from a timebased perspective. The materials development activities fall into three areas: (1) alloy assessment and approval for test reactor applications, (2) alloy development for use at commercial FHR power plants, and (3) CFC materials development for in-vessel FHR components. A set of proposed activities is listed for the development, standardization, and fabrication of large and complex FHR structures using CFC materials. Parallel efforts to evaluate, and/or qualify Alloy N and SS316 for use in FHR test reactors are also identified. Finally, activities are identified to support the development of higher strength, creep resistant, salt compatible alloys to enable longer structure and component lifetimes. More details on the technology development aspects for each of these three areas are discussed in Chapter 5 . The materials RD\&D activities presented in the current document only provide a high-level outline of the necessary development activities. Thus, preparing a more detailed, focused material development roadmap is recommended as a near-term task in Fig. 11.

FHRs rely upon an integrated suite of technologies that do not subdivide cleanly into separate topic areas. Thus, development tasks for fuels, licensing, materials, coolants, thermal hydraulics, etc. overlap and/or are closely coupled. Every development chapter includes a set of recommended tasks as the next step to address each FHR technology issue. The listed tasks are most closely associated with the chapter in which they are presented. References to other report locations where associated issues are discussed are also provided. Table 8 presents a compilation of recommended tasks as a quick reference to the primary and secondary locations where specific development issues are presented in the roadmap. 


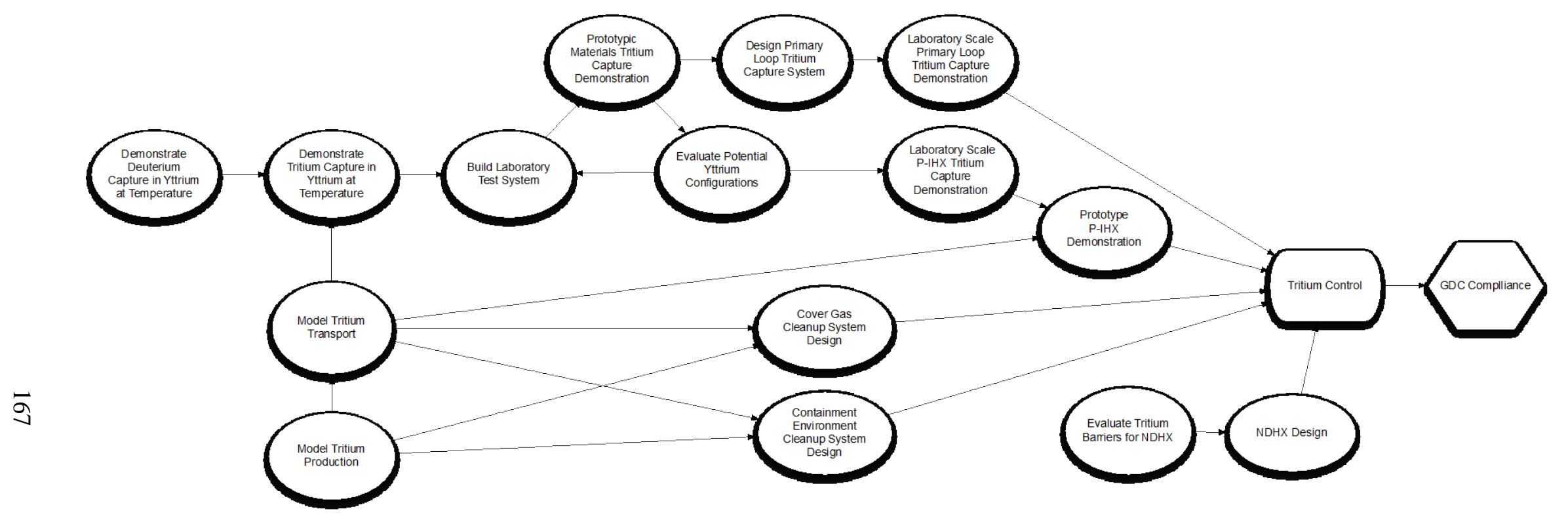

Fig. 10. Tritium capture technology development tasks. 


\section{Materials Development for Test Reactors}

Limited Term Alloy N Qualification

SS316 Primary Loop Assessment

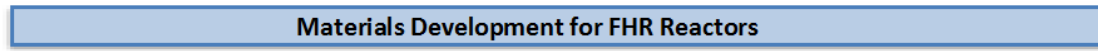

Alloy 800 H Code Activities

Weld Overlay Coating Code Acceptance

Precipitation Strengthened Salt Compatible Alloy

Development

Assessment

Joining \& Forming

Qualification

Continuous Fiber Composite (CFC) Development

\begin{tabular}{|c|c|c|}
\hline Continuous Fiber Composite (CFC) Development \\
\hline CFC Specification & $\begin{array}{c}\text { Develop CFC } \\
\text { Characterization } \\
\text { Procedure }\end{array}$ & $\begin{array}{c}\text { CFC Radiation } \\
\text { Performance Testing }\end{array}$ \\
\hline $\begin{array}{l}\text { CFC Environmental } \\
\text { Compatibility Testing }\end{array} \quad$ CFC Code Development Fabrication Technology
\end{tabular}

Development of FHR Focused Materials Roadmap

Fig. 11. Principal materials-related RD\&D tasks for FHRs. 


\begin{tabular}{|c|c|c|c|}
\hline \multicolumn{2}{|c|}{$\begin{array}{r}\text { Chapter } \\
\end{array}$} & \multirow[t]{2}{*}{ Task overview } & \multirow[t]{2}{*}{ Related chapters (\#) } \\
\hline 2. $\mathrm{Co}$ & ept Development & & \\
\hline 2.4 .1 & $\begin{array}{l}\text { Overall FHR concept } \\
\text { development }\end{array}$ & $\begin{array}{l}\text { Modify the plant concept and associated development plan to } \\
\text { reflect new information as the design and technology develop. }\end{array}$ & \\
\hline 2.4 .2 & $\begin{array}{l}\text { AHTR thermal and } \\
\text { hydraulic evaluation }\end{array}$ & $\begin{array}{l}\text { Develop an integrated system model of the NO condition fluid } \\
\text { flows and heat transfer. Progressively add additional details to } \\
\text { the model such as: flows within individual fuel assemblies, } \\
\text { impact of fuel plate warping and potential vibration, upper } \\
\text { plenum flow mixing, and core support plat stress; transient } \\
\text { evaluation capabilities; and start-up, power level changes, and } \\
\text { refueling cooling capabilities. }\end{array}$ & $\begin{array}{l}\text { Design Tools and Methods (11) and Safety and } \\
\text { Licensing (6) }\end{array}$ \\
\hline 2.4 .3 & Salt cleanup system & $\begin{array}{l}\text { Perform an initial assessment of how to couple the salt cleanup } \\
\text { system to the primary coolant loop, required system size and } \\
\text { plant location, and the construction materials. }\end{array}$ & $\begin{array}{l}\text { Salt (7), Fuel Development and Qualification (4), } \\
\text { Structural and Functional Materials (5), and } \\
\text { Demonstration and Validation Facilities (14) }\end{array}$ \\
\hline 2.4 .4 & $\begin{array}{l}\text { Reactor cavity and } \\
\text { component cooling } \\
\text { system }\end{array}$ & $\begin{array}{l}\text { Design the reactor cavity cooling system and the necessary } \\
\text { ducting to ensure cooling of the reactor vessel silo. Explore the } \\
\text { design issues for cooling the primary pumps with inert gas. } \\
\text { Develop the reactor cavity heat-up models to develop } \\
\text { confidence that even during loss of forced flow accidents, the } \\
\text { reactor cavity will not heat up unacceptably. }\end{array}$ & Safety and Licensing (6) \\
\hline 2.4 .5 & $\begin{array}{l}\text { Cover gas cooling and } \\
\text { cleanup system }\end{array}$ & $\begin{array}{l}\text { Evaluate the technology options and design requirements for the } \\
\text { AHTR cover gas cooling and cleanup system and based upon } \\
\text { the technology options selected, provide an initial system } \\
\text { layout. }\end{array}$ & \\
\hline 2.4 .6 & $\begin{array}{l}\text { Salt loop heating } \\
\text { systems }\end{array}$ & $\begin{array}{l}\text { Perform a preliminary system layout for the salt electrical } \\
\text { heaters and electrical power distribution system. }\end{array}$ & \\
\hline 2.4 .7 & $\begin{array}{l}\text { Cathodic fluoride salt } \\
\text { redox control system }\end{array}$ & $\begin{array}{l}\text { Assess the performance of the primary coolant loop and design } \\
\text { a mechanically robust cathodic type redox protection system for } \\
\text { the system. }\end{array}$ & $\begin{array}{l}\text { Salt (7), Structural and Functional Materials (5), } \\
\text { Demonstration and Validation Facilities (14), and } \\
\text { Component Development and Testing (8) }\end{array}$ \\
\hline
\end{tabular}


Table 8. FHR development task summary (continued)

\begin{tabular}{|c|c|c|c|}
\hline & Chapter & Task overview & Related chapters (\#) \\
\hline \multicolumn{4}{|c|}{ 2. Concept Development (continued) } \\
\hline 2.4 .8 & $\begin{array}{l}\text { Plant lifecycle } \\
\text { functional evaluation }\end{array}$ & $\begin{array}{l}\text { Divide the plant lifecycle into states and assess the SSC } \\
\text { performance requirements for each state to ensure that the full } \\
\text { AHTR plant lifecycle has been considered in the concept } \\
\text { development process and that the SSC requirements reflect all } \\
\text { of the required functions. }\end{array}$ & Operations and Maintenance (10) \\
\hline 2.4 .9 & $\begin{array}{l}\text { Tritium capture/control } \\
\text { technology assessment }\end{array}$ & $\begin{array}{l}\text { Assess and demonstrate tritium trapping and control technology } \\
\text { and develop an acceptable means to block tritium transport into } \\
\text { the AHTR intermediate coolant loop. }\end{array}$ & $\begin{array}{l}\text { Safety and Licensing (6), Structural and Functional } \\
\text { Materials (5), Component Development and Testing } \\
\text { (8), Demonstration and Validation Facilities (14), } \\
\text { and Design Tools and Methods (11) }\end{array}$ \\
\hline \multicolumn{4}{|c|}{ 3. FHR Technology Gap Analysis } \\
\hline 3.2 & $\begin{array}{l}\text { Gap analysis task } \\
\text { description }\end{array}$ & $\begin{array}{l}\text { Use a structured peer review process to ensure that all of the } \\
\text { technology hurdles required to develop FHR test reactors, as } \\
\text { well as a first-of-a-kind commercial power plant, have been } \\
\text { identified and assessed. }\end{array}$ & Concept Development (2) \\
\hline \multicolumn{4}{|c|}{ 4. Fuel Development and Qualification } \\
\hline 4.5 .1 & $\begin{array}{l}\text { Mechanical validation } \\
\text { of layered TRISO fuel } \\
\text { structures }\end{array}$ & $\begin{array}{l}\text { Fabricate test layered TRISO fuel coupons to demonstrate } \\
\text { mechanical characteristics of layered TRISO fuel structures to } \\
\text { ensure adequate mechanical performance in service. }\end{array}$ & $\begin{array}{l}\text { Safety and Licensing (6), Demonstration and } \\
\text { Validation Facilities (14), and Structural and } \\
\text { Functional Materials (5) }\end{array}$ \\
\hline 4.5 .2 & $\begin{array}{l}\text { Layered TRISO fuel } \\
\text { structures scaling rule } \\
\text { development }\end{array}$ & $\begin{array}{l}\text { Fabricate, irradiate, and test coupons of various sizes to develop } \\
\text { the capability to extrapolate the performance of large multilayer } \\
\text { ceramic nuclear fuel structures using materials property data } \\
\text { acquired by testing small-scale coupons. }\end{array}$ & $\begin{array}{l}\text { Safety and Licensing (6) and Design Tools and } \\
\text { Methods (11) }\end{array}$ \\
\hline 4.5 .3 & $\begin{array}{l}\text { Integrated } \\
\text { demonstration of fuel } \\
\text { assemblies }\end{array}$ & $\begin{array}{l}\text { Fabricate fuel assembly segments from prototypical materials to } \\
\text { ensure that no unforeseen issues arise as a result of fabrication, } \\
\text { assembly, or thermal cycling. }\end{array}$ & $\begin{array}{l}\text { Safety and Licensing (6), Structural and Functional } \\
\text { Materials (5), and Test Reactors (15) }\end{array}$ \\
\hline 4.5 .4 & $\begin{array}{l}\text { Salt cleanup system } \\
\text { design and } \\
\text { demonstration }\end{array}$ & $\begin{array}{l}\text { Develop and demonstrate the capability to cleanup small fuel } \\
\text { leaks from primary salt system. }\end{array}$ & $\begin{array}{l}\text { Salt (7), Structural and Functional Materials (5), } \\
\text { and Demonstration and Validation Facilities (14) }\end{array}$ \\
\hline
\end{tabular}


Table 8. FHR development task summary (continued)

\begin{tabular}{|c|c|c|c|}
\hline \multicolumn{2}{|r|}{ Chapter } & Task overview & Related chapters (\#) \\
\hline \multicolumn{4}{|c|}{ 5. Structural and Functional Materials } \\
\hline 5.2 .7 & Control blades & $\begin{array}{l}\text { Establish chemical compatibility of MHC with primary coolant. } \\
\text { Establish mechanical tolerances and allowable fuel assembly } \\
\text { bowing. }\end{array}$ & $\begin{array}{l}\text { Safety and Licensing (6), Component Development and } \\
\text { Testing (8), Demonstration and Validation Facilities } \\
\text { (14), and Fuel Development and Qualification (4) }\end{array}$ \\
\hline $\begin{array}{l}5.2 .7 \\
5.2 .9\end{array}$ & Fuse links & $\begin{array}{l}\text { Select specific alloy compositions for temperature yield points. } \\
\text { Establish chemical compatibility with primary coolant. }\end{array}$ & $\begin{array}{l}\text { Component Development and Testing (8) and } \\
\text { Demonstration and Validation Facilities (14) }\end{array}$ \\
\hline \multirow[t]{2}{*}{5.2 .11} & Salt compatible bearings & $\begin{array}{l}\text { Assess and demonstrate performance of commercially available } \\
\mathrm{SiC} \text { and diamond bearings for use in fluoride salts. }\end{array}$ & $\begin{array}{l}\text { Demonstration and Validation Facilities (14) and } \\
\text { Component Development and Testing (8) }\end{array}$ \\
\hline & Dry gas seals & $\begin{array}{l}\text { Assess and demonstrate performance of dry gas seals in FHR } \\
\text { conditions at appropriate scale. }\end{array}$ & $\begin{array}{l}\text { Demonstration and Validation Facilities (14) and } \\
\text { Component Development and Testing (8) }\end{array}$ \\
\hline 5.2 .19 & SG & $\begin{array}{l}\text { Mature the advanced alloy and in situ reconditioning technique } \\
\text { sufficiently to bring them into industrial practice. }\end{array}$ & $\begin{array}{l}\text { Demonstration and Validation Facilities (14) and } \\
\text { Component Development and Testing (8) }\end{array}$ \\
\hline \multirow[t]{7}{*}{5.3} & $\begin{array}{l}\text { FHR focused materials } \\
\text { roadmap }\end{array}$ & $\begin{array}{l}\text { Develop an FHR materials roadmap with sufficient depth to } \\
\text { describe the required development effort at a specific task level. }\end{array}$ & \\
\hline & $\begin{array}{l}\text { Salt compatible CFC } \\
\text { development }\end{array}$ & $\begin{array}{l}\text { Add fluoride salt environmental qualification during the } \\
\text { development process to the existing DOE-NE sponsored CFC } \\
\text { development programs-in particular the SiC/SiC BWR channel } \\
\text { box development effort. }\end{array}$ & \\
\hline & $\begin{array}{l}\text { Salt compatible C-C } \\
\text { CFC development }\end{array}$ & $\begin{array}{l}\text { Revive the C-C development effort from the NGNP program } \\
\text { and include the testing, standardization, and quality assurance. }\end{array}$ & \\
\hline & $\begin{array}{l}\text { Limited use case Alloy } \\
\mathrm{N} \text { qualification }\end{array}$ & Perform a limited term qualification of Alloy N. & Test Reactors (15) \\
\hline & $\begin{array}{l}\text { Code case development } \\
\text { for weld on liners }\end{array}$ & $\begin{array}{l}\text { Add design rules to apply analogous procedures to cladding low } \\
\text { alloy steel with stainless steel for PWRs to HTRs. }\end{array}$ & \\
\hline & $\begin{array}{l}\text { SS316 evaluation for } \\
\text { primary loop } \\
\text { components }\end{array}$ & $\begin{array}{l}\text { Evaluate the capability of online redox control to enable the use } \\
\text { of SS316 in the primary loop. }\end{array}$ & Salt (7) \\
\hline & $\begin{array}{l}\text { Advanced salt- } \\
\text { compatible alloy } \\
\text { development }\end{array}$ & $\begin{array}{l}\text { Continue property and performance measurements on higher- } \\
\text { performance nickel-based alloys, so that the alloys will be } \\
\text { qualified for use in first-generation commercial FHRs. Include } \\
\text { qualification activities as funding becomes available. }\end{array}$ & \\
\hline
\end{tabular}


Table 8. FHR development task summary (continued)

\begin{tabular}{|c|c|c|c|}
\hline \multirow{2}{*}{\multicolumn{2}{|c|}{$\begin{array}{c}\text { Chapter } \\
\text { 6. Safety and Licensing }\end{array}$}} & Task overview & \multirow[t]{2}{*}{ Related chapters (\#) } \\
\hline & & & \\
\hline 6.2 .1 & $\begin{array}{l}\text { Define FHR specific } \\
\text { GDC }\end{array}$ & $\begin{array}{l}\text { Work with the ANS } 20.1 \text { standard development group to create } \\
\text { consensus FHR specific GDCs that follow the generic GDCs } \\
\text { being developed by the joint NRC-DOE development effort. }\end{array}$ & \\
\hline 6.2 .2 & Establish a QA program & $\begin{array}{l}\text { Define the QA program based on either the requirements in } \\
\text { Appendix B of } 10 \text { CFR } 50 \text { and/or the ASME NQA-1 program. }\end{array}$ & \\
\hline 6.2.3.1 & $\begin{array}{l}\text { Identify accident } \\
\text { initiating events }\end{array}$ & $\begin{array}{l}\text { Develop an FHR specific list of initiating events and provide } \\
\text { estimates of the initiating event frequencies. }\end{array}$ & Design Tools and Methods (11) \\
\hline 6.2.3.2 & Select LBEs & $\begin{array}{l}\text { Develop the accident sequences (LBEs) that represent the FHR } \\
\text { designed response to the initiating events using loss of primary } \\
\text { system boundary integrity as a surrogate for CDF. }\end{array}$ & Design Tools and Methods (11) \\
\hline 6.2.3.3 & Categorize LBEs & $\begin{array}{l}\text { Estimate the frequencies of the LBEs and establish the AC, } \\
\text { which together will be used to categorize the LBEs into } \\
\text { abnormal operational occurrences, DBAs, or BDBAs. }\end{array}$ & Design Tools and Methods (11) \\
\hline 6.2.3.4 & $\begin{array}{l}\text { Identify and classify } \\
\text { SSC }\end{array}$ & $\begin{array}{l}\text { Identify and categorize the SSCs based upon their function and } \\
\text { safety significance. }\end{array}$ & \\
\hline 6.2.4.1 & $\begin{array}{l}\text { Perform a regulatory } \\
\text { gap analysis }\end{array}$ & $\begin{array}{l}\text { Perform a gap analysis to determine applicability of the LWR } \\
\text { guidance provided in Chaps. } 4-11 \text { of NUREG-0800 (Ref. 11) to } \\
\text { an FHR and to define separate or additional requirements } \\
\text { associated with the unique features or systems of the FHR. }\end{array}$ & Technology Gap Analysis (3) \\
\hline 6.2.4.2 & $\begin{array}{l}\text { Implement a fuel } \\
\text { qualification program }\end{array}$ & $\begin{array}{l}\text { Supplement the existing AGR fuel qualification program with } \\
\text { FHR specific elements }\end{array}$ & Fuel Development and Qualification (4) \\
\hline 6.2 .4 .3 & $\begin{array}{l}\text { Develop severe accident } \\
\text { evaluation capability }\end{array}$ & $\begin{array}{l}\text { Address the design margin related to severe accidents along } \\
\text { with severe accident modeling capability to ensure that } \\
\text { consequences of these events are adequately estimated. }\end{array}$ & \\
\hline 6.2 .5 & $\begin{array}{l}\text { Determine the adequacy } \\
\text { of codes and standards }\end{array}$ & $\begin{array}{l}\text { Perform a gap analysis to determine the codes and standards } \\
\text { that are applicable to FHRs, determine required changes in } \\
\text { existing codes and standards, and identify new codes and } \\
\text { standards needed to address the unique features of an FHR. }\end{array}$ & Technology Gap Analysis (3) \\
\hline
\end{tabular}




\begin{tabular}{|c|c|c|c|}
\hline \multicolumn{2}{|r|}{ Chapter } & Task overview & Related chapters (\#) \\
\hline \multicolumn{4}{|c|}{ 6. Safety and Licensing (continued) } \\
\hline 6.2 .6 & Beryllium hazards & $\begin{array}{l}\text { Define a program that will ensure that all aspects of beryllium } \\
\text { handling and storage (including waste) will meet applicable } \\
\text { federal and state requirements for test loops, test and } \\
\text { commercial reactors. }\end{array}$ & \\
\hline 6.3 & $\begin{array}{l}\text { Demonstrate the } \\
\text { adequacy of models }\end{array}$ & $\begin{array}{l}\text { Develop a validation process for models and simulations that } \\
\text { would be used to support the safety case for an FHR. }\end{array}$ & Design Tools and Methods (11) \\
\hline 6.4 & $\begin{array}{l}\text { Demonstrate adequacy } \\
\text { of design }\end{array}$ & $\begin{array}{l}\text { Establish the process for proceeding from a prototype to a } \\
\text { commercial operating license via a series of hold-points during } \\
\text { the plant commissioning and initial operations that would } \\
\text { require NRC permission to proceed beyond. }\end{array}$ & Test Reactors (15) \\
\hline \multicolumn{4}{|l|}{ 7. Salt } \\
\hline 7.2 .4 & $\begin{array}{l}\text { Lithium isotope } \\
\text { separation trade study } \\
\text { and evaluation }\end{array}$ & $\begin{array}{l}\text { Perform a trade study on lithium isotope separation } \\
\text { technologies and perform engineering and economic } \\
\text { evaluations of selected isotope separation technology. End-to- } \\
\text { end demonstration of selected technology. }\end{array}$ & Economics and Commercialization (12) \\
\hline 7.3.2.3 & $\begin{array}{l}\text { Primary loop redox } \\
\text { control }\end{array}$ & $\begin{array}{l}\text { Design primary intermediate loop redox control system and } \\
\text { demonstrate in electrically heated loops. }\end{array}$ & $\begin{array}{l}\text { Demonstration and Validation Facilities (14) and } \\
\text { Instrumentation (9) }\end{array}$ \\
\hline 7.3 .3 & $\begin{array}{l}\text { Intermediate loop redox } \\
\text { control }\end{array}$ & $\begin{array}{l}\text { Establish } \mathrm{KF}-\mathrm{ZrF}_{4} \text { properties. Evaluate and rank potential redox } \\
\text { couples. Design intermediate loop redox control system. } \\
\text { Demonstrate selected redox control technology. }\end{array}$ & $\begin{array}{l}\text { Salt (7) and Demonstration and Validation } \\
\text { Facilities (14) }\end{array}$ \\
\hline 7.4 .5 & $\begin{array}{l}\text { Secondary shutdown } \\
\text { salt removal }\end{array}$ & $\begin{array}{l}\text { Design, build, and demonstrate a side-stream, lithium-bismuth- } \\
\text { based rare earth extraction system. }\end{array}$ & $\begin{array}{l}\text { Concept Development (2), Structural and } \\
\text { Functional Materials (5), and Design Tools and } \\
\text { Methods (11) }\end{array}$ \\
\hline 7.5 .4 & Fission product removal & $\begin{array}{l}\text { Develop a basic conceptual design for the primary salt cleanup } \\
\text { system and integrate it into the AHTR. Define a process for } \\
\text { progressive system maturation and validation. }\end{array}$ & $\begin{array}{l}\text { Concept Development (2), Safety and Licensing (6), } \\
\text { Structural and Functional Materials (5), and } \\
\text { Design Tools and Methods (11) }\end{array}$ \\
\hline \multicolumn{4}{|c|}{ 8. Component Development and Testing } \\
\hline 8.2.1.2 & Mechanical pumps & $\begin{array}{l}\text { Demonstrate the performance of the recently built pump within } \\
\text { the LSTL. Refine and optimize the current pump and evaluate } \\
\text { design issues for larger pumps. }\end{array}$ & $\begin{array}{l}\text { Concept Development (2) and Demonstration and } \\
\text { Validation Facilities (14) }\end{array}$ \\
\hline
\end{tabular}


Table 8. FHR development task summary (continued)

\begin{tabular}{|c|c|c|c|}
\hline \multicolumn{2}{|r|}{ Chapter } & Task overview & Related chapters (\#) \\
\hline \multicolumn{4}{|c|}{ 8. Component Development and Testing (continued) } \\
\hline \multirow[t]{3}{*}{ 8.2.2.2 } & $\begin{array}{l}\text { Tritium-trapping } \\
\text { double-walled heat } \\
\text { exchangers }\end{array}$ & $\begin{array}{l}\text { Develop, assess, and demonstrate doubled-walled P-IHX with } \\
\text { integrated tritium trapping. }\end{array}$ & $\begin{array}{l}\text { Structural and Functional Materials (5), Construction } \\
\text { and Manufacturing (13), and Safety and Licensing (6) }\end{array}$ \\
\hline & $\begin{array}{l}\text { Tritium trapping from } \\
\text { primary coolant }\end{array}$ & $\begin{array}{l}\text { Design and demonstrate precious metal coated yttrium trapping } \\
\text { system. }\end{array}$ & $\begin{array}{l}\text { Demonstration and Validation Facilities (14) and } \\
\text { Safety and Licensing (6) }\end{array}$ \\
\hline & $\begin{array}{l}\text { Natural circulation heat } \\
\text { exchanger design }\end{array}$ & $\begin{array}{l}\text { Demonstrate the modeling performance of buoyancy driven } \\
\text { flow, complex geometry, and flow development. }\end{array}$ & $\begin{array}{l}\text { Demonstration and Validation Facilities (14) and } \\
\text { Design Tools and Methods (11) }\end{array}$ \\
\hline 8.2 .3 & Bellows validation & $\begin{array}{l}\text { Select a particular bellows configuration based upon } \\
\text { performance requirements estimates, identify a manufacturer, } \\
\text { and integrate a test part into a test facility. }\end{array}$ & Demonstration and Validation Facilities (14) \\
\hline 8.2 .4 & Rupture disks & $\begin{array}{l}\text { Assess the licensing issues involved with implementing rupture } \\
\text { disks as a safety element on the intermediate loop. }\end{array}$ & $\begin{array}{l}\text { Demonstration and Validation Facilities (14) and } \\
\text { Safety and Licensing (6) }\end{array}$ \\
\hline \multirow[t]{2}{*}{8.2 .5} & Mechanical valves & $\begin{array}{l}\text { Use carbide-coated materials to design, fabricate, and } \\
\text { demonstrate fluoride salt mechanical valves. }\end{array}$ & $\begin{array}{l}\text { Structural and Functional Materials (5), } \\
\text { Demonstration and Validation Facilities (14), and } \\
\text { Operations and Maintenance (10) }\end{array}$ \\
\hline & Freeze valves & Develop modern freeze valves. & \\
\hline 8.2 .6 & Flanges & $\begin{array}{l}\text { Develop guidance for both spiral wound carbon-nickel, } \\
\text { metallic, and pressurized O-ring type gasket materials for use in } \\
\text { flange joints in liquid fluoride salt loops. }\end{array}$ & $\begin{array}{l}\text { Structural and Functional Materials (5), } \\
\text { Demonstration and Validation Facilities (14), and } \\
\text { Operations and Maintenance (10) }\end{array}$ \\
\hline 8.2 .7 & $\begin{array}{l}\text { Fuel assemblies and } \\
\text { control blade vibration }\end{array}$ & $\begin{array}{l}\text { Assess fuel plate and control blade vibration issues using } \\
\text { surrogate materials and the utility of SiC leaf springs for } \\
\text { vibration damping. }\end{array}$ & $\begin{array}{l}\text { Demonstration and Validation Facilities (14), Fuel } \\
\text { Development and Qualification (4), and Structural } \\
\text { and Functional Materials (5) }\end{array}$ \\
\hline 8.2 .8 & Control blade drive & $\begin{array}{l}\text { Demonstrate performance of representative control blade drive } \\
\text { mechanisms in representative operating conditions. }\end{array}$ & $\begin{array}{l}\text { Demonstration and Validation Facilities (14), Safety } \\
\text { and Licensing (6) }\end{array}$ \\
\hline 8.2 .10 & Used fuel pool cooling & $\begin{array}{l}\text { Design and model the natural draft-based used fuel pool backup } \\
\text { cooling system. }\end{array}$ & $\begin{array}{l}\text { Design Tools and Methods (11), Safety and Licensing } \\
\text { (6), and Demonstration and Validation Facilities (14) }\end{array}$ \\
\hline 8.2.11 & Refueling & $\begin{array}{l}\text { Create a computer-based model of the refueling system } \\
\text { operation and its interaction with I\&C. A scaled, surrogate } \\
\text { material mock-up, followed by a more detailed mock-up using } \\
\text { fluoride salt is then recommended. }\end{array}$ & $\begin{array}{l}\text { Instrumentation (9), Operations and Maintenance (1), } \\
\text { and Demonstration and Validation Facilities (14) }\end{array}$ \\
\hline
\end{tabular}


Table 8. FHR development task summary (continued)

\begin{tabular}{|c|c|c|c|}
\hline \multicolumn{2}{|r|}{ Chapter } & Task overview & Related chapters (\#) \\
\hline \multicolumn{4}{|c|}{ 9. Instrumentation (continued) } \\
\hline \multirow[t]{7}{*}{9.7} & I\&C architecture & Develop a specification for the plant I\&C architecture. & \\
\hline & $\begin{array}{l}\text { Complete NEET and } \\
\text { AdvSMR I\&C projects }\end{array}$ & $\begin{array}{l}\text { Key existing projects are (1) advanced I\&C technologies for } \\
\text { improved NPP components, for which a canned-rotor, magnetic } \\
\text { bearing fluoride salt pump has been selected as the } \\
\text { demonstration vehicle; (2) AdvSMR system performance } \\
\text { modeling tool development; ( } 3 \text { ) high-temperature fission } \\
\text { chamber development; (4) JNT; and (5) optical access into } \\
\text { reactor primary coolant loops. }\end{array}$ & \\
\hline & $\begin{array}{l}\text { Optical liquid salt } \\
\text { diagnostic techniques }\end{array}$ & $\begin{array}{l}\text { Develop optical liquid salt measurement and diagnostic } \\
\text { technologies. }\end{array}$ & Salt (7) and Structural and Functional Materials (5) \\
\hline & $\begin{array}{l}\text { Activation flowmeter } \\
\text { development }\end{array}$ & $\begin{array}{l}\text { Develop a gamma-based flowmeter for primary loop flow } \\
\text { measurements. }\end{array}$ & \\
\hline & $\begin{array}{l}\text { Redox measurement } \\
\text { technologies }\end{array}$ & $\begin{array}{l}\text { Develop of primary loop compatible online, electrochemical } \\
\text { salt redox-condition measurement instrumentation. }\end{array}$ & Structural and Functional Materials (5) \\
\hline & Ultrasonic flowmeters & $\begin{array}{l}\text { Demonstrate and validate the ultrasonic flowmeters for liquid } \\
\text { salt loops under reactor operating conditions. }\end{array}$ & \\
\hline & Au-Pt thermocouples & Develop an industrial version of the Au-Pt thermocouple. & \\
\hline \multicolumn{4}{|c|}{ 10. Operations and Maintenance } \\
\hline 10.4 .2 & $\begin{array}{l}\text { Diagnostics and } \\
\text { inspections }\end{array}$ & $\begin{array}{l}\text { Develop and demonstrate online surveillance and periodic } \\
\text { offline inspection. }\end{array}$ & Component Development and Testing (8) \\
\hline 10.4.3 & Concept of operations & Perform a functional evaluation over the plant lifecycle. & \\
\hline 10.4 .4 & Visual inspection & Demonstrate and validate under-salt visual inspection. & $\begin{array}{l}\text { Structural and Functional Materials (5) and } \\
\text { Demonstration and Validation Facilities (14) }\end{array}$ \\
\hline 10.4 .5 & $\begin{array}{l}\text { Control mechanism } \\
\text { surveillance and testing }\end{array}$ & $\begin{array}{l}\text { Develop and demonstrate control mechanism testing and } \\
\text { surveillance procedures. }\end{array}$ & $\begin{array}{l}\text { Demonstration and Validation Facilities (14) and } \\
\text { Component Development and Testing (8) }\end{array}$ \\
\hline 10.4.6 & $\begin{array}{l}\text { Testing methods for } \\
\text { secondary shutdown }\end{array}$ & $\begin{array}{l}\text { Demonstrate the performance of the poison salt injectors using } \\
\text { the component test loops and performing hydraulic and } \\
\text { neutronic modeling and simulation of the salt injection process. }\end{array}$ & Demonstration and Validation Facilities (14) \\
\hline
\end{tabular}


Table 8. FHR development task summary (continued)

\begin{tabular}{|c|c|c|c|}
\hline \multicolumn{2}{|r|}{ Chapter } & Task overview & Related chapters (\#) \\
\hline \multicolumn{4}{|c|}{ 10. Operations and Maintenance (continued) } \\
\hline 10.4 .7 & $\begin{array}{l}\text { Demonstrate operation } \\
\text { of salt cleanup system }\end{array}$ & $\begin{array}{l}\text { Demonstrate the efficacy of the salt cleanup system using } \\
\text { nonradioactive and non-isotopically selected materials in an } \\
\text { FLiBe test facility. }\end{array}$ & $\begin{array}{l}\text { Salt (7) and Demonstration and Validation } \\
\text { Facilities (14) }\end{array}$ \\
\hline 10.4 .8 & $\begin{array}{l}\text { Demonstrate operation } \\
\text { of refueling system } \\
\text { monitoring }\end{array}$ & $\begin{array}{l}\text { Develop a virtual reality-type display of the fuel motion during } \\
\text { fuel transfers and a virtual reality reconstruction of the in-vessel } \\
\text { process that will need to be provided to improve the ability of } \\
\text { the operators to oversee the interrelated series of refueling } \\
\text { motions. }\end{array}$ & Instrumentation (9) and Concept Development (2) \\
\hline \multicolumn{4}{|c|}{ 11. Design Tools and Methods } \\
\hline \multirow[t]{3}{*}{11.4} & $\begin{array}{l}\text { Preliminary thermal- } \\
\text { hydraulic design }\end{array}$ & $\begin{array}{l}\text { Develop a preliminary thermal-hydraulic design based on } \\
\text { recent core design studies. Use TRACE for system analysis and } \\
\text { sizing and higher resolution modeling using codes such as } \\
\text { STAR-CCM+ for more detailed designs of select subsystems } \\
\text { and components. }\end{array}$ & \\
\hline & Develop a PIRT & Develop a PIRT to identify areas requiring further study. & \\
\hline & $\begin{array}{l}\text { Update and optimize } \\
\text { TRACE }\end{array}$ & Update and optimize TRACE to include liquid salt properties. & \\
\hline 11.5 .3 & $\begin{array}{l}\text { Reactor physics } \\
\text { modeling }\end{array}$ & $\begin{array}{l}\text { Assess and validate the fidelity of the SCALE modeling } \\
\text { package for FHR core designs. }\end{array}$ & Test Reactors (15) \\
\hline 11.5 .4 & $\begin{array}{l}\text { Optimize SCALE for } \\
\text { FHRs }\end{array}$ & $\begin{array}{l}\text { Automate the ability of SCALE to address multiscale core } \\
\text { heterogeneity evaluation and core geometry definition. }\end{array}$ & \\
\hline \multicolumn{4}{|c|}{ 12. Economics and Commercialization } \\
\hline 12.5 .1 & $\begin{array}{l}\text { International } \\
\text { collaboration }\end{array}$ & $\begin{array}{l}\text { Develop and maintain a strong working relationship with CAS } \\
\text { and other international FHR programs. }\end{array}$ & \\
\hline 12.5 .2 & $\begin{array}{l}\text { Economic model } \\
\text { development }\end{array}$ & $\begin{array}{l}\text { Integrate improved FHR technology understanding into the } \\
\text { AHTR economic model as improvements develop. }\end{array}$ & \\
\hline
\end{tabular}


Table 8. FHR development task summary (continued)

\begin{tabular}{|c|c|c|c|}
\hline \multicolumn{2}{|r|}{ Chapter } & Task overview & Related chapters (\#) \\
\hline \multicolumn{4}{|c|}{ 12. Economics and Commercialization (continued) } \\
\hline 12.5 .3 & Utility guidance & $\begin{array}{l}\text { Seek to inform utilities about this developing reactor class and } \\
\text { seek guidance about specific FHR design features much as } \\
\text { utility guidance documents have provided input to LWR } \\
\text { developments. }\end{array}$ & \\
\hline 12.5 .4 & $\begin{array}{l}\text { FHR technology } \\
\text { maturation }\end{array}$ & $\begin{array}{l}\text { Develop the capability to evaluate FHR accident progression to } \\
\text { assess the potential to reduce the emergency planning zone to } \\
\text { the site boundary. }\end{array}$ & Concept Development (2) \\
\hline \multicolumn{4}{|c|}{ 13. Construction and Manufacturing } \\
\hline \multirow[t]{4}{*}{13.9} & Safety classification & $\begin{array}{l}\text { Perform preliminary SSC safety classification reflective of } \\
\text { FHR passive safety characteristics. }\end{array}$ & \\
\hline & $\begin{array}{l}\text { Construction and } \\
\text { manufacturing } \\
\text { evaluation }\end{array}$ & $\begin{array}{l}\text { Perform a more detailed construction and manufacturing } \\
\text { breakdown of the AHTR to begin to evaluate bottlenecks and } \\
\text { unresolved issues in FHR manufacturing and construction. }\end{array}$ & Concept Development (2) \\
\hline & $\begin{array}{l}\text { System engineering } \\
\text { tools }\end{array}$ & $\begin{array}{l}\text { Perform a trade study to evaluate systems engineering tools for } \\
\text { FHR requirements tracking and inspections during } \\
\text { construction. }\end{array}$ & \\
\hline & $\begin{array}{l}\text { Economic assessment of } \\
\text { fuel and coolant } \\
\text { manufacturing }\end{array}$ & $\begin{array}{l}\text { Perform more detailed economic assessments of fuel and } \\
\text { coolant manufacturing costs to provide additional confidence in } \\
\text { FHR economic viability. }\end{array}$ & Fuel Development and Qualification (4) and Salt (7) \\
\hline \multicolumn{4}{|c|}{ 14. Demonstration and Validation Facilities } \\
\hline \multirow[t]{2}{*}{ 14.3.1 } & CIET-UC Berkeley & $\begin{array}{l}\text { Complete the simulant fluid testing program planned for CIET } \\
\text { including simulating start-up and shutdown, loss of forced } \\
\text { circulation with scram, and passive insertion of a buoyant } \\
\text { shutdown rod in a bypass channel. }\end{array}$ & \\
\hline & $\begin{array}{l}\text { Low temperature } \\
\text { DRACS-OSU }\end{array}$ & $\begin{array}{l}\text { Assess the performance of a DRACS and the performance and } \\
\text { viability of its components. }\end{array}$ & \\
\hline \multirow[t]{2}{*}{ 14.3.2.1 } & Control blade testing & $\begin{array}{l}\text { Design, construct, and operate a control blade test stand at } \\
\text { prototypic temperature. }\end{array}$ & $\begin{array}{l}\text { Operations and Maintenance (10), Structural and } \\
\text { Functional Materials (5), and Safety and Licensing (6) }\end{array}$ \\
\hline & $\begin{array}{l}\text { Secondary shutdown } \\
\text { mechanism }\end{array}$ & Demonstrate secondary shutdown mechanism performance. & $\begin{array}{l}\text { Operations and Maintenance (10), Structural and } \\
\text { Functional Materials (5), and Salt (7) }\end{array}$ \\
\hline
\end{tabular}


Table 8. FHR development task summary (continued)

\begin{tabular}{|c|c|c|c|}
\hline \multicolumn{2}{|r|}{ Chapter } & Task overview & Related chapters (\#) \\
\hline \multicolumn{4}{|c|}{ 14. Demonstration and Validation Facilities (continued) } \\
\hline \multirow[t]{3}{*}{ 14.3.2.2 } & Tritium trapping & Develop a tritium trapping test plan. & Safety and Licensing (6), Component Development \\
\hline & & $\begin{array}{l}\text { Assess the capability of the STAR facility at INL to } \\
\text { accommodate the testing. }\end{array}$ & $\begin{array}{l}\text { and Testing (8), and Structural and Functional } \\
\text { Materials (5) }\end{array}$ \\
\hline & NDHX tritium capture & $\begin{array}{l}\text { Demonstrate that tritium will not escape during NO, and to } \\
\text { prove that the fusible links are effective in allowing the } \\
\text { DRACS to remove decay heat when required. }\end{array}$ & $\begin{array}{l}\text { Safety and Licensing (6) and Component } \\
\text { Development and Testing (8) }\end{array}$ \\
\hline 14.3.2.3 & Refueling demonstration & $\begin{array}{l}\text { Develop progressively more realistic mock-ups of the refueling } \\
\text { process. }\end{array}$ & $\begin{array}{l}\text { Instrumentation (9), Safety and Licensing (6), } \\
\text { Structural and Functional Materials (5), Design } \\
\text { Tools and Methods (11) }\end{array}$ \\
\hline 14.3.2.4 & DRACS demonstration & $\begin{array}{l}\text { Use CIET, OSU high-temperature DRACS test facility, and the } \\
\text { ORNL LSTL to validate the performance of DRACS. }\end{array}$ & $\begin{array}{l}\text { Safety and Licensing (6), Design Tools and } \\
\text { Methods (11), and Concept Development (2) }\end{array}$ \\
\hline 14.3.2.5 & $\begin{array}{l}\text { Used fuel decay heat } \\
\text { rejection demonstration }\end{array}$ & $\begin{array}{l}\text { Demonstrate proper functioning of the passive used fuel decay } \\
\text { heat rejection system. }\end{array}$ & Safety and Licensing (6) \\
\hline 14.3.3.1 & $\begin{array}{l}\text { LSTL commissioning } \\
\text { and operation }\end{array}$ & Commission and operate the ORNL LSTL. & $\begin{array}{l}\text { Instrumentation (9), Component Development and } \\
\text { Testing (8), Structural and Functional Materials } \\
\text { (5), and Operations and Maintenance (10) }\end{array}$ \\
\hline 14.3.3.2 & $\begin{array}{l}\text { In-Line Test Facility } \\
\text { design and construction }\end{array}$ & $\begin{array}{l}\text { Develop a versatile testing platform for component testing in } \\
\text { high-temperature fluoride salts. }\end{array}$ & \\
\hline & $\begin{array}{l}\text { Integral Pool Test } \\
\text { Facility }\end{array}$ & $\begin{array}{l}\text { Develop a scaled version of the core and vessel that includes } \\
\text { the major components of the reactor system. }\end{array}$ & \\
\hline \multicolumn{4}{|c|}{ 15. Test Reactors } \\
\hline 15.4.1 & $\begin{array}{l}\text { Establish SINAP-ORNL } \\
\text { CRADA }\end{array}$ & $\begin{array}{l}\text { Initiate a CRADA between ORNL and SINAP on FHRs under } \\
\text { the aegis of the Memorandum of Understanding between DOE } \\
\text { and the CAS on nuclear energy sciences and technologies } \\
\text { signed in December } 2011 \text {. }\end{array}$ & \\
\hline 15.4 .2 & $\begin{array}{l}\text { Collaborate on FHR } \\
\text { reactor physics } \\
\text { benchmark experiments } \\
\text { with Czech Republic }\end{array}$ & $\begin{array}{l}\text { Work with Czech researchers to ensure that the reactor physics } \\
\text { data obtained from LR-0 testing supports FHR reactor physics } \\
\text { model validation. }\end{array}$ & \\
\hline
\end{tabular}


Table 8. FHR development task summary (continued)

Chapter

Task overview

Related chapters (\#)

15. Test Reactors (continued)

15.4.4 Develop test reactor

experimental plan

Develop experimental plans for the envisioned FHR test

reactors to ensure that desired capabilities are included from

the design stage. 


\section{CONCLUSIONS AND RECOMMENDATIONS}

FHRs have the potential to provide large quantities of safe, cost effective energy on demand, thus providing the potential to positively impact US national interests. The potential to provide a significant portion of US electricity and support the production of hydrocarbon fuels with minimal adverse environmental impact and limited water resource requirements could significantly impact the US economy. Private sector energy policy evaluations have recently begun to recognize the high potential for FHRs to substantially lower the price for nuclear power (Ref. 118). FHRs have an easy to understand safety case that can be leveraged to lower plant costs and, unlike other advanced reactor classes, are solely focused on minimizing the cost of energy.

First-generation FHRs do not require any technology breakthroughs but do require significant concept development, system integration, and technology maturation. Later generation FHRs will have substantial remaining room for improved performance once first-generation systems have been introduced into the market. Higher temperature alloys would enable both higher thermal efficiency and additional process heat applications. Online refueling would enable higher power density cores, reducing plant capital costs. Advanced power cycles such as the supercritical carbon dioxide Brayton cycle would enable smaller, lessexpensive components. The open-air Brayton power cycle may enable efficient integration with natural gas for improved peaking performance. An integrated thorium/uranium power cycle could lower the fuel cycle cost and improve resource sustainability. FHRs do not include fissile material separations technology development but otherwise include nearly all of the technologies necessary for MSRs. Thus, FHR development would also support denatured MSRs (e.g., MSRs without integrated fuel reprocessing).

The Chinese FHR development program offers the potential for first-generation systems to enter the market significantly more rapidly than would otherwise be possible. The planned, initial Chinese test reactors and the accompanying technology development program will generate a substantial amount of the information necessary for commercial FHR deployment. However, a prototype reactor (constructed after these reactors) that is subject to US licensing appears to be the most expeditious path for widespread commercial deployment. The strong FHR passive safety characteristics combined with recently initiated non-LWR advanced reactor licensing framework development efforts in the US appears likely to make obtaining DCs for particular FHR designs reasonable at predictable costs and schedules.

Nevertheless, FHR development in the US will not happen without sustained RD\&D investment. A primary limitation to private sector investment is in the lengthy time frame for development and deployment prior to receiving a return on investment. Also, multiple private sector evaluations explain why federal investment in energy RD\&D is in the national interest (Refs. 92 and 119). Further, the societal benefits of improved energy technologies such as cleaner air or the capability to produce hydrocarbon fuel from domestic sources is primarily in the domain of the federal government.

Maintaining a core US FHR RD\&D program is necessary both to advance the technology and to effectively collaborate with international partners (and thereby obtain access to their technology developments). A core US FHR RD\&D effort would consist of (1) continuing the TRISO fuel testing effort underway and (2) funding the US FHR concept and technology development efforts sufficiently to contribute to the broad set of technology development projects currently underway. US experts can remain relevant to the development efforts at an initial funding level of a few million dollars per year ramping up to approximately $\$ 10$ million per year in the 2016-2017 time frame. It is recommended that the RD\&D program be centered in the DOE national laboratory system but that use be made of US university capabilities. It is anticipated that a decade of US investment, along with the international programs, would enable confident FHR economic performance assessments of sufficient fidelity to trigger private sector investment and enable prototype FHR power plant deployment in the United States with limited federal support. 


\section{REFERENCES}

1. V. K. Varma, D. E. Holcomb, F. J. Peretz, E. C. Bradley, D. Ilas, A. L. Qualls, and N. M. Zaharia, AHTR Mechanical, Structural, and Neutronic Preconceptual Design, ORNL/TM-2012/320, ORNL, Oak Ridge, TN, September 2012.

2. D. E. Holcomb, F. J. Peretz, and A. L. Qualls, Advanced High Temperature Reactor Systems and Economics Analysis, ORNL/TM-2011/364, ORNL, Oak Ridge, TN, September 2011.

3. NGNP Industry Alliance, HTGR Technology Downselect Decision Paper-NGNP Industry Alliance, February 7, 2012, http://www.ngnpalliance.org/index.php/resources/category/general-documents.

4. Foster Wheeler Corporation, Task1-Final Report, Design Studies of Steam Generators for MoltenSalt Reactors, Report ND/74/66, Livingston, NJ, December 1974.

5. R. W. Swindeman, The Mechanical Properties of INOR-8, ORNL-2780, ORNL, Oak Ridge, TN, January 1961.

6. U.S. Atomic Energy Commission, An Evaluation of the Molten Salt Breeder Reactor, WASH-1222, September 1972.

7. G. T. Mays, A. N. Smith, and J. R. Engel, Distribution and Behavior of Tritium in the Coolant-Salt Technology Facility, ORNL-TM-5759, ORNL, Oak Ridge, TN, April 1977.

8. D. F. Williams, Assessment of Candidate Molten Salt Coolants for the NGNP/NHI Heat-Transfer Loop, ORNL-TM-2006/69, ORNL, Oak Ridge, TN.

9. G. F. Flanagan, D. E. Holcomb, and M. S. Cetiner, FHR Generic Design Criteria, ORNL/TM2012/226, ORNL, Oak Ridge, TN, June 2012.

10. Report to Congress: Advanced Reactor Licensing, US Nuclear Regulatory Commission (NRC), Washington, DC, August 2012.

11. Standard Review Plan for the Review of Safety Analysis Reports for Nuclear Power Plants, LWR Edition, NUREG-0800, NRC, Washington, DC, March 2007.

12. A Proposed Risk Management Regulatory Framework, NUREG-2150, NRC, Washington, DC, April 2012.

13. Y. Chikazawa, M. Farmer, and C. Grandy, "Technology Gap Analysis on Sodium-Heated Steam Generators Supporting Advanced Burner Reactor Development,” Nuclear Technology, 164, 410 432 (2008).

14. S. J. Ball, Next Generation Nuclear Plant GAP Analysis Report, ORNL-TM-2007/228, ORNL, Oak Ridge, TN, July 2008.

15. TRISO-Coated Particle Fuel Phenomenon Identification and Ranking Tables (PIRTs) for Fission Product Transport Due to Manufacturing, Operations, and Accidents: Main Report, NUREG/CR6844, Vol. 1, NRC, Washington, DC, July 2004.

16. Technical Program Plan for the Next Generation Nuclear Plant/Advanced Gas Reactor Fuel Development and Qualification Program, PLN-3636, INL, Idaho Falls, ID, September 2010.

17. Evaluation of MHTGR Fuel Reliability-Chapter 6 LWR Fuel Reliability Perspective, NUREG/CR5810 and ORNL/TM-12014, NRC, Washington, DC and ORNL, Oak Ridge, TN. 
18. Next Generation Nuclear Plant Fuel Qualification White Paper, INL/EXT-10-17686, INL, Idaho Falls, ID, July 2010.

19. Assessment of White Paper Submittals on Fuel Qualification and Mechanistic Source Terms, Revision 1, NRC, Office of New Reactors, Washington, DC, March 2013.

20. J. R. Engel and R. C. Steffy, Xenon Behavior in the Molten Salt Reactor Experiment, ORNL-TM3464, ORNL, Oak Ridge, TN, October 1971.

21. A Review of Radionuclide Release from HTGR Cores During Normal Operation, EPRI-1009382, Palo Alto, CA, February 2004.

22. H. E. McCoy and B. McNabb, Post Irradiation Examination of Materials from the MSRE, ORNLTM-4174, ORNL, Oak Ridge, TN, December 1972.

23. "Fuel Performance and Fission Product Behavior in Gas-Cooled Reactors," Section 5.3, Water Ingress Accidents, IAEA-TECDOC-978, International Atomic Energy Agency, Vienna, Austria, 1997.

24. J. D. Hunn, R. N. Morris, J. H. Miller, and R. D. Hunt, Overview of Key Issues and Guidelines for Regulatory Oversight and Inspection of High Temperature Gas Reactor Fuel Fabrication and Quality Control Activities, ORNL/TM-2009/041 Revision 1, ORNL, Oak Ridge, TN, May 2009.

25. Y. Katoh, L. L. Snead, C. M. Parish, and T. Hinoki, "Observation and Possible Mechanism of Irradiation-Induced Creep in Ceramics,” Journal of Nuclear Materials, 434 (2013) 141-151.

26. M. W. Rosenthal et al., "Recent Progress in Molten Salt Reactor Development,” Atomic Energy Review, IX, No. 3, 601-650 (1971).

27. L. M. Ferris, "Measurement of Distribution Coefficients in Molten-Salt-Metal Systems,” pp. 279284 in Molten-Salt Reactor Program Semiannual Progress Report, ORNL-TM-4396, ORNL, Oak Ridge, TN, June 1974.

28. W. R. Corwin et al., Generation IV Reactors Integrated Materials Program Plan: Focus on Very High Temperature Reactor Materials, ORNL/TM-2008/129, ORNL, Oak Ridge, TN, August 2008.

29. Y. Katoh, D. F. Wilson, and C. W. Forsberg, Assessment of Silicon Carbide Composites for Advanced Salt-Cooled Reactors, ORNL/TM-2007/168 Revision 1, ORNL, Oak Ridge, TN, September 2007.

30. Y. Katoh, L. L. Snead, T. D. Burchell, and W. E. Windes, Composite Technology Development Plan, ORNL/TM-2009/185 Revision 2, ORNL, Oak Ridge, TN, January 2010.

31. P. S. Weitzel, Steam Generator for Advanced Ultra-Supercritical Power Plants 700 to $760^{\circ} \mathrm{C}$, Technical Paper BR-1852, ASME 2011 Power Conference, July 12-14, 2011, Denver, CO.

32. R. Sims and J. Nestell, Roadmap to Develop ASME Code Rules for the Construction of High Temperature Gas Cooled Reactors (HTGRs), STP-NU-045-1, ASME Standards Technology, LLC, June 2012.

33. W. Ren, M. Govindarajan, D. F. Wilson, and D. E. Holcomb, Considerations of Alloy $N$ for Fluoride Salt-Cooled High-Temperature Reactor Applications, Proceedings of the ASME 2011 Pressure Vessels and Piping Division Conference, Baltimore, MD, July 2011.

34. J. R. Keiser, Compatibility Studies of Potential Molten-Salt Breeder Reactor Materials in Molten Fluoride Salts, ORNL/TM-5783, ORNL, Oak Ridge, TN, May 1977. 
35. M. Kondoa, T. Nagasaka, Q. Xu, T. Muroga, A. Sagara, N. Noda, D. Ninomiya, M. Nagurac, A. Suzuki, T. Terai, and N. Fujii, "Corrosion Characteristics of Reduced Activation Ferritic Steel, JLF1 (8.92Cr-2W) in Molten Salts Flibe and Flinak,” Fusion Engineering and Design, 84 (2009) 1081-1085.

36. C. Hoffmann and A. J. McEvily, "The Effect of High Temperature Low Cycle Fatigue on the Corrosion Resistance of Austenitic Stainless Steels,” Metallurgical Transactions A, 13A, May 1982, 923-927.

37. P. G. Smith, Experience with High-Temperature Centrifugal Pumps in Nuclear Reactors and Their Application to Molten-Salt Thermal Breeder Reactors, ORNL-TM-1993, ORNL, Oak Ridge, TN, September 1967.

38. H. C. Savage and J. R. Hightower, Jr., Engineering Tests of the Metal Transfer Process of Extraction of Rare-Earth Fission Products from a Molten-Salt Breeder Reactor Fuel Salt, ORNL5176, ORNL, Oak Ridge, TN, February 1977.

39. J. R. DiStefano and O. B. Cavin, Temperature Gradient Compatibility Tests of Some Refractory Metals and Alloys in Bismuth and Bismuth-Lithium Solutions, ORNL-TM-5503, ORNL, Oak Ridge, TN, November 1976.

40. R. A. Causey, R. A. Karnesky, and C. S. Marchi, "Tritium Barriers and Tritium Diffusion in Fusion Reactors,” Comprehensive Nuclear Materials, 2010, 511-549.

41. S. R. Sherman and T. M. Adams, Tritium Barrier Materials and Separation Systems for the NGNP, WSRC-STI-2008-00358, Rev. 1, Savannah River National Laboratory, Aiken, SC, November 2008.

42 R. E. Buxbaum and E. F. Johnson, Use of Yttrium for the Recovery of Tritium from Lithium at Low Concentrations, PPPL-1548, Princeton Plasma Physics Laboratory, Princeton, NJ, June 1979

43. U.S. Nuclear Regulatory Commission, "Policy Statement on the Regulation of Advanced Reactors,” NRC-2008-0237, Federal Register, 73(199), October 14, 2008.

44. M. D. Muhlheim, Identification of Initiating Events for aSMRs, ORNL/TM-2013/513, ORNL, Oak Ridge, TN, June 2013.

45. G. F. Flanagan, Development of Surrogates for Core Damage Frequency and Large Early Release Frequency for Advanced Small Modular Reactors, ORNL/TM-2013/516, ORNL, Oak Ridge, TN, June 2013.

46. D. F. Williams, L. M. Toth, and K. T. Clarno, Assessment of Candidate Molten Salt Coolants for the Advanced High-Temperature Reactor (AHTR), ORNL/TM-2006/12, ORNL, Oak Ridge, TN, March 2006.

47. D. F. Williams, Assessment of Candidate Molten Salt Coolants for the NGNP/NHI Heat-Transfer Loop, ORNL/TM-2006/69, ORNL, Oak Ridge, TN, June 2006.

48. Ceramatec: Lithium Separation, http://www.ceramatec.com/technology/ceramic-solid-state-ionictechnologies/separation-\&-purification-technologies/lithium.php.

49. T. Hoshino and T. Terai, "Basic Technology for ${ }^{6} \mathrm{Li}$ Enrichment Using an Ionic-Liquid Impregnated Organic Membrane,” Journal of Nuclear Materials, 417 (2011) 696-699.

50. T. Sugiyamaa, K. Sugiura, M. Tanaka, and Y. Enokida, "Lithium Isotope Separation With Displacement Chromatography Using Crown Ether Resin Immobilized on Porous Silica Beads,” Fusion Engineering and Design, 87 (2012) 1186-1189. 
51. M. G. Raizen and B. Klappauf, "Magnetically Activated and Guided Isotope Separation,” New Journal of Physics, 14 (2012) 023059.

52. J. H. Shaffer, Preparation and Handling of Salt Mixtures for the Molten Salt Reactor Experiment, ORNL-4616, ORNL, Oak Ridge, TN, January 1971.

53. S. Cantor, Physical Properties of Molten-Salt Reactor Fuel, Coolant, and Flush Salts, ORNL-TM2316, ORNL, Oak Ridge, TN, August 1968.

54. H. C. Savage and J. R. Hightower, Jr., Engineering Tests of the Metal Transfer Process of Extraction of Rare-Earth Fission Products from a Molten-Salt Breeder Reactor Fuel Salt, ORNL5176, ORNL, Oak Ridge, TN, February 1977.

55. L. E. McNeese, "Part 4, Molten-Salt Processing and Preparation” p. 181 in Molten-Salt Reactor Program Semiannual Progress Report for Period Ending August 31, 1971, ORNL-4728, ORNL, Oak Ridge, TN.

56. R. B. Briggs and J. R. Tallackson, "Distribution of Noble-Metal Fission Products and Their Decay Heat,” pp. 62-64 in Molten-Salt Reactor Program Semiannual Progress Report for Period Ending February 28, 1969, ORNL-4396, ORNL, Oak Ridge, TN.

57. H. Moriyama, M. Miyazaki, Y. Asaoka, K. Moritani, and J. Oishi, "Kinetics of Reductive Extraction of Actinide and Lanthanide Elements from Molten Fluoride into Liquid Bismuth,” Journal of Nuclear Materials, 182 (1991) 113-117.

58. R. C. Robertson, MSRE Design and Operations Report, Part I, Description of Reactor Design, ORNL-TM-728, ORNL, Oak Ridge, TN.

59. D. Scott, A. G. Grindell, Components and Systems Development for Molten Salt Breeder Reactor, ORNL-TM-1855, June 1967.

60. P. G. Smith, Development of Fuel- and Coolant-Salt Centrifugal Pumps for the Molten-Salt Reactor Experiment, ORNL-TM-2987, October 1970.

61. W. R. Huntley and P. A. Gnadt, Design and Operation of a Forced-Circulation Corrosion Test Facility (MSR-FCL-1) Employing Hastelloy N Alloy and Sodium Fluoroborate Salt, ORNL-TM3863, ORNL, Oak Ridge, TN, January 1973.

62. A. N. Smith, Experience with Sodium Fluoroborate Circulation in an MSRE-Scale Facility, ORNLTM-3344, ORNL, Oak Ridge, TN, September 1972.

63. M. W. Rosenthal, P. N. Haubenreich, and R. B. Briggs, The Development Status of Molten-Salt Breeder Reactors, p. 263, ORNL-4812, ORNL, Oak Ridge, TN, August 1972.

64. R. H. Guymon, MSRE Systems and Components Performance, ORNL-TM-3039, ORNL, Oak Ridge, TN, June 1973.

65. G. L. Yoder, Y. M. Elkassabgi, G. I. De Leon, C. N. Fetterly, J. A. Ramos, and R. B. Cunningham, Vortex Diode Analysis and Testing for Fluoride Salt-Cooled High-Temperature Reactors, ORNL/TM-2011/425, ORNL, Oak Ridge, TN, September 2011.

66. V. K. Varma, D. E. Holcomb, E. C. Bradley, N. M. Zaharia, and E. J. Cooper, AHTR Refueling Systems and Process Description, ORNL/TM-2012/292, ORNL, Oak Ridge, TN, July 2012.

67. D. D. Dudenhoeffer, D. E. Holcomb, B. P. Hallbert, R. T. Wood, L. J. Bond, D. W. Miller, J. M. O’Hara, E. L. Quinn, H. E. Garcia, S. A. Arndt, and J. Naser, Technology Roadmap- 
Instrumentation, Control, and Human-Machine Interface to Support DOE Advanced Nuclear Energy Programs, INL/EXT-06-11862, INL, Idaho Falls, ID, March 2007.

68. K. Korsah, D. E. Holcomb, M. D. Muhlheim, J. A. Mullens, A. Loebl, M. Bobrek, M. K. Howlader, S. M. Killough, M. R. Moore, P. D. Ewing, M. Sharpe, A. A. Shourbaji, M. S. Cetiner, T. L. Wilson, Jr., and R. A. Kisner, Instrumentation and Controls in Nuclear Power Plants: An Emerging Technologies Update, NUREG/CR-6992, ORNL/TM-2008/184, NRC, Washington, DC and ORNL, Oak Ridge, TN, October 2009.

69. S. J. Ball, D. E. Holcomb, and M. S. Cetiner, HTGR Measurements and Instrumentation Systems, ORNL/TM-2012/107, ORNL, Oak Ridge, TN, May 2012.

70. S. E. Rippon, “Cherenkov Detectors for the Measurement of Reactor Power,” Nuclear Instruments and Methods, 21 (1963) 192-196.

71 S. G. Tsypin, V. V. Lysenko, A. I. Musorin, L. N. Bogachek, V. F. Bai, V. V. Kuz’min, and A. B. Koshelev, " ${ }^{16} \mathrm{~N}$ y-ray Diagnostics in a Nuclear Reactor in a Nuclear Power Plant,” Atomic Energy, 95(3), 2003.

72. R. Gopal and H. H. Weiss, N-16 Nuclear Reactor Coolant Flow Rate Measuring System, US Patent No. 3,818,231, June 1974.

73. K. F. Graham and R. Gopal, Nuclear Reactor Primary Coolant Loop Flowmeter with Phase Shift Tracking Compensation, US Patent No. 4,232,224, November 1980.

74. J. M. Vavennec, G. Jossinet, and P. Thomas, Primary Flow and Temperature Measurements in $P W R s$ using Non-invasive Techniques, SMORN VII-v1, $7^{\text {th }}$ Symposium on Reactor Surveillance and Diagnostics, Avignon France, June 19-23, 1995, 462-470.

75. S. Horányi, D. Pallagi, T. Hargitai, and S. Tózsér, "Experience with the Operation of an On-Line Primary Coolant Flowmeter System Based on N-16 Noise Analysis at Paks PWR,” Progress in Nuclear Energy, 15, 1985, 709-717.

76. Techniques for Approximating the International Temperature Scale of 1990, Organisation Intergouvernementale de la Convention du Mètre, Bureau International Des Poids et Mesures, 1997 (reprinting of the 1990 first edition, Chapter 9 "Platinum Thermocouples").

77. D. L. Manning, H. W. Jenkins, and G. Mamantov, MSR Program Semiannual Progress Report, p. 162, ORNL-4119, ORNL, Oak Ridge, TN, February 28, 1967.

78. J. M. Dale and A. S. Meyer, "In-Line Chemical Analysis of Molten Fluoride Salt Streams,” p. 69 in Molten-Salt Reactor Program Semiannual Progress Report, Period Ending August 31, 1971, ORNL-4728, ORNL, Oak Ridge, TN.

79. J. P. Young, “Absorption Spectra of 3D Transition-Metal Ions in Molten LiF-BeF 2 ,” p. 204 in Molten-Salt Reactor Program Semiannual Progress Report, Period Ending February 28, 1969, ORNL, Oak Ridge, TN.

80. K. Ara, M. Katagiri, K. P. Termaat, P. Mostert, T. Johnston, and K. Knudsen, Design and Experience with the BICOTH-Type Reactor Water Level Gauge for the Dodewaard Nuclear Power Plant, 36(1), 1989, 1251-1255.

81. S. A Loehlein, Root Cause Analysis Report-Failure to Identify Significant Degradation of the Reactor Pressure Vessel Head, ML022750405, August 2002.

82. World Nuclear News article, "Duke Gives Up on Crystal River,” http://www.world-nuclearnews.org/C_Duke_gives_up_on_Crystal_River_0502131.html. 
83. R. Fairley and R. Thayer, "The Concept of Operations: The Bridge from Operational Requirements to Technical Specifications,” Annals of Software Engineering 3, 417-432 (1977).

84. J. O’Hara, J. Higgins, J. Persensky, P. Lewis, and J. Bongarra, Human Factors Engineering Program Review Model, NUREG-0711, Rev. 2, NRC, Washington, DC, 2004.

85. U.S.-Canada Power System Outage Task Force, Final Report on the August 14, 2003 Blackout in the United States and Canada: Causes and Recommendations, p. 111, April 2004.

86. Integrated Research Project Workshop 2 Report: http://fhr.nuc.berkeley.edu/wpcontent/uploads/2013/08/12-002-FHR-Workshop-2-Report-Final.pdf.

87. Integrated Research Project Workshop 1 Report: http://fhr.nuc.berkeley.edu/wpcontent/uploads/2013/08/12-001-FHR-Workshop-1-Report-Final.pdf.

88. W. K. Terry, J. K. Jewell, J. B. Briggs, T. A. Taiwo, W. S. Park, and H. S. Khalil, Preliminary Assessment of Existing Experimental Data for Validation of Reactor Physics Codes and Data for NGNP Design and Analysis,ANL-05/05, Argonne National Laboratory, Lemont, IL, September 2004.

89. SCALE homepage: http://scale.ornl.gov/.

90. J. Gehin, M. Jessee, M. Williams, D. Lee, S. Goluoglu, G. Ilas, D. Ilas, and S. Bowman, "Development and Validation of Scale Nuclear Analysis Methods for High Temperature GasCooled Reactors,” Proceedings of HTR 2010, Prague, Czech Republic, October 18-20, 2010.

91. Organisation for Economic Co-operation and Development Nuclear Energy Agency Nuclear Science Committee, International Handbook of Evaluated Reactor Physics Benchmark Experiments, NEA7081, 1999.

92. N. Augustine, U. Burns, J. Doerr, B. Gates, C. Holliday, J. Immelt, and T. Linebarger, Catalyzing American Ingenuity: The Role of Government in Energy Innovation, 2011, American Energy Innovation Council, www.americanenergyinnovation.org.

93. A Business Plan for Commercialization, The Nuclear Generation Nuclear Plan Industry Alliance, August 2012.

94. World Nuclear Association Report, Nuclear Power Economics and Project Structuring, WNA2012/002, September 2012, p. 16, http://www.worldnuclear.org/uploadedFiles/org/WNA/Publications/Working_Group_Reports/REPORT_Economics_ Report\%20(1).pdf.

95. E. S. Beckjord et al., The Future of Nuclear Power, Massachusetts Institute of Technology, Cambridge, MA, 2003.

96. World Nuclear Association, http://www.world-nuclear.org/info/Nuclear-Fuel-Cycle/UraniumResources/Supply-of-Uranium/.

97. J. N. Adkins, W. B. Heroy, W. E. Benson, M. King Hubbert, J. C. Frye, R. J. Russell, and C. V. Theis, "Report on the Committee on Waste Disposal of the Division of Earth Sciences," National Academy of Sciences-National Research Council, Washington, DC, September 1957.

98. Tennessee Valley Authority, The Way Forward to Complete TVA's Seventh Reactor, April 2012, http://www.tva.com/power/nuclear/pdf/Watts Bar 2 White Paper.pdf. 
99. D. E. Shropshire, K. A. Williams, J. D. Smith, B. W. Dixon, M. Dunzik-Gougar, R. D. Adams, D. Gombert, J. T. Carter, E. Schneider, and D. Hebditch, Advanced Fuel Cycle Cost Basis, INL/EXT07-12107 Rev. 2, INL, Idaho Falls, ID, December 2009.

100. A. R. Olsen, R. R. Judkins, W. L. Carter, and J. G. Delene, Fuel Cycle Cost Studies-Fabrication, Reprocessing, and Refabrication of LWR, SSCR, HWR, LMFBR, and HTGR Fuels, ORNL/TM6522, ORNL, Oak Ridge, TN, March 1979.

101. C. Forsberg, Future Cost of Isotopically Separated Lithium for PWRs, Fluoride-salt-cooled Hightemperature Reactors (FHRs) and Lithium Batteries, American Nuclear Society Annual Meeting Transactions Paper: 8712; Washington, DC, November 10-14, 2013.

102. NRC, "Prototype Decisions for Advanced Reactor Designs," Enclosure 2 Process for Determining Testing Needs, SECY-91-074, Washington, DC.

103. T. Yokomine, J. Takeuchi, H. Nakaharai, S. Satake, T. Kunugi, N. B. Morley, and M. A. Abdou, "Experimental Investigation of Turbulent Heat Transfer of High Prandtl Number Fluid Flow Under Strong Magnetic Field,” Fusion Science and Technology, 52, October 2007.

104. G. L. Yoder, Jr., A. Aaron, B. Cunningham, D. Fugate, D. Holcomb, R. Kisner, F. Peretz, K. Robb, J. Wilgen, and D. Wilson, "An Experimental Test Facility to Support Development of the FluorideSalt-Cooled High-Temperature Reactor,” Annals of Nuclear Energy, ISSN 0306-4549, http://dx.doi.org/10.1016/j.anucene.2013.08.008.

105. G. H. Golden, H. P. Planchon, J. I. Sackett, and R. M. Singer, "Evolution of Thermal-Hydraulics Testing in EBR-II,” Nuclear Engineering and Design, 101 (1987) 3-12.

106. S. M. Modro, S. N. Aksan, V. T. Berta, A. B. Wahba, Review of LOFT Large Break Experiments, NUREG/IA-0028, NRC, Washington, DC, October 1989.

107. M. Hron and M. Mikisek, "Reactor Physical Program in the Frame of the MSR-SPHINX Transmuter Concept Development,” Proceedings of ICAPP ’08, Anaheim, CA, June 8-12, 2008, Paper 8315.

108. http://www.oecd-nea.org/science/wprs/irphe/.

109. Department of Defense, Technology Readiness Assessment (TRA) Guidance, Assistant Secretary of Defense for Research and Engineering, Washington, DC, April 2011.

110. United States Government Accountability Office, Department of Energy Major Construction Projects Need a Consistent Approach for Assessing Technology Readiness to Help Avoid Cost Increases and Delays, GAO-07-336, Washington, DC, March 2007.

111. N. Li, "Lead-Alloy Coolant Technology and Materials-Technology Readiness Level Evaluation," Progress in Nuclear Energy, 50, pp. 140-15 (2008).

112. P. Sabharwall, J. Collins, D. Clark, A. Siahpush, W. Phoenix, M. McKellar, and M. Patterson, Technology Development Roadmap for the Advanced High Temperature Reactor Secondary Heat Exchanger, INL/EXT-12-26219, INL, Idaho Falls, ID, 2012.

113. H. E. McCoy, Jr., Influence of Several Metallurgical Variables on the Tensile Properties of Hastelloy N, ORNL-3361, ORNL, Oak Ridge, TN, 1964.

114. H. E. McCoy, Jr. and J. R. Weir, Jr., In- and Ex-Reactor Stress Rupture Properties of Hastelloy N Tubing, ORNL/TM-1906, ORNL, Oak Ridge, TN, 1967. 
115. J. W. Koger, Evaluation of Hastelloy N Alloys After Nine Years Exposure to Both Molten Fluoride Salt and Air at Temperatures from 700 to 560 ${ }^{\circ} \mathrm{C}$, ORNL/TM-4189, ORNL, Oak Ridge, TN, 1972.

116. G. M. Slaughter and P. Patriarca, Welding and Brazing of High-Temperature Radiators and Heat Exchangers, ORNL/TM-147, ORNL, Oak Ridge, TN, 1962.

117. R. G. Gilliand and J. T. Venard, Elevated Temperature Mechanical Properties of Welds in a NiMo-Cr-Fe Alloy, ORNL/TM-1341, ORNL, Oak Ridge, TN, 1966.

118. T. Nordhaus, J. Lovering, and M. Shellenberger, How To Make Nuclear Cheap, Breakthrough Institute, July 2013.

119. J. Duderstadt, G. Was, R. McGrath, M. Muro, M. Corradini, L. Katehi, R. Shangraw, and A. Sarzynski, Energy Discovery-Innovation Institutes: A Step Toward America's Energy Sustainability, Brookings Institution, February 2009. 